\title{
Monitorización de las variables ambientales durante el transporte de productos perecederos para estimar en tiempo real las pérdidas de calidad
}

\section{Tesis Doctoral \\ María Teresa Martínez Zafra}

Directores:

Roque Torres Sánchez

Francisco Artés Hernández

2020 


\section{AGRADECIMIENTOS}

La realización de esta Tesis ha supuesto un arduo camino tanto a nivel académico como personal y no podría haber llegado hasta aquí sin todos vosotros.

Gracias a vosotros, mis directores de Tesis, Roque Torres Sánchez y Francisco de Asís Artés Hernández. Gracias por confiar en mí. Gracias por vuestra generosidad, vuestro esfuerzo y apoyo. Por ayudarme, guiarme y exigirme a cada paso que íbamos dando juntos, buscando siempre la excelencia académica y la superación personal, sin olvidar la complicidad que estos años ha forjado.

Gracias a Widhoc Smart Solutions SL y a todo su equipo técnico, sin el cual el dispositivo no se habría desarrollado.

Gracias a la ayuda recibida por parte la UPCT a través del programa PROVALOR 2016 para la cofinanciación del proyecto y la convocatoria TRANSFER 2016 para la gestión en el proceso de aceptación de la patente de invención.

Gracias a las empresas Fruca Marketing SL por abastecer a la investigación de todas las lechugas que necesitáramos; a Transportes Directos del Segura SL y a Transportes Mesa SL por poner a nuestra disposición su logística y su confianza.

Gracias al equipo del Instituto de Biotecnología Vegetal, en especial a Noelia Castillejo y a Paqui Andreo por haber sido capaces de ayudarme a comer tantas lechugas sin tirármelas a la cara y sobre todo por dedicarme vuestro tiempo, esfuerzo y alegría.

Gracias a Antonio Guillamón por sus lecciones de estadística.

Gracias, MV, por meterme en este lío.

Gracias, MC, por obligarme a ir a una fiesta y hacer de "alcahueta" académica.

Gracias a vosotros, mis padres. Mamá por leer, corregir y apoyar. Papá por ni preguntar porque total, esto lo sacas tú sin problemas. Gracias por inculcarme el querer superarme y por saber que podía aunque yo no lo supiera.

Gracias, Juanjo, por saber cuándo preguntar y cuándo no, sin soltar mi mano.

Gracias a todos los que habéis estado, incluso sin estar, porque llegar hasta aquí ha sido gracias a vosotros y para vosotros. 


\section{RESUMEN}

El control de los principales factores ambientales que influyen en la calidad de los productos perecederos es uno de los principales desafíos de la industria alimentaria. La temperatura es el principal factor que afecta la calidad, pero otros factores como la humedad relativa y las concentraciones de gas (principalmente $\mathrm{C}_{2} \mathrm{H}_{4}, \mathrm{O}_{2}$ y $\mathrm{CO}_{2}$ ) también juegan un papel importante en el mantenimiento de la calidad postcosecha de los productos hortícolas. Por esta razón, la monitorización de dichos factores ambientales es un procedimiento clave para asegurar la calidad durante toda la vida útil y evaluar las pérdidas. Para estimar las pérdidas de calidad que un producto perecedero puede sufrir durante el almacenamiento $y$ el transporte, se ha desarrollado un sistema de monitorización de las variables accesible en tiempo real. Este sistema se puede utilizar en todas las etapas de la cadena de frío gracias a su arquitectura de comunicación inalámbrica registrando las variables en múltiples puntos de la carga. Se realizaron varios ensayos de laboratorio, utilizando lechuga como modelo, para determinar distintas puntuaciones de calidad (score) durante la vida útil en diferentes condiciones de temperatura de almacenamiento. Como resultado se proponen modelos de regresión que relacionan la temperatura que ha sufrido el producto, con la vida comercial de este, lo que permitiría optimizar su consumo redirigiendo el producto a mercados con más rotación y anticipándose así a una posible pérdida del producto. El sistema desarrollado como una herramienta basada en sensores, ha sido probado durante varios viajes de transporte terrestre por Europa y validado en cámaras climáticas del Instituto de Biotecnología Vegetal de la Universidad Politécnica de Cartagena. 


\section{ABSTRACT}

Controlling the main environmental factors that influence the quality of perishable products is one of the main challenges within the food industry. Temperature is the main factor affecting quality, but other factors such as relative humidity and gas concentrations (mainly $\mathrm{C}_{2} \mathrm{H}_{4}, \mathrm{O}_{2}$ and $\mathrm{CO}_{2}$ ) also play an important role in maintaining the post-harvest quality of horticultural products. For this reason, monitoring these environmental factors is a key procedure to ensure quality throughout the shelf life and to assess losses. To estimate the quality losses that a perishable product may suffer during storage and transport, a variable monitoring system accessible in real-time has been developed. This system can be used at all stages of the cold chain thanks to its wireless communication architecture, recording variables at multiple points during loading. Several laboratory tests have been performed, using lettuce as a model, to determine different quality shelf life scores under different storage temperature conditions. As a result, regression models are proposed that relate the temperature that the product has suffered, with its commercial life, which would optimize its consumption, redirecting the product to markets with more rotation and therefore anticipating a possible loss of the product. The system developed as a sensor-based tool, has been tested during many road-based trips across Europe and validated in climatic chambers of the Instituto de Biotecnología Vegetal of the Universidad Politécnica de Cartagena. 


\section{LISTADO DE ABREVIATURAS}

6LowPAN: "Low power Wireless Personal Area Networks".

ANN: $\quad$ "Artificial Neural Networks". Redes Neuronales Artificiales.

APPCC: $\quad$ Análisis de Peligros y Puntos de Control Crítico.

ASLT: $\quad$ "Accelerated Shelf Life Testing". Prueba de Vida Útil Acelerada.

AT: $\quad$ Acidez titulable.

Balun: "BALanced-UNbalanced lines transformer".

BLE: "Bluetooth Low Energy".

BMBF: "Bundesministerium für Bildung und Forschung".

BPA: Buenas Prácticas Agrícolas.

BRC: "British Retail Consortium".

$\mathrm{C}_{2} \mathrm{H}_{4}$ : $\quad$ Etileno.

CCD: $\quad$ "Cold Chain Database".

CCP: $\quad$ "Cold Chain Predictor".

CEPA: Confederación Europea de Asociaciones de Empresas de Control de Plagas.

CMR: "Convention relative au contrat de transport international de Marchandise par Route". Contrato de Transporte Internacional de Mercancías por Carretera.

$\mathrm{CO}_{2}: \quad$ Dióxido de carbono.

CoAP: $\quad$ "Constrained Application Protocol". Protocolo de Aplicación Restringida.

EAM: $\quad$ Envasado en Atmósfera Modificada.

EE. UU.: Estados Unidos de América.

ES: "Standard Error". Error estándar.

FAO: "Food and Agriculture Organization". Organización de las Naciones Unidas para la alimentación y la agricultura.

FEFO: $\quad$ "First Expired - First Out".

FIV: "Variance Inflation Factor". Factor de Inflación de la Varianza.

FRISBEE: "Food Refrigeration Innovation, Safety Consumers' Benefit, Environmental Impact and Energy Optimisation".

FSU: $\quad$ "Freight Supervision Unit".

FTP: $\quad$ "File Transfer Protocol".

GFSI: "Global Food Safety Iniciative". Iniciativa Mundial de Seguridad Alimentaria.

GPIO: $\quad$ "General Purpose Input/Output". Entrada/Salida de Propósito General.

GPRS: "General Packet Radio Service". Servicio de Radio transmisión de Paquetes Generales.

GPS: $\quad$ "Global Positioning System".

GSM: $\quad$ "Global System for Mobile". Sistema Global para las Comunicaciones Móviles.

HR: $\quad$ Humedad relativa.

IBV: Instituto de Biotecnología Vegetal.

IFS: "International Food Standard". 


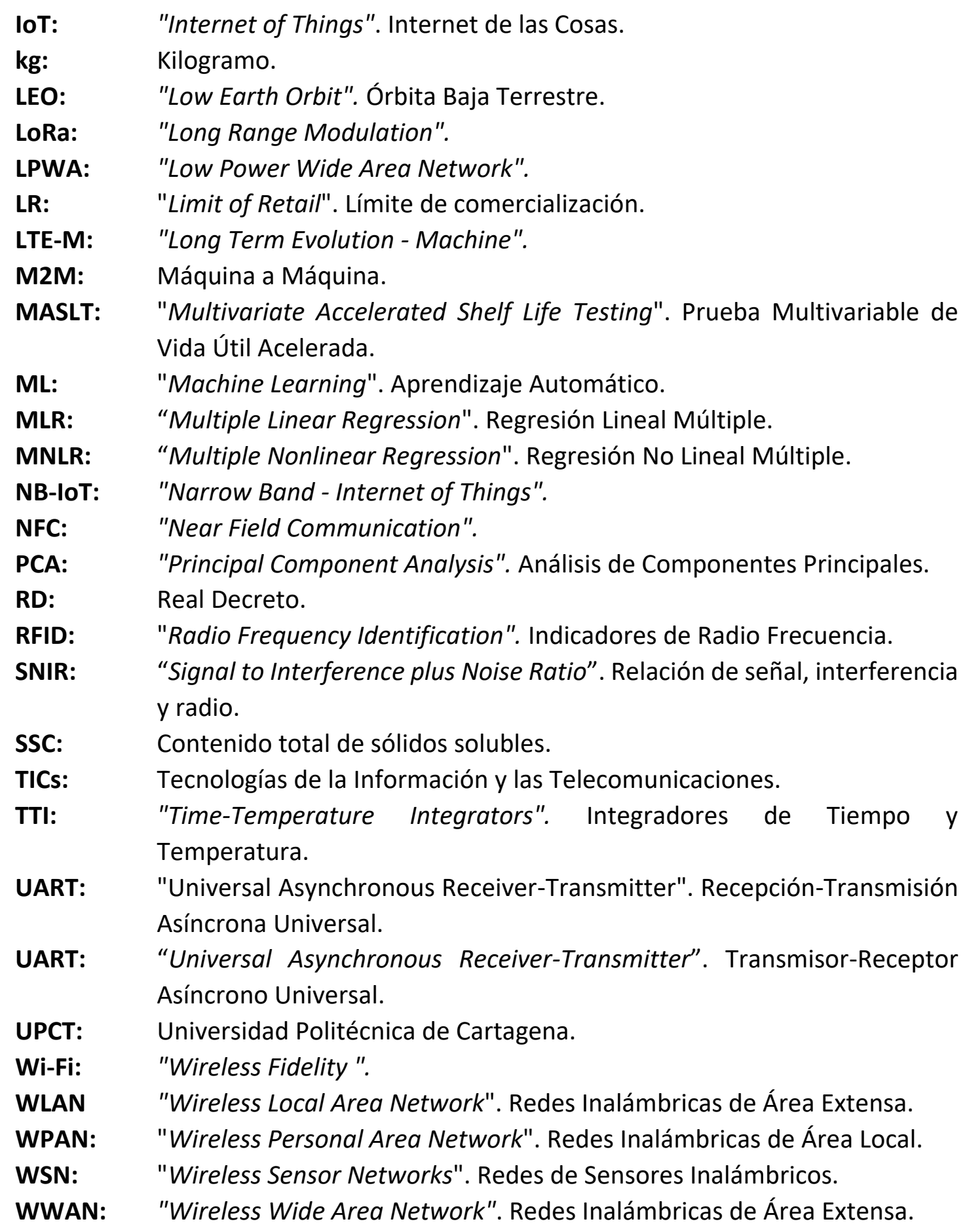




\section{ÍNDICE}

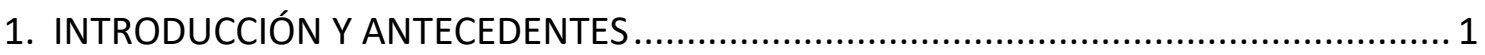

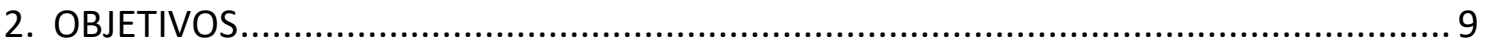

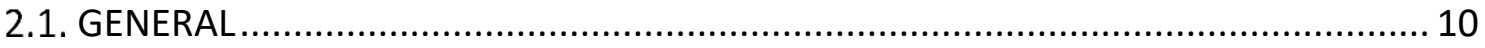

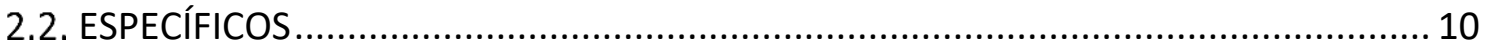

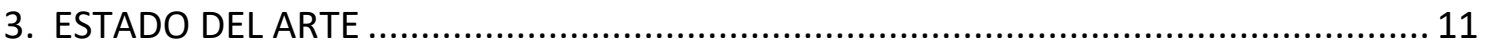

3.1. MEDICIÓN DE VARIABLES AMBIENTALES DURANTE LA CONSERVACIÓN Y TRANSPORTE DE PRODUCTOS PERECEDEROS.................................................. 12

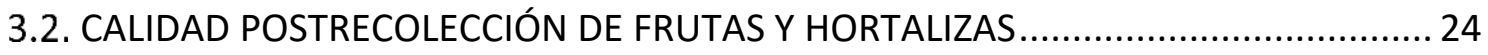

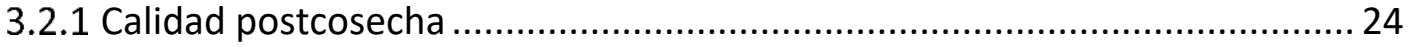

3.2.2 Principales factores ambientales que influyen en la calidad .......................26

3.2.3 Condiciones recomendadas de conservación y transporte de frutas

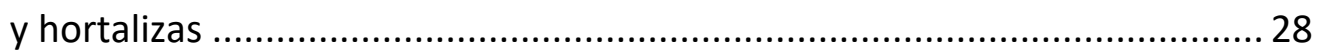

3.2.4 Estrategias para minimizar las pérdidas de calidad durante la

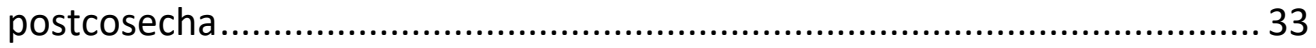

3.3. MODELOS DE ESTIMACIÓN DEL VIDA COMERCIAL DE PRODUCTOS

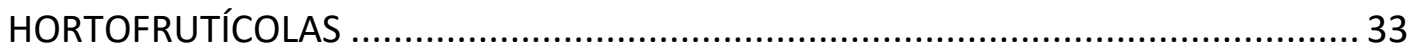

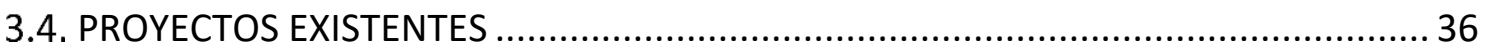

4. DISEÑO Y DESARROLLO DEL DISPOSITIVO DE MONITORIZACIÓN ............................ 44

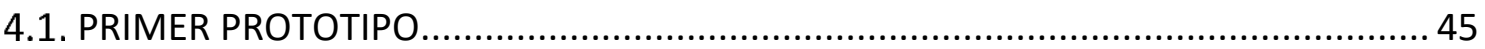

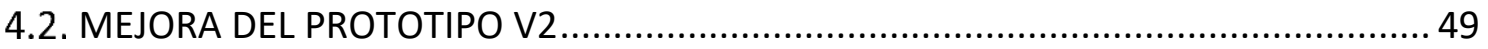

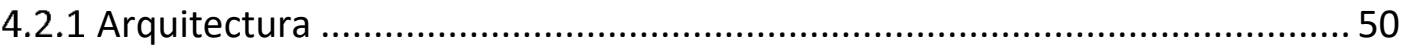

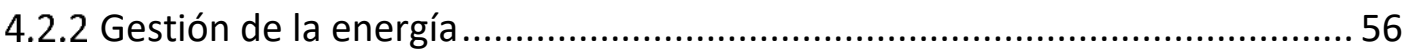

4.2.3 Gestión de la instrumentación en los nodos Slave - Gateway ..................... 57

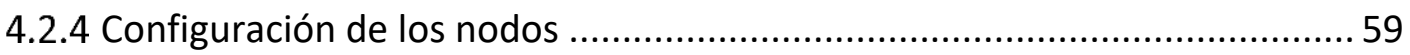

4.2.5 Gestión de la información instrumentada.............................................. 59

5. ENSAYOS Y METODOLOGÍA PARA LA DETERMINACIÓN DE LA VIDA ÚTIL ................61

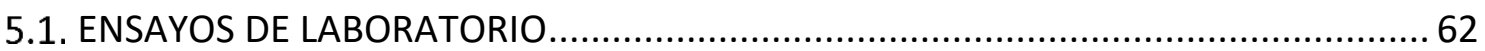

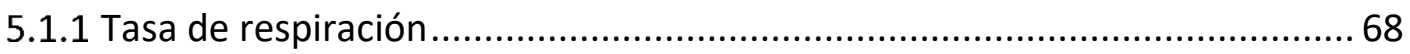

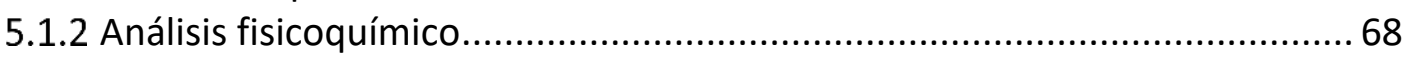

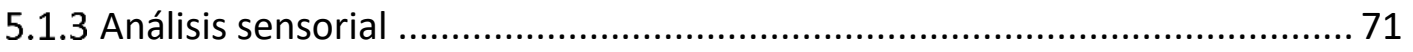

5.2. ENSAYOS EN TRANSPORTE TERRESTRE Y ENSAYOS EN CÁMARAS
FRIGORÍFICAS EN CONDICIONES DE TRANSPORTE

5.3. MODELO DE REGRESIÓN PARA LA ESTIMACION DE LA VIDA COMERCIAL

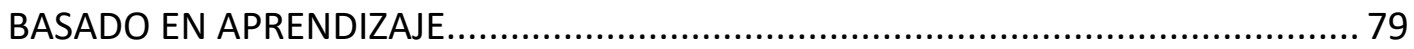

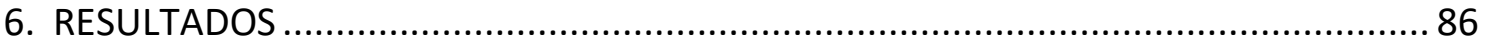

6.1. RESULTADOS DE LA VIDA COMERCIAL DE LAS LECHUGAS ................................... 87 


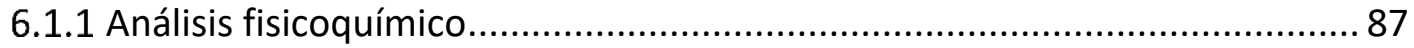

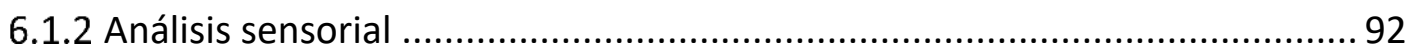

6.2. RESULTADOS DE LAS MEDIDAS CON EL SISTEMA DE MONITORIZACION .............. 109

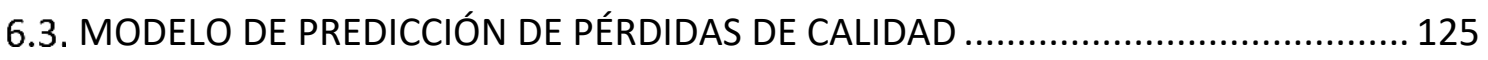

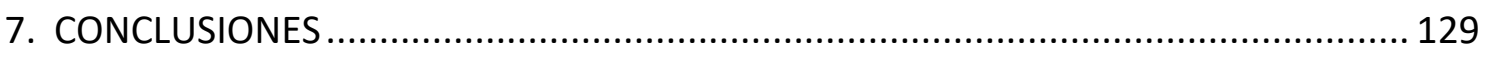

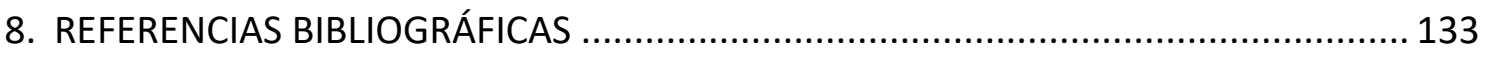

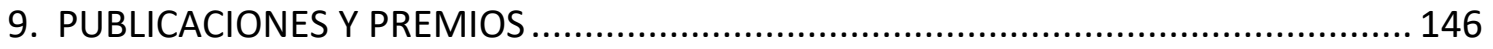




\section{ÍNDICE DE FIGURAS}

Figura 1. Volúmenes de producción de cada grupo de productos básicos por región (en millones de toneladas) (FAO, 2012).

Figura 2. Principales etapas de la producción y comercialización refrigerada de productos hortofrutícolas.

Figura 3. Pérdidas de alimentos en el grupo de frutas y hortalizas (FAO, 2013).

Figura 4. Porcentajes de consumo de los alimentos en función de su procesado (Jareño, 2017).

Figura 5. Consumo de productos transformados en supermercados (primera línea) frente a tiendas tradicionales, desde enero de 2013 hasta diciembre de 2018 (Ministerio de Agricultura Pesca y Alimentación, 2018a).

Figura 6. Desglose del coste económico en pérdidas. De izquierda a derecha las columnas representan las pérdidas económicas que absorben las granjas, los explotadores, los sectores que brindan el servicio al consumidor (transporte, distribución y comercialización) y los hogares estadounidenses (ReFED, 2015). ....... 7

Figura 7. Esquema RFID con detalle de la antena y el microchip. 13

Figura 8. TTI de la marca WarmMark ${ }^{\circledR}$ modelo 51013-51035 («WarmMark ${ }^{\circledR}$ Time- $^{-}$ Temperature Indicator, Model 51013-51035 - DeltaTrak», 2015).

Figura 9. Esquema de las distintas tecnologías satélite geolocalizables (Wikipedia, 2018).

Figura 10. Comparativa de redes LPWAN (Mekki et al., 2019).

Figura 11. Características de los sistemas de comunicación más utilizados para la ejecución de proyectos de Internet de las cosas (IoT - "Internet of Things") (Efor, 2016).

Figura 12. Relación de empresas por países que comercializan con la monitorización en tiempo real de la cadena de suministro. Elaboración propia...... 19

Figura 13. Detalle de los logos de los distintos tipos de certificación.

Figura 14. Perfil típico de temperatura en la cadena de frío de productos perecederos (Mercier et al., 2017).

Figura 15. Elementos básicos del metabolismo primario y relación con el metabolismo secundario de las plantas (Ávalos-García y Pérez-Urria, 2009)...

Figura 16. Efecto de la disminución de la concentración de oxígeno en la respiración (Artés-Hernández, 2016a).

Figura 17.Temperaturas, Composiciones Gaseosas para las Atmósferas de Equilibrio, Beneficio Esperado, Duración de la Conservación y/o Transporte y Aplicación Industrial del Envasado en Atmósfera Modificada a Hortalizas (Artés, 2006).

Figura 18. Temperaturas, Composiciones Gaseosas para las Atmósferas de Equilibrio, Beneficio Esperado, Duración de la Conservación y/o Transporte y 
Aplicación Industrial del Envasado en Atmósfera Modificada a Frutas (Artés, 2006)...

Figura 19. Fotografía del sistema desarrollado para el caso de la carne (Guillory y Strandhardt, 2012)

Figura 20. Página web del proyecto Frisbee (European Proyect, 2010)........................ 38

Figura 21. Interfaz de la herramienta Frisbee (European Proyect, 2010). .................... 39

Figura 22. Detalle del registro de datos individual (Taoukis et al., 2016). .................... 39

Figura 23. Interfaz de búsqueda de datos (demo) con el ejemplo de la gráfica t-T para 4.400 minutos y un rango de temperaturas de entre $2,5^{\circ} \mathrm{C}$ y $5,5^{\circ} \mathrm{C}$ (Gwanpua, 2015).

Figura 24. Prototipo a escala reducida del "Intelligent Container"(Lang et al., 2011).

Figura 25. Detalle de los sensores en el interior de la caja de transporte de los plátanos (Jedermann et al., 2011).

Figura 26. Sistema de comunicación del "Intelligent Container" (Jedermann et al., 2017).

Figura 27. Sensor TelosB (TelosB, 2015).

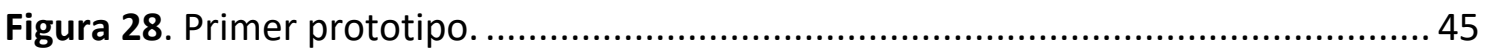

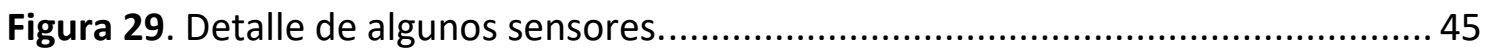

Figura 30. Componentes principales del nodo inicia y otros sensores......................... 45

Figura 31. Detalle de las pruebas bajo condiciones controladas en planta piloto y de la configuración de los datos registrados por sondas de la instalación frigorífica y por el nodo.

Figura 32. Interfaz web donde se observan los detalles del primer viaje de prueba realizado en mayo de 2016 .

Figura 33. Detalle del nodo Gateway (1) y de dos nodos Slave (2)............................ 50

Figura 34. Componentes del nodo Gateway actual. .............................................. 50

Figura 35. Doble sistema de comunicación: (a) comunicación de la red colaborativa Gateway/Slave dentro de un recinto aislado como un camión y (b) comunicación de los nodos Slave de forma independiente utilizando infraestructuras preexistentes Wi-Fi.

Figura 36. Placa de desarrollo Wipy 3.0 (WiPy 3.0 - Pycom, 2019)............................... 53

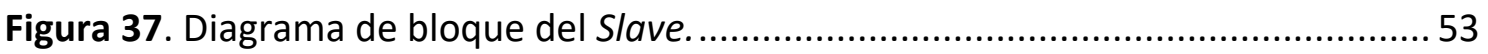

Figura 38. Cronograma de acceso a la medición del sensor AM2302 (Aosong

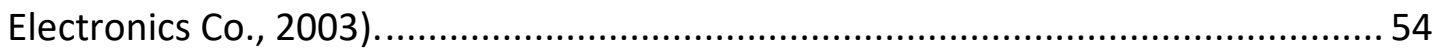

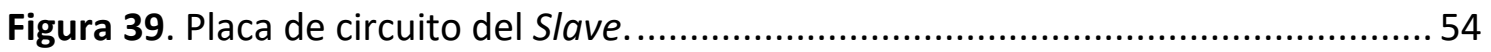

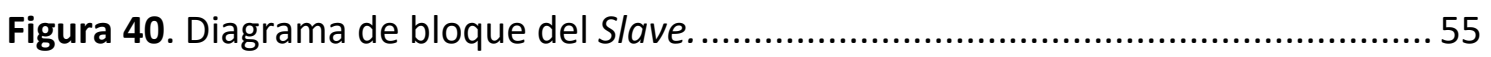

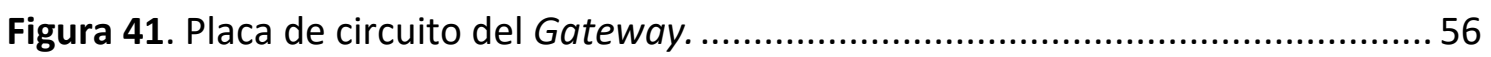


Figura 42. Diagrama de ejecución de la función "time-syncroniciting".

Figura 43. Funcionamiento general del Gateway. ....................................................... 58

Figura 44. Funcionamiento general del Slave. 59

Figura 45. Representación de la temperatura en diferentes puntos en un viaje de camión (www.widhoc.com).

Figura 46. Alimentos más producidos a nivel mundial. Valores medios del periodo 1994-2018 (FAO, 2020).

Figura 47. Evolución de la producción y superficie de cultivo de lechugas y endivias. Valores medios del periodo 1994-2018 (FAO, 2020).

Figura 48. Principales países productores a nivel mundial de lechuga y endivia. Valores medios del periodo 1994-2018 (FAO, 2020).

Figura 49. Datos de la producción anual de la Región de Murcia de lechuga Iceberg (Ministerio de Agricultura Pesca y Alimentación, 2018b).

Figura 50. Datos de la producción anual de la Región de Murcia de lechuga Romana (Ministerio de Agricultura Pesca y Alimentación, 2018b).

Figura 51. Evolución de las exportaciones a nivel nacional y regional (Proexport, 2019).

Figura 52. Diagrama de flujo del proceso de ensayo .................................................66

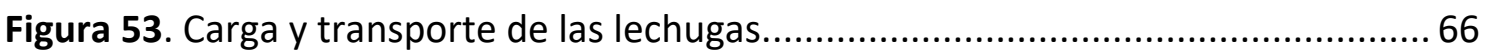

Figura 54. Detalle de la ruta desde la empresa productora hasta las instalaciones de la UPCT.

Figura 55. Sala de cámaras y proceso de etiquetado para las salidas de los ensayos.

Figura 56. Detalle de la posición de medición de color en la lechuga Iceberg..............69

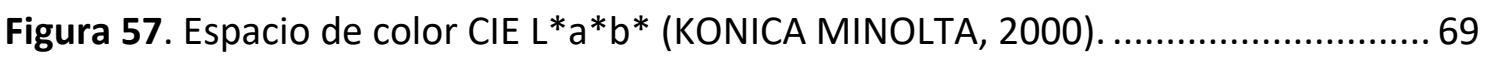

Figura 58. Pruebas de firmeza sobre la lechuga Iceberg............................................. 70

Figura 59. Aparatos de medida para las pruebas químicas......................................... 71

Figura 60. Estadillo utilizado para el análisis sensorial............................................. 72

Figura 61. Detalle de las lechugas romanas enteras y cortadas longitudinalmente ..... 73

Figura 62. Detalle de las lechugas Iceberg enteras y cortadas longitudinalmente........ 73

Figura 63. Estados de madurez de la lechuga tipo Iceberg (Martínez-López, 2011). .... 74

Figura 64. Aspecto de los daños por congelación en lechuga Iceberg. ......................... 75

Figura 65. Aspecto del russet spotting en las lechugas Iceberg. …............................... 75

Figura 66. Aspecto del brown stain en lechuga Romana (Cantwell y Suslow, 2002)..... 76

Figura 67. Aspecto del pink rib en las nervaduras centrales. ......................................... 76

Figura 68. Aspecto de daño mecánico en las nervaduras centrales.............................. 76 
Figura 69. Imágenes de Equipo de Investigación colocando los nodos en un camión.

Figura 70. Distribución de los nodos y distancia en metros en la instalación en el remolque refrigerado del transporte (a) vista longitudinal y (b) vista planta.

Figura 71. Nodos Gateway y Slave registrando datos en el interior de las cámaras.

Figura 72. Diferenciación entre regresión lineal múltiple y regresión polinomial ( $\mathrm{Ng}, 2016)$.

Figura 73. Detalle de los sensores utilizados para la medición de la diferencia dinámica entre la temperatura del aire en la cámara y en el interior de la lechuga

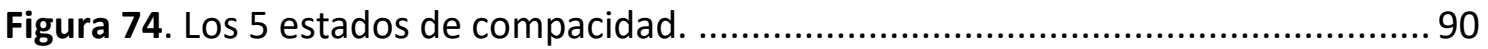

Figura 75. Evolución de las pérdidas de peso para (a) Iceberg y (b) Romana. 91

Figura 76. Evolución de las lechugas tipo Iceberg en cada salida (día de ensayo) y temperatura.

Figura 77. Evolución de las lechugas tipo Romana en cada salida (día de ensayo) y temperatura.

Figura 78. Historial tiempo temperatura en las tres cámaras.

Figura 79. Temperaturas registradas en tiempo real para (a) Alemania, (b) Países Bajos, (c) Reino Unido, (d) Bélgica y (e) Alemania. La línea horizontal es la temperatura de consigna o set-point.

Figura 80. Nodos instalados en el contenedor.

Figura 81. Históricos de las temperaturas registradas en tiempo real para cada nodo.....

Figura 82. Históricos de las HR registradas en tiempo real para cada nodo.

Figura 83. Históricos del $\mathrm{CO}_{2}$ registrado en tiempo real por el Gateway.

Figura 84. Históricos de las tensiones de las baterías registradas en tiempo real en cada nodo.

Figura 85. Nodos instalados en el contenedor.

Figura 86. Históricos de las temperaturas registradas en tiempo real para cada nodo.

Figura 87. Históricos de las HR registradas en tiempo real para cada nodo. ............... 116

Figura 88. Históricos del $\mathrm{CO}_{2}$ registrado en tiempo real por el Gateway.

Figura 89. Históricos de las tensiones de las baterías registradas en tiempo real en cada nodo.

Figura 90. Históricos de las temperaturas registradas en tiempo real para cada nodo.

Figura 91. Históricos de las HR registradas en tiempo real para cada nodo. 119 
Figura 92. Históricos del $\mathrm{CO}_{2}$ registrado en tiempo real por el Gateway.

Figura 93. Históricos de las tensiones de las baterías registradas en tiempo real en cada nodo.

Figura 94. Históricos de las temperaturas registradas en tiempo real para cada nodo....

Figura 95. Históricos de las HR registradas en tiempo real para cada nodo.

Figura 96. Históricos de las tensiones de las baterías registradas en tiempo real en cada nodo.

Figura 97. Históricos de las temperaturas registradas en tiempo real para cada nodo.

Figura 98. Históricos de las HR registradas en tiempo real para cada nodo.

Figura 99. Históricos del $\mathrm{CO}_{2}$ registrado en tiempo real por el Gateway.

Figura 100. Históricos de las tensiones de las baterías registradas en tiempo real en cada nodo

Figura 101. Históricos de las temperaturas registradas en tiempo real analizando la calidad con el índice de área para (a) Gateway, (b) Slave 1 y (c) Slave 2. El destino de este transporte fue Alemania, y los nodos se colocaron como se muestra en la Figura 70. 


\section{ÍNDICE DE TABLAS}

Tabla 1. Información de los distintos sistemas de monitoreo existentes en el

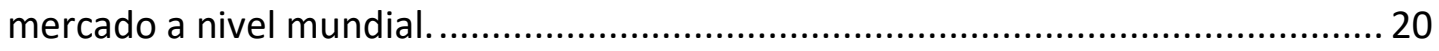

Tabla 2. Datos de los primeros viajes realizados...................................................... 47

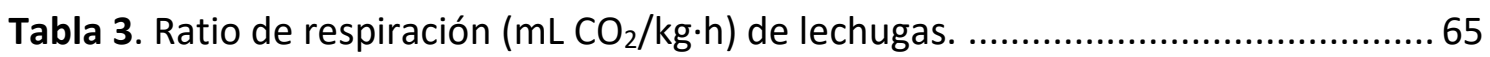

Tabla 4. Vida útil recomendada y días de análisis de calidad realizados de acuerdo

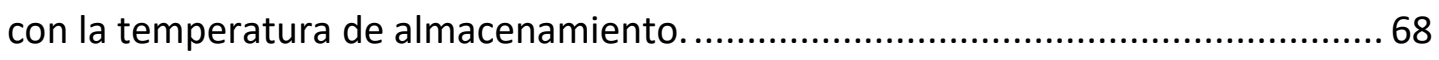

Tabla 5. Rangos de respiración $\left(\mathrm{mL} \mathrm{CO}_{2} / \mathrm{kg} \mathrm{h}\right.$ ) de las lechugas Iceberg y Romana......... 87

Tabla 6. Resultados de los parámetros fisicoquímicos de la lechuga Iceberg................ 88

Tabla 7. Resultados de los parámetros fisicoquímicos de la lechuga Romana.............. 89

Tabla 8. Porcentajes de pérdida de peso por temperaturas y tipo de lechuga..............91

Tabla 9. Coeficientes de correlación lineal para la pérdida de peso con parámetros de calidad subjetivos bajo 5 temperaturas de almacenamiento diferentes, en lechuga Iceberg y lechuga Romana.

Tabla 10. Resultados de la medición de $\Delta \mathrm{E}$ obtenidos con el colorímetro por temperatura, día de ensayo y tipo de lechuga.................................................... 93

Tabla 11. Puntuaciones para el color obtenidas mediante el análisis sensorial por temperatura, día de ensayo y tipo de lechuga.

Tabla 12. Mediciones de firmeza realizadas mediante el analizador de textura por temperatura, día de ensayo y tipo de lechuga.

Tabla 13. Mediciones de compacidad al tacto mediante sensorial por temperatura, día de ensayo y tipo de lechuga.

Tabla 14. Mediciones de apariencia visual por temperatura, día de ensayo y tipo de lechuga.

Tabla 15. Mediciones de sabor por temperatura, día de ensayo y tipo de lechuga...... 98

Tabla 16. Mediciones de aceptabilidad global por temperatura, día de ensayo y tipo de lechuga.

Tabla 17. Mediciones de olor por temperatura, día de ensayo y tipo de lechuga...... 100

Tabla 18. Mediciones de daños mecánicos por temperatura, día de ensayo y tipo de lechuga.

Tabla 19. Mediciones de pardeamiento por temperatura, día de ensayo y tipo de lechuga.102

Tabla 20. Mediciones de Russet spotting por temperatura, día de ensayo y tipo de lechuga.103

Tabla 21. Mediciones de Pink ribs por temperatura, día de ensayo y tipo de lechuga.104

Tabla 22. Mediciones de daños mecánicos por temperatura, día de ensayo y tipo de lechuga. 
Tabla 23. Vida comercial en función de las temperaturas de almacenamiento de ambos tipos de lechugas (Score 3).

Tabla 24. Temperaturas y desviaciones promedio ........................................................ 108

Tabla 25. Estudio de las temperaturas en los viajes más representativos.................. 110

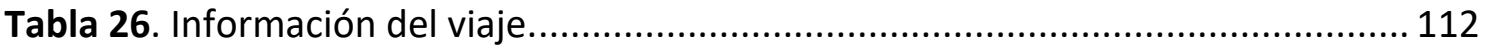

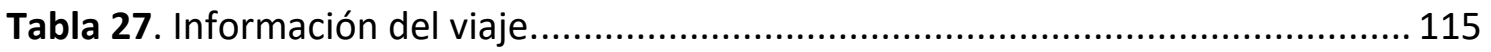

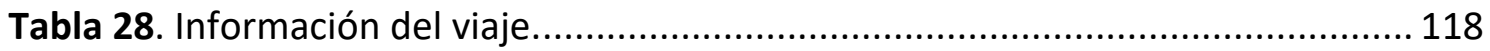

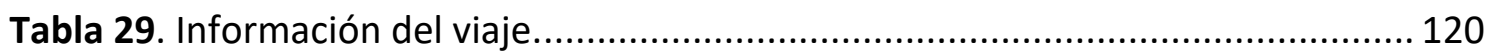

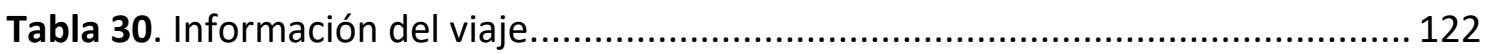

Tabla 31. Análisis coeficientes de validación del modelo 1 MNLR con interacciones.

Tabla 32. Resumen análisis mínimos cuadrados del modelo 1 ................................... 125

Tabla 33. Análisis coeficientes de validación del modelo 2 MLR con interacciones.... 125

Tabla 34. Resumen análisis mínimos cuadrados del modelo 2 .................................. 125

Tabla 35. Análisis coeficientes de validación del modelo 3 MNLR sin interacciones.

Tabla 36. Resumen análisis mínimos cuadrados del modelo 3................................ 126

Tabla 37. Días perdidos en los destinos más significativos, calculados para la temperatura promedio y para cada uno de los nodos. 
1. INTRODUCCIÓN Y ANTECEDENTES 
Se estima que en 2050 la población mundial será de 9.100 millones de personas, un 34\% superior a la actual, lo que implicará un aumento en las necesidades mundiales de alimentos de un $100 \%$ sobre lo que se está produciendo actualmente. Este hecho supone un importante reto tecnológico para avanzar hacia sistemas agrícolas y alimentarios más sostenibles (FAO, 2017). Esta situación unida a la demanda del consumidor hace que la producción, transporte y distribución de alimentos sea una de las sinergias globales más importantes para alimentar a la población. Dejando a un lado los efectos positivos a nivel económico, esta demanda global tiene también sus efectos negativos. El consumidor se ha acostumbrado a disponer de cualquier alimento sin importar la procedencia o época del año, lo que genera un mercado global de alimentos donde el transporte, para salvar las distancias entre la producción y el consumo, adquiere una importancia fundamental. Además, la disponibilidad en todo el momento de grandes cantidades de alimentos añade la variable de la sobreoferta de producto que, inevitablemente, desemboca en una pérdida de alimentos, ya que muchos de ellos no se llegan a vender y otros, aunque sean adquiridos por los consumidores, nunca llegan a consumirse.

La expresión pérdidas de alimentos ("Food losses") hace referencia a los alimentos que se pierden durante cualquier etapa de la cadena de suministro atendiendo básicamente a razones fisiológicas (calidad, madurez, etc.), tecnológicas y por alteraciones (daños mecánicos o microbianos). La expresión desperdicio de alimentos ("Food waste") hace referencia a los alimentos que no se consumen finalmente porque se desechan, en mayor medida, en las últimas etapas de la cadena alimentaria a causa del comportamiento de los vendedores minoristas y los consumidores (Artés-Hernández, 2020).

Cuantificar las pérdidas alimentarias es una tarea compleja y costosa, puesto que se analiza el alcance, la ubicación y las causas de la pérdida y el desperdicio de alimentos. Además, la variabilidad de las observaciones resalta la necesidad de realizar mediciones exhaustivas para poder identificar concretamente dónde ocurren dichas pérdidas.

Solo 39 países oficialmente han aportado a la FAO datos anuales entre 1990 y 2017 (FAO, 2019b). Estos informes determinan que 1.300 millones de toneladas se desperdician anualmente (FAO, 2019). Estas cifras son insostenibles en la sociedad actual y se exige dedicar muchos más esfuerzos a minimizar estas elevadísimas pérdidas de alimentos. En primer lugar, hay que conocer con mayor precisión donde se producen esas pérdidas y ser capaces de plantear acciones para minimizarlas. Además, la huella de carbono asociada a la pérdida de alimentos es aproximadamente de 3.300 millones de toneladas de equivalente de $\mathrm{CO}_{2}$ de gases de efecto invernadero liberados a la atmósfera por año (FAO, 2014).

La Figura 1 muestra los volúmenes de producción de 2007 de los siete grupos de productos básicos en su forma primaria, en las diferentes regiones del mundo estudiadas, observándose una alta producción de cereales a nivel mundial, aunque muy 
diferenciada para el caso de África cuya producción es aproximadamente de 100 millones de toneladas. Dichas producciones solo se igualan para el caso de frutas y hortalizas en la zona de Asia industrializada (FAO, 2012).

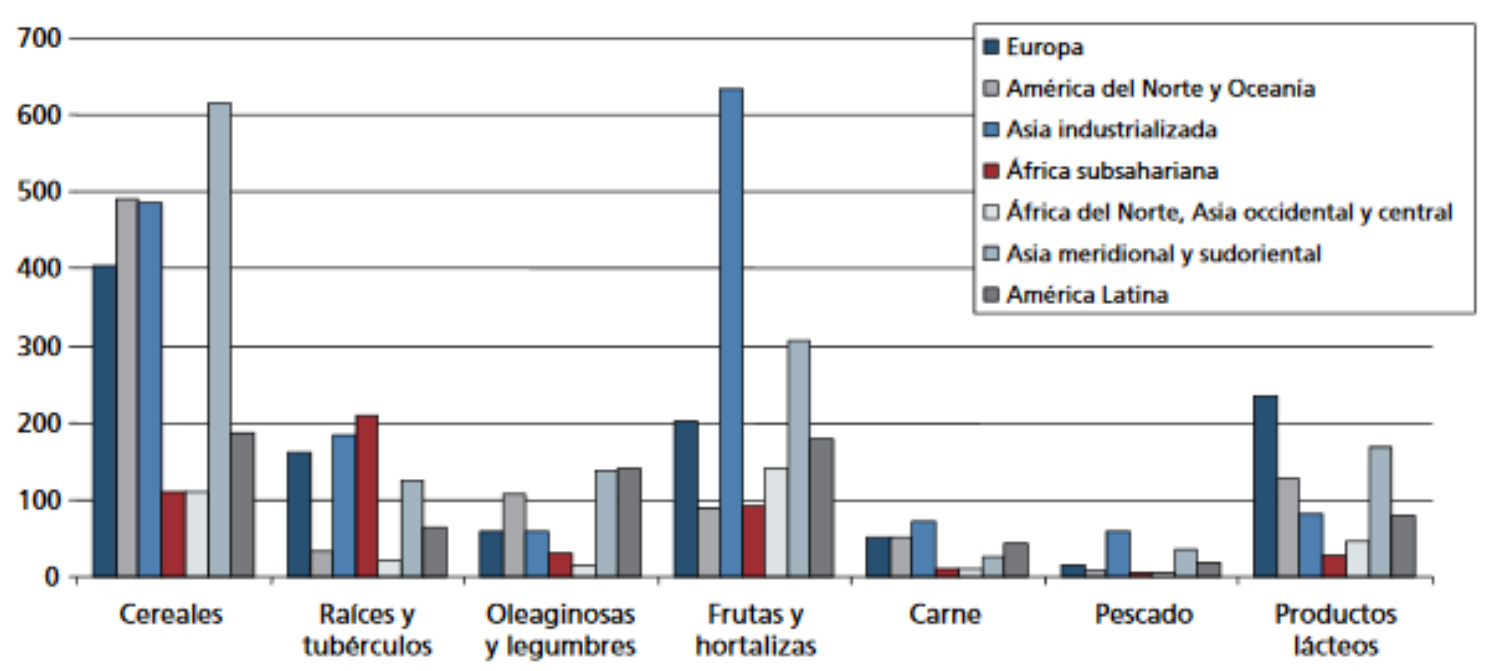

Figura 1. Volúmenes de producción de cada grupo de productos básicos por región (en millones de toneladas) (FAO, 2012).

Cada uno de estos grupos de alimentos básicos, tiene un porcentaje de pérdida de producto asociado a su producción mundial (Acuña Reyes et al., 2018):

- Cereales: $30 \%$.

- Raíces y tubérculos: $45 \%$.

- Legumbres y oleaginosas: $20 \%$.

- Frutas y hortalizas: $45 \%$.

- Carne: $20 \%$.

- Pescado: $35 \%$.

- Productos lácteos: $20 \%$.

En total, se estima que un $33 \%$ de toda la producción mundial de alimentos se pierde o se desecha a lo largo de la cadena de suministro o como producto no consumido (FAO, 2013).

Dicha cadena alimentaria se define como un sistema de producción, manipulación, almacenamiento, transporte y venta de alimentos a temperatura controlada, constante y sin grandes fluctuaciones, entre proveedores, distribuidores y consumidores, que permita mantener la calidad y seguridad de los mismos (Montanari, 2008). De una manera muy general, las principales etapas de la producción y comercialización refrigerada de productos hortofrutícolas se muestran en la Figura 2. 


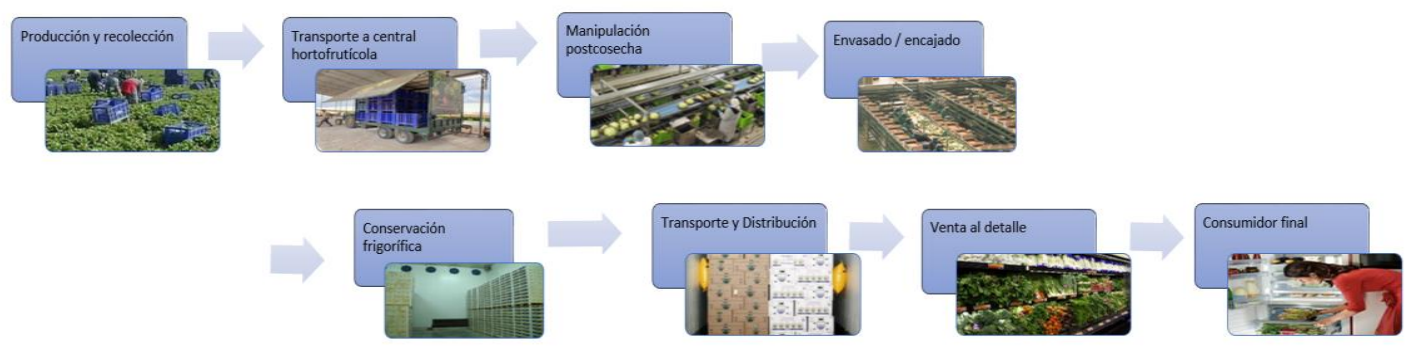

Figura 2. Principales etapas de la producción y comercialización refrigerada de productos hortofrutícolas.

Centrando la atención en el grupo alimenticio de frutas y hortalizas, por ser productos muy perecederos que tiene la particularidad de ser seres vivos (Figura 3), las mayores pérdidas en los países industrializados y suficientemente desarrollados (como son Europa, América del Norte y Oceanía) se ubican en las etapas de producción y recolección, seguido del transporte, distribución y de la etapa de manipulación, envasado y conservación. Esto es principalmente debido a los altos estándares de calidad establecidos por los vendedores minoristas, suponiendo en dichos países entre un 25 y un $40 \%$ de las pérdidas. Además, el consumidor final desecha entre un 15 y un $30 \%$ de los productos adquiridos, lo que supone una gran parte de las pérdidas totales. En las regiones en desarrollo, las pérdidas se centran en la producción agrícola, observándose también pérdidas elevadas durante la postcosecha y distribución, causadas tanto por el deterioro de los cultivos perecederos en los climas calientes y húmedos, la falta de tecnología que garantice las calidades de los productos, así como al carácter estacional que conlleva un excedente imposible de vender (FAO, 2013).

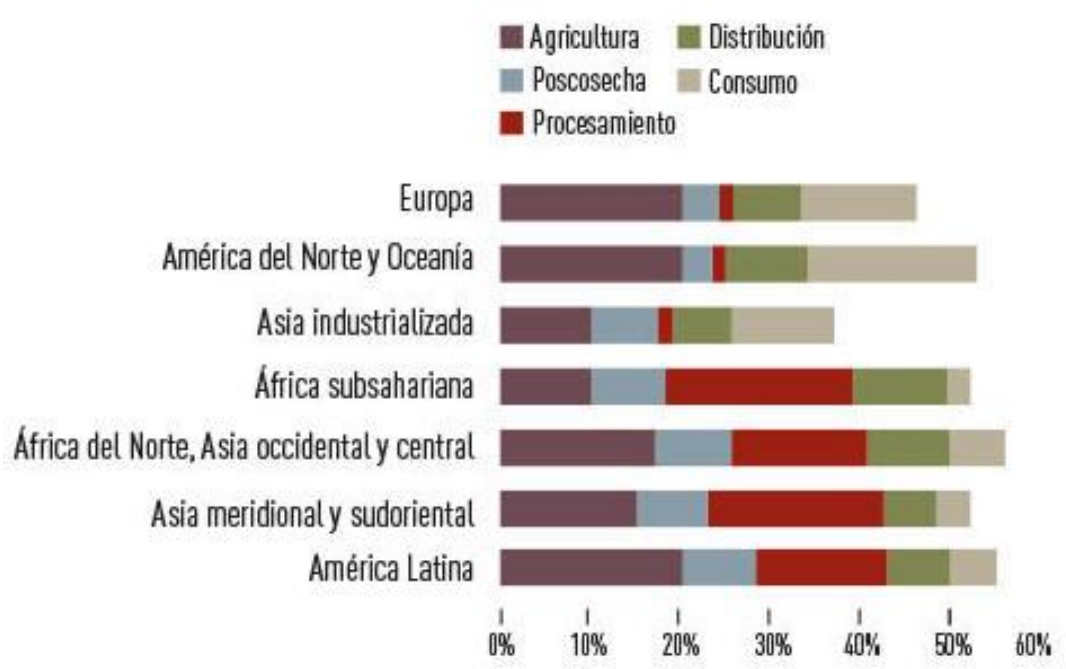

Figura 3. Pérdidas de alimentos en el grupo de frutas y hortalizas (FAO, 2013).

En España, según el sector exportador de lechugas una media del $5 \pm 2 \%$ de los envíos de exportación son rechazados anualmente debido a las condiciones inadecuadas de almacenamiento o transporte en la cadena de frío, que son medidas por los propios termógrafos o registradores instalados en los sistemas de transporte en cumplimiento 
de la normativa para productos no ultracongelados contemplada en el R.D, 237/2000, de 18 de febrero, que establece las especificaciones técnicas y los procedimientos para el control de conformidad y en el RD 2483/1986, de 14 de noviembre, de reglamentación técnico sanitaria sobre condiciones generales de transporte terrestre de alimentos y productos alimentarios a temperatura regulada.

Esto subraya la necesidad de hacer avances significativos en la mejora de las condiciones bajo las cuales los productos son manipulados y conservados y transportados antes de llegar al consumidor, garantizando su calidad final, tal como se viene demandando desde hace tiempo (FAO, 1989).

Actualmente los consumidores están cada vez más preocupados por la calidad de los productos que adquieren siendo los principales factores de compra los que se corresponden con la alimentación saludable en un 69\%, la calidad (sabor, color, textura) con un 53,6\% y del precio con el 48,2\% (Asociación de Industrias de Alimentación de Aragón, 2017). Y es que el consumidor ha pasado de ser un mero observador que se limita a adquirir el producto eligiendo entre las opciones que tiene a su alcance, a un agente activo en la definición y formulación de nuevos productos. Observa con una visión crítica al sector retándolo a aunar competitividad y responsabilidad (Institut Cerdà, 2018). De este modo, los consumidores ya no piden solo precio bajo y seguridad, por lo que hay que especializarse en suministrarles productos de alta calidad a un costo competitivo.

En los últimos años se ha observado que cada vez se consumen más productos ecológicos, debido a la conciencia medioambiental actual, así como a las nuevas tendencias de consumo y modas alimentarias, aumentando el número de flexivegetarianos, vegetarianos y veganos, que adquieren productos de forma natural y menos procesada (Figura 4).

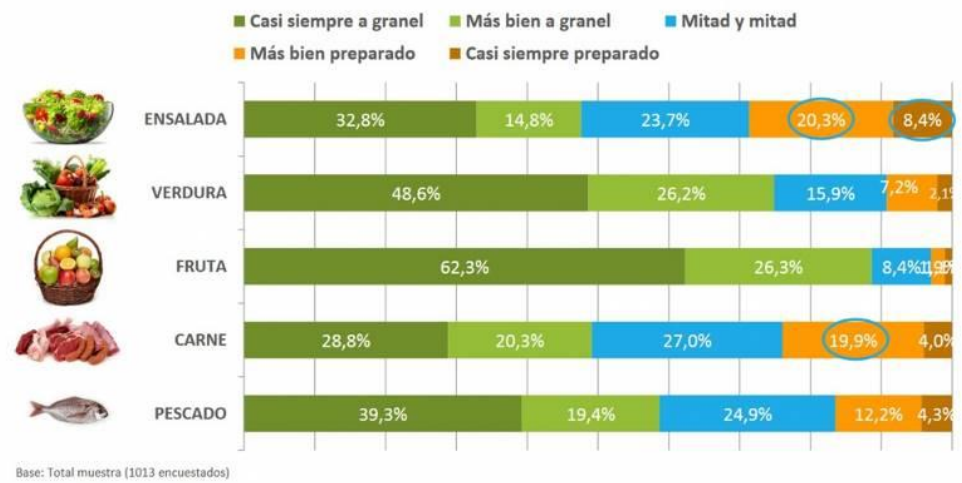

Figura 4. Porcentajes de consumo de los alimentos en función de su procesado (Jareño, 2017).

La adquisición de productos frescos sigue teniendo como protagonista a los supermercados como canal preferido por los consumidores, representando el $36,5 \%$ de las compras de productos de alimentación, pese a reducirse respecto al año 2017 en torno al $1,9 \%$. Las tiendas tradicionales, pierden un $15,7 \%$ del volumen de compra con 
respecto al mismo periodo del año anterior (Ministerio de Agricultura Pesca y Alimentación, 2018a).

La posibilidad de encontrar todos los productos deseados (ya sean frescos, o no) en un único centro distribuidor, además de una mayor gama de frutas y hortalizas transformadas en los supermercados frente a las tiendas tradicionales, se ha traducido principalmente en una disminución del tiempo dedicado a la compra.

Datos de consumo

\begin{tabular}{|lrrr|}
\hline \multicolumn{1}{|c|}{ GRUPO DE PRODUCTOS: Frutas y hortalizas transformadas } & & \\
\hline \multicolumn{1}{|c|}{ Producto } & Volumen (miles de kg) & Valor (miles de $€$ ) & Precio medio kg \\
\hline Total frutas y hortalizas transformadas & $1.938 .226,52$ & $4.079 .872,75$ & 2,10 \\
\hline Total frutas y hortalizas transformadas & $27.886,74$ & $80.095,57$ & 2,87
\end{tabular}

Figura 5. Consumo de productos transformados en supermercados (primera línea) frente a tiendas tradicionales, desde enero de 2013 hasta diciembre de 2018 (Ministerio de Agricultura Pesca y Alimentación, 2018a).

El mercado de frutas y hortalizas frescas está cambiando rápidamente gracias a los nuevos enfoques de validación y optimización de procesos que demanda el consumidor (Awuah et al., 2007) además de un aumento en la calidad de alimentos y dietas diferenciadas y a las constantes innovaciones tecnológicas que permiten conservar mejor y por más tiempo los productos perecederos (Nicola y Fontana, 2010). Todos estos enfoques se centran en la trazabilidad de dichos productos, ya que según Opara (2003), la trazabilidad en la cadena de frío de productos hortofrutícolas facilita:

- La identificación de las prácticas de producción.

- La identificación de la historia del producto a través de registros verificables.

- La segregación, aislamiento y elaboración de registros de productos defectuosos.

El mismo autor señala seis elementos básicos que definen una buena trazabilidad (Opara, 2002):

- Trazabilidad del producto: determinación de la localización física del ítem en cualquier momento.

- Trazabilidad del proceso: determinación del tipo y secuencia de los eventos ocurridos al producto.

- Trazabilidad de las entradas: determinación del tipo, fuente, suministrador etc. de los ingredientes usados para crear el producto.

- Trazabilidad de afecciones: para la traza de enfermedades y peligros biológicos.

- Trazabilidad genética: para determinar la constitución genética del producto, incluyendo variedad, tipo, origen y alteraciones en la estructura básica del ADN.

- Trazabilidad de mediciones: trazabilidad de mediciones individuales realizadas al producto tales como calidad, atributos de seguridad etc. a través de una cadena continua de mediciones. 
Una correcta trazabilidad de los productos perecederos no solo reduciría los problemas de salud de la población (se calcula que 420.000 personas mueren y alrededor de 600 millones enferman debido al mal estado de la comida (FAO, 2019a) y del hambre a nivel mundial (Stuart, 2009), sino que también disminuiría las pérdidas económicas aumentando así el beneficio de todos los actores que intervienen en la cadena de distribución (Stone y Sidel, 2004). A modo de ejemplo, sólo en Estados Unidos se estima que el coste de dicha mala trazabilidad en 2018 ascendió a 218.000 millones de dólares. En gran medida, el mayor costo fue asumido por los consumidores, ya que pagaron precios minoristas por los alimentos, mientras que las empresas se beneficiaron del pago a mayoristas, reduciendo así sus pérdidas, tal y como muestra la Figura 6.

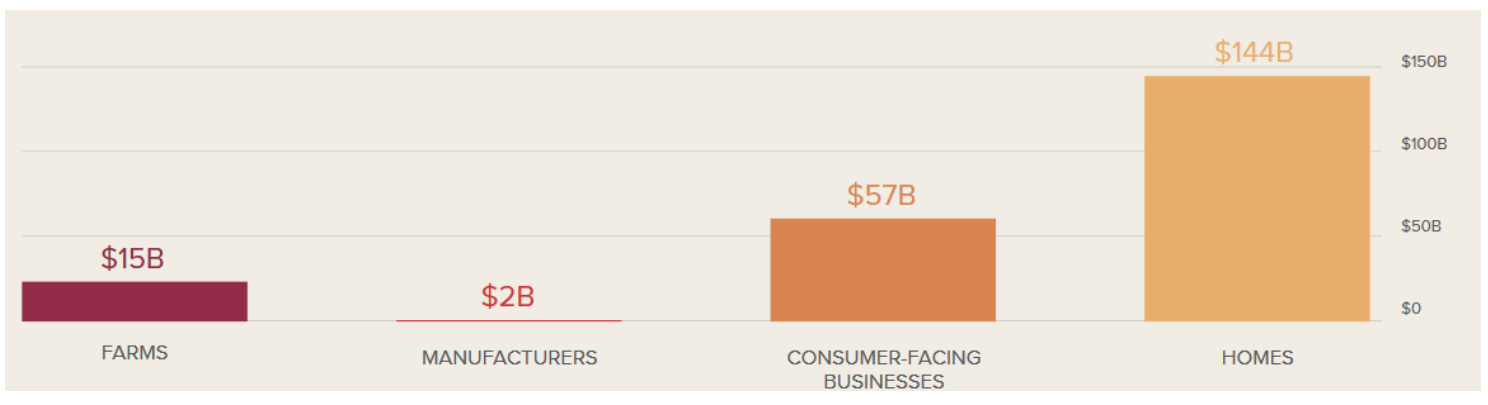

Figura 6. Desglose del coste económico en pérdidas. De izquierda a derecha las columnas representan las pérdidas económicas que absorben las granjas, los explotadores, los sectores que brindan el servicio al consumidor (transporte, distribución y comercialización) y los hogares estadounidenses (ReFED, 2015).

Una completa y total trazabilidad no es posible (Golan et al., 2007). Esto se deduce analizando únicamente la trazabilidad de mediciones puesto que el parámetro más representativo en la calidad de los productos perecederos es la temperatura y no es sencillo mantener sus condiciones estables a lo largo de la cadena de frío, ni saber qué ocurre en cada punto, ni tampoco las condiciones reales en las que se ha conservado o ha transportado la mercancía.

Compartir este tipo de información beneficia a todos los implicados en la cadena de frío, ya que se puede determinar y clarificar quién o quiénes son los responsables en la pérdida de las condiciones óptimas en función de la mercancía transportada (Hsiao y Huang, 2016). Pero para eso también habría que conocer toda la información. Además, el intercambio de información en tiempo real durante todo el suministro no solo mejoraría la seguridad y la calidad de los alimentos, sino que también mejoraría la optimización logística y de procesos (Giannakourou et al., 2001).

Las principales causas del deterioro de la calidad por las que el consumidor desecha estos productos son fundamentalmente su baja calidad inicial o una inadecuada madurez; la sobreproducción debido a incertidumbres del mercado; las altas especificaciones alimenticias después de la cosecha; el embalaje inadecuado, incrementando la presencia de daños mecánicos, podredumbres o inadecuada desinfección; el inadecuado manejo de la temperatura durante la cadena de suministro sin permanecer a la temperatura recomendada; una excesiva deshidratación; 
inadecuados niveles de $\mathrm{O}_{2}, \mathrm{CO}_{2} \mathrm{C}_{2} \mathrm{H}_{4}$ y otros volátiles (etanol, acetaldehído, etc.); un excesivo retraso entre la cosecha y el consumo que las hace atractivas y acaban desechándose a la basura; y el exceso de existencias durante toda la cadena de suministro, que acarrea el amontonamiento y consiguiente aplastamiento (ArtésHernández, 2019c; Buzby y Hyman, 2012; Edjabou et al., 2016; Hanssen et al., 2016; Quested et al., 2013; Silvennoinen et al., 2014; Wikström et al., 2019).

Muchas de estas causas ocurren durante las etapas del transporte y almacenamiento en las cuales es donde se declara la durabilidad comercial del producto, y donde más esfuerzos tecnológicos se están realizando para ajustar las condiciones de conservación a la duración del producto. Por un lado, evitando las perturbaciones que sufren las variables durante estos procesos puesto que, si las condiciones ambientales están continuamente fuera de especificación durante estas etapas el producto se deteriora (Tsang et al., 2018). Y por otro, ajustando el valor de la vida comercial del producto a estas condiciones de forma que se pueda destinar el producto a mercados con más rotación o con consumos más frecuentes.

Asegurar la calidad de los productos perecederos es un pilar esencial dentro de la industria alimentaria, la cual continúa implementando distintos sistemas de gestión de calidad y seguridad (Aung y Chang, 2014; Göransson et al., 2018; Díaz-Ruiz et al., 2019).

Uno de estos sistemas utilizados en la UE para el transporte terrestre es la denominada carta de portes bajo el Contrato de Transporte Internacional de Mercancías por Carretera (CMR - "Convention relative au contrat de transport international de Marchandise par Route"). Ésta formaliza un contrato de transporte de mercancías mediante un documento (papel o digital) probatorio de las condiciones del contrato y de la recepción de la mercancía por el transportista. De esta forma, si el transportista no respeta las instrucciones del cargador sobre las condiciones a la que debe viajar la mercancía produciéndole daños, el transportista sería responsable y debería indemnizar su valor (hasta el límite máximo por kilo). En caso de ser el cliente el que indica de forma inadecuada la información relevante para el correcto mantenimiento de la calidad de la mercancía, según el Convenio CMR, el transportista se vería exonerado de dicha responsabilidad (Sánchez-Gamborino, 2019). Pero esta carta no aporta una información en tiempo real de las condiciones en las cuales viaja la mercancía, puesto que los documentos se entregan en el punto de carga y en el de descarga, de tal forma que no se puede saber si las condiciones ambientales establecidas, siendo correctas, se han cumplido. Por ello, además del preenfriamiento de la mercancía, en transporte refrigerado es conveniente introducir equipos para poder acceder a la lectura de dichas condiciones durante el recorrido hasta destino. 
2. OBJETIVOS 


\subsection{GENERAL}

El principal objetivo de esta Tesis es definir y diseñar soluciones en el ámbito de los sistemas de la información y las telecomunicaciones (TICS) que permitan la estimación dinámica de la vida comercial de un producto perecedero mediante la monitorización de las principales variables ambientales durante su distribución y transporte.

Para ello se estudian los sistemas de monitorización existentes concluyendo en el desarrollo de un equipo que permite monitorizar en tiempo real y mediante una configuración distribuida, las variables ambientales que más influyen en la calidad de los productos perecederos, tomando como modelo los productos hortofrutícolas. Esta información se registra y procesa estando accesible en todo momento a través de Internet, para estimar la vida útil de las mercancías que se transportan.

El objetivo se completa con la realización de un análisis de pérdida de calidad del producto sometiéndolo en diferentes ensayos a escenarios climáticos diferentes. Esta información junto con los datos obtenidos en diferentes transportes reales de mercancía con el equipo desarrollado instalado permite concluir el objetivo con la propuesta de metodologías y modelos de predicción de dinámicos de la vida útil basados en las características y parámetros analizados y validados en los ensayos.

\subsection{ESPECÍFICOS}

De forma más específica se pueden concretar los siguientes objetivos:

- Estudio, diseño y desarrollo de equipos y sistemas que permitan medir las variables ambientales más influyentes en la calidad y vida comercial postcosecha de productos perecederos de forma flexible, autónoma y en tiempo real.

- Determinación del comportamiento real de las variables durante el transporte y conservación de las mercancías perecederas mediante la realización de transportes terrestres reales por Europa, registrando las diferentes condiciones ambientales existentes en diferentes ubicaciones dentro de la carga.

- Establecer umbrales de calidad durante la conservación de los productos hortofrutícolas utilizando lechugas como modelo de ensayo. Se basarán en un estudio cualitativo y cuantitativo, mediante ensayos de laboratorio sometiendo los productos a distintas condiciones ambientales en cámaras frigoríficas controladas, para su posterior evaluación y de la calidad y de la vida útil.

- Obtención de características relacionadas con las medidas entiempo real de la temperatura que permitan correlacionarlas con las pérdidas de calidad.

- Estudio y desarrollo de modelos regresivos basados en observaciones medidas por los equipos para estimar la vida comercial del producto teniendo en cuenta las condiciones de temperatura variables con respecto a la consigna. 
ESTADO DEL ARTE

3. ESTADO DEL ARTE 


\subsection{MEDICIÓN DE VARIABLES AMBIENTALES DURANTE LA CONSERVACIÓN Y TRANSPORTE DE PRODUCTOS PERECEDEROS}

Cuanto más lejana sea la distancia que los alimentos deben recorrer, mayor es el potencial de alimentos que son desechados, máxime si precisan de refrigeración durante su vida comercial. La solución idónea para preservar la calidad (sensorial, microbiológica y nutritiva) de los productos hortofrutícolas y satisfacer las crecientes exigencias de los mercados internacionales, consiste en aplicar idóneamente las técnicas postrecolección existentes (Artés-Hernández, 2016b). Dentro de las técnicas postcosecha más utilizadas para la conservación de frutas y hortalizas se encuentran la refrigeración, conservación en elevada humedad relativa (HR), eliminación de etileno $\left(\mathrm{C}_{2} \mathrm{H}_{4}\right)$, empleo de atmósferas modificadas, recubrimientos, higienización, reducción de daños mecánicos, etc. (Gómez et al., 2013). Entre ellas, la principal es mantener los productos a una temperatura de refrigeración óptima para cada uno de ellos, evitando fluctuaciones y rangos excesivamente bajos y/o altos. En este sentido, existen diferentes tecnologías que se pueden utilizar durante el transporte refrigerado como coadyuvantes. Dichas técnicas tienen el propósito de conservar la calidad de las frutas y hortalizas teniendo en cuenta las condiciones ambientales adecuadas que permitan reducir la velocidad de degradación de la calidad mediante la disminución de la actividad fisiológica y bioquímica de los productos hortofrutícolas, y disponer de ellos por períodos más prolongados de los habituales. De este modo, se podrán ofrecer productos frescos a mercados distantes y reducir pérdidas durante su comercialización.

Mantener los productos recolectados a una temperatura de refrigeración adecuada, constante y sin fluctuaciones es el aspecto más crucial para preservar la calidad y la seguridad de las frutas y hortalizas. De no realizarse correctamente, aunque únicamente sea en un punto de la cadena, provocará un rápido deterioro de la calidad del producto. El problema es que estas deficiencias se suelen descubrir demasiado tarde, bien por falta de conocimiento, por omisión de este, o por no ser la temperatura idónea para el tipo de mercancía que se transporta.

Como consecuencia de este desconocimiento, se acuña el término trazabilidad térmica, que se define como el historial de tiempo y temperatura al que se ha visto expuesto un producto alimenticio. Sin embargo, el problema radica en que no siempre es sencillo poder conocer las condiciones térmicas a las que se han sometido los alimentos durante su vida comercial.

Ndraha et al. (2018) determinaron las cuatro áreas clave cuya mejora supondría una mejor trazabilidad y mayor eficiencia en la cadena de frío; las relativas a la tecnología, los equipos de monitorización y medición de la temperatura en tiempo real, la fácil utilización de un software de modelado de vida útil y los requisitos legales en cuanto a las distintas normativas exigidas por distintos países en relación con la calidad alimentaria. 
El cuanto a las relativas a la tecnología, actualmente la más utilizada para medir, registrar y monitorizar la temperatura de los productos son los denominados Identificadores de Radio Frecuencia (RFID -"Radio Frequency Identification") (Figura 7), dispositivos para comunicarse sin cables entre dos o más objetos, dónde uno emite señales de radio y el otro responde en función de la señal recibida, utilizando un microchip inalámbrico y una antena en la etiqueta, de modo que no es necesario el contacto físico o visual como sería en el caso de un lector de código de barras, además de no necesitar de batería (Lorite et al., 2017). Y pese a que la lectura sea muy rápida el coste de las etiquetas, así como la falta de estandarización (Abad et al., 2009), el tiempo requerido para cargar grandes cantidades de datos, la limitación en la entrega en tiempo real de los datos (Le et al., 2016), la capacidad de detección (Becker et al., 2009; RuizGarcía y Lunadei, 2011), o ser fácilmente extraviados (Zou et al., 2014), suponen un problema en cuanto a viabilidad y mantenimiento (Sedghy y Sedghy, 2018).

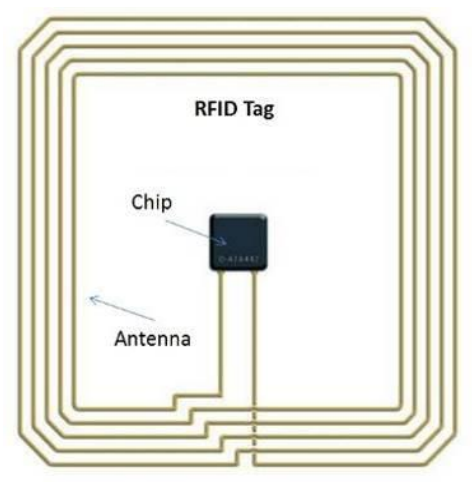

Figura 7. Esquema RFID con detalle de la antena y el microchip.

Otra técnica utilizada está basada en las redes de sensores inalámbricos (WSN "Wireless Sensor Networks"), ampliamente utilizadas en otros ámbitos como la agricultura de precisión. El uso de las WSN, aunque se ha demostrado que la calidad de los enlaces inalámbricos varía según el espacio y el tiempo (Lal et al., 2003), tiene la capacidad para desplegar pequeños sensores entre la mercancía y permite el uso de las estrategias de comunicación colaborativas como multi-hop para compensar otras deficiencias de cobertura o alcance de comunicación. El uso de los protocolos de comunicación adecuados al entorno que se desea medir es fundamental para poder desplegar con eficiencia estas WSN, por lo que, aunque protocolos como ZigBee, Bluetooth o Wi-Fi (“Wireless Fidelity") son utilizados con estas técnicas (Qi et al., 2014), es necesario un estudio en profundidad para determinar cuál es el más adecuado en estas aplicaciones. Además, la relación de señal versus interferencias y ruido (SINR "Signal to Interference plus Noise Ratio") aumenta conforme aumentan el número de interferentes (Son et al., 2006), con lo que es importante determinar el número de nodos de la WSN que forman parte del sistema de medida.

Recientemente, los dispositivos LoRa ${ }^{\circledR}$ (“Long Range modulation") se han introducido en soluciones de refrigeración inteligentes para rastrear la temperatura de los alimentos en la cadena de suministro de frío (Semtech, 2019). Sin embargo, para optimizar el destino o el uso de alimentos perecederos en caso de cambios en las condiciones 
térmicas de transporte, es necesario implementar un sistema de seguimiento y monitorización en tiempo real (Badia-Melis y Ruiz-García, 2016). Algunos sensores basados en RFID, i-Button o Zigbee requieren un equipo especial para leer los datos medidos, lo que hace que sea más complicado realizar el sistema de seguimiento y monitorización en tiempo real.

Diferenciándose de este tipo de tecnología, aparecen los denominados integradores de tiempo y temperatura (TTI - "Time-Temperature Integrators"). El principio de operación de los TTI consiste en un cambio de aspecto irreversible (Figura 8) y fácilmente observable de unas etiquetas, bien en forma de un cambio de color o de una deformación mecánica, de mayor o menor intensidad en función del tipo de indicador y los principios fisicoquímicos por los que se rija (Koutsoumanis y Gougouli, 2015).
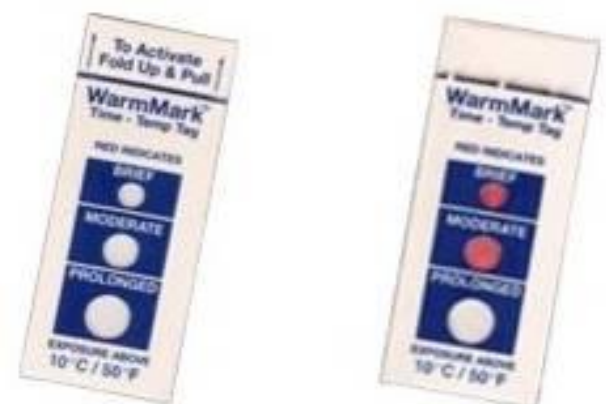

Figura 8. TTI de la marca WarmMark ${ }^{\circledR}$ modelo 51013-51035 ( WarmMark ${ }^{\circledR}$ Time-Temperature Indicator, Model 51013-51035 - DeltaTrak», 2015).

Para saber traducir la información que ofrece la visualización del TTI hay que conocer su principio de trabajo, si se activan en cuanto alcanzan la temperatura tasada, si es por su exposición acumulada bajo una determinada temperatura, o si en vez de variar en función de la temperatura lo hacen basándose en reacciones químicas, electroquímicas, enzimáticas, microbiológicas o fotoquímicas. (Taoukis y Labuza, 2003). En este caso, lo importante es que exista una dependencia de la temperatura a la cual responde el TTI y que sea similar a la de la pérdida de calidad del alimento. Del mismo modo el límite de activación del TTI debería coincidir con el final de la vida útil del producto (Koutsoumanis y Gougouli, 2015).

El uso de estos sistemas es caduco, con una vida útil limitada a un solo uso, lo que incrementa la cantidad de etiquetas que se deben utilizar a lo largo de la cadena de frío, lo que supone una merma en el coste de distribución, además de que al situarse en la superficie de los alimentos, tienen en cuenta la temperatura y la degradación superficial de estos (Arias-Méndez et al., 2014). Por otro lado, no poseen ningún sistema de comunicación, con lo que la información no se obtiene hasta que el producto llega a destino con la incapacidad de poder corregir condiciones inadecuadas durante el transporte (Jedermann et al., 2014).

Aunque las condiciones térmicas de los productos que se transportan pueden variar dependiendo de muchos aspectos, como el tipo de producto, su embalaje o la densidad 
de carga, entre otros, instalar un dispositivo de medición en cada caja o paleta para medir la temperatura tampoco es realista ni práctica (Semtech, 2019).

Independientemente de la capacidad de los sistemas para obtener la información por medio de sensores, esta información ha de ser transmitida para poder tomar decisiones sobre la mercancía antes de que las condiciones mermen su calidad. Para ello, las tecnologías de información y comunicaciones proveen diversos medios que pueden ser utilizados para la transmisión de la información, que se podrían dividir en:

- Tecnología de largo alcance por satélite, que utiliza órbitas bajas LEO (“Low Earth Orbit") a una distancia de la Tierra de entre 161 y $322 \mathrm{~km}$, como las que operan Iridium Satellite LLC (con 66 satélites), ORBCOM (con 31 satélites) o Globalstar, Inc. (con 24 satélites) (Wild, 2015).

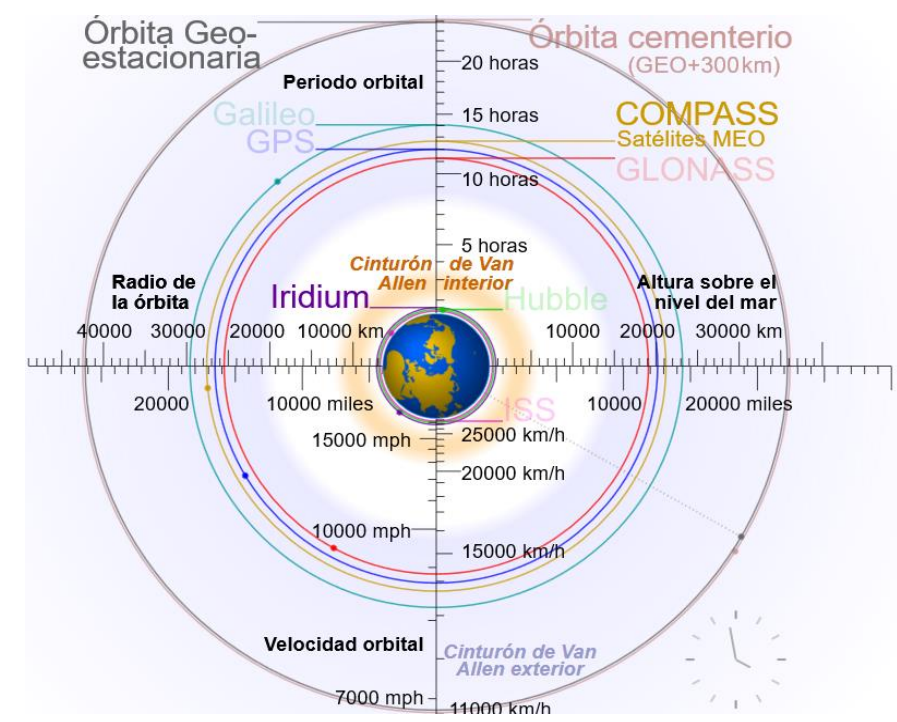

Figura 9. Esquema de las distintas tecnologías satélite geolocalizables (Wikipedia, 2018).

- Tecnologías de conexión inalámbrica basadas en las redes inalámbricas de área local (WLAN - "Wireless Personal Area Network") con alto consumo energético, pero con alta disponibilidad y cobertura:

- Wi-Fi con una banda de ancho de $2,4 \mathrm{GHz}$, que permite transmitir 11 Mbps bajo los estándares que engloba el IEEE 802.11. Puede alcanzar mayores velocidades operando en $802.11 \mathrm{~g}$ con 55 Mbps a 2,4 y la 802.11a con 55Mbps a una frecuencia de $5,7 \mathrm{GHz}$ (Vázquez Mouzo et al., 2017).

- Tecnologías de conexión inalámbrica basadas en redes inalámbricas de área extensa (WWAN - "Wireless Wide Área Network"). Son redes de área extensa, en ellas están englobados los protocolos de comunicaciones móviles.

- Sistema global para las comunicaciones móviles (GSM - "Global System for Mobile communications"), que ha ido evolucionando, permitiendo realizar no solo llamadas sino transmitir información a diferentes 
velocidades y anchos de banda que han ido progresivamente ampliándose, desde el inicial $2 \mathrm{G}$ con una cobertura prácticamente ilimitada, pasando por conexiones a Internet desde el 3G, con sus progresivas mejoras (4G/5G). Como inconveniente, al aumentar el ancho de banda, se reducen las distancias de envío, por lo que se necesita de una red de repetidores que dé sustento a la capacidad de comunicación. (Martínez Hernández, 2016).

- Tecnologías de corto alcance basadas en el tipo de señal LPWAN ("Low Power Wide Area Network"), con un volumen de datos muy bajos, lo que permite una mayor duración de las baterías, así como mayores distancias (5-50 km), aunque aún presenta una falta de estandarización; lo que impide la adopción a larga escala de la tecnología por terceros (Al-Kashoash y Kemp, 2016):

- SigFox: nodos con capacidad de envío de hasta 12 bytes, con un ancho de banda que varía en función de la situación geográfica: $868 \mathrm{MHz}$ (Europa), de $915 \mathrm{MHz}$ (América del Norte) y de $433 \mathrm{MHz}$ (Asia). Al ser un protocolo privado, su servicio es bajo pago por suscripción (Sigfox España, 2015).

- LoRa ${ }^{\circledR}$ : nodos con capacidad de envío de hasta 255 bytes, y que utiliza las mismas bandas de frecuencia de radio, sin licencia, que SigFox. Existe un protocolo de capa superior denominado LoraWAN, basado en una red con gateway conectado a los nodos.

- NB-IoT ("Narrow Band-loT"): nodos con capacidad de envío de hasta 10 kbps, con un ancho de banda de $180 \mathrm{KHz}$, con aproximadamente 100.000 conexiones por red (Accent Systems, 2018).

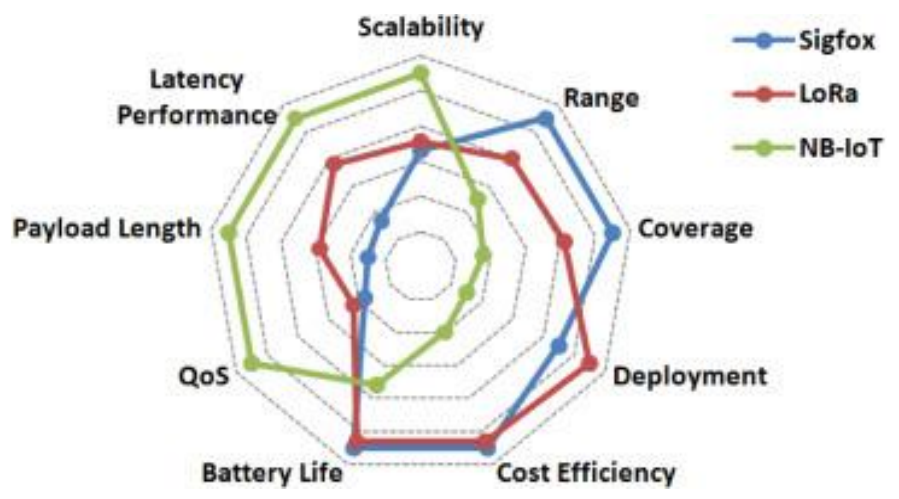

Figura 10. Comparativa de redes LPWAN (Mekki et al., 2019).

- LTE-M (“Long Term Evolution-Machine”): nodos con capacidad de envío de hasta $1 \mathrm{Mbps}$, con un ancho de banda de 1,4 MHz, que permite enviar voz y está preparada para dispositivos en movimiento.

- Tecnologías WSN de corto alcance, que requieren de despliegue de repetidores o pasarelas (como las expuestas en el punto WWAN) para la conexión exterior a internet: 
- ZigBee: protocolo de bajo consumo basado en el estándar IEEE 802.15.4, que emite a nivel global a $2,4 \mathrm{GHz}$. Se suelen conectar en forma de red de malla permitiendo bajas tasas de envío de datos con un bajo consumo energético (Bonnin-Torres y Alorda, 2012).

- 6LowPAN ("Low power Wireless Personal Area Networks") es un estándar que posibilita el uso de IPv6 sobre redes basadas en el estándar IEEE 802.15.4, además de posibilitar la conexión directa entre distintos dispositivos IP. Poseen un alcance de entre 10 y $100 \mathrm{~m}$.

- Tecnologías de corto alcance punto a punto basadas en comunicación objeto y dispositivo y con un muy bajo consumo energético, también necesitan de pasarelas para la conexión:

- BLE ("Bluetooth Low Energy"): con un alcance de hasta 0,5 m y una potencia de $0,5 \mathrm{~mW}$ con capacidad para desarrollar rápidamente enlaces sencillos. Opera en la banda ISM de 2,4 a 2,5 GHz. La tasa de transmisión de datos es de $721 \mathrm{Kbps}$ de forma asimétrica y de $432 \mathrm{Kbps}$ si lo hace de manera simétrica. Está asociado a las WPAN ("Wireless Personal Area Networks") (Mayne, 2005).

- NFC (“Near Field Communication”): trabaja en la banda sin licencia 13,56 $\mathrm{MHz}$, y se comunica mediante inducción en un campo magnético, hasta una distancia de $20 \mathrm{~cm}$. Su capacidad varía entre 106, 212 y $424 \mathrm{Kbps}$, ya que deriva de la tecnología RFID (Carignano y Ferreyra, 2011).

Los transportes marítimos y aéreos necesitan de tecnologías de largo alcance puesto que solo hay disponibilidad de enlaces vía satélite en los cuales el envío de mensajes se limita a mensajes cortos cuyo coste es significativamente elevado. Las tecnologías terrestres difieren en cuanto al uso, alcance e información que pueden transmitir (Figura 11). Últimamente las redes de banda estrecha, como Sigfox o NB, permiten enlaces cuasi-ubicuos con consumos muy reducidos a costa de una tasa de datos muy baja y una disponibilidad media o baja. Por el contrario, tecnologías muy maduras y compatibles como el GSM o el Wi-Fi proporcionan una alta disponibilidad lo que garantiza una gran flexibilidad en el uso de los dispositivos con rangos de alcance altos (GSM). El rango de alcance reducido de la tecnología Wi-Fi se suple con puntos de acceso inalámbricos disponibles en cualquier ubicación (lo que coloquialmente se denomina "router"), o en todo caso, es fácil y barato adquirirlos. No hay que olvidar que en pleno auge de las "Smart cities", existen una alta densidad de redes Wi-Fi-disponibles ("hot spot") que permiten ser utilizadas como puerta de enlace para enviar información a servidores remotos. 


\begin{tabular}{|l|l|l|l|l|l|l|l|}
\hline TECNOLogí & CONSUMO & ALCANCE & MADUREZ & DISPONIBILIDAD & SEGURIDAD & USABILIDAD & TASA DE DATOS \\
\hline GSM/GPRS & Muy alto & Alto & Muy Alto & Muy alto & Alta & Alta & Alta \\
\hline SigFox & Bajo & Medio & Alto & Medio & Media & Alta & Muy baja \\
\hline LoRa & Bajo & Medio & Bajo & Muy bajo lad hocl & N A & Baja & Muy baja \\
\hline NB loT & & & & & & & \\
\hline WiFi & Alto & Bajo & Muy alto & Alto & Baja & Alta & Muy alta \\
\hline BLE & Muy bajo & Muy bajo & Alto & Bajo & Baja & Media & Baja \\
\hline ZigBee & Medio & Bajo & Medio & Muy bajo & Alta & Baja & Baja \\
\hline
\end{tabular}

Figura 11. Características de los sistemas de comunicación más utilizados para la ejecución de proyectos de Internet de las cosas (IoT - "Internet of Things") (Efor, 2016).

Actualmente la apertura del mercado tecnológico al mercado hortofrutícola está permitiendo la aplicación de las bondades tecnológicas en cuanto a la mejora en los sistemas de medición y procesamiento de datos. De hecho, ya es posible encontrar empresas que comercializan dispositivos que ofrecen la monitorización de la temperatura con distintos sistemas de sensores y comunicaciones. Aunque muchas de ellas se han iniciado y centrado en la industria farmacéutica, algunas están aplicando una tímida apertura horizontal de mercado, puesto que ya han estudiado el cómo monitorizar las atmósferas controladas en sus almacenes o laboratorios.

La mayoría de estas empresas ofrecen plataformas online de visualización de datos en tiempo real o registradores de temperatura y $\mathrm{HR}$, pero en ningún caso incluyen un servicio completo en cuanto a control de las variables principales que influyen en la calidad de las atmósferas controladas y cómo las fluctuaciones afectan a la vida útil de las mercancías que transportan o del estado de estas cuando llegan al siguiente punto en la cadena de suministro. Además, muchas de ellas ofrecen servicios ampliados orientados al consumidor, aunque dicha sinergia depende en la mayoría de los casos de la capacidad que tenga este para registrar y/o comunicar los datos recopilados.

La Figura 12 presenta la relación de empresas por países que comercializan monitorización en tiempo real de la cadena de suministro y en la Tabla 1 se especifican las características técnicas de los mismos. 


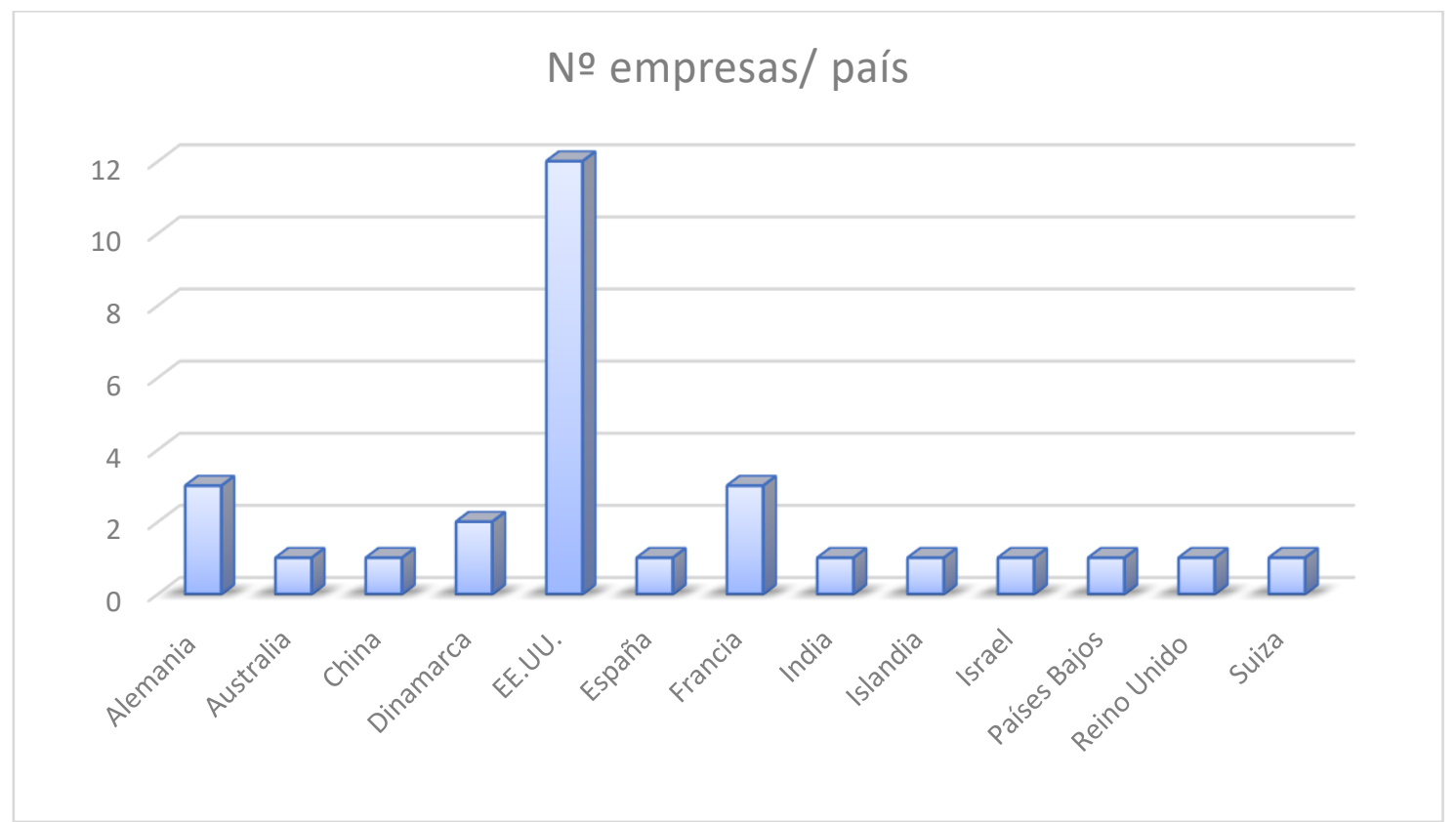

Figura 12. Relación de empresas por países que comercializan con la monitorización en tiempo real de la cadena de suministro. Elaboración propia. 
Tabla 1. Información de los distintos sistemas de monitoreo existentes en el mercado a nivel mundial.

\begin{tabular}{|c|c|c|c|c|c|c|}
\hline Empresa & País & Dispositivo & Gateway & Nodos & Medición & Transporte \\
\hline Secure System & Alemania & SecureSystem & GSM e Iridium & $\begin{array}{l}\text { RFID Mesh } \\
\text { Sensor } \\
\text { Network }\end{array}$ & $\begin{array}{c}\text { Seguridad, Tạ, HR y } \\
\text { localización. }\end{array}$ & Marítimo \\
\hline Tempmate & Alemania & Tempmate $^{\circledR} \mathrm{GS}$ & GSM Quad Band & & $\begin{array}{l}\text { Ta, HR, luz y } \\
\text { localización }\end{array}$ & Terrestre \\
\hline Faubel & Alemania & & No & $\begin{array}{l}\text { RFID con } \\
\text { NFC }\end{array}$ & Tạ & $\begin{array}{c}\text { Terrestre y } \\
\text { aéreo }\end{array}$ \\
\hline Smart Trace & Australia & Smart Trace & No & & $\begin{array}{c}\text { Temperatura, luz, y } \\
\text { situación }\end{array}$ & \\
\hline TempSen & China & Tempod $^{\circledR}$ & No & Bluetooth & Temperatura & Terrestre \\
\hline Globe Tracker & Dinamarca & $\begin{array}{c}\text { Reefer, Veesel, } \\
\text { Genset }\end{array}$ & No & $\begin{array}{c}\text { Lora y } \\
\text { Bluetooth }\end{array}$ & $\begin{array}{c}\text { Seguridad, Ta, HR, } \\
\text { luz, vibraciones. }\end{array}$ & $\begin{array}{c}\text { Marítimo y } \\
\text { terrestre }\end{array}$ \\
\hline Eupry & Dinamarca & Eupry & No & Wi-Fi & Tá y HR & $\begin{array}{c}\text { Terrestre y } \\
\text { aéreo }\end{array}$ \\
\hline ORBCOMM & EE. UU. & Euroscan MX2 & GSM e Iridium & Bluetooth & Tạ y localización & \\
\hline Sense Aware & EE. UU. & SenseAware $^{\circledR}$ & & Wi-Fi & Tạ & $\begin{array}{c}\text { Terrestre y } \\
\text { aéreo }\end{array}$ \\
\hline $\begin{array}{c}\text { Onset Data } \\
\text { Loggers }\end{array}$ & EE. UU. & CX e InTemp & No & Bluetooth & 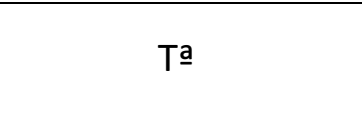 & $\begin{array}{c}\text { Terrestre y } \\
\text { aéreo }\end{array}$ \\
\hline TemPolar & EE. UU. & $\begin{array}{c}\text { Temprecord } \\
\text { Active Display }\end{array}$ & & & Ta & \\
\hline
\end{tabular}




\begin{tabular}{|c|c|c|c|c|c|c|}
\hline Sensitech & EE. UU. & TempTale $^{\circledR}$ & GSM & RFID & $\begin{array}{l}\text { Tá, HR, luz y } \\
\text { localización }\end{array}$ & Terrestre \\
\hline LogTag & EE. UU. & $\operatorname{LogTag}^{\circledR}$ & No & USB & Ta y HR & $\begin{array}{c}\text { Terrestre y } \\
\text { aéreo }\end{array}$ \\
\hline $\begin{array}{l}\text { Marathon } \\
\text { Products }\end{array}$ & EE. UU. & $\begin{array}{c}\text { Tempcheck, } \\
\text { MaxiLog }\end{array}$ & No & NFC & Ta y HR & Terrestre \\
\hline 7P Solutions & EE. UU. & SMARTBOX & GSM & & $\begin{array}{c}\text { Tạ, seguridad y } \\
\text { localización }\end{array}$ & $\begin{array}{c}\text { Terrestre y } \\
\text { aéreo }\end{array}$ \\
\hline RoamBee & EE. UU. & Bee & GSM & BLE & Tạ, luz y localización & Terrestre \\
\hline SwiftSensor & EE. UU. & Swift Sensors & GSM y Wi-Fi & BLE y RF & Tạ, HR y localización & Terrestre \\
\hline Aeris & EE. UU. & & GSM & & Tá y localización & Terrestre \\
\hline SmartSense & EE. UU. & SmartSense & GSM & & $\begin{array}{c}\text { Tạ, seguridad y } \\
\text { localización }\end{array}$ & Terrestre \\
\hline $\begin{array}{c}\text { OnAsset } \\
\text { Intelligence }\end{array}$ & EE. UU. & $\begin{array}{l}\text { Nodo SENTRY } \\
\text { FlightSafe }^{\circledR}\end{array}$ & GSM & RFID y BLE & $\begin{array}{c}\text { Ta, vibración, luz } \\
\text { presión y } \\
\text { geolocalización. }\end{array}$ & Aéreo \\
\hline inMolecular & España & TRK & NB-IOT y LTE-M & BLE & $\begin{array}{l}\text { Tá, vibración y } \\
\text { localización }\end{array}$ & \\
\hline Traxens & Francia & & GSM & GNSS & $\begin{array}{c}\text { Vibración, } \\
\text { seguridad, Tํ y HR }\end{array}$ & $\begin{array}{c}\text { Marítimo y } \\
\text { terrestre }\end{array}$ \\
\hline OceanSoft & Francia & $\begin{array}{c}\text { Atlas/Emerald/ } \\
\text { Cobalt }\end{array}$ & No & $\begin{array}{l}\text { Bluetooth y } \\
\text { Lora }\end{array}$ & Tạ y localización & $\begin{array}{c}\text { Terrestre y } \\
\text { aéreo }\end{array}$ \\
\hline$J R I$ & Francia & Verigo & No & $\begin{array}{l}\text { Bluetooth y } \\
\text { LoRa }\end{array}$ & Ta $\underline{\text { y }} \mathrm{HR}$ & Terrestre \\
\hline
\end{tabular}




\begin{tabular}{|c|c|c|c|c|c|c|}
\hline $\begin{array}{c}\text { TagBox } \\
\text { Solutions }\end{array}$ & India & $\begin{array}{l}\text { Tag360 } \\
\text { Sensors }\end{array}$ & Wi-Fi o GSM & & $\begin{array}{l}\text { Ta , HR, luz y } \\
\text { vibraciones }\end{array}$ & $\begin{array}{c}\text { Terrestre y } \\
\text { aéreo }\end{array}$ \\
\hline Controlant & Islandia & & GSM & GSM & Tạ y localización & $\begin{array}{c}\text { Terrestre y } \\
\text { aéreo }\end{array}$ \\
\hline BT9 & Israel & $\begin{array}{l}\text { X-Sence } \\
\text { wireless }\end{array}$ & & & $\mathrm{T}$ a y HR & \\
\hline Dyzle & $\begin{array}{l}\text { Países } \\
\text { Bajos }\end{array}$ & Dyzle & GSM & Wi-Fi & Tạ y localización & Aérea \\
\hline Timestrip & $\begin{array}{l}\text { Reino } \\
\text { Unido }\end{array}$ & Timestrip $^{\circledR}$ & No & $\mathrm{TTI}$ & T⿳a & $\begin{array}{c}\text { Terrestre y } \\
\text { aéreo }\end{array}$ \\
\hline Elpro & Suiza & LIBERO & & & $\mathrm{T}$ a y HR & $\begin{array}{c}\text { Terrestre y } \\
\text { aéreo }\end{array}$ \\
\hline
\end{tabular}


El estudio de mercado realizado ha permitido estudiar las tecnologías que ofrecen distintas empresas a nivel mundial.

Analizando los tipos de sensores utilizados, en muchas ocasiones las mediciones que se ofrecen son tipo RFID, NFC e incluso TTI de tal modo que la descarga de los datos registrados se hace de forma manual una vez se alcanza el punto de entrega impidiendo así su medición en tiempo real. Esto hace que, no sólo no se pueda tener la posibilidad de modificar las condiciones ambientales durante el transporte, sino que además encarece el mismo puesto que en algunos casos son no reutilizables. Como mejora, muchas empresas impulsan la utilización de mediciones mediante sensores inalámbricos conectados mediante Bluetooth, ZigBee o LoRa ${ }^{\circledR}$ que, si bien permiten comunicaciones inalámbricas entre puntos de medida, necesitan routers o puertas de enlace (gateways) para enviar los datos a Internet, lo que hace que los puntos de medida (nodos) no sean compatibles con otra plataforma inalámbrica que la desplegada y dependan de dichos gateways.

El caso de SigFox está teniendo mucho auge en la actualidad, consiste en una plataforma de comunicación propietaria que utiliza su infraestructura para loT, integrando protocolos de radio en microcontroladores. Permite una comunicación en tiempo real, pero limita el número de mensajes diarios a 144 y el ancho del mensaje a 12 bytes. Estas limitaciones condicionan la medición multipunto ya que haría falta un sistema para cada punto de medida lo que encarece la monitorización. Todos los datos pasan por los servidores de Sigfox con los condicionantes de licencia que conlleva.

De los sistemas analizados que tienen sistema de medida colaborativa multipunto (nodos), la mayor parte de ellos usan tecnologías propietarias entre los nodos y los gateway.

Con toda esta información se determinó en qué modo el diseño y desarrollo de un sistema de monitorización podía paliar el nicho de mercado, puesto que existen sistemas que en base podrían ser similares. Se estudió el tipo de comunicación colaborativa entre nodos que permitiera, además, la posibilidad de comunicación sin necesidad de gateway lo que implica un protocolo de comunicaciones standard. Esta decisión implica el diseño de sistemas de coste reducido y con bajo consumo de energía para utilizarlos en el ámbito descrito. Además, y puesto que en algunos casos el apoyo logístico y técnico de las empresas simplemente consiste en avisar en caso de que las condiciones ambientales no fueran las idóneas, se incluyó en el desarrollo e implementación de los equipos un asesoramiento en el cual dichas condiciones estén directamente relacionadas con la carga que se transporta de tal forma que se pueda determinar cómo la incorrecta manipulación de las variables ambientales afecta a la calidad de dicha carga. 


\subsection{CALIDAD POSTRECOLECCIÓN DE FRUTAS Y HORTALIZAS}

\subsubsection{Calidad postcosecha}

La postcosecha de productos hortofrutícolas comienza en el momento y lugar de la cosecha y termina en la mesa del consumidor, donde desde el primer momento hasta que se consumen los productos se deben buscar técnicas encaminadas a preservar la calidad durante el mayor tiempo posible, minimizando a la vez las pérdidas, lo que asegurará una renta máxima a todos los que intervienen, maximizando los beneficios (The hidden harvest, 1976).

Según la FAO (2019), anualmente se pierde o desperdicia un tercio de la cantidad total de los alimentos producidos para el consumo humano, mientras que 870 millones de personas pasan hambre en el mundo. En Europa y Norteamérica, el desperdicio per cápita promedio es de entre 95 y $115 \mathrm{~kg} /$ año.

Actualmente, los gobiernos de los países desarrollados están fijando mucha atención en la seguridad de los alimentos, en cómo se producen o manipulan y en los procesos que se llevan a cabo antes de llegar a los consumidores. Es por eso por lo que cada día los certificados de calidad alimentarios se tienen más en consideración, ya que establecen las condiciones óptimas en las cuales se ha de mantener la mercancía, garantizando su fiabilidad, además de reconocer la seguridad de los productos, lo que se traduce en una garantía para adquirir una imagen adecuada por parte de las empresas en el mercado. Entre los distintos certificados de seguridad en la cadena alimentaria se encuentran:

- British Retail Consortium (BRC): es uno de los modelos más difundidos internacionalmente para la cualificación de los proveedores a distribuidores y grandes superficies. Es un protocolo mundial que garantiza que los proveedores cumplen con unos requisitos preestablecidos de seguridad de sus alimentos, además de incluir herramientas de mejora en la gestión. Las empresas del sector alimentario deben de disponer de sistemas necesarios para identificar $y$ controlar los peligros que puedan afectar negativamente a la seguridad de los alimentos mediante un sistema de Análisis de Peligros y Puntos de Control Crítico (APPCC) y contando con el firme compromiso del equipo directivo de la empresa. Actualmente y dada la situación política inglesa, si se accede a la página web del certificado, de lo primero que informan es de las condiciones extraordinarias de adhesión y mantenimiento de este certificado anual, debido al Brexit (BRC, 2019).

- International Food Standard (IFS): norma común que trata la inocuidad de los alimentos con un sistema uniforme de evaluación utilizado para clasificar y seleccionar a proveedores. Ayuda a los minoristas a garantizar la seguridad alimentaria de sus productos y controla el nivel de calidad de los productores de la cadena minorista de productos alimenticios de marca (IFS Database - Home, 2019). 
- ISO 22000: norma de la serie ISO que define los requisitos para implementar un Sistema de Gestión de Inocuidad de los alimentos a lo largo de toda la cadena alimentaria hasta que llegan al consumidor final. Es aplicable a cualquier tipo de empresa, independientemente de su tamaño, que esté implicada en el proceso alimentario: producción, manipulación, almacenamiento y distribución (ISO 22000 Sistema de gestión de la Seguridad Alimentaria, 2019).

- PAS 220:2008: norma que especifica los requisitos para programas de requisitos previos, con el fin de ayudar en el control de riesgos de inocuidad de alimentos, dentro de los procesos de fabricación de las cadenas internacionales de suministros de alimentos. Se ha creado para ser usado en conjunción con la norma ISO 22000, el estándar reconocido internacionalmente sobre sistemas de gestión de seguridad alimentaria, puesto que uno de sus requerimientos es establecer, implementar y mantener programas de prerrequisitos que ayuden a controlar los riesgos de seguridad alimentaria en las organizaciones.

- FSSC 22000: combinación de las normas ISO 22000 y PAS 220, la cual ha sido comparada y aprobada por la Iniciativa Mundial de Seguridad Alimentaria (GFSI - "Global Food Safety Iniciative"). Se posiciona al mismo nivel que otras normas aprobadas de GFSI (BRC, IFS) e incluso podría reemplazarlas (FSSC 22000, 2019).

- HACCP: rige los peligros y puntos críticos de control.

- ISO 22005: marca las directrices relacionadas con la trazabilidad.

- CEPA: (Confederación Europea de Asociaciones de Empresas de Control de Plagas) está basada en la Norma UNE -EN 16636:2015 y va más allá del mero cumplimiento legal, facilitando una serie de buenas prácticas que normalizan las actividades de las empresas de control de plagas haciéndolas más dinámicas y eficientes.

Además, y de forma más específica, existen otros certificados para el sector hortofrutícola:

- GLOBALG.A.P.: organismo privado que establece normas voluntarias a través de las cuales se pueden certificar productos agrícolas en todas partes del mundo. El objetivo es establecer una norma única de buenas prácticas agrícolas (BPA), aplicable a diferentes productos y capaz de abarcar la globalidad de la producción agrícola. Para los consumidores y distribuidores este certificado es una garantía de que el producto cumple con los niveles establecidos de calidad, seguridad y que se han elaborado siguiendo criterios de sostenibilidad, respetando la seguridad, higiene y seguridad de los trabajadores, el medio ambiente y teniendo en cuenta el respeto a los animales (GLOBALG.A.P., 2019).

- Tesco Nurture: estándar privado de origen británico que es requisito que cumplir por todos aquellos agricultores proveedores de fruta y verdura de los supermercados de origen inglés Tesco. Exige un mayor control en el empleo de fitosanitarios, estableciendo listas de productos permitidos más restrictivas que 
las que están establecidas por las administraciones de los diversos países productivos, incluidos la Unión Europea (AENOR, 2016).

- Albert Heijn: estándar privado de origen holandés, requisito que deben cumplir todos aquellos agricultores proveedores de fruta y verdura de los supermercados de origen holandés Albert Heijn. El objetivo principal es el de asegurar al consumidor que las frutas y hortalizas de los proveedores de ALBERT HEIJN cumplen plenamente con la legislación europea y holandesa de límites de residuos de productos fitosanitarios (CAAE, 2015).

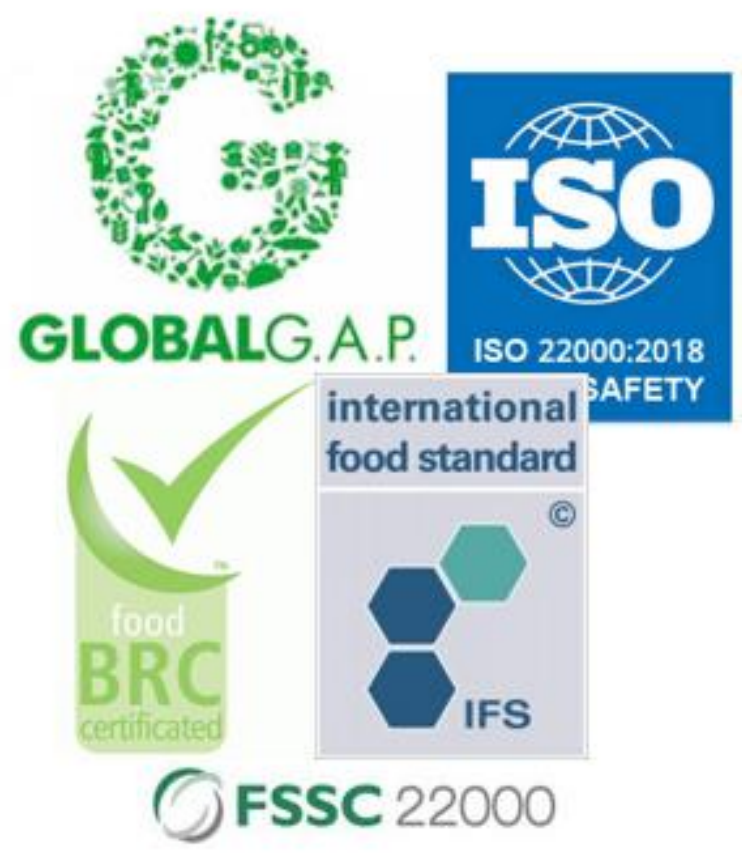

Figura 13. Detalle de los logos de los distintos tipos de certificación.

\subsubsection{Principales factores ambientales que influyen en la calidad}

La calidad y maduración de los productos agroalimentarios, su seguridad alimentaria y el desperdicio de alimentos están íntimamente conectados a través de las condiciones ambientales en las que dichos productos se manipulan, conservan, transportan y venden. De dichas condiciones ambientales, la temperatura (necesaria para la refrigeración durante la cadena de suministro) es con diferencia el principal factor que va a determinar el éxito de preservar con elevada calidad y seguridad un producto hortofrutícola durante el mayor tiempo posible. Sin embargo, suele suceder que la temperatura durante la cadena de suministro no es la recomendada como óptima o no es tan estable como debería ser, acelerando así el proceso de maduración de las frutas y hortalizas.

Mercier et al. (2017) ilustraron los cuatro puntos típicos donde se producen potencialmente los abusos de temperatura durante la cadena de suministro y en los cuales hay que llevar un control más exhaustivo de los rangos de temperaturas dentro 
de los cuales deben permanecer, diferenciando varios rangos como temperatura ambiente $\left(25^{\circ} \mathrm{C}\right.$ a $\left.15^{\circ} \mathrm{C}\right)$, refrigeración $\left(15^{\circ} \mathrm{C}\right.$ a $\left.20^{\circ} \mathrm{C}\right)$, y congelación $\left(\leq-18^{\circ} \mathrm{C}\right)$ (Figura 14$)$.

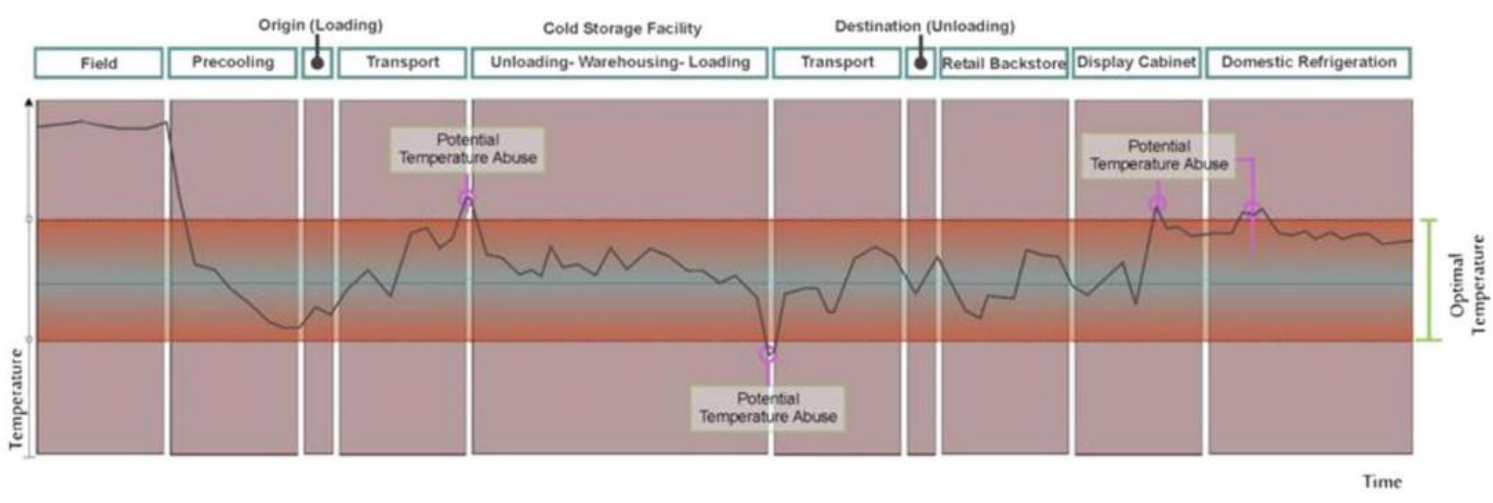

Figura 14. Perfil típico de temperatura en la cadena de frío de productos perecederos (Mercier et al., 2017).

Como se puede observar, los puntos en los cuales se produce una mayor variación de la temperatura de consigna son aquellos en los que se produce un cambio de situación de la mercancía, durante las transiciones entre la recogida en campo, el transporte, el centro logístico, el mostrador del supermercado y el frigorífico del consumidor final. Esos puntos están contrastados con la bibliografía existente (Jedermann et al., 2014), lo que corrobora que la gestión en el control de la temperatura durante la cadena de frío es inadecuada (Badia-Melis y Ruiz-García, 2016).

Otro efecto secundario que tiene la temperatura es que modifica variables como la humedad relativa, la concentración de gases fisiológicamente como el oxígeno $\left(\mathrm{O}_{2}\right)$, dióxido de carbono $\left(\mathrm{CO}_{2}\right)$ y el etileno $\left(\mathrm{C}_{2} \mathrm{H}_{4}\right)$, conocido como la hormona de la maduración, los cuales juegan un papel decisivo en los procesos metabólicos primarios y secundarios en los órganos vegetales. Si bien se define metabolismo como el conjunto de reacciones químicas que se llevan a cabo en el interior de las células de los seres vivos para sintetizar sustancias complejas partiendo de otras más simples o, al contrario, para degradar las complejas con la finalidad de conseguir las simples, el diferenciar primario de secundario se debe al objetivo que presentan esas acciones de síntesis y/o degradación (Taiz y Zeiger, 2006).

Así pues, los procesos metabólicos primarios se pueden reducir a procesos fotosintéticos, respiratorios, de asimilación de nutrientes, transporte de solutos o síntesis de proteínas, carbohidratos o lípidos; procesos todos ellos esenciales para el desarrollo y funcionamiento de cualquier individuo del reino vegetal (Carrera, 2014). Sin embargo, en el caso de los procesos metabólicos secundarios, pese a trabajar con las mismas sustancias (carbono, nitrógeno y energía), estos nada tienen que ver con las actividades básicas de desarrollo de las plantas, sino que presentan distintos objetivos: protectora frente a predadores, atrayentes para facilitar su polinización, formadoras de pigmentos, etc. Es por eso por lo que estos procesos no son iguales y presentan una distribución definida dentro del reino vegetal (Ávalos-García y Pérez-Urria, 2009). 


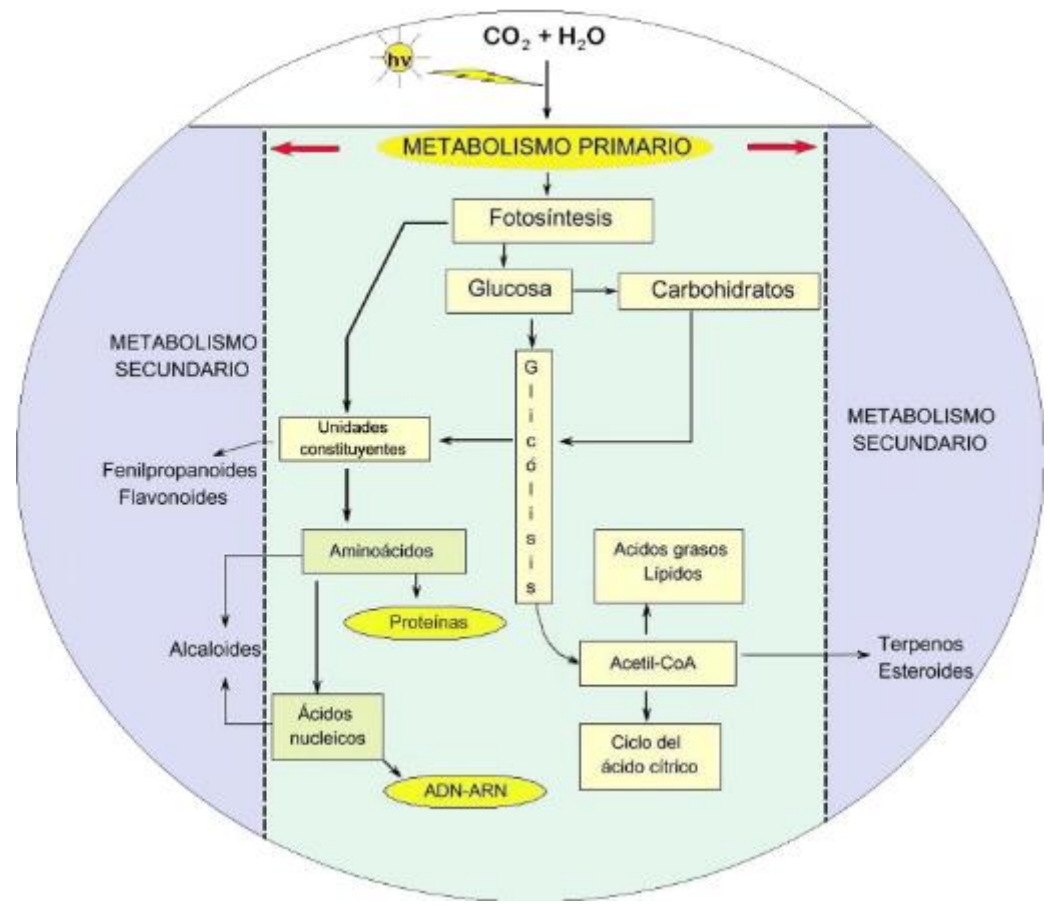

Figura 15. Elementos básicos del metabolismo primario y relación con el metabolismo secundario de las plantas (Ávalos-García y Pérez-Urria, 2009).

Pero lo que tienen en común ambos procesos metabólicos es el consumo de sustancias como el $\mathrm{O}_{2}$ y el $\mathrm{CO}_{2}$ durante toda la vida de estos. Y es que las frutas y verduras continúan vivas y por lo tanto respirando después de ser recolectadas. Esto hace que al producirse y consumirse dichas sustancias, se favorezca la maduración y senescencia de los productos durante toda la cadena de frío. De ahí la importancia de garantirzar las condiciones climáticas adecuadas.

\subsubsection{Condiciones recomendadas de conservación y transporte de frutas y hortalizas}

Por lo que antecede, diversos investigadores se han centrado en prolongar la vida útil de los productos mediante técnicas como cosechar el producto en su estado de madurez óptima, reduciendo al mínimo las lesiones mecánicas, con los procedimientos de saneamiento adecuados y manteniendo la temperatura y la HR óptima durante el manejo postcosecha, ayuda a prolongarla (Artés et al., 2012).

De la temperatura ya se ha hablado ampliamente, la cual debe ir acompañada de una elevada HR (superior al 90\%), puesto que las frutas y hortalizas están constituidas fundamentalmente por agua y el adecuado mantenimiento de dicha HR durante el almacenamiento es otro de los aspectos claves para mantener la calidad durante la postcosecha. La pérdida de agua o deshidratación no solamente significa la disminución del peso fresco sino también afecta la apariencia, la textura, y en algunos casos el sabor. La pérdida de textura crujiente y turgencia están directamente asociadas a la sensación de frescura o de recién cosechadas que son apreciadas por todos los consumidores. 
La HR es el parámetro más usado para expresar la cantidad de agua presente en el aire y se define como la relación porcentual entre la presión de vapor del agua real y aquella en el punto de saturación del aire a esa temperatura. Como todos los gases, el vapor de agua se mueve de una zona de mayor a otra de menor presión parcial. En los tejidos vegetales, el agua se encuentra mayormente en forma líquida, formando parte de los jugos celulares, pero en equilibrio con los espacios intercelulares en donde se halla en forma gaseosa en concentraciones muy próximas a la saturación (100\% HR). A menos que ese tejido vegetal esté expuesto a un ambiente saturado y de idéntica temperatura, siempre va a existir una diferencia de presiones parciales de vapor de agua que hace que el producto se deshidrate. La capacidad del aire para retener vapor de agua aumenta con la temperatura y, por lo tanto, se incrementa la cantidad que es necesaria para saturarlo. Basado en este principio, la disminución de la temperatura por medio de la refrigeración incrementa la humedad relativa de la masa de aire refrigerada, pero aun así muchas veces es necesario agregar humedad adicional mediante humidificadores para que alcance los niveles ideales durante el almacenamiento y transporte (LópezCamelo, 2003).

Otro de los métodos utilizados para conseguir maximizar la vida útil es modificando las concentraciones de $\mathrm{O}_{2}, \mathrm{CO}_{2} \circ \mathrm{C}_{2} \mathrm{H}_{4}$ que rodea el producto. Esta modificación se puede realizar disminuyendo la concentración de $\mathrm{O}_{2}$ o moderando la de $\mathrm{CO}_{2}$ de forma que se minimiza la respiración y otros procesos vitales del metabolismo del producto. De esta manera se consigue prolongar la vida útil bajo una calidad superior al no reducirse determinados compuestos nutritivos de los productos que son sustratos respiratorio, entre otras cosas (Artés et al., 2006).

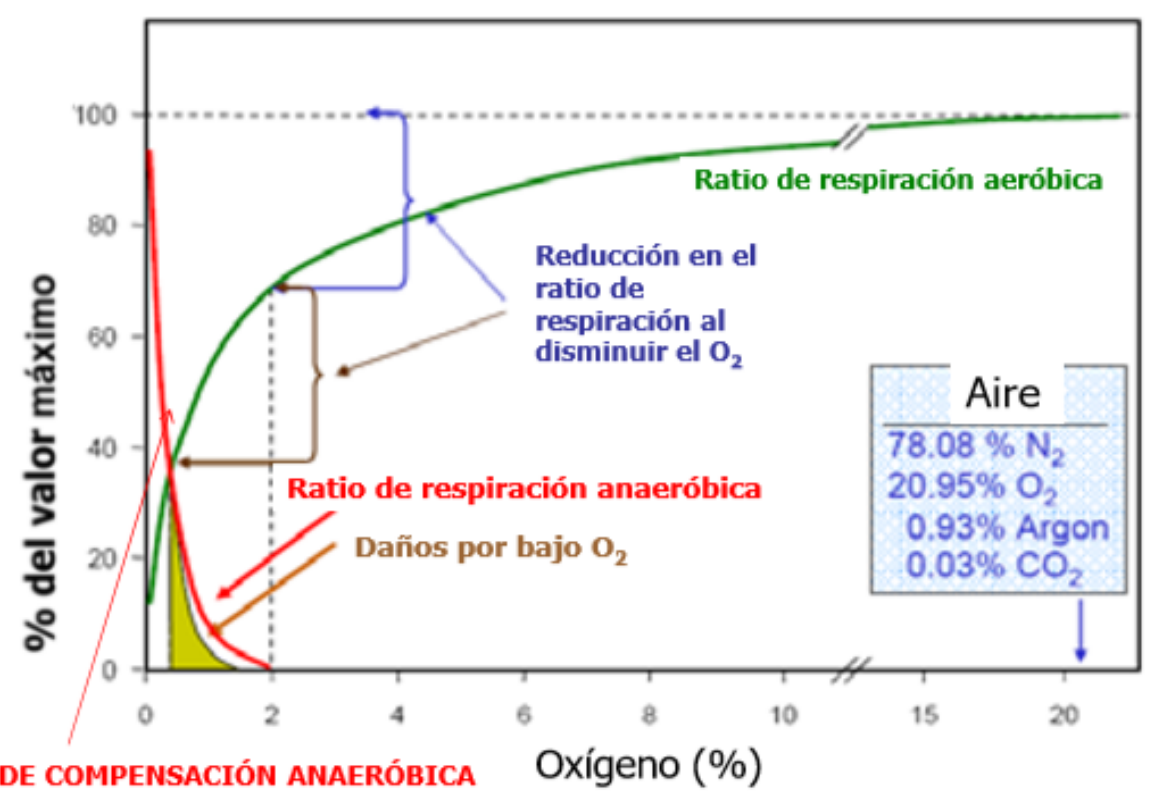

Figura 16. Efecto de la disminución de la concentración de oxígeno en la respiración (Artés-Hernández, 2016a).

Se acuña por tanto el término de envasado en atmósfera modificada (EAM), que permite almacenar frutas y hortalizas, mediante films envolventes de permeabilidad selectiva a 
los gases, para generar una atmósfera modificada en el interior del envasar, que sea la óptima para la conservación, reduciendo así su tasa de respiración. Esta técnica es coadyuvante de la refrigeración y no puede utilizarse sin ella.

En la bibliografía, se pueden encontrar concentraciones de gases recomendadas para los cuales se amplía la vida útil de hortalizas y frutas (Figuras 17 y 18), si bien es cierto que éstos solo se deben como recomendaciones y sería preciso determinar con precisión los rangos óptimos para los productos que se vayan a conservar o transportar bajo esta técnica. 


\begin{tabular}{|c|c|c|c|c|c|c|c|}
\hline Producto & $\begin{array}{c}\text { Temper. } \\
\text { óptima } \\
\left({ }^{\circ} \mathrm{C}\right)^{*}\end{array}$ & $\begin{array}{c}\text { Rango } \\
\text { máximo } \\
\left({ }^{\circ} \mathrm{C}\right)^{*}\end{array}$ & $\begin{array}{r}\text { Concer } \\
\text { gase } \\
\mathbf{k P a ~ O _ { 2 }}\end{array}$ & $\begin{array}{l}\text { aciones } \\
\mathrm{as}_{\mathrm{as}} \& \\
\mathrm{PPa} \mathrm{CO}_{2}\end{array}$ & $\begin{array}{c}\text { Beneficio } \\
\text { potencial } \\
\star\end{array}$ & $\begin{array}{c}\text { Duración } \\
\text { máxima } \\
\text { (días) }\end{array}$ & $\begin{array}{c}\text { Aplicación } \\
\text { industrial }\end{array}$ \\
\hline Alcachofa & 0 & $0-4$ & $2-3$ & $1-3$ & $A-B$ & $10-16$ & $\mathrm{x}$ \\
\hline Apio & 0 & $0-4$ & $2-5$ & $5-10$ & B & $21-28$ & $\mathrm{Y}$ \\
\hline Berenjena & 8 & $8-12$ & 21 & 5 & $\mathrm{C}$ & $10-14$ & $\mathrm{Y}$ \\
\hline Berza & 0 & $0-5$ & $3-5$ & $5-7$ & B & $21-28$ & $\mathrm{Y}$ \\
\hline Boniato o batata & $12-16$ & $12-16$ & 21 & 0 & D & $120-200$ & z \\
\hline Bróculi & 0 & $0-4$ & $1-2$ & $5-10$ & $A-B$ & $10-14$ & $\bar{W}$ \\
\hline Calabaza & $10-15$ & $12-15$ & $3-5$ & $5-10$ & B & $60-90$ & W \\
\hline Calabacín & $7-10$ & $7-10$ & $3-5$ & $5-10$ & $A-B$ & $7-14$ & W \\
\hline Cebolla (seca) & $-2-0$ & $0-4$ & $1-3$ & $5-10$ & $\mathrm{~B}$ & $30-240$ & $\mathrm{Y}$ \\
\hline $\begin{array}{l}\text { Cebolla (verde) } \\
\text { Col de Bruselas }\end{array}$ & $\begin{array}{c}0 \\
-1-0\end{array}$ & $\begin{array}{l}0-4 \\
0-4\end{array}$ & $\begin{array}{l}2-4 \\
1-2\end{array}$ & $\begin{array}{l}5-20 \\
5-7\end{array}$ & $\underset{A-B}{C}$ & $\begin{array}{l}14-21 \\
21-35\end{array}$ & $\begin{array}{l}Y \\
Y\end{array}$ \\
\hline Col picuda y repollo & 0 & $0-4$ & $1-2$ & $1-5$ & $\mathrm{C}$ & $30-60$ & $X-Y$ \\
\hline Coliflor & 0 & $0-4$ & $3-5$ & $2-4$ & $\mathrm{C}$ & $21-35$ & $X-Y$ \\
\hline Colirrábano con hoja & 0 & $0-4$ & $3-5$ & $5-10$ & $A-B$ & $12-16$ & $\mathrm{Y}$ \\
\hline Endivia- escarola & 0 & $0-4$ & $2-3$ & $2-5$ & A & $10-14$ & W \\
\hline Espárrago & 0 & $0-4$ & 21 & $5-10$ & $A-B$ & $14-21$ & W \\
\hline Espinaca & 0 & $0-4$ & 21 & $10-20$ & $B-C$ & $10-14$ & W \\
\hline Guisante & 0 & $0-4$ & $2-5$ & $5-10$ & B & $7-10$ & $\mathrm{Y}$ \\
\hline Hinojo & 0 & $0-4$ & $2-5$ & $10-15$ & $A-B$ & $21-28$ & $\mathrm{Y}$ \\
\hline Judía verde & $5-6$ & $4-8$ & $2-3$ & $5-10$ & $\mathrm{C}$ & $10-14$ & $\mathrm{Y}$ \\
\hline Lechuga & 0 & $0-4$ & $2-5$ & $0-1$ & $A-B$ & $14-21$ & $w-x$ \\
\hline Maíz dulce & 0 & $0-4$ & $2-4$ & $10-20$ & B & $4-7$ & $\mathrm{Y}$ \\
\hline $\begin{array}{l}\text { Melones Cantaloup, Galia y } \\
\text { Ogen }\end{array}$ & $3-9$ & $3-7$ & $3-5$ & $10-15$ & $B-C$ & $10-15$ & $X-Y$ \\
\hline Melón honeydew & $10-14$ & $10-12$ & $3-5$ & 0 & C & $21-28$ & $\mathrm{Y}$ \\
\hline Melón de agua (Sandía) & 12 & $10-15$ & 21 & 0 & D & $14-21$ & $z$ \\
\hline Nabo & 0 & $0-4$ & 21 & 0 & D & $120-150$ & z \\
\hline Patata & $4-6$ & $4-8$ & $3-5$ & 10 & $C-D$ & $10-14$ & z \\
\hline Pepino & $8-13$ & $13-16$ & $3-5$ & $2-5$ & $\mathrm{C}$ & $10-14$ & $\mathrm{Y}$ \\
\hline Perejil & 0 & $0-4$ & $8-10$ & $8-10$ & B & $10-14$ & $\mathrm{Y}$ \\
\hline Pimiento & $7-12$ & $8-12$ & $2-5$ & $2-5$ & $B-C$ & $14-21$ & $\mathrm{Y}$ \\
\hline Puerro & $-1-0$ & $0-4$ & $1-2$ & $3-5$ & B & $50-60$ & $X-Y$ \\
\hline Rábano & 0 & $0-4$ & $1-2$ & $2-3$ & $A-B$ & $30-60$ & $\mathrm{x}$ \\
\hline Remolacha & 0 & $0-4$ & 21 & 0 & $\mathrm{D}$ & $100-140$ & z \\
\hline Setas & 0 & $0-4$ & $3-21$ & $5-15$ & B & $7-14$ & $X-Y$ \\
\hline Tomate verde/pintón & $11-13$ & $11-15$ & $3-5$ & $1-3$ & $A-B$ & $14-30$ & $\mathrm{Y}$ \\
\hline Tomate rosado/rojo & $9-10$ & $9-12$ & $3-5$ & $1-5$ & $A-B$ & $7-21$ & $\mathrm{x}$ \\
\hline Zanahoria & $0-1$ & $0-4$ & $5-10$ & $0-3$ & $\mathrm{C}$ & $180-240$ & $Y-Z$ \\
\hline
\end{tabular}

Figura 17.Temperaturas, Composiciones Gaseosas para las Atmósferas de Equilibrio, Beneficio Esperado, Duración de la Conservación y/o Transporte y Aplicación Industrial del Envasado en Atmósfera Modificada a Hortalizas (Artés, 2006). 


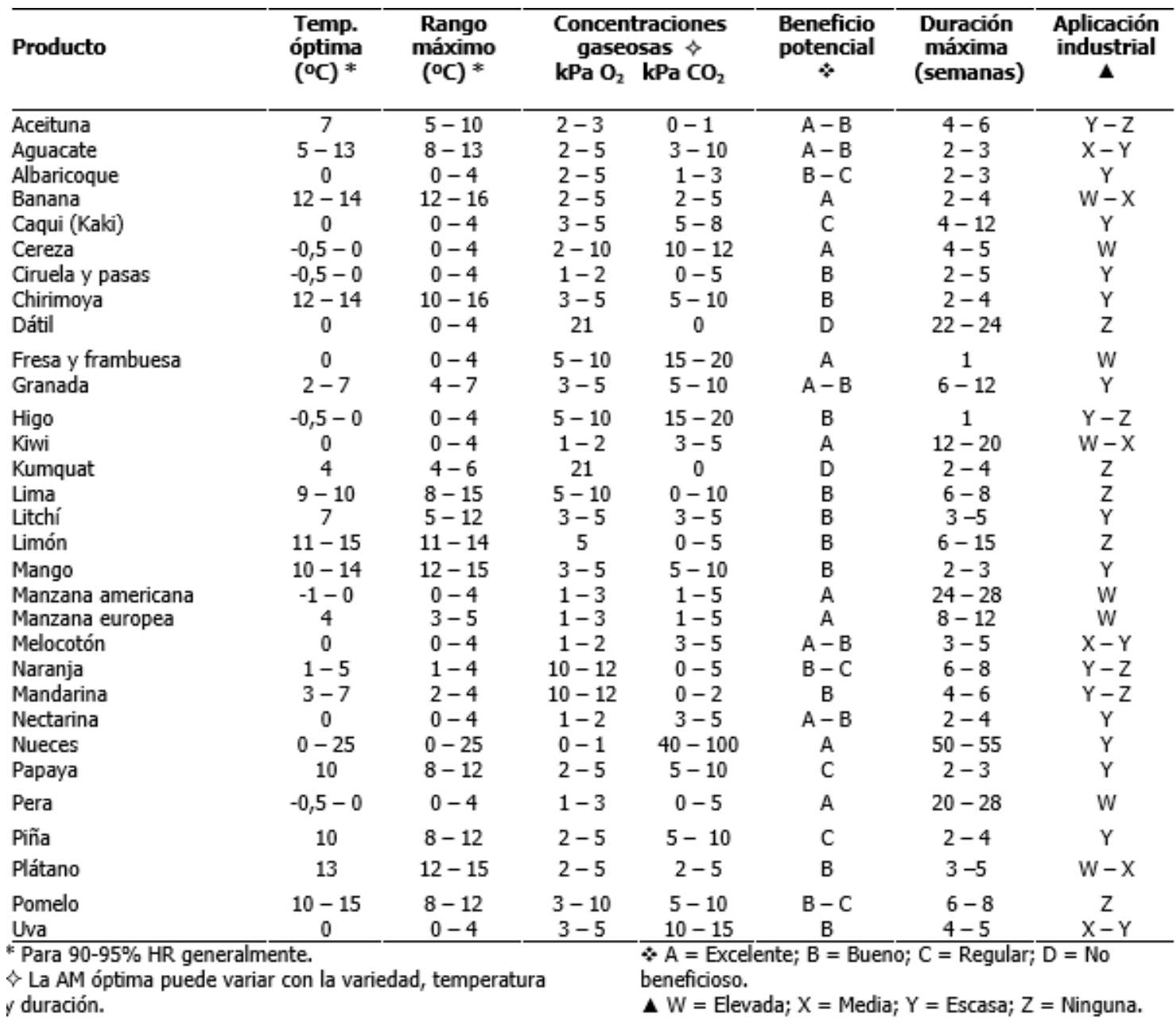

Figura 18. Temperaturas, Composiciones Gaseosas para las Atmósferas de Equilibrio, Beneficio Esperado, Duración de la Conservación y/o Transporte y Aplicación Industrial del Envasado en Atmósfera Modificada a Frutas (Artés, 2006).

El etileno $\left(\mathrm{C}_{2} \mathrm{H}_{4}\right)$ es un hidrocarbono naturalmente producido por productos hortofrutícolas, entre otras fuentes. Es conocido como "la hormona de la maduración" porque regula procesos asociados como la maduración y la senescencia. Su origen puede ser endógeno, biosintetizado por los frutos, climatéricos o no climatéricos, siendo autocatalítico (especialmente importante en los frutos climatéricos). Igualmente puede ser exógeno, aportado desde el exterior por diversos medios. Es fisiológicamente activo en muchos productos hortofrutícolas y ornamentales incluso a muy bajas concentraciones $(<0,1 \mathrm{ppm})$. El $\mathrm{C}_{2} \mathrm{H}_{4}$ se usa para regular el crecimiento, desarrollo y maduración de muchos productos. Su principal aplicación postcosecha es controlar la maduración de los frutos. Entre sus efectos negativos destaca que su presencia induce a madurar los productos hortofrutícolas cuando no interesa, por lo que, en la mayoría de los casos durante la conservación y el transporte se deben buscar técnicas que permitan eliminar el $\mathrm{C}_{2} \mathrm{H}_{4}$ del ambiente de conservación y que no interfieran con una madurez inadecuada e inapropiada para la mercancía (Álvarez-Hernández et al., 2018). 


\subsubsection{Estrategias para minimizar las pérdidas de calidad durante la postcosecha}

De cuanto antecede, se ha expuesto que existen diversas estrategias para minimizar las pérdidas de calidad que se deben tener en cuenta para reducir esas elevadas pérdidas de alimentos. A modo de resumen en este apartado, entre dichas técnicas se encuentra recolectar el producto con la madurez adecuada en función de su destino, para que las frutas y hortalizas lleguen al consumidor con la calidad óptima, seleccionar la variedad adecuada en función del mercado de destino, evitar los daños mecánicos como los golpes, rozaduras, aplastamientos y vibraciones, permanecer en todo momento a la temperatura idónea de conservación/transporte/venta al detalle, disminuir la deshidratación (aumentando la humedad relativa en el ambiente circundante mediante un envasado apropiado o mediante encerado o recubrimientos comestibles). De todas estas tecnologías, sobre todo el mantenimiento a la temperatura postcosecha adecuada y el mantenimiento de una humedad relativa alta son las claves más importantes para ralentizar las pérdidas de calidad. Del mismo modo, se pueden aplicar diversos tratamientos suplementarios como la modificación de la atmósfera (mediante la conservación en atmósferas controladas o el envasado en atmósferas modificadas), la eliminación de etileno (especialmente en productos climatéricos), la higienización mediante agentes químicos o físicos autorizados, el biocontrol, etc. (Artés-Hernández, 2019b).

La correcta aplicación de las tecnologías comentadas, con el correspondiente conocimiento técnico, supondrá sin duda una minimización de las pérdidas de calidad de los productos hortofrutícolas que permitirá conservarlos con la calidad adecuada durante más tiempo, y permitir por tanto alargar su vida útil y que por diversas causas no sean desechados y desperdiciados.

\subsection{MODELOS DE ESTIMACIÓN DEL VIDA COMERCIAL DE PRODUCTOS HORTOFRUTÍCOLAS}

El control en tiempo real de la temperatura ambiental durante el transporte permitirá la venta de los productos, en el peor de los casos cuando no se mantengan a los niveles recomendados, destinándolos a otros canales de venta menos exigentes o con menos rotaciones y minimizar la tasa de rechazo en destino (estimada en un 5\%). Sin embargo, los sistemas de transporte terrestre no miden la temperatura de la pulpa dentro de la fruta. Solo algunos contenedores refrigerados pueden tener hasta 3 sondas de medición de temperatura de pulpa, que se utilizan básicamente para llevar a cabo tratamientos de cuarentena cuando se exportan a países que lo requieren, pero no como un procedimiento habitual para medir la temperatura de los productos. Además, debido a que los sistemas de transporte no están diseñados para enfriar eficientemente el producto, éstos deben ingresar al contenedor/camión a la temperatura de transporte para que el sistema frigorífico pueda compensar el calor proveniente del exterior 
mediante transmisión o irradiación, y el calor de respiración producido por los productos transportados (Thomson y Bretch, 2002)

Debido a que la dinámica térmica del aire es más alta que la de los productos refrigerados ya que éstos tienen una "inercia térmica", la temperatura del aire cambia mucho más rápido que la temperatura del producto (Thompson et al., 2002). Por esta razón, la medición de la temperatura ambiental para determinar roturas de la cadena de frío, que puedan ser perjudiciales a los productos requiere indicadores estadísticos apropiados que permitan la integración de las diferencias en la dinámica entre ambas temperaturas del aire y producto (Do Nascimento Nunes et al., 2014).

Modelar las condiciones atmosféricas durante la línea de distribución en función de la calidad es una de las formas más utilizadas. Ejemplo de ello es la prueba de vida útil acelerada (ASLT - “Accelerated Shelf Life Testing") propuesta por Labuza (1982) basada en tres pasos: la descripción cinética de las reacciones de degradación más importantes de los alimentos a diferentes temperaturas, definir la dependencia de la temperatura y las constantes de velocidad (utilizando mayoritariamente la ecuación de Arrhenius) y el cálculo de la vida útil del producto alimenticio. Pese a ser una buena herramienta de cálculo para una estimación aceptable de la vida útil (Amodio et al., 2015) el problema que presenta esta metodología radica en que no hay forma de asegurar que lo que estima se pueda relacionar con lo que se observa experimentalmente. Además, de que a la hora de definir de los criterios de corte resulta bastante complicada, ya que hay que tener en cuenta las regulaciones de seguridad o los intereses de los actores que intervienen en la distribución.

Otra de las metodologías utilizadas es la prueba multivariable de vida útil acelerada (MASLT - "Multivariate Accelerated Shelf Life Testing") (Pedro y Ferreira, 2009) basada en el análisis de componentes principales (PCA - "Principal Component Analysis") que encuentra nuevos ejes en el espacio multivariable para mejorar la descripción de la estructura de datos experimentales. La base en la que se apoya es que las reacciones en la pérdida de calidad son el principal causante de las fluctuaciones en el histórico de datos, dado que el PCA está directamente relacionado con el tiempo. Mediante este método, se pueden utilizar los valores de PCA para describir un cuadro de cinética multivariable que muestre la información de degradación de todos los atributos de calidad estudiados. Una vez optimizado el modelo es posible estimar la vida útil del producto teniendo en cuenta los cambios de calidad. Sin embargo, aunque se presenta como una buena herramienta de estimación de la vida útil, se ha utilizado en escasas ocasiones, ya que la calidad en productos frescos procesados se ve afectada más rápidamente por tener cambios simultáneos en las condiciones de almacenamiento (Pedro y Ferreira, 2006; Córdova et al., 2011).

Si se dispone de las herramientas adecuadas, es posible desarrollar modelos de predicción basados en la correlación de variables observadas (medidas por los sensores) 
y las analizadas en el laboratorio. Los modelos utilizables pueden ser puramente regresores (regresión lineal polinomial, múltiple, etc.) puesto que se utilizan para:

- Identificar las variables predictivas en función de una variable respuesta.

- Describir cómo se relacionan estas variables de forma que al derivarse dicha relación ofrece una expresión matemática óptima que modela la dependencia.

- Predecir la variable de respuesta a partir de la/s predictora/s.

El ajuste de dichos métodos se realiza mediante mínimos cuadrados, ya que garantiza encontrar el valor de máxima verosimilitud de los parámetros del modelo lineal para un conjunto de datos, al minimizar la magnitud de la diferencia entre los puntos y la recta (Vinuesa, 2016).

Recientemente, las técnicas de aprendizaje automático como las redes neuronales artificiales (ANN - "Artificial Neural Networks") se muestran como una herramienta de modelado flexible, ya que en principio, pueden trabajar con cualquier tipo de relación de datos con una alta precisión (Zhang y Qi, 2005).

Se define aprendizaje automático (ML - "Machine Learning") como el campo de estudio que ofrece a los ordenadores la capacidad de aprender sin ser programados explícitamente (Samuel, 1959). El ML se aplica a las ANN con una gran repercusión en los últimos años en el ámbito de los procesos agrícolas. En la etapa postcosecha también se han utilizado específicamente para la predicción de la vida útil (Doganis et al., 2006) junto con sistemas de lógica difusa para una descripción de la estructura del uso de sistemas inteligentes artificiales en la cadena de frío. Sin embargo, debido a la gran cantidad de parámetros involucrados en la decisión final de una predicción de calidad de un producto perecedero, es necesaria la decisión humana final en estos sistemas.

Los sistemas de apoyo a la decisión (DSS - "Decision Support System") son una aplicación de aprendizaje automático que utiliza el conocimiento de un experto para la capacitación continua de un modelo que calcula o clasifica los valores de salida de un modelo entrenado. Los valores de salida del modelo entrenado sirven como soporte para la decisión final que debe tomar el experto, lo que permite un trabajo mucho más escalable. En Qi et al. (2014), un DSS específico fue diseñado para el manejo de la cadena de frío de productos alimenticios perecederos. El sistema se implementa en base a las características WSN y TTI. El contenedor inteligente utiliza sensores y sistemas cognitivos basados en DSS para estimar las pérdidas de calidad (Lang et al., 2011).

Sin embargo, los modelos basados en ML necesitan de una alta cantidad de datos validados, lo que hace que su aplicación en este tipo de proyectos precise de un gran número de ensayos y de cooperación internacional en forma de proyectos europeos (ensayos de calidad en productos marcados en destino) para poder ser llevados a cabo. 


\subsection{PROYECTOS EXISTENTES}

En el mercado se pueden encontrar actualmente diversos proyectos de investigación europeos que enfatizan la importancia de esta problemática. A modo de referencia, se han querido reflejar en esta Tesis estos proyectos ya que muestran la utilización de estas tecnologías con el objetivo de controlar y monitorizar las condiciones atmosféricas de las mercancías perecederas en las fases de postcosecha. A continuación, se describen los más influyentes.

\section{Chill-on}

Proyecto europeo, cuyos coordinadores principales fueron Dr. Gudrun Olafsdottir de la Universidad de Islandia y Maria Eden del centro de investigación alemán ttz Bremerhaven y que se desarrollaría entre 2006-2010, enfocado en una investigación sobre cada eslabón de la cadena de suministro de pescado, tanto refrigerado como congelado. En él incluyen las tecnologías existentes, así como en desarrollo, enfocándose en la monitorización y el rastreo de toda la cadena de suministro mediante un nuevo sistema desarrollado llamado eCHILL-ON. El proyecto se basaba en la predicción de la vida comercial utilizando RFID y TTI, y entrenando (Chill-On, 2010). Actualmente el acceso al proyecto mediante su página web es imposible, ya que el dominio está a la venta.

\section{PASTEUR}

Con una duración de 3 años (julio de 2009 a septiembre de 2012), empresas y universidades de los Países Bajos, Bélgica, Austria y España desarrollaron un sensor basado en la tecnología RFID tipo etiqueta, para controlar de forma rápida, barata y eficiente, las condiciones ambientales en la cadena de suministro (NVC Netherlands Packaging Centre, 2012). El estudio se dividió en dos debido a la naturaleza de las mercancías a estudiar (fruta y carne) y a las diferencias en los sistemas de medición:

- Etiqueta de sensor inteligente integrada, tipo RFID (con capacidad de medición de temperatura, humedad y $\mathrm{CO}_{2}$ ) para la caja de fruta.

- Sensor inteligente integrado en stick (con capacidad de medición de temperatura y de $\mathrm{pH}$ ) para la caja de carne. 


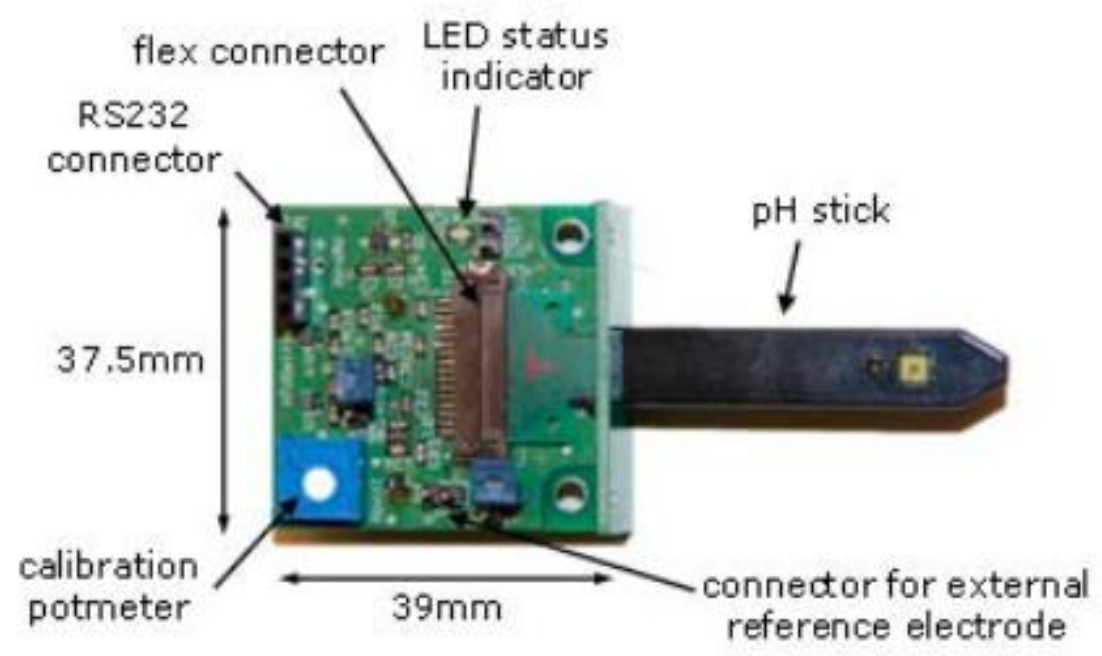

Figura 19. Fotografía del sistema desarrollado para el caso de la carne (Guillory y Strandhardt, 2012).

La comunicación con las etiquetas del sensor inteligente está disponible a través de una interfaz gráfica de usuario basada en la web. Al comunicarse a través del lector, se pueden identificar e interrogar etiquetas cercanas. La etiqueta del sensor inteligente contiene un modelo de control estadístico, el cual identifica rápidamente cualquier desajuste o variación en los parámetros establecidos previamente, siguiendo los límites específicos del producto para las condiciones monitoreadas por los sensores.

Por otro lado, la etiqueta del sensor contiene un modelo genérico de vida útil que calcula las fechas de caducidad dinámicas en función de las condiciones reales soportadas por el producto hasta la fecha. Esto es lo que la interfaz define el número de días de vida útil restante. En el caso de no conformidades o vida útil restante limitada, se pueden descargar, almacenar y comparar datos completos del sensor con los datos históricos disponibles en la base de datos.

Actualmente el proyecto está cerrado y no se puede acceder al software de funcionamiento. Puesto que este proyecto se ayudó de la asociación de empresas NVC, Netherlands Packaging Center fundada en 1953, en su página web uno puede registrarte como miembro y así participar en los cursos/actos en los cuales se exponen los avances relativos a las metodologías y tecnologías actuales de envasado de productos frescos. Pero no hacen referencia al proyecto antes descrito.

\section{Frisbee}

Su nombre proviene de las siglas: Food Refrigeration Innovation, Safety Consumers' Benefit, Environmental Impact and Energy Optimisation. Que podría traducirse como "La innovación en la alimentación refrigerada, el beneficio de la seguridad del consumidor, el impacto medioambiental y la optimización de energía". Y en esos cuatro pilares se apoya este proyecto europeo, cuyo trabajo se desarrolló desde el año 2010 hasta el año 2014 (European Proyect, 2010). La coordinadora principal es Graciela Álvarez, de la francesa Research Unit GPAN. 


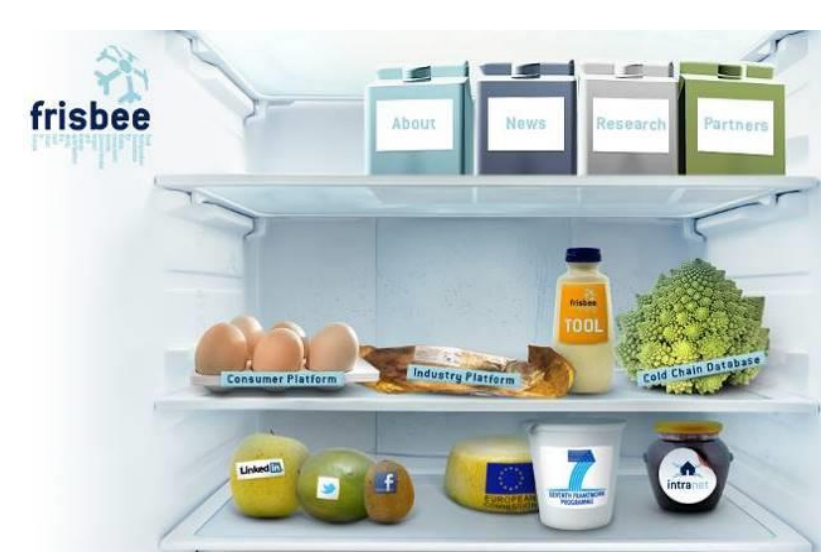

Figura 20. Página web del proyecto Frisbee (European Proyect, 2010).

El objetivo del proyecto era crear una base de datos con la información de la temperatura en tiempo real durante el transporte de mercancía helada y congelada, de forma que se compartiera dicha información con la finalidad de evolucionar y mejorar la cadena de frío. Como primer paso se compararon las líneas de distribución de 4 países europeos: Francia, Grecia, Reino Unido y Hungría, transportando la misma mercancía (jamón cocido envasado), aplicando la misma logística y utilizando los mismos protocolos (Derens-Bertheau et al., 2014). De esta forma se desarrolló la base de datos de la cadena de frío (CCD - "Cold Chain Database"), una plataforma online fácil de usar donde los datos recopilados de todas las etapas de la cadena de frío estuvieran disponibles para todos los agentes que intervienen en la cadena de frío. Así se podrían obtener perfiles de temperatura-tiempo a lo largo de la cadena de frío utilizando criterios de búsqueda tales como etapa, rango de temperatura de almacenamiento, tipo de alimento.

Además, se podría estimar la temperatura ideal para aumentar la vida útil de los alimentos utilizando la herramienta de predicción de la cadena de frío (CCP - "Cold Chain Predictor"), que se basa en la aplicación de las simulaciones Monte Carlo. Estas simulaciones utilizan un enfoque numérico para generar una distribución de probabilidad basada en escenarios hipotéticos en términos de valores de tiempotemperatura registrados durante la cadena de frío.

Hasta la fecha las pruebas se han realizado con manzanas, espinacas y helados, demostrando que la herramienta es útil a la hora de evaluar la huella de las fluctuaciones de temperatura y las opciones en cuanto a la de gestión logística (Ndraha et al., 2018). Como se intuye, el proyecto se centra en qué hacer con los datos recogidos y compartidos por los distintos países, pero no entra a cuestionar el cómo se registran, procesan y comparten los datos relacionados con la temperatura en tiempo real. $Y$ es que, en ningún momento la herramienta trata de dar respuesta a la pregunta de ¿qué está pasando en la línea de distribución específica de un producto y/o empresa? 


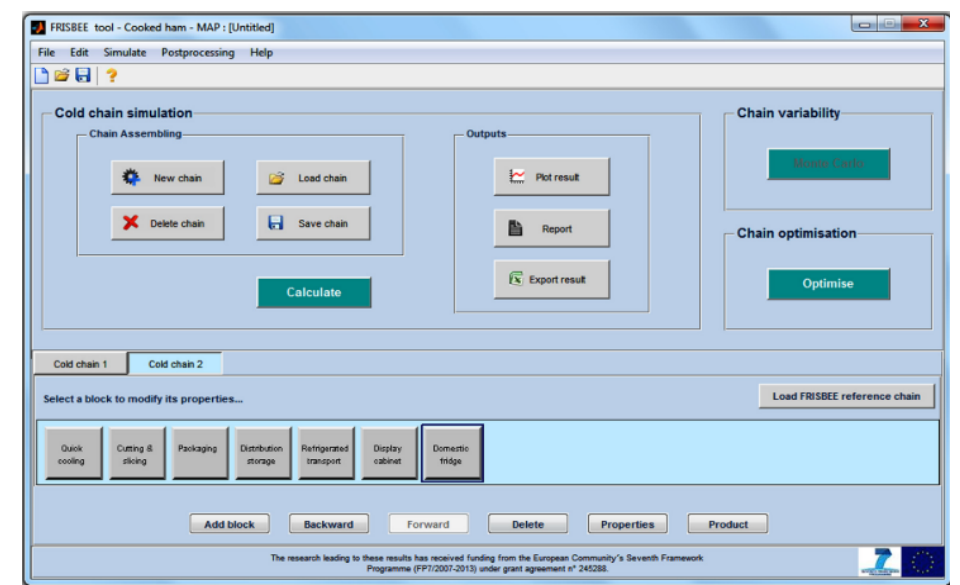

Figura 21. Interfaz de la herramienta Frisbee (European Proyect, 2010).

Una vez se tuvieran los datos, el usuario podría cargar un perfil de temperatura y simular la calidad del producto y la evolución de la seguridad basada en ese perfil de temperatura. Además, el software debe ser capaz de calcular el uso de energía de los sistemas de refrigeración, así como la emisión de $\mathrm{CO}_{2}$ para los diferentes tipos principales de vitrinas y frigoríficos domésticos (Gwanpua, 2015). De forma online, creando un perfil, se puede tener acceso a la base de datos, realizando una contribución inicial, cargando un historial de los datos propio registrado en cualquier paso de la cadena indicando el producto utilizado.

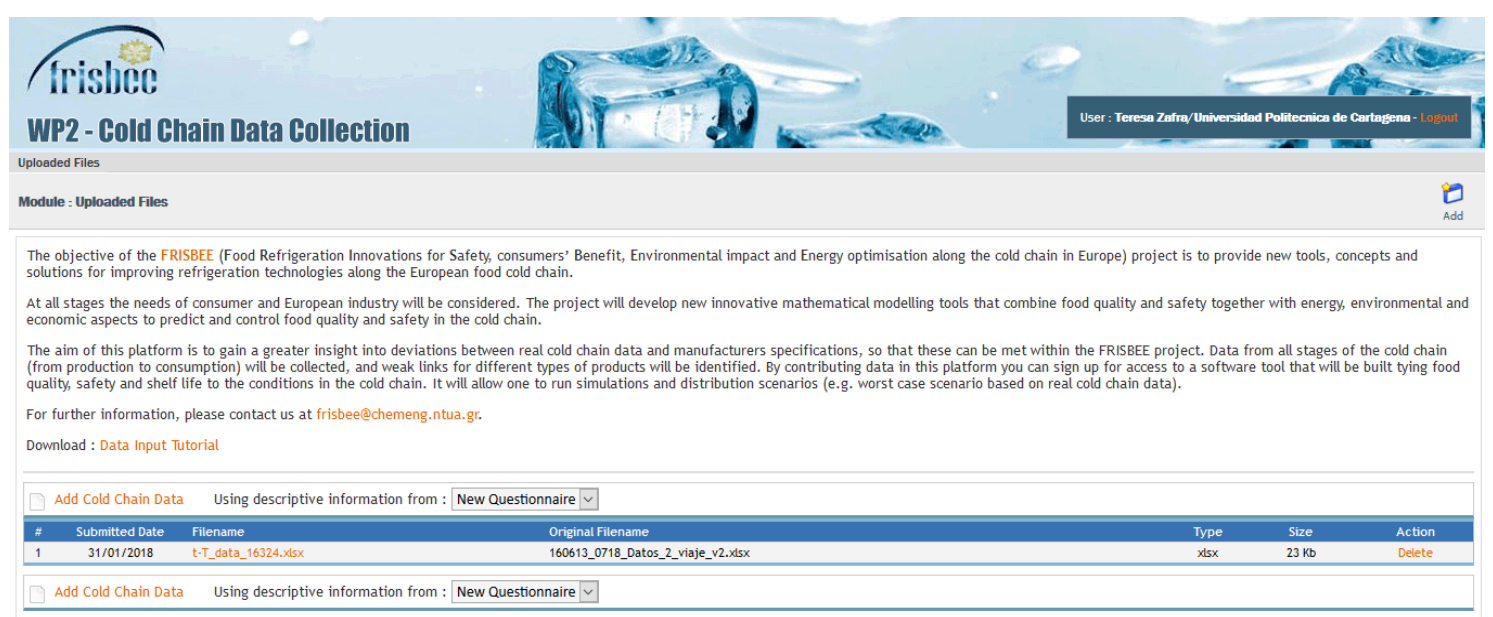

Figura 22. Detalle del registro de datos individual (Taoukis et al., 2016).

En caso de no hacerlo, el sistema solo permite acceder a unos datos preestablecidos, dentro de los cuales se puede descargar un fichero tipo Excel, con la información relativa a una cantidad de tiempo y unas variaciones de temperatura fijadas. 


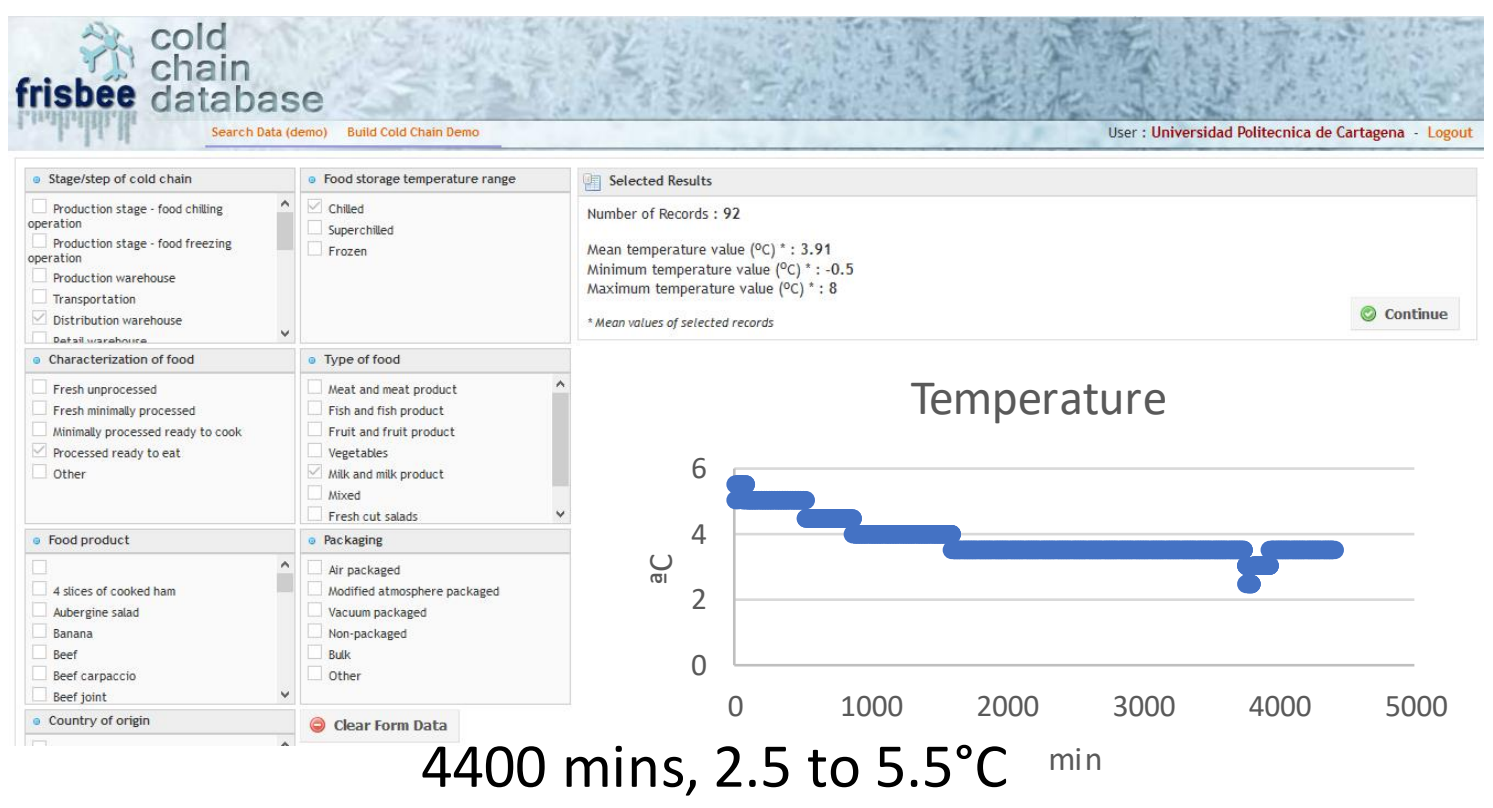

Figura 23. Interfaz de búsqueda de datos (demo) con el ejemplo de la gráfica t-T para 4.400 minutos y un rango de temperaturas de entre $2,5^{\circ} \mathrm{C}$ y $5,5^{\circ} \mathrm{C}$ (Gwanpua, 2015).

\section{Intelligent Container}

Proyecto financiado por el Ministerio Federal de Educación e Investigación (BMBF "Bundesministerium für Bildung und Forschung") del gobierno alemán, desde julio de 2010 a junio de 2013 (tres años). El primer proyecto de seguimiento comenzó en octubre de 2013, y desde entonces han publicado ciertos avances en el ámbito de la investigación referente a las pruebas acaecidas, así como de nuevos sensores desarrollados dentro del mismo proyecto. El coordinador principal es el Dr. Ing. Reiner Jedermann de la Universidad de Bremen en Alemania.

Gracias al trabajo de colaboración con 21 socios (todos ellos dedicados a la industria e investigación), desarrollaron una tecnología propia y la implantaron, marcándose los siguientes objetivos:

- Mejorar la trazabilidad de los alimentos mediante el control autónomo de su calidad.

- Reducción de pérdidas utilizando la metodología "el primero que caduca debe ser el primero que salga" (FEFO - "First Expired - First Out").

- Desarrollo de modelos de vida útil para predecir cambios de calidad en función de la temperatura.

- Implementación de prototipos y pruebas de campo del "Intelligent Container".

Fruto de esas investigaciones desarrollaron lo que han llamado el "Contenedor inteligente" que se aprecia en la Figura 24. 


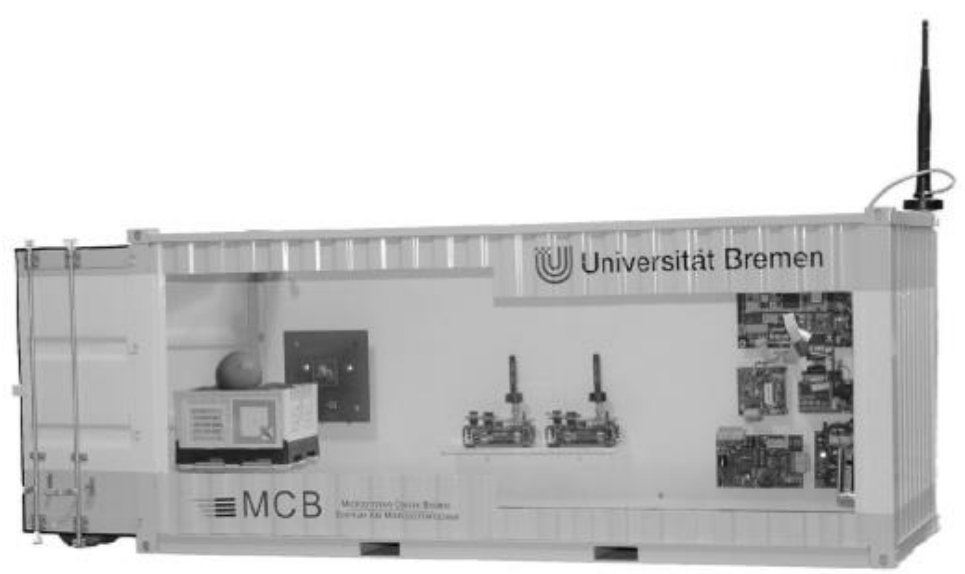

Figura 24. Prototipo a escala reducida del “Intelligent Container"(Lang et al., 2011).

Los estudios realizados hasta la fecha se basan en modelos de vida útil de carne y de plátanos. En el caso de los plátanos, quisieron estimar su tiempo de vida útil, o como se denomina: green-live, basándose en cómo el color (alto indicador del estado de maduración de estos) se ve afectado por las variaciones de temperatura.

Inicialmente realizaron pruebas de laboratorio en las cuales simularon en atmósfera controlada, las condiciones atmosféricas bajo las cuales se transporta este producto. Para ello colocaron los sensores en una de las esquinas de cada caja y lo introdujeron en las cámaras frigoríficas durante el tiempo necesario en función de si el viaje se realizaba por mar o tierra, con una duración de aproximadamente dos semanas. Por otro lado, y ya como prueba de transporte real, colocaron en el interior de las bolsas microperforadas donde viajaban los plátanos, los sensores (Figura 25), de tal modo que estaban directamente en contacto con estos, repartidos a lo largo del interior del contenedor.

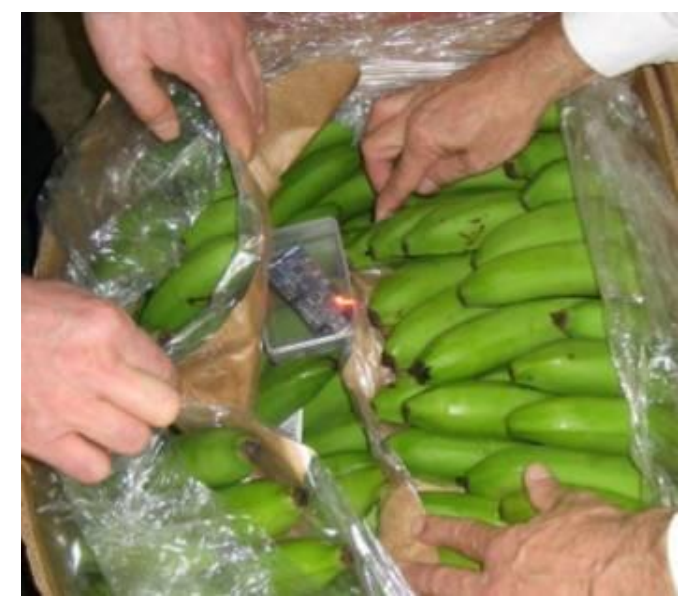

Figura 25. Detalle de los sensores en el interior de la caja de transporte de los plátanos (Jedermann et al., 2011).

Gracias a eso observaron una disminución en la capacidad de envío de señales, debido a la alta condensación de agua en el interior de los paquetes, así como a la posición, llegando a ser nula la emisión en aquellos sensores situados en el centro e interior de los contenedores (Jedermann et al., 2011). Aun así, fueron capaces de estimar su vida 
útil en función de la capacidad de maduración, observando variaciones significativas entre los ensayos realizados (Praeger et al., 2013). Los nodos se colocan en el interior de las cajas que transportan la mercancía iniciándose el sistema de comunicaciones. Este está basado en dos WSN, conectadas entre sí mediante un enlace puente, denominado FSU ("Freight Supervision Unit"), de modo que el interior registra los datos y el exterior los envía (Figura 26). Los protocolos que se utilizan son dos:

- El protocolo 6LoWPAN, que permite a los nodos de una red inalámbrica comunicarse directamente con otros dispositivos IP.

- El Protocolo de aplicación restringida (CoAP - "Constrained Application Protocol") que se adapta a los requisitos de comunicación Máquina a Máquina (M2M). Este protocolo tiene como desventaja que proporciona una longitud de mensaje reducida.

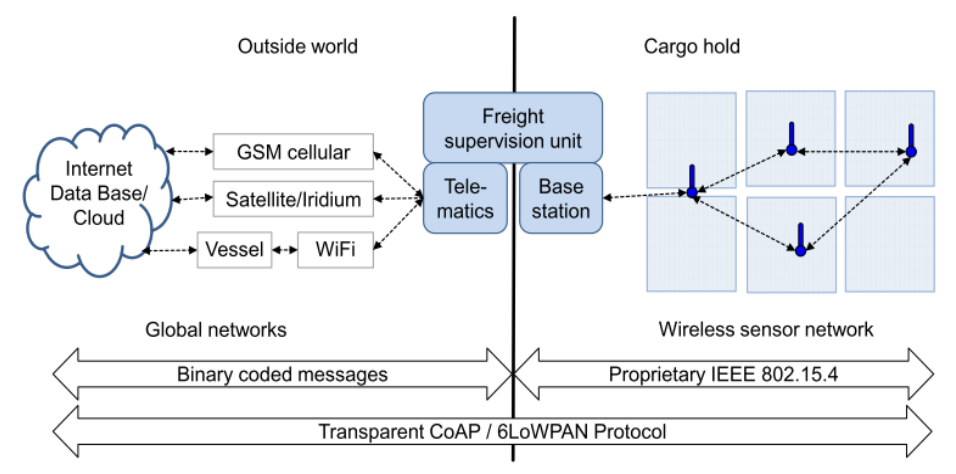

Figura 26. Sistema de comunicación del "Intelligent Container" (Jedermann et al., 2017).

Aunque el hardware de los sensores consiste esencialmente en la plataforma TelosB de 2,4 GHz (Figura 27), también han aplicado otros, tipo RFID o el denominado Preon32, desarrollado por Virtenio ${ }^{\circledR}$, socio del proyecto. Este caso se observó que utilizar un rango de 2,4 GHz no era adecuado, ya que a una distancia superior de 0,5 m, los enlaces de comunicación llegaron a fallar en hasta un tercio del total (Jedermann et al., 2017). Actualmente y pese a haber realizado pruebas de campo, no comercializan su tecnología.

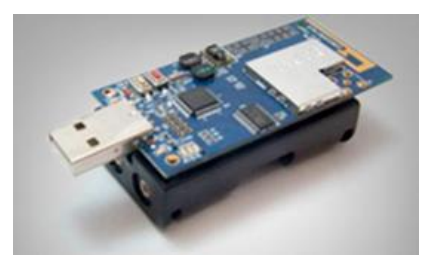

Figura 27. Sensor TelosB (TelosB, 2015).

\section{NOMORE}

Proyecto europeo solicitado en esta anualidad a la UE en su convocatoria HORIZON 2020 H2020-RUR-2018-2020, con el tópico: RUR-07-2020- Reducing food losses and waste along the agri-food value chain. Tipo de acción: IA. El título de la propuesta enviada es: No more losses and waste along the chain of fresh fruit and vegetables, cuyo acrónimo 
es NOMORE. Intervienen 18 participantes de universidades y empresas de España, Italia, Republica Checa, Alemania, Grecia e Israel y está coordinado por la Universidad degli Studi di Foggia (Italia).

El objetivo de este proyecto es contribuir a la reducción de pérdidas y desperdicios en la cadena de distribución de productos frescos y perecederos al mejorar la transferencia de innovación en diferentes niveles de la cadena de frutas y verduras. Para ello se involucran en el proyecto distintos actores de la cadena como son las asociaciones de agricultores; los encargados de logística, almacenamiento, transporte y distribución; los entes públicos y privados de los gobiernos de la UE y las asociaciones de consumidores

Entre otros grupos de trabajo (WP - "Work Package"), en el WP 4 coordinado por la UPCT, se utilizarán sensores para monitorizar, en tiempo real, la detección temprana de daños por frío y cómo las condiciones ambientales afectan a la pérdida de calidad. La recopilación de datos permitirá el desarrollo de soluciones digitales para las diferentes cadenas de producción que servirán como demostración de la reducción efectiva de las pérdidas cuantitativas y cualitativas. Se aplicarán tratamientos innovadores, así como el uso y aplicación de materiales de embalaje ecológicas, sostenibles y que prolonguen la vida útil del producto. Durante el transporte se instalarán los sensores que se describen en esta Tesis, además de nuevos materiales para eliminar o inhibir la acción del etileno, mediante reactores a base de UV y materiales patentados a base de óxido de tungsteno. 
DISEÑO Y DESARROLLO DEL DISPOSITIVO DE MONITORIZACIÓN

4. DISEÑO Y DESARROLLO DEL DISPOSITIVO DE MONITORIZACIÓN 


\subsection{PRIMER PROTOTIPO}

El primer prototipo se diseñó con el objetivo de monitorizar, registrar y enviar en tiempo real las variables de temperatura, humedad relativa, luminosidad y concentración de gases de $\mathrm{CO}_{2}$ y etileno.

El desarrollo se llevó a cabo en conjunto con la Spin off Widhoc Smart Solutions S.L. de la UPCT, la cual ya había desarrollado nodos de medida de variables con sensores, pero centrados en el ámbito agrícola para la gestión del ahorro hídrico en riego.

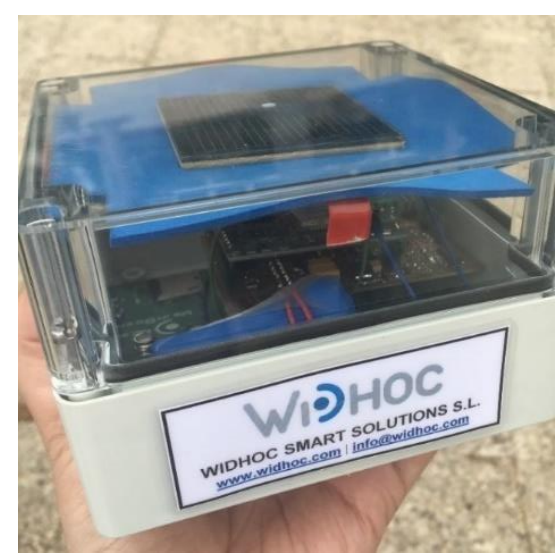

Figura 28. Primer prototipo.

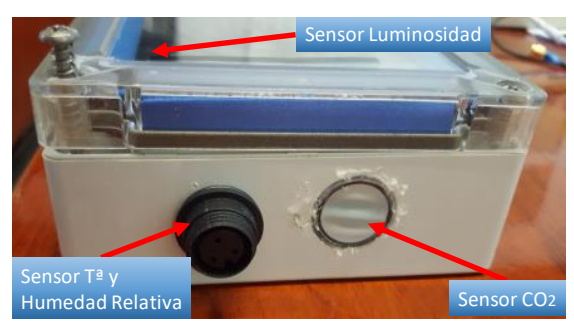

Figura 29. Detalle de algunos sensores.

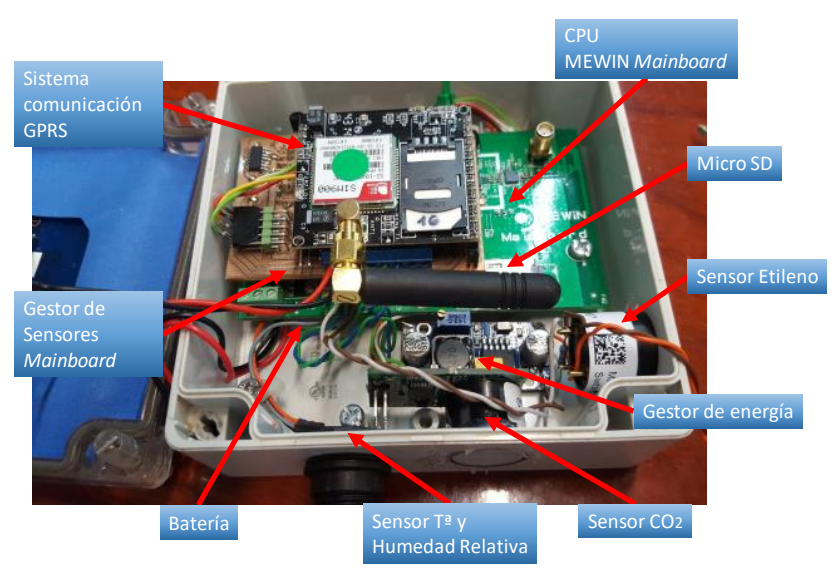

Figura 30. Componentes principales del nodo inicia y otros sensores.

Este primer prototipo está basado en un microcontrolador Texas Instruments MSP430 ya que se partió de la placa base MEWIN, propiedad de Widhoc Smart Solutions, a la 
que se le acoplaron los subsistemas dedicados para la instrumentación de los sensores, la gestión de la energía y las comunicaciones GPRS.

Los sensores que componen este primer prototipo son:

- Temperatura (-30 a 80 $\mathrm{C}$, LMT86 Texas Instruments, Dallas, TX, EE. UU.)

- Humedad Relativa (0 a 100\%, HIH 5030 Honeywell, Charlotte, NC, EE. UU.)

- Luminosidad (0 a 300 lux, NSL06S53 Advanced Photonics, Ann Arbor, MI, EE. UU.)

- $\mathrm{CO}_{2}$ (0 a 20000ppm, COZIR-GC16 CO2Meter, Ormond Beach, FL, EE. UU.)

- $\mathrm{C}_{2} \mathrm{H}_{4}$ (0 a 400ppm, M-10 Membrapor, Wallisellen, Suiza).

La gestión de las comunicaciones recae sobre un módulo GPRS SIM900 con tarjeta SIM multi-hop provista por DIFERENZA Communications. La interfaz entre la placa MEWIN y el módulo SIM900 se realiza mediante comandos AT.

La gestión energética se realiza mediante conmutación a través de la placa MEWIN, dotando al conjunto de un convertidor DC-DC de $5 \mathrm{Vcc}$ para los sensores de temperatura, humedad, luminosidad y $\mathrm{CO}_{2}$ y uno específico de $12 \mathrm{Vcc}$ para el sensor de etileno. La comunicación de los sensores es analógica por voltaje utilizando los ADC del microcontrolador excepto el sensor de $\mathrm{CO}_{2}$ que utiliza un Transmisor-Receptor Asíncrono Universal (UART-- "Universal Asynchronous Receiver-Transmitter") de comunicación serie.

Los datos registrados se envían al servidor de la UPCT, "fclould.upct.es" y se visualizan a través del interfaz web de www.widhoc.com

Se realizaron pruebas en laboratorio para comprobar las medidas de los sensores en un entorno controlado (Figura 31). 

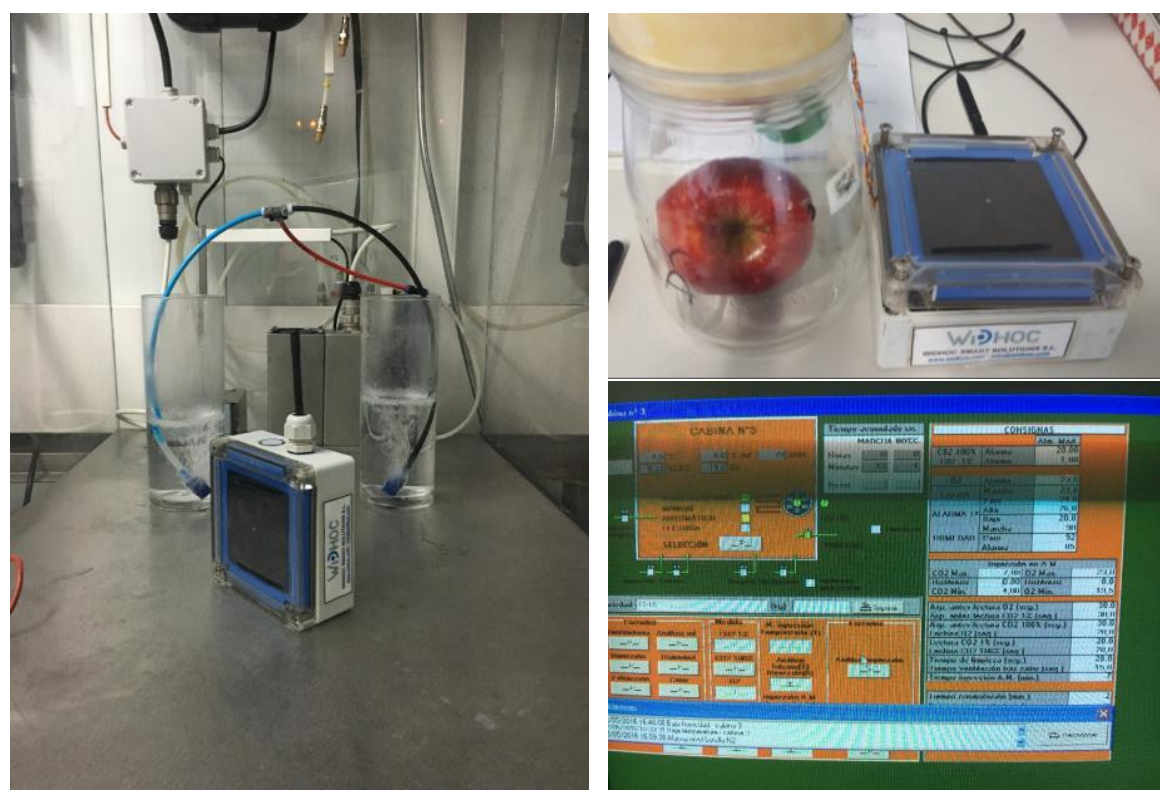

Figura 31. Detalle de las pruebas bajo condiciones controladas en planta piloto y de la configuración de los datos registrados por sondas de la instalación frigorífica y por el nodo.

Tras la superación de las pruebas en laboratorio, el prototipo se instaló en diversos viajes en transportes de camión con diferentes mercancías detalladas en la Tabla 2, en las cuales ya se pudo registrar los datos tanto de los sensores como de la localización, mediante el interfaz web (Figura 32), donde se pueden observar una caída brusca en el nivel de $\mathrm{CO}_{2}$, mientras que la temperatura se mantiene estable, lo que indica una apertura de puertas no programada, sin embargo se observa otra caída de $\mathrm{CO}_{2}$ posterior para la descarga del producto dado que la temperatura del aire sube. Las caídas de $\mathrm{CO}_{2}$ implican una renovación del aire debido a la apertura de las puertas.

Tabla 2. Datos de los primeros viajes realizados.

\begin{tabular}{cccccc}
\hline Mercancía & $\begin{array}{c}\text { Fecha } \\
\text { salida }\end{array}$ & $\begin{array}{c}\text { Fecha } \\
\text { llegada }\end{array}$ & Destino & $\begin{array}{c}\text { Peso } \\
\text { aproximado }\end{array}$ & $\begin{array}{c}\text { Ta } \\
\text { consigna }\end{array}$ \\
\hline \hline Lechuga & $06 / 05 / 2016$ & $10 / 05 / 2016$ & $\begin{array}{c}\text { Países } \\
\text { Bajos }\end{array}$ & $14.000 \mathrm{~kg}$ & $+4^{\circ} \mathrm{C}$ \\
\hline Sandía & $01 / 07 / 2016$ & $05 / 07 / 2016$ & $\begin{array}{c}\text { Países } \\
\text { Bajos }\end{array}$ & $23.000 \mathrm{~kg}$ & $+9^{\circ} \mathrm{C}$ \\
\hline Lechuga & $02 / 12 / 2016$ & $05 / 12 / 2016$ & Alemania & $13.000 \mathrm{~kg}$ & $+3^{\circ} \mathrm{C}$ \\
\hline \hline
\end{tabular}




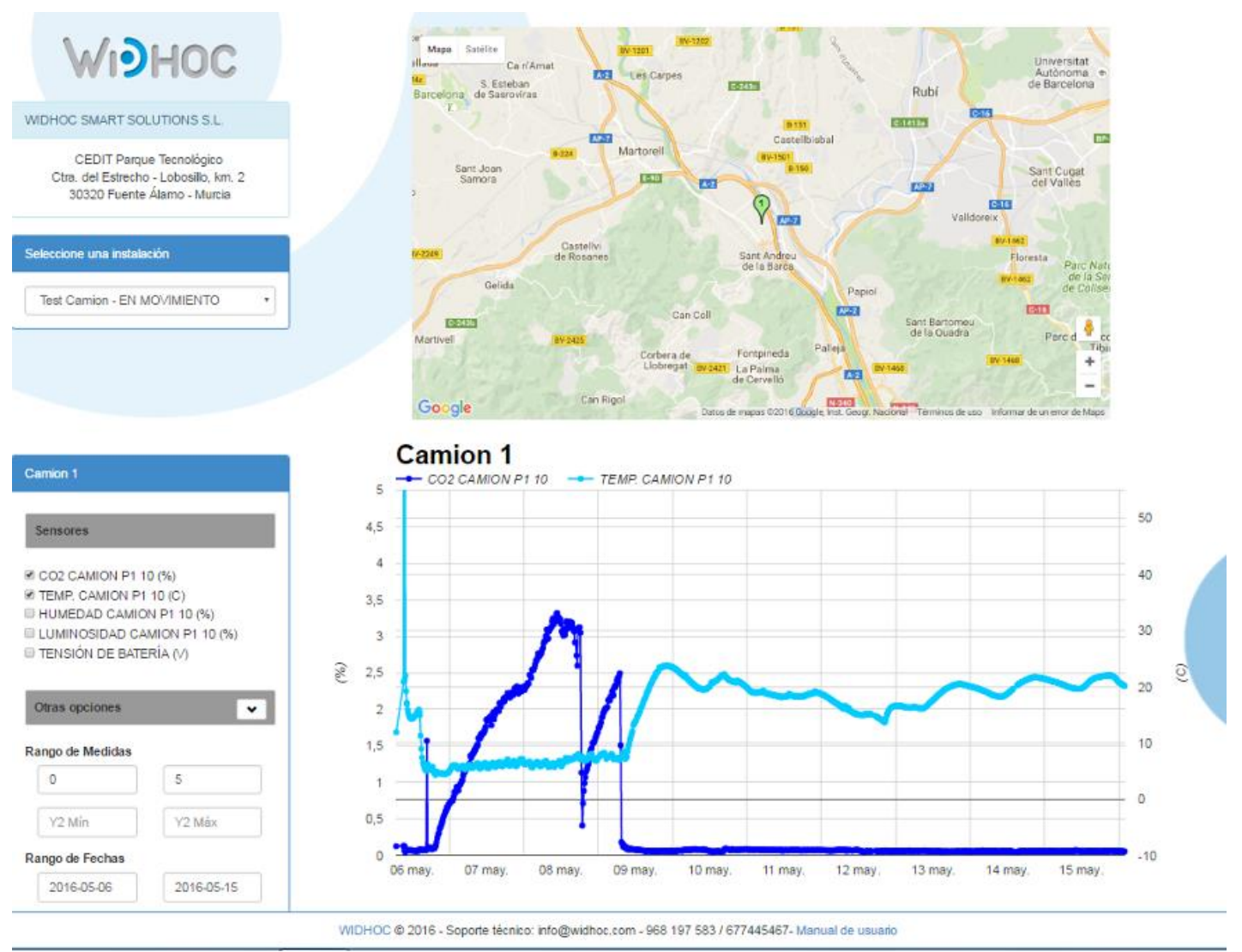

Figura 32. Interfaz web donde se observan los detalles del primer viaje de prueba realizado en mayo de 2016.

En el interfaz web puede observarse la geolocalización del nodo en el mapa y la representación de los datos, aso como la selección de las variables a representar. El desarrollo del equipo tuvo una cofinanciación de la UPCT a través del programa PROVALOR 2016.

En marzo de 2017, se solicita la patente de invención del dispositivo de medición cubriendo una brecha del mercado que no disponía de ningún equipo que cumpliera con las prestaciones de medición descritas.

La solicitud se llevó a cabo a través de la UPCT mediante la convocatoria TRANSFER 2016, siendo los inventores:

- Dr. Roque Torres Sánchez. Profesor Titular de Universidad en el área de ingeniería de sistemas de la UPCT.

- Dr. Francisco de Asís Artés Hernández. Catedrático de Universidad en el área de tecnología de alimentos de la UPCT.

- María Teresa Martínez Zafra. Estudiante de doctorado de la UPCT.

El 17 de abril de 2018, la patente de invención fue concedida a la UPCT como titular de ésta, con fecha de publicación de la concesión el 24 de abril de 2018 con número de solicitud P201730301 y número de publicación ES2640027 (ES 2640027 B1, 2017). 


\subsection{MEJORA DEL PROTOTIPO V2}

Durante las sucesivas pruebas del prototipo diseñado se evidenciaron ciertas carencias que había que depurar con una nueva versión del equipo. Por tanto, el dispositivo y el sistema evolucionó y mejoró enfocándose dichas mejoras en dos aspectos fundamentales.

Por un lado, se hizo más compacto y pequeño, más fácil de manejar e instalar, más barato de fabricar y más autónomo energéticamente gracias a la mejora en el sistema de energía con una vida útil de las baterías que puede llegar a los 30 días.

Por otro lado, se modificó la configuración hardware, no sólo para obtener las mejoras reseñadas anteriormente, sino para ampliar y mejorar prestacionalmente el sistema de comunicaciones haciéndose más versátil. En esta nueva versión, el sistema tiene capacidad de conexión colaborativa permitiendo mediciones multipunto, es decir, es capaz de medir en distintas localizaciones dentro del mismo cargamento, lo que permite evidenciar las carencias de las cargas en cuanto a la homogeneidad de distribución térmica debida a una sobrecarga de producto o deficiencias en los equipos de refrigeración. A tal efecto y partiendo de la misma plataforma "low-cost", se han diseñado los equipos con dos roles diferentes denominados ahora "nodos" debido a la capacidad de comunicación colaborativa entre ellos. Los dos sistemas tienen la misma configuración de sensores: todos los nodos son capaces de monitorizar las variables, almacenarlas internamente una vez procesadas y de transmitirlas inalámbricamente a servidores donde pueden ser consultadas en tiempo real y con periodos de muestreo programables.

Los roles diferentes de los equipos se asignan por su capacidad de comunicaciones, así se diferencian el nodo "Gateway" o "Puerta de enlace" que actúa como nodo sumidero y coordinador de los nodos "Slaves" o "Esclavos". Las prestaciones de comunicación son explicadas en detalle en epígrafes posteriores. Las dimensiones de ambos nodos han sido reducidas notablemente respecto al prototipo inicial: $89 \times 74 \times 41 \mathrm{~mm}$ y $80 \times 60 \times 30$ mm (Figura 33). 


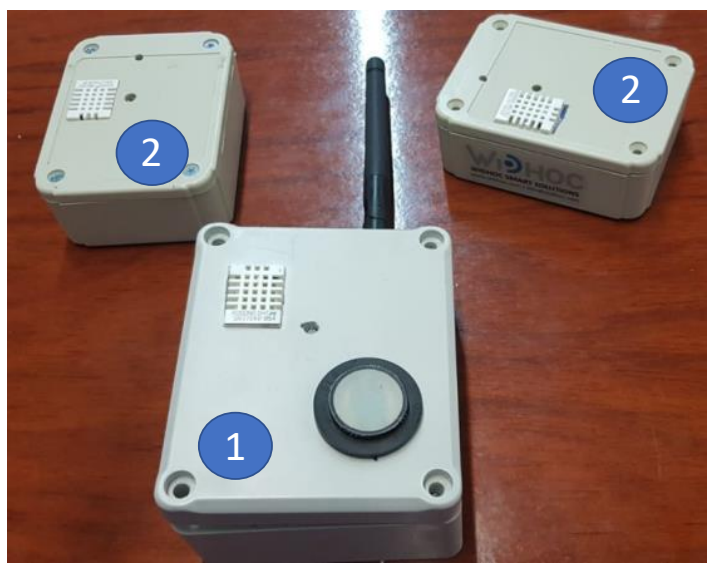

Figura 33. Detalle del nodo Gateway (1) y de dos nodos Slave (2).

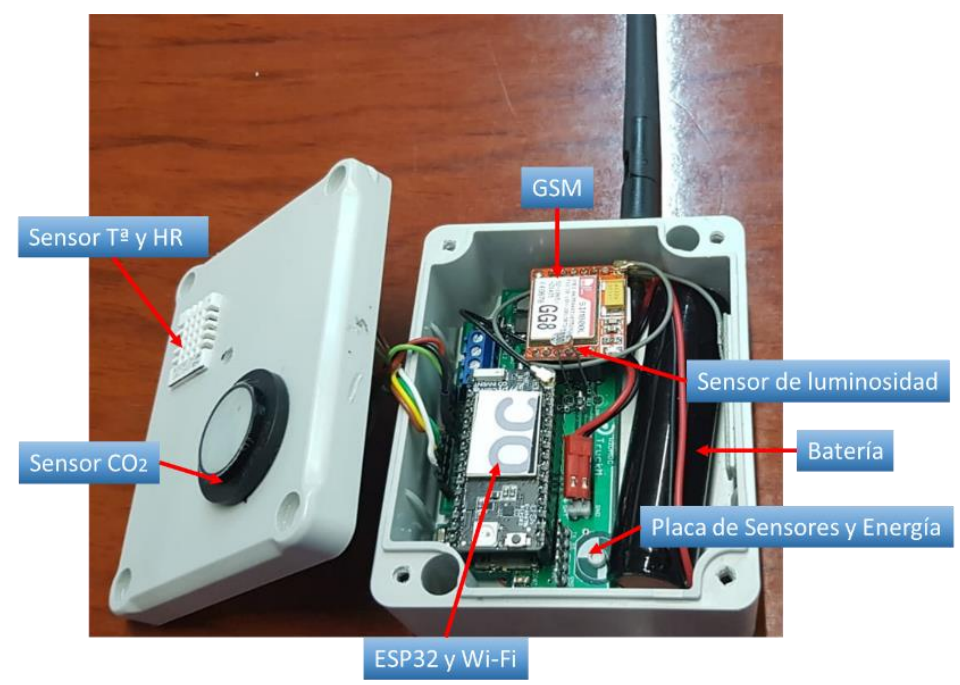

Figura 34. Componentes del nodo Gateway actual.

\subsubsection{Arquitectura}

Como se ha comentado en párrafos anteriores, la arquitectura de monitorización mejorada de la versión 2 está compuesta por dos actores con roles diferentes.

La diferencia entre los nodos Gateway y los Slave estriba en la comunicación que pueden realizar. Los nodos Gateway actúan como sumideros y coordinadores gestionando la información medida por ellos mismos y la recibida por los nodos Slave y comunicándola a los servidores a través de Internet mediante redes de comunicación de datos comerciales (GSM, SigFox o LTE), mientras que los nodos Slave se pueden conectar al nodo Gateway pero, a diferencia de una res inalámbrica de sensores tradicional (WSN), el protocolo utilizado es estándar ( $\mathrm{Wi}-\mathrm{Fi})$ y permite que en caso de que estén adecuadamente configurados, los nodos Slave puedan enviar la información medida y registrada sin necesidad de puerta de enlace o nodo Gateway.

Para funcionar con nodo sumidero, el nodo Gateway genera una infraestructura Wi-Fi portátil actuando como punto de acceso similar al utilizado de forma regular en cualquier router comercial, permitiendo a los nodos Slave acceder a Internet en aquellos 
sitios donde no es posible disponer de un acceso de red $\mathrm{Wi}-\mathrm{Fi}$, como dentro de un camión (Figura 35a). Sin embargo, el uso independiente de los nodos Slave es posible en aquellos lugares donde pueda usar infraestructura de Wi-Fi previamente configurada para enviar la información grabada (Figura 35b), como es factible en cámaras de preenfriamiento, cámaras logísticas o incluso en grandes superficies comerciales.

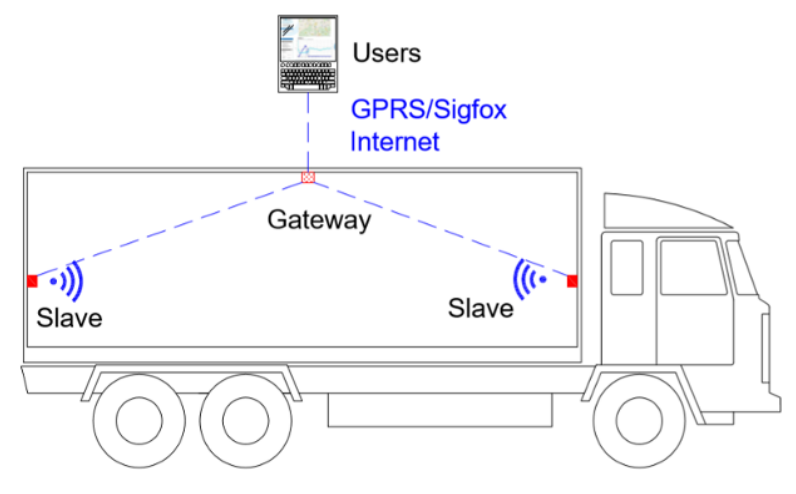

(a)

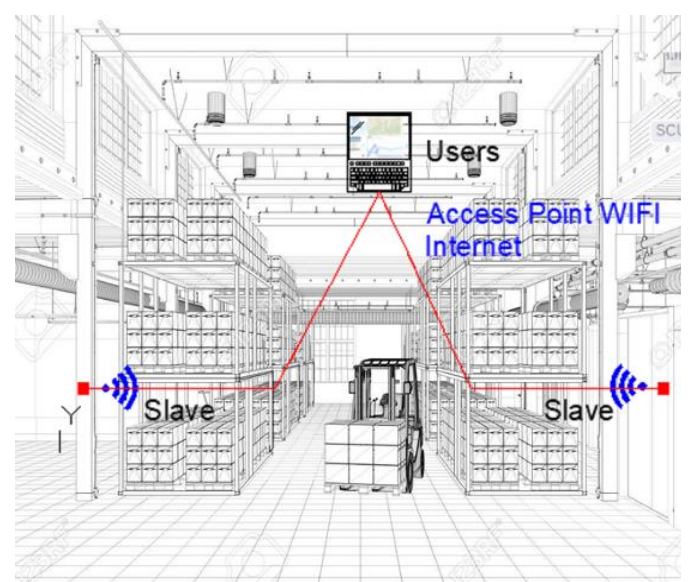

(b)

Figura 35. Doble sistema de comunicación: (a) comunicación de la red colaborativa Gateway/Slave dentro de un recinto aislado como un camión y (b) comunicación de los nodos Slave de forma independiente utilizando infraestructuras preexistentes $\mathrm{Wi}-\mathrm{Fi}$.

La hipótesis de uso de este tipo de comunicación Wi-Fi estriba en que la arquitectura de monitorización propuesta para esta solución de seguimiento de las condiciones de conservación de toda la cadena de postcosecha necesita que los nodos que monitorizan las variables puedan enviar los datos a los servidores durante todo el proceso de distribución del producto, desde la recolección, preparación en campo y/o centros logísticos y el transporte, hasta expositor de la superficie comercial.

Por ese motivo, entre los diversos protocolos para establecer redes colaborativas (WSN) existentes que utilicen acceso libre y de alcance limitado (ZigBee, BLE, LoRa, Wi-Fi) se propone el estándar de comunicación Wi-Fi 802.11 por la alta compatibilidad, gracias a su estandarización, con las infraestructuras existentes en los centros donde la mercancía va a estar presente en la cadena de distribución (recolección, envasado, transporte, recepción logística, distribución y exposición al público) En todos estos centros es muy usual disponer de redes Wi-Fi para acceso de los trabajadores.

Los nodos Slave se programarán con las listas de SSIDs y Passwords a los que se conectará conforme la mercancía se ubique en cada lugar a lo largo de su ruta de distribución, de modo que sean capaces de enviar los datos almacenados. De esta forma se reduce el consumo de energía de las baterías en todos los nodos, ya que no se requiere un alto tiempo de activación Wi-Fi Para solventar los problemas de falta de conexión, el sistema propuesto, debe tener capacidad de almacenamiento propia.

Para solventar la falta de infraestructura Wi-Fi en algunas ubicaciones, se utiliza el nodo Gateway ya que sirve de puerta de enlace entre los nodos Slave e Internet. Como se ha 
comentado, el nodo genera una puerta de enlace a Internet (similar a un router doméstico) al que los nodos Slave se pueden conectar para enviar sus datos a los servidores.

Para la elección de la plataforma hardware que alberga el nuevo sistema propuesto, se definieron las siguientes premisas:

- Coste reducido, ya que, en la gran mayoría de las veces, el Slave acabará desechado o inutilizado durante un gran periodo de tiempo.

- Debe ser capaz de disponer de modos de bajo consumo, ya que serán necesarias varias semanas de autonomía con capacidades energéticas reducidas.

- Disponer de varias Entrada/Salida de Propósito General (GPIO - "General Purpose Input/Output ") para conexión de diversos interfaces analógicos y digitales para los sensores.

Para la primera premisa se optó por un cambio de plataformas de microcontrolador. Si en la V1 se utilizó una base del MSP430 de Texas Instruments (utilizada por Widhoc en sus nodos MEWIN), en la V2 se ha desarrollado una plataforma propia completamente nueva basada en el nuevo microprocesador ESP32 de Expressif (ESP32 Overview I Espressif Systems, 2017), la cual proporciona interfaz Wi-Fi y BLE además de capacidad de instrumentar los sensores conectados. El microcontrolador ESP32 es capaz de funcionar de manera fiable en entornos industriales, con una temperatura de funcionamiento que varía de $-40^{\circ} \mathrm{C}$ a $+125^{\circ} \mathrm{C}$. Está diseñado para dispositivos móviles, dispositivos electrónicos portátiles y aplicaciones loT, logrando un consumo de energía ultra bajo. El ESP32 también incluye características como la activación de reloj de alta precisión, y escala de potencia dinámica para optimización de consumo energético a través de cambios en la velocidad de procesamiento. Incluye antenas para los interfaces inalámbricos de tipo balun ("balanced-unbalanced lines transformer"). Además, el ESP32 puede interactuar con otros a través de sus interfaces SPI/SDIO o I2C/UART (ESP32 Overview | Espressif Systems, 2017), lo cual es útil para la interfase con los sensores de medición.

Se ha utilizado una plataforma loT de la empresa holandesa Pycom denominada Wipy3.0 que implementa el microcontrolador ESP32 externalizando las GPIOS, UARTs, DC/DC, etc., lo que permite una rápida integración en cualquier desarrollo de bajo coste y altas prestaciones. Las plataformas de desarrollo WiPy están habilitadas para MicroPython y un conjunto completo de servicios y librerías gratuitos, así como una comunidad colaborativa a través de foros muy activa (Introduction, 2018) ("The WiPy libraries, releases, hardware files and docs», 2015)(Figura 36). 


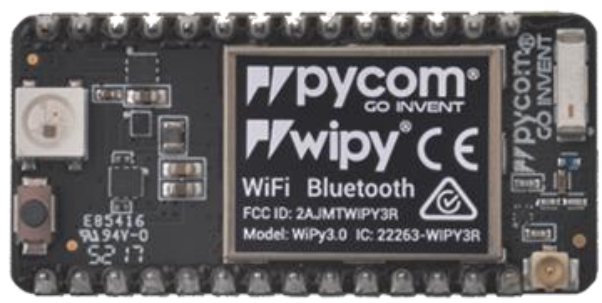

Figura 36. Placa de desarrollo Wipy 3.0 (WiPy 3.0 - Pycom, 2019).

\section{Diseño del nodo tipo Slave}

A partir de la plataforma Wipy se han desarrollado los nodos. El diagrama de bloques del Slave se puede observar en la Figura 37.

\section{Sensor Node}

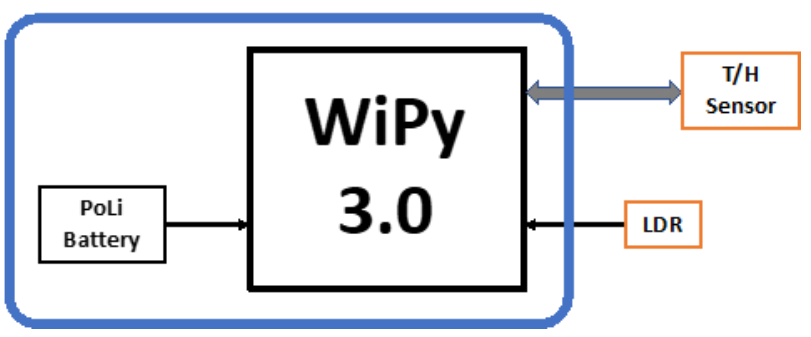

Figura 37. Diagrama de bloque del Slave.

La alimentación del nodo se realiza mediante una batería de PoLi de 3,7V y $3500 \mathrm{mAH}$, que alimenta directamente al módulo WiPy 3.0 (su rango de alimentación es de 3,5V a $5,5 \mathrm{~V}$ ) conectando ésta al pin $\mathrm{V}_{\text {in }}$ del módulo. El WiPy posee un regulador de tensión que proporciona como salida una tensión estable de 3,3V y $550 \mathrm{~mA}$, externalizada en el pin 3V3 del módulo. Dicha tensión se utiliza para alimentar los sensores que posee el Slave, pero no de forma directa, sino mediante un transistor PNP que permite, controlando su estado (corte/saturación), la activación o no de la alimentación de los sensores. La activación de dicho transistor se controla mediante el pin P9 del módulo, configurado como salida digital. Como se puede controlar la conexión de $3 \mathrm{~V} 3$ a la alimentación de los sensores por software, se logra una optimización máxima de la energía al estar alimentados los sensores sólo en el instante de la medida.

Los sensores con los que cuenta el nodo Slave son:

- 1 LDR (NSL06S53 Advanced Photonics, Ann Arbor, MI, EE. UU.) que permitirá conocer condiciones lumínicas de la carga (se quiere detectar con ello la apertura y cierre de la puerta del camión de transporte). La LDR forma parte junto con una resistencia fija de $113 \mathrm{~K} \Omega$ de un divisor resistivo alimentado con los 3,3V proporcionados por el WiPy. La tensión de salida de dicho divisor resistivo (que será proporcional al valor de la LDR) está conectada a pin P19 del módulo WiPy 3.0 que se corresponde con su entrada analógica ADC1_4 del ESP32. 
- 1 sensor de temperatura y humedad relativa (DHT22/AM2302 Aosong (Guangzhou) Electronics Co., Ltd China) con un rango de medida de temperatura de -40 a $125^{\circ} \mathrm{C}$ (precisión $\pm 0,5^{\circ} \mathrm{C}$ y resolución $0,1^{\circ} \mathrm{C}$ ) y un rango de humedad relativa de 0 a $100 \%$ (precisión $\pm 2 \%$ y resolución $0,1 \%$ ). El protocolo " 1 -wire" es usado como enlace de comunicación entre el Wipy 3.0 y el sensor, estando dicho bus conectado al pin P11 del módulo, configurado como pin digital. Las tramas de datos del sensor constan de 40 bits (1):

Dato=16 bits datos HR+ 16 bits datos Temperatura+8 bits check-sum

El acceso a la información del sensor se realiza mediante un protocolo "1-wire" definido por el fabricante y cuyo cronograma se expresa en la Figura 38.

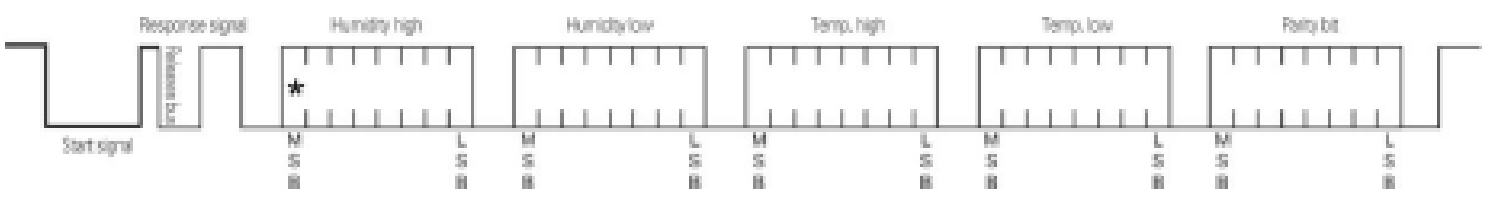

Figura 38. Cronograma de acceso a la medición del sensor AM2302 (Aosong Electronics Co., 2003).

Además de las medidas de dichos sensores, el equipo también registra y envía el valor de tensión de la batería, alimentando con dicha tensión un divisor resistivo cuya salida se conecta al pin P16 del módulo, que se corresponde con su entrada analógica ADC1_3 del ESP32.

El diseño del equipo se implementa con una placa de circuito impreso (TruckC) con unas dimensiones de 73×28 mm, cuya infografía se presenta en la Figura 39.

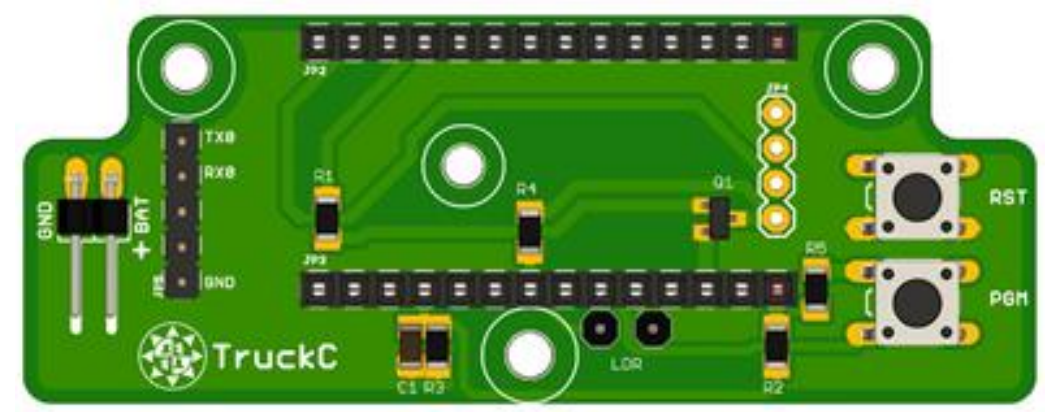

Figura 39. Placa de circuito del Slave.

En dicha figura se puede observar el conector para la batería, el conector de programación (JP5), los conectores en los que se coloca el WiPy 3.0 (JP2 y JP3), el conector para la LDR y el conector para el sensor de T/H (JP4). Se puede observar también que cuenta con dos pulsadores, uno (RST) para resetear el equipo y otro (PGM) que servirá para para llevar al equipo a diferentes modos de programación.

Además de estas variables, los nodos son geolocalizables utilizando los sistemas de triangulación de las redes móviles (cuando están conectados al nodo Gateway) o a través de la IP del router Wi-Fi al que están conectados (centro logístico, supermercado, etc.) 


\section{Diseño del nodo tipo Gateway}

El diagrama de bloques del Gateway se puede observar en la Figura 40.

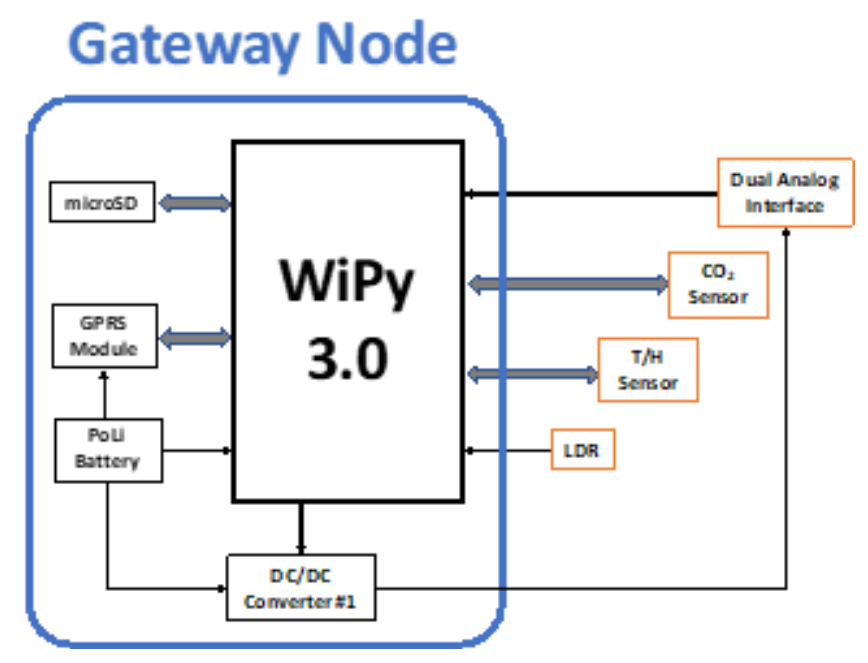

Figura 40. Diagrama de bloque del Slave.

Este equipo cuenta además de los elementos con los que contaba el Slave con:

- 1 slot para tarjetas microSD en la que almacenar todos los datos registrados

- 1 módulo de comunicaciones GPRS (MPN SIM800 Shanghai SIMCom Wireless Solutions Ltd China) que se alimenta directamente de la batería del nodo (el mismo tipo que el Slave) y se controla mediante comandos $\mathrm{AT}$, vía puerto serie desde el WiPy. Para ello se conectan las señas Tx y Rx del SIM800 a los pines P5 y P6 del WiPy a los que están direccionada la UARTXXX y el reset del SIM800 al pin P7, configurado como una salida digital.

- 1 sensor de CO2 (COZIR-GC16 CO2Meter, Ormond Beach, FL, EE. UU.) con un rango de medida del 0 al $20 \%$ (precisión de 70 ppm $\pm 5 \%$ de la lectura). El sensor está controlado vía serie, para lo cual se conectan las señas Tx y Rx del sensor a los pines P20 y P19 del WiPy a los que están direccionada la UARTXXX, estando en este caso conectada el circuito de la LDR al pin P18.

- 1 convertidor DC/DC que a partir de la tensión de la batería genera 12V, disponibles para alimentar otros posibles sensores a conectar.

- 2 entradas para sensores analógicos, con salida en tensión (0-3V) o en corriente (4-20mA) para la conexión eventual de otros sensores como el de Etileno (0 hasta 400ppm, M-10 Membrapor, Wallisellen, Suiza) u otros sensores de gases.

La alimentación de la microSD y del sensor de $\mathrm{CO}_{2}$ se realiza al igual que con el resto de los sensores mediante los 3,3V conmutados con un transistor, permitiendo de nuevo mediante software una adecuada gestión de la energía. 
La electrónica del equipo se corresponde una placa de circuito impreso (TruckM) con unas dimensiones de $82 \times 40 \mathrm{~mm}$, cuya infografía se presenta en la Figura 41.

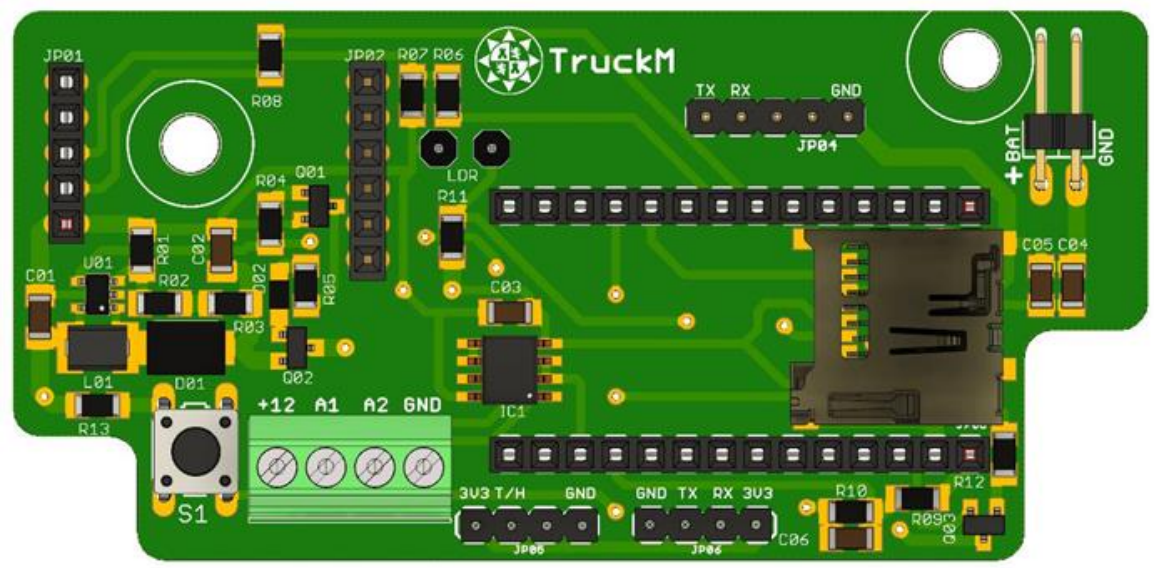

Figura 41. Placa de circuito del Gateway.

El módulo GPRS SIM800 va colocado en los conectores JP01 y JP02. En este caso el equipo cuenta con un solo pulsador (S1) cuya función es entrar en modo programación para poder modificar los parámetros de uso como se explica en el epígrafe 4.2.4 "Configuración de los módulos".

\subsubsection{Gestión de la energía}

La segunda restricción, relativa al ahorro de energía y, dado que el protocolo Wi-Fi no está diseñado con especificaciones de baja energía, debido a su capacidad de banda ancha, se ha desarrollado un algoritmo "time Synchroniziting" el cual permite reducir a pocos segundos el tiempo por el que los nodos Slave están conectados a la red Wi-Fi, lo que redunda en una amplia autonomía de energía.

La gestión de la energía de los nodos es una función prioritaria del sistema, ya que es necesaria la operatividad de los nodos durante varias semanas. La mayor parte del tiempo, los nodos están en estado de reposo por lo que se utiliza la función asociada Deepsleep (time-out) que requiere sólo de $25 \mu \mathrm{A}$. Dicha función puede ser "despertada" mediante un time-out especificado como parámetro de dicha función y que el sistema diseñado calcula en función del tiempo transcurrido en la ejecución del proceso y el restante que queda para que el sistema despierte según el muestreo elegido.

La compatibilidad de comunicación aportada por el uso de la comunicación Wi-Fi tiene, sin embargo, el hándicap del alto consumo de energía que conlleva. Por este motivo, es necesario reducir al mínimo imprescindible el tiempo en el que los dispositivos están conectados a la red Wi-Fi. Para realizar este proceso y que la comunicación sea eficaz, se ha desarrollado un algoritmo de sincronización temporal: "time-syncroniciting", de tal modo que los nodos Slave y Gateway están sincronizados entre sí minimizando el tiempo de conexión entre ellos. El patrón temporal siempre es manejado por el coordinador, el Gateway, ya que es el que tiene que "esperar" a que los Slave se 
conecten y envíen la información. El flujograma de actuación del algoritmo se presenta en la Figura 42.

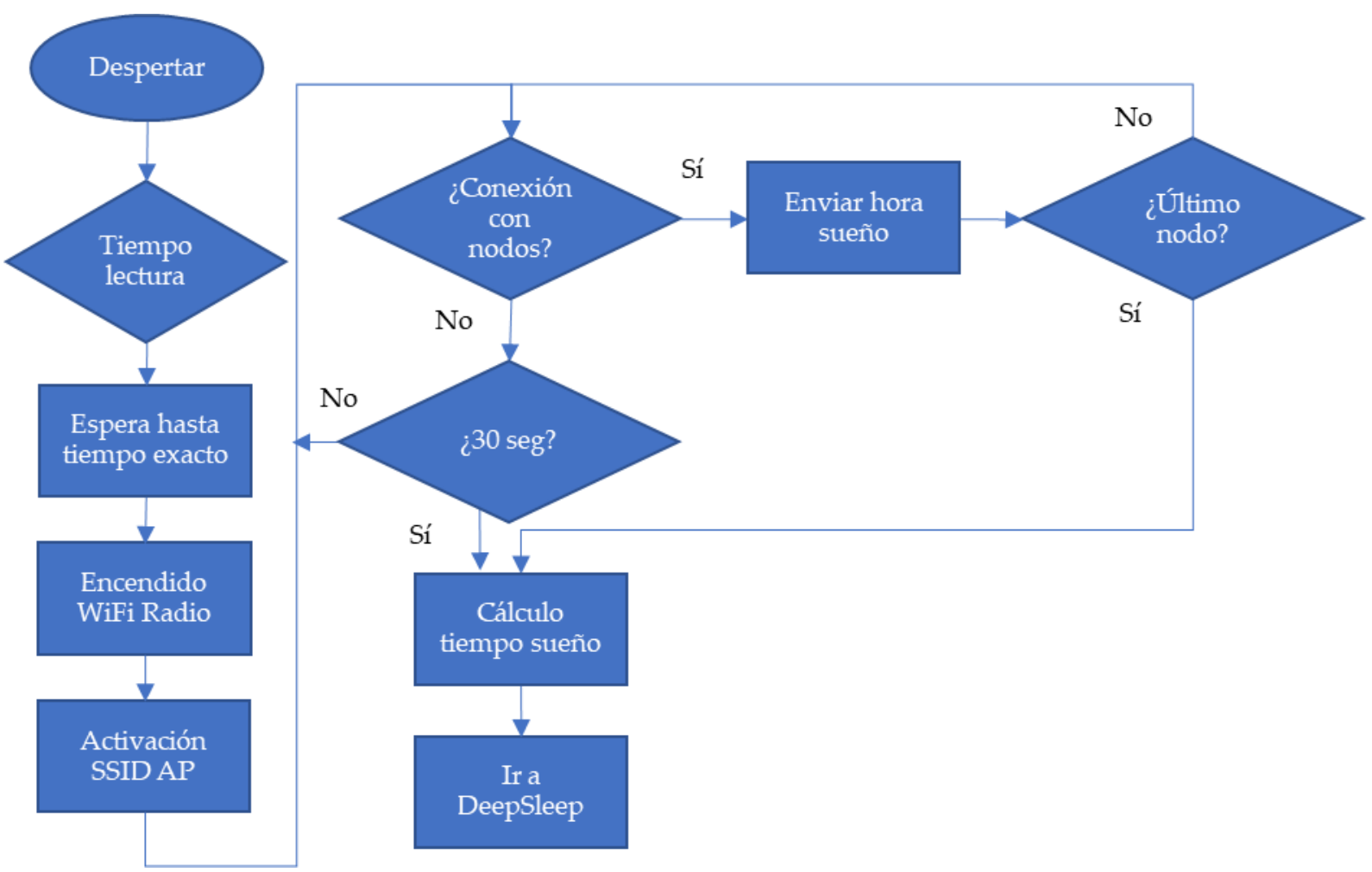

Figura 42. Diagrama de ejecución de la función "time-syncroniciting".

\subsubsection{Gestión de la instrumentación en los nodos Slave - Gateway}

El proceso de instrumentación se ejecuta en función del tiempo de muestreo programado, el cual define la frecuencia con la que el sistema instrumenta los sensores y registra la información. En el diseño de los nodos el tiempo de instrumentación se ha definido como un valor entero del número de muestras deseadas por hora, con un máximo de 12. Este proceso hace que el sistema siempre instrumente en los mismos minutos cada hora. La ecuación para calcular los segundos restantes que el sistema tiene que dormir antes del siguiente muestreo, se calcula con la siguiente secuencia:

1. Se calcula en qué minuto de la hora se producirá el siguiente muestreo en función de la hora actual (2):

$$
\text { minutos }_{\text {muestreo }}=\text { muestreo } \cdot \operatorname{int}\left(\frac{\text { minutos }_{\text {actuales }}}{\text { muestreo }}\right)+1
$$

2. Se calculan los segundos que faltan para que se alcance dicho muestreo y, por tanto, para que se despierte el nodo restando los segundos actuales (3):

$$
\text { segundos }_{\text {DeepSleep }}=60 \cdot \text { minutos }_{\text {muestreo }}-60 \cdot \text { minutos }_{\text {actuales }}-\text { segundos }_{\text {actuales }}
$$

Los sensores utilizados en los nodos tienen tanto comunicación digital como analógica. Para la medición de la luminosidad, los sensores analógicos como el sensor de etileno, 
así como la tensión de la batería, se utilizan los ADC integrados en el ESP32 configurados a 12 bit y calibrados con funciones específicas a partir de patrones. El sensor DTH22 utiliza un protocolo digital de un pin, previamente descrito (1) y, por tanto, es leído por un GPIO del Wipy mediante la trama de la Figura 38. El sensor de $\mathrm{CO}_{2}$ utiliza un puerto RS-232 y es configurado por una de las UARTs disponibles en el Wipy.

Para mejorar la estabilidad de las lecturas de los sensores, se realiza una media sesgada de 20 instrumentaciones cada $25 \mathrm{msg}$.

El proceso de lectura de los sensores devuelve un diccionario Python con 7 keys y sus correspondientes valores:

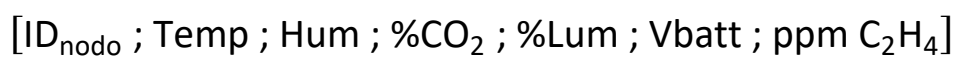

Este es almacenado de forma temporal en una partición de la memoria flash del dispositivo. Si no es posible ejecutar el proceso de comunicación para el envío de la información, el valor es almacenado junto con el time-stamp asignado a dicho diccionario en una tarjeta $\mu$ SD disponible en los nodos.

El funcionamiento general de Gateway (Figura 43) y del Slave (Figura 44), se muestra en los siguientes diagramas de estado:

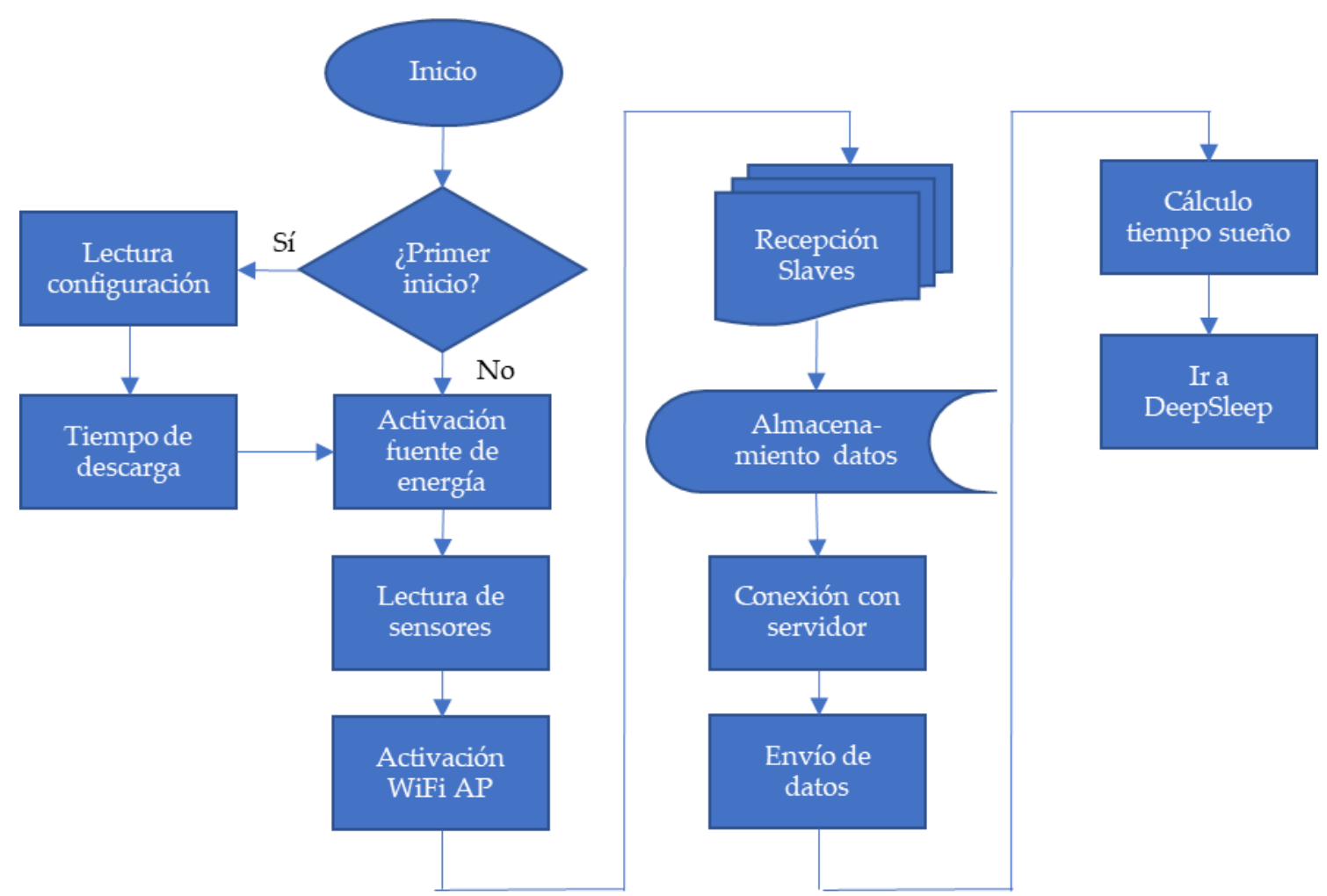

Figura 43. Funcionamiento general del Gateway. 


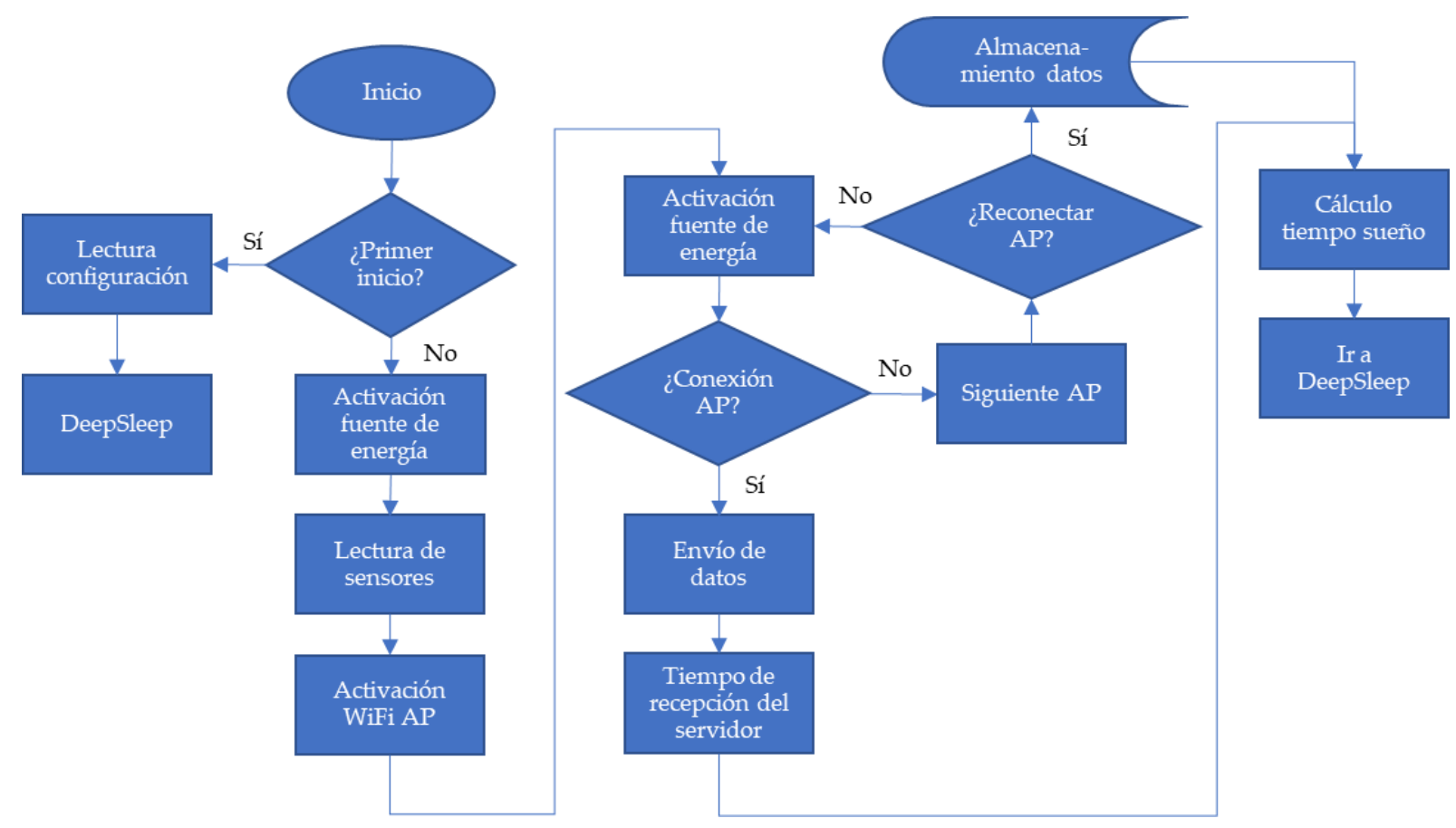

Figura 44. Funcionamiento general del Slave.

\subsubsection{Configuración de los nodos}

Tanto los nodos Gateway como Slave, permiten modificar la configuración de uso. Este proceso puede realizarse mediante a la extracción de la tarjeta microSD y modificando el fichero "Config.txt". Dicho fichero contiene, en el caso del nodo Slave, las variables de muestreo (cada cuanto tiempo se miden las variables), los envíos al servidor/Gateway (número de muestreos por cada envío) y una lista de SSID y Passwords asignados para comunicarse al Gateway o a los puntos de acceso disponibles. En el caso del nodo Gateway, el campo de SSIDs y Passwords es sustituido por el APN y PIN para el acceso a la red GPRS.

Adicionalmente a la extracción de la tarjeta SD, el fichero de configuración puede modificarse mediante un acceso "File Transfer Protocol" (FTP) a través de la red Wi-Fi. En este caso tanto el Gateway como el Slave generan un punto de acceso Wi-Fi al pulsar el botón "config" del nodo durante más de 2 segundos. Dicho punto de acceso se denomina "Config_Nodo_Slave/Gateway_№X" y puede accederse mediante cualquier dispositivo tipo Smartphone o similar. Tiene un time-out limitado a $2 \mathrm{~min}$. El acceso permite enviar el fichero "Config.txt" a través de FTP y sustituye al que está disponible en la microSD y que es leído por el nodo en su rutina de inicialización.

\subsubsection{Gestión de la información instrumentada.}

Las tramas de información (4) generadas en forma de diccionario Python son enviadas a través de sockets a la base de datos alojada en 'fcloud1.upct.es', con el puerto 49217, salvo en el caso de conexión Wi-Fi de los Slaves con el Gateway en cuyo caso el envío de la información por parte de los nodos es a través de una IP interna habilitada por el 
Gateway (192.168.4.1) común para todos los nodos Slave que se comuniquen con el exterior a través de él. En este caso, el nodo Gateway recibe y coordina la información de los nodos Slave, sincronizando en cada comunicación el slot del "time-sincroniziting" y creando las tramas necesarias para el socket del servidor que aloja los datos.

En el siguiente ejemplo se describen las tramas de datos enviadas por el nodo Gateway al servidor una vez recepcionada la información de 4 nodos Slave distribuidos y conectados al punto de acceso generado:

$$
\begin{aligned}
\text { [GTW }_{1} ; & \text { Temp ; Hum ; \% } \left.\mathrm{CO}_{2} ; \% \text { Lum ; Vbatt ; ppm } \mathrm{C}_{2} \mathrm{H}_{4}\right] \\
& {[\mathrm{SLV} 1 ; \text { Temp } ; \text { Hum ; \%Lum ; Vbatt }] } \\
& {[\text { SLV_2; Temp ; Hum ; \%Lum ; Vbatt }] } \\
& {[\text { SLV_3; Temp ; Hum ; \%Lum ; Vbatt }] } \\
& {[\text { SLV_4; Temp ; Hum ; \%Lum ; Vbatt }] }
\end{aligned}
$$

Una vez recibido la confirmación de la recepción de la trama (ACK), el nodo Gateway envía la fecha y hora en formato epoch "timestamp" del envío (el tiempo Epoch es la hora habitual medida en número de segundos desde el Epoch Unix. Epoch 0 es enero 1 1970 00:00:00 GMT) y las coordenadas de geolocalización mediante el comando "AT+CENG?".

El servidor que aloja la información dispone de una interfaz web donde se pueden visualizar todos los datos, en este caso se ha contado con el interfaz utilizado por la empresa Widhoc Smart Solutions que, a través del acuerdo de explotación de la patente del dispositivo, se prestó a dejarnos utilizar su interfaz, accesible mediante control de accesos a través de fcloud.upct.es y representada en la Figura 45.

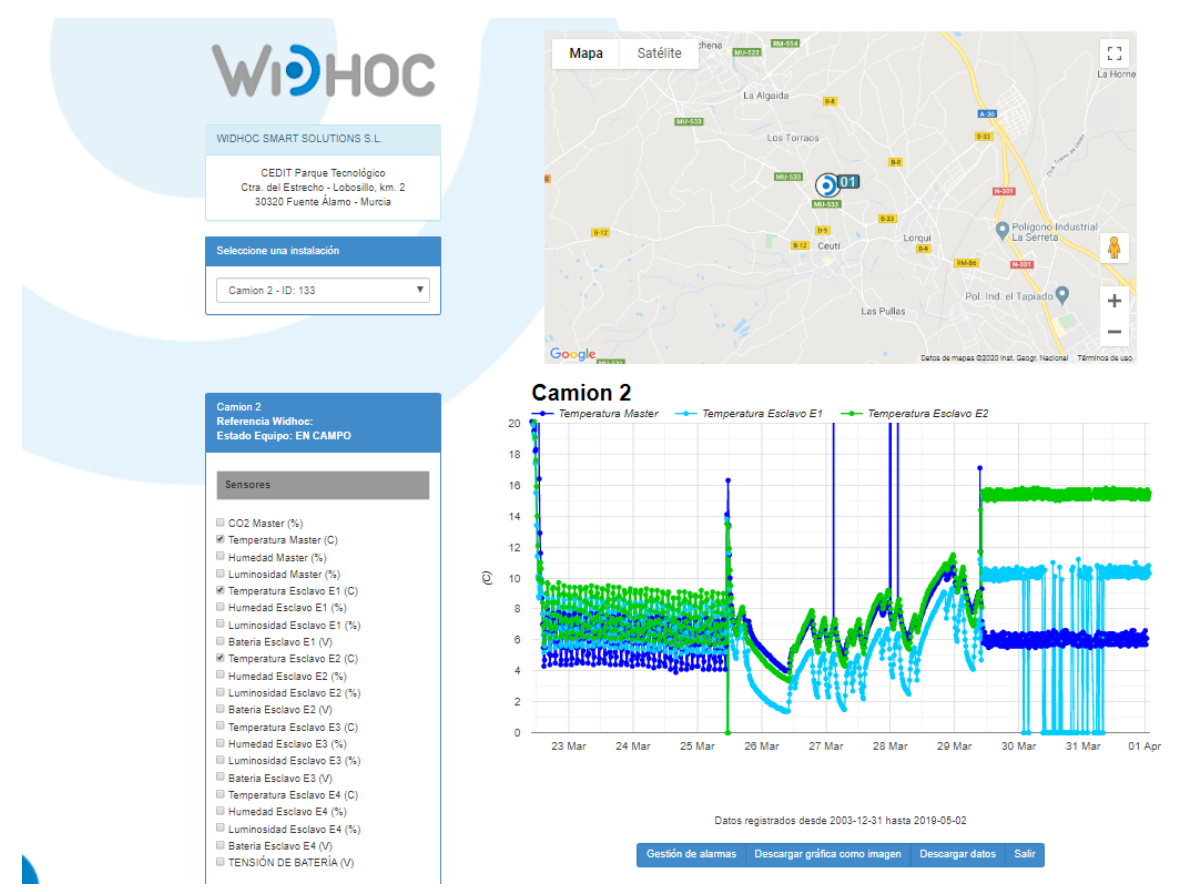

Figura 45. Representación de la temperatura en diferentes puntos en un viaje de camión (www.widhoc.com). 
ENSAYOS Y METODOLOGÍA PARA LA DETERMINACIÓN DE LA VIDA ÚTIL

5. ENSAYOS Y METODOLOGÍA PARA LA DETERMINACIÓN DE LA VIDA ÚTIL 


\subsection{ENSAYOS DE LABORATORIO}

A nivel mundial, los vegetales ocupan el quinto puesto entre los diez productos alimenticios más producidos (Figura 46) y en el caso de las lechugas (Lactuca sativa) y las endivias, esa producción aumenta año a año, junto con las superficies de cultivo (Figura 47).

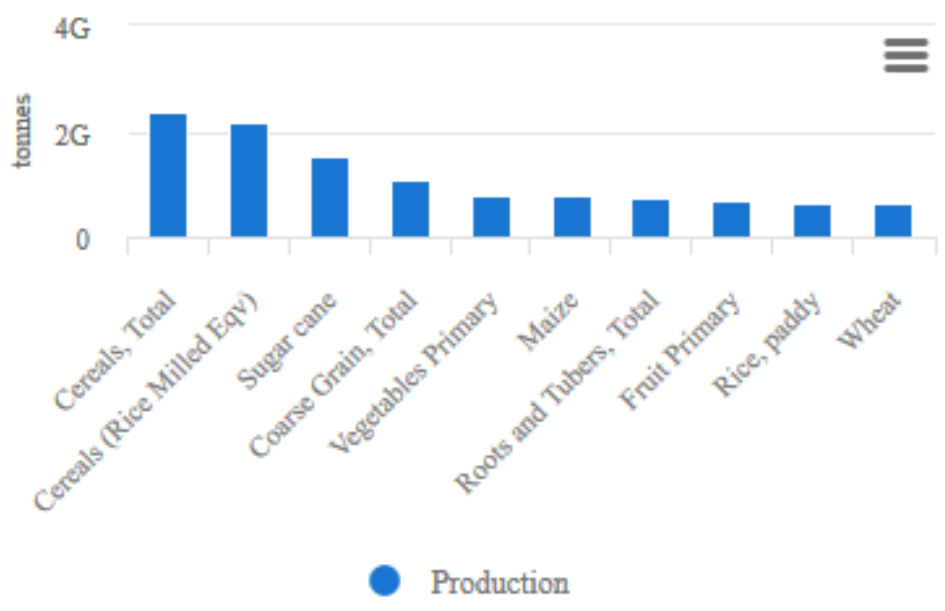

Figura 46. Alimentos más producidos a nivel mundial. Valores medios del periodo 1994-2018 (FAO, 2020).

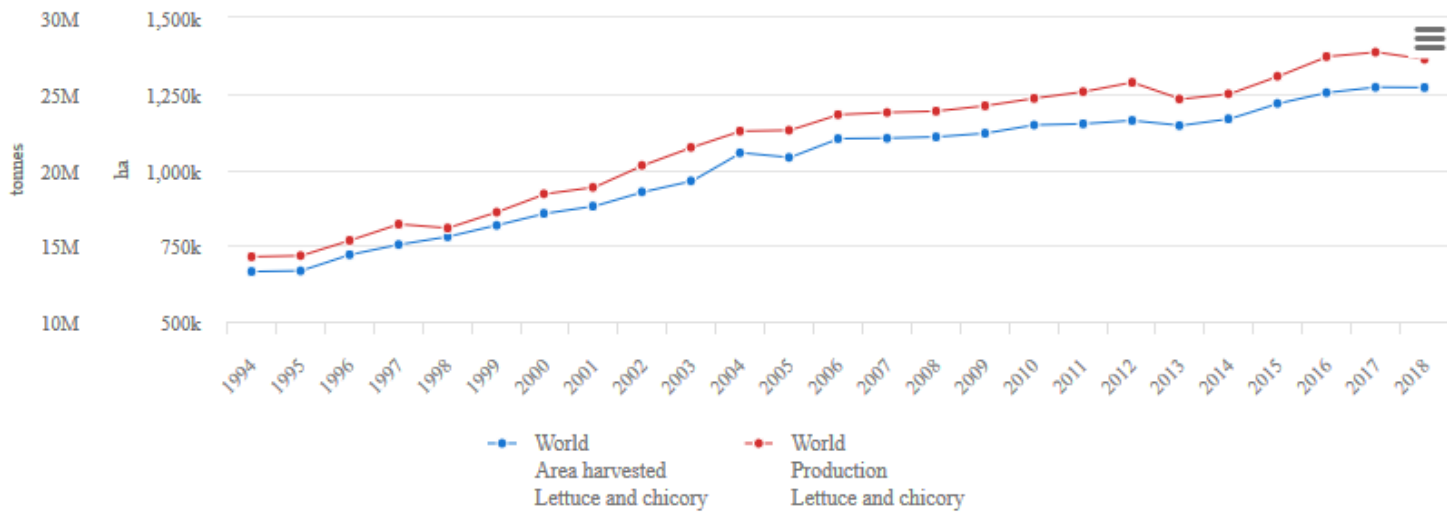

Figura 47. Evolución de la producción y superficie de cultivo de lechugas y endivias. Valores medios del periodo 1994-2018 (FAO, 2020).

Si bien China es el primer productor de lechugas con una producción media de 10.321.740,58 toneladas, seguido de EE. UU., con una notable diferencia de más de la mitad, 4.146.279,71 toneladas, España se sitúa en la tercera posición mundial con una producción anual de 956.787,58 toneladas. Todos ellos desde 1994 hasta 2018 (Figura 48). 


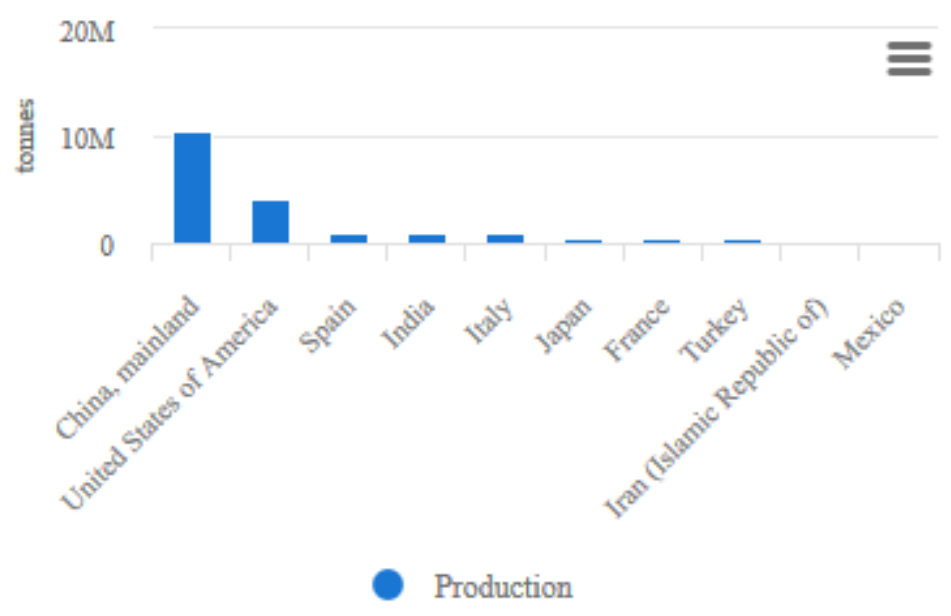

Figura 48. Principales países productores a nivel mundial de lechuga y endivia. Valores medios del periodo 1994-2018 (FAO, 2020).

La Región de Murcia es el primer productor de lechugas de España. Produciendo en el caso de la lechuga tipo Iceberg 38.4152 toneladas anuales (lo que supone un $51 \%$ del total español) (Figura 49) y en el caso de la lechuga tipo Romana 68.947 toneladas anuales (lo que se traduce en un $31 \%$ del total español) (Figura 50). 
ENSAYOS Y METODOLOGÍA PARA LA DETERMINACIÓN DE LA VIDA ÚTIL

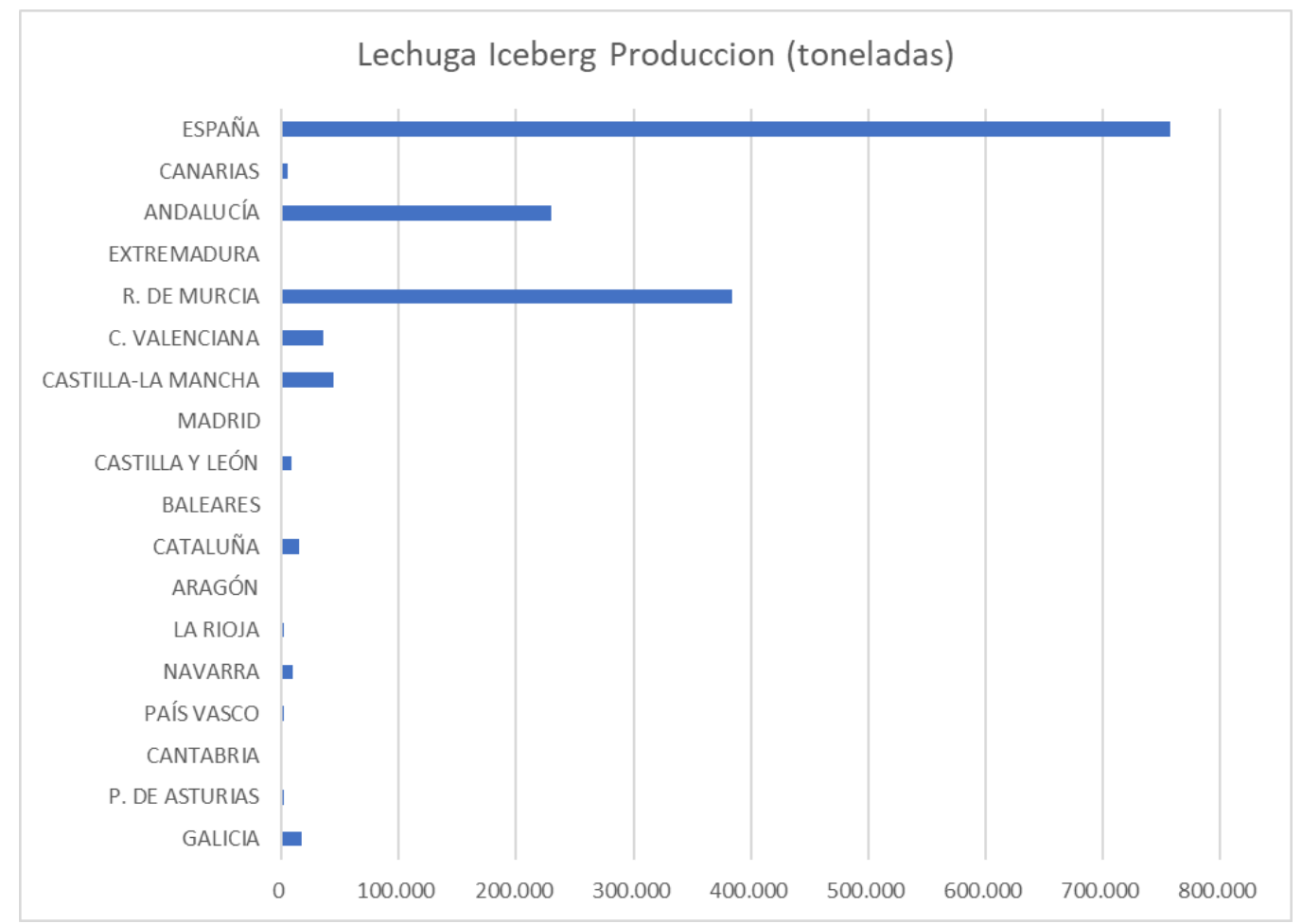

Figura 49. Datos de la producción anual de la Región de Murcia de lechuga Iceberg (Ministerio de Agricultura Pesca y Alimentación, 2018b).

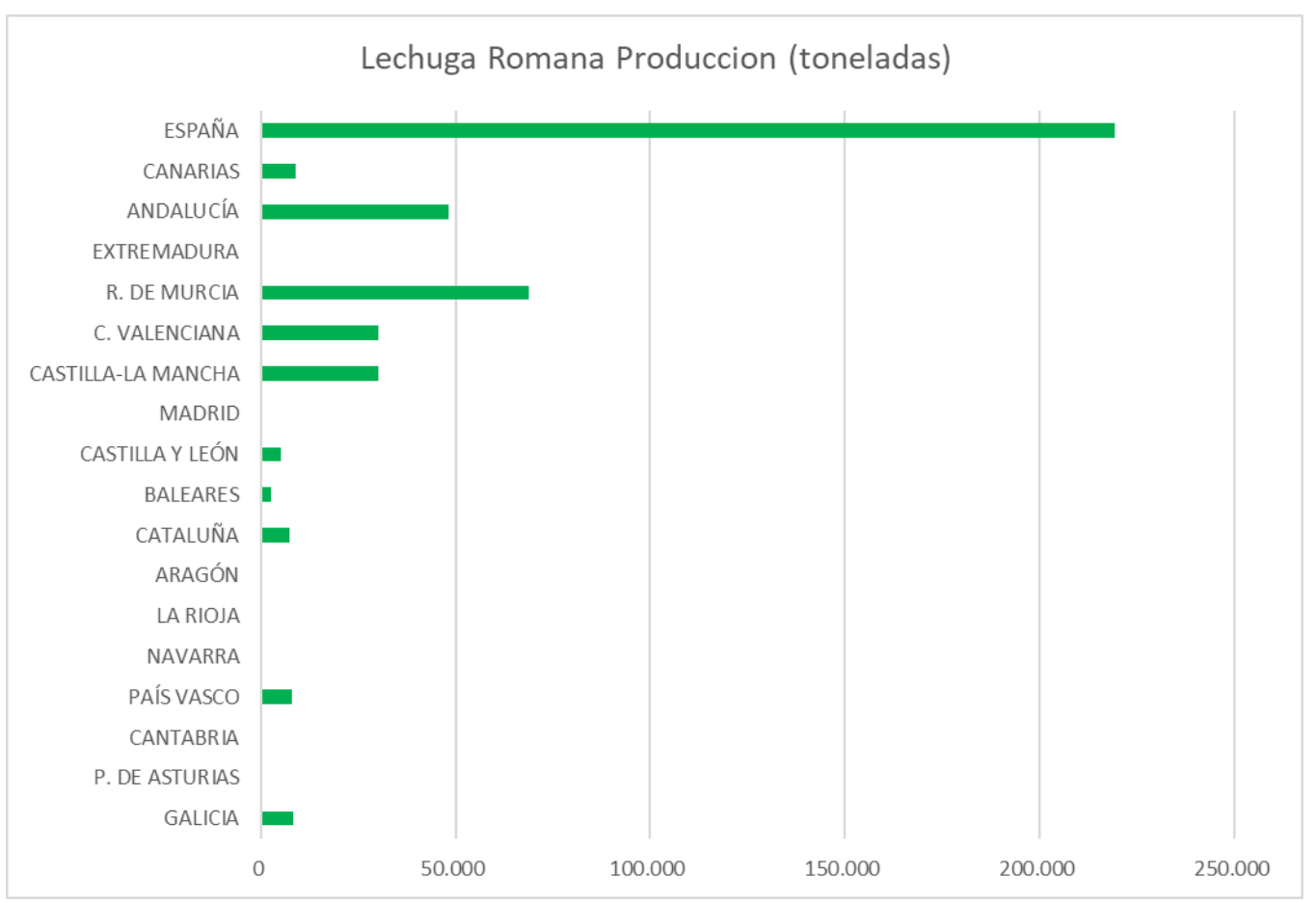

Figura 50. Datos de la producción anual de la Región de Murcia de lechuga Romana (Ministerio de Agricultura Pesca y Alimentación, 2018b).

La Región de Murcia se sitúa en el año 2018 como el principal exportador de España (Figura 51), superando las 550.000 toneladas, elevando en un 2,6\% su valor económico, alcanzando los 469 millones de euros. Los principales países de destino fueron Alemania, Francia, Reino Unido (con un incremento del 7,5\%), Italia, Países bajos y Polonia (con un aumento del 22,7\%) (Proexport, 2019). 


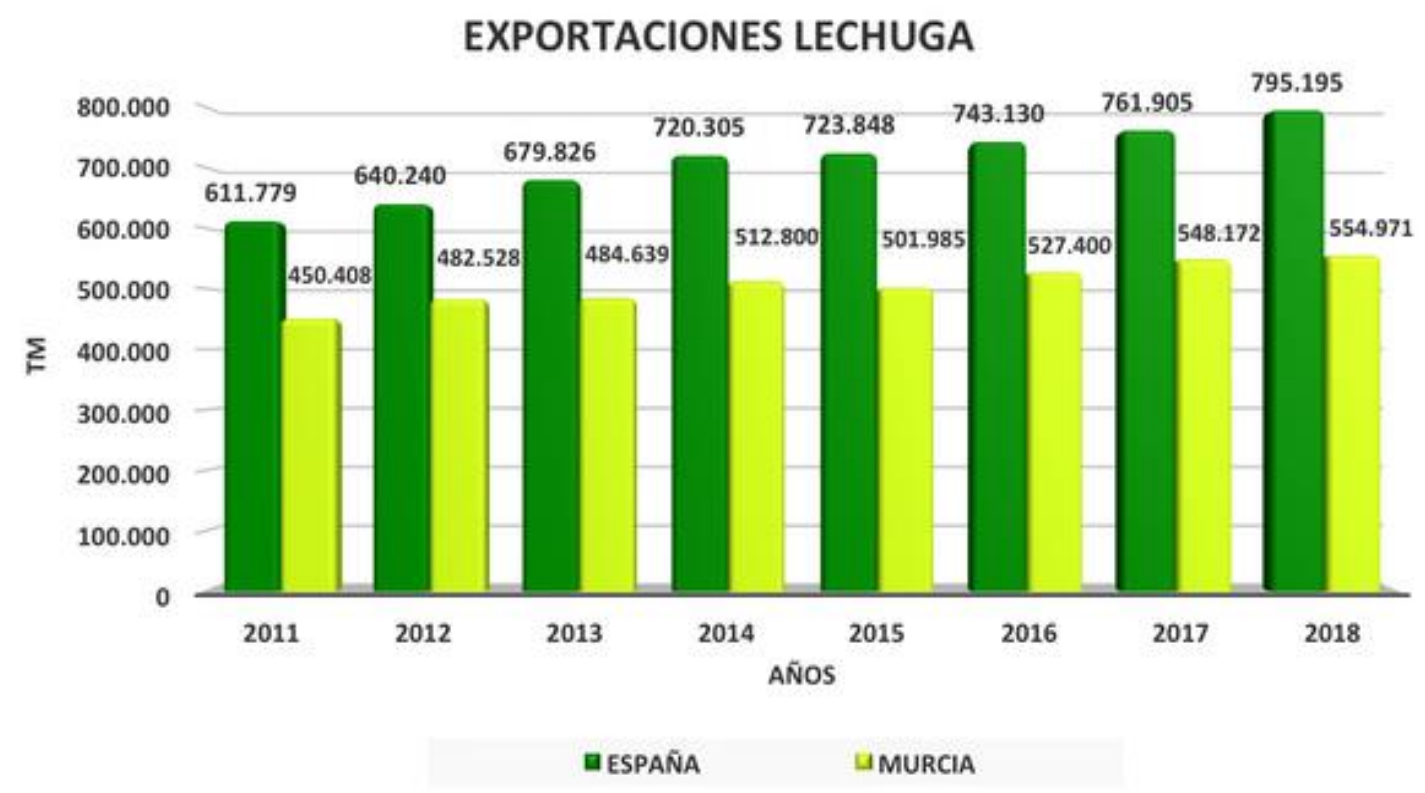

Figura 51. Evolución de las exportaciones a nivel nacional y regional (Proexport, 2019).

La temperatura optima de conservación y transporte de lechugas es de $0^{\circ} \mathrm{C}$, pudiendo lograr una vida útil entre 14 y 21 días en un rango de temperaturas de $0-4^{\circ} \mathrm{C}$ y bajo una HR de entre 95 y 90\%, respectivamente. La tasa de respiración de las lechugas es muy baja según se aprecia en el Tabla 3 y bajo un nivel de oxígeno del 1 al 3\% se consigue disminuir considerablemente su ratio de producción del etileno a niveles ínfimos $(<0,1$ $\mu \mathrm{L} / \mathrm{kg} \cdot \mathrm{h}$ a $20^{\circ} \mathrm{C}$ ) (Cantwell y Suslow, 2002).

Tabla 3. Ratio de respiración $(\mathrm{mL} \mathrm{CO} / \mathrm{kg} \cdot \mathrm{h})$ de lechugas.

\begin{tabular}{cccccc}
\hline Ta & $\mathbf{0}^{\circ} \mathbf{C}$ & $\mathbf{5}^{\circ} \mathbf{C}$ & $\mathbf{1 0}^{\circ} \mathbf{C}$ & $1^{\circ} \mathbf{C}$ & $\mathbf{2 0}^{\circ} \mathbf{C}$ \\
\hline \hline Iceberg & $3-8$ & $6-10$ & $11-20$ & $16-23$ & $25-30$ \\
\hline Romana & $4-8$ & $9-12$ & $15-20$ & $19-25$ & $30-38$ \\
\hline \hline
\end{tabular}

La disponibilidad de este producto en la Región de Murcia, su importancia en la exportación a la UE, su amplia estacionalidad y sus condiciones recomendadas de conservación y transporte postcosecha (estricta baja temperatura, sensibilidad al etileno y al $\mathrm{CO}_{2}$ ) han sido los factores clave para la elección de la lechuga como modelo de alimento perecedero para la estimación de su vida útil.

Estos ensayos se han realizado mediante dos tipos de pruebas para determinar la validez del sistema objeto de esta Tesis: en primer lugar, se realizaron pruebas para determinar la vida útil de las lechugas a diferentes temperaturas establecidas dentro de cámaras frigoríficas donde se controlaron al máximo todos los factores ambientales. Por otro lado, los sistemas de monitorización se instalaron en camiones de transporte cargados con lechugas y se evaluaron las variaciones de temperatura durante varios viajes reales por la UE, para replicar las condiciones de las cámaras climáticas donde se probó y validó 
la vida útil de las lechugas. La Figura 52 muestra el diagrama de flujo del proceso descrito.

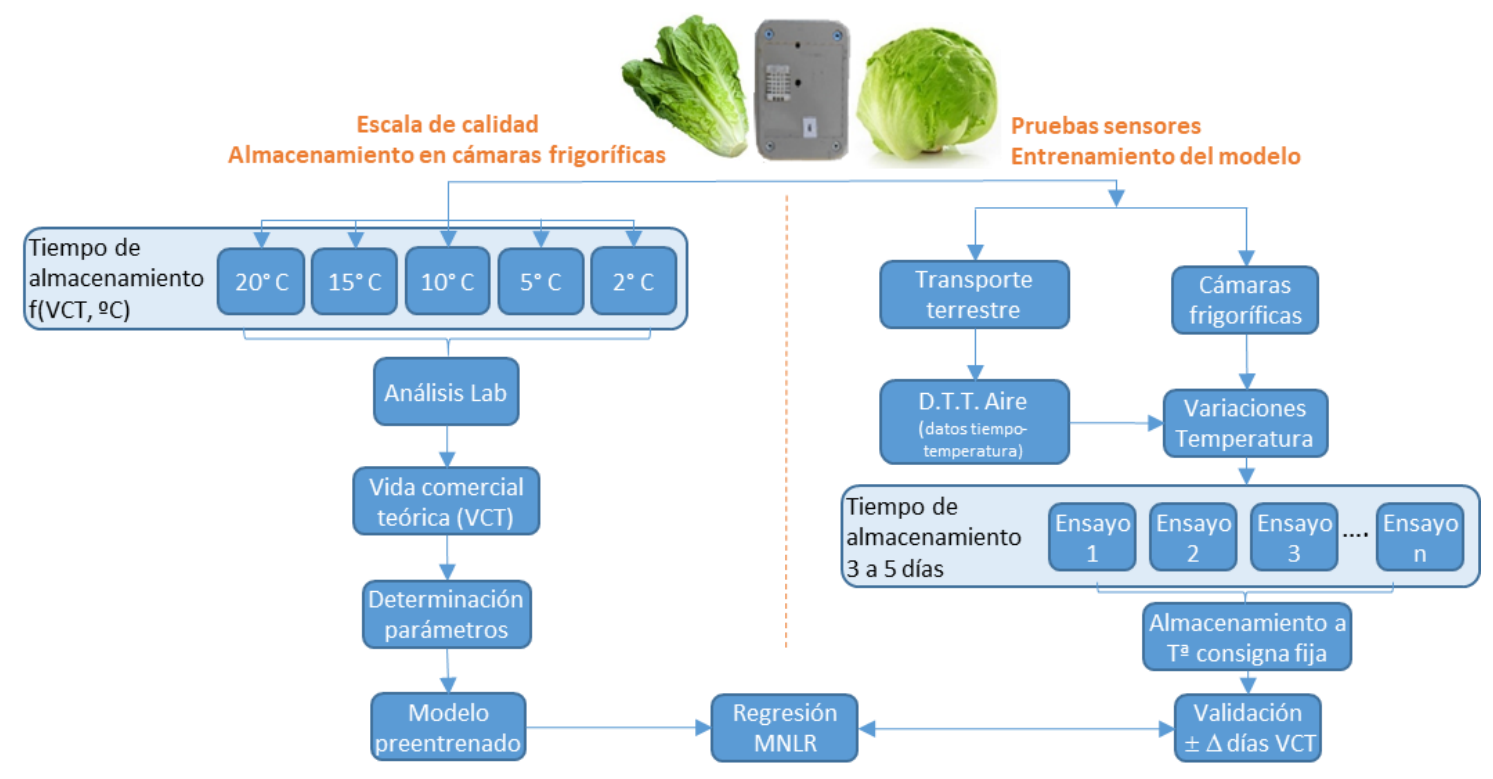

Figura 52. Diagrama de flujo del proceso de ensayo

Las lechugas Romana e Iceberg se obtuvieron en Fruca Marketing S.L. (Fuente Álamo, Murcia, España). Los ensayos se llevaron a cabo en febrero, marzo, abril y noviembre de 2019.

Tras su recolección en el campo, las lechugas se envasaron en bolsas de $33 \times 23 \mathrm{~cm}$ con perforaciones de $2 \mathrm{~mm}$ de diámetro, para el caso de las Iceberg, y en bolsas de $37 \times 24,8 \mathrm{~cm}$ con perforaciones de $8 \mathrm{~mm}$ de diámetro, para las Romanas, 0 , enfriándose al vacío una vez llegaron al almacén, donde los miembros del Equipo de Investigación de estos trabajos recogieron la materia prima para llevarla a la UPCT.
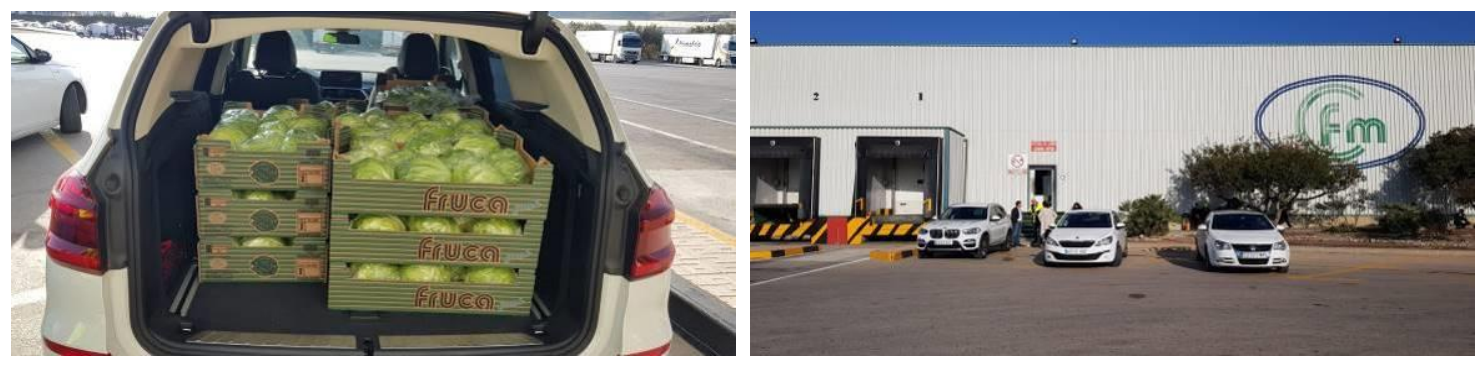

Figura 53. Carga y transporte de las lechugas. 


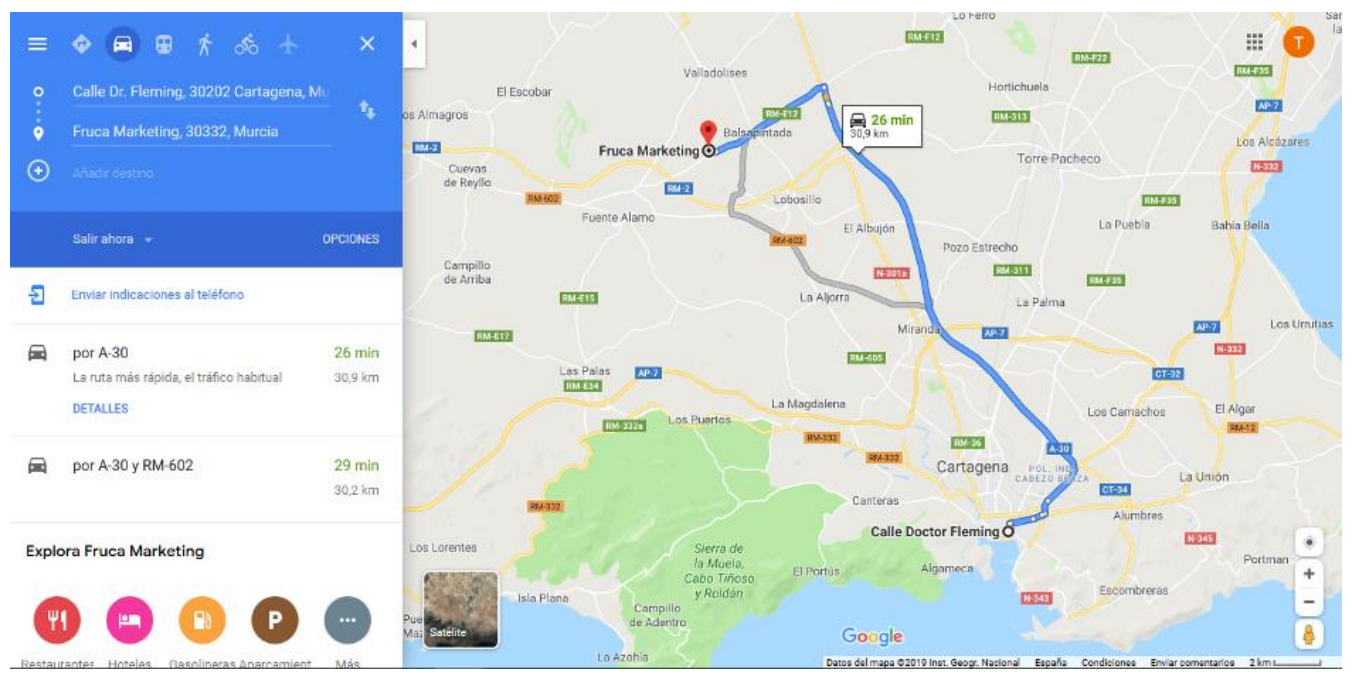

Figura 54. Detalle de la ruta desde la empresa productora hasta las instalaciones de la UPCT.
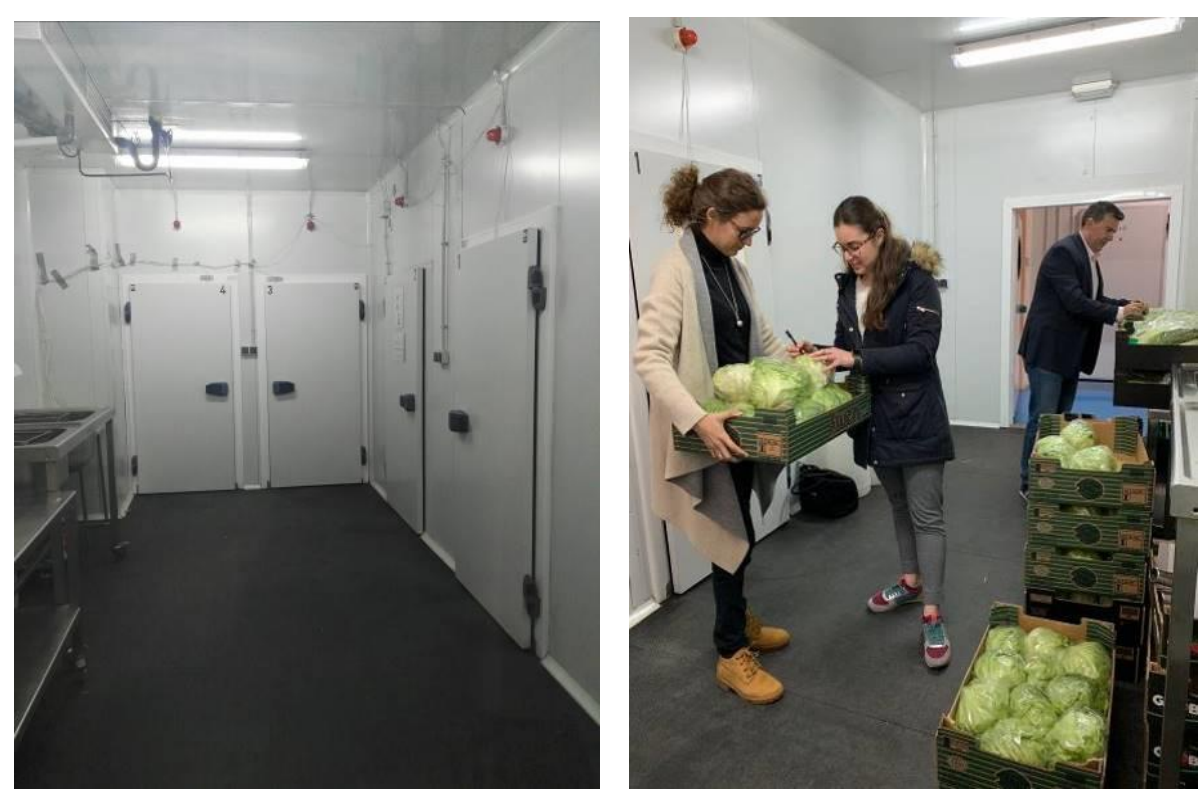

Figura 55. Sala de cámaras y proceso de etiquetado para las salidas de los ensayos.

Estas se transportaron $31 \mathrm{~km}$ desde el emplazamiento de la empresa hasta las cámaras frigoríficas de las instalaciones del Instituto de Biotecnología Vegetal (IBV) de la UPCT, donde se dividieron en lote homogéneos para ser almacenadas a 5 temperaturas distintas $\left(2,5,10,15\right.$ y $\left.20^{\circ} \mathrm{C}\right)$ durante $29,21,15,9$ y 6 días respectivamente (Tabla 4). Dicha vida útil se basó en ensayos preliminares no publicados y está en concordancia con las recomendaciones de vida útil de UCDavis (CA, USA) (Cantwell y Suslow, 2002). Dado que en los datos obtenidos en los viajes reales de lechugas durante su exportación por la UE nunca se alcanzaron los $0^{\circ} \mathrm{C}$, se decidió no testear dicha temperatura, que además es difícil alcanzar en la instalación frigorífica del IBV donde se realizaron las pruebas. 
Tabla 4. Vida útil recomendada y días de análisis de calidad realizados de acuerdo con la temperatura de almacenamiento.

\begin{tabular}{ccc}
\hline $\begin{array}{c}\text { Temperatura de } \\
\text { almacenamiento }\left({ }^{\circ} \mathbf{C}\right)\end{array}$ & $\begin{array}{c}\text { Vida útil } \\
\text { recomendada (días) }\end{array}$ & Días análisis cualitativo \\
\hline \hline 20 & 6 & $0,1,2,3,6$ \\
\hline 15 & 9 & $0,2,3,6,8,9,10$ \\
\hline 10 & 15 & $0,3,6,9,14,15,16$ \\
\hline 5 & 21 & $0,3,9,15,20,21,22$ \\
\hline 2 & 29 & $0,3,9,15,21,28,29,30$ \\
\hline
\end{tabular}

Una vez se almacenaron en las distintas cámaras a las temperaturas correspondientes, las lechugas fueron evaluadas en distintas salidas función del tiempo de almacenamiento y la temperatura bajo la cual estuvieron expuestas. En cada una de las salidas se evaluaron cinco lechugas Iceberg y cinco Romana.

\subsubsection{Tasa de respiración}

La tasa de respiración se determinó utilizando un cromatógrafo de gases (7820A, Agilent Technologies, Santa Clara CA, EE. UU.), equipado con un detector de conductividad térmica $\left(200^{\circ} \mathrm{C}\right)$, un horno $\left(80^{\circ} \mathrm{C}\right)$, un inyector $\left(120^{\circ} \mathrm{C}\right)$ y con un Columna Hayesep $\mathrm{Q}$ (Teknokroma, Barcelona, España). Se usaron aire y $\mathrm{H}_{2}$ como portadores de gas a 30 y 3 $\mathrm{mL} \mathrm{min}^{-1}$. Para cada temperatura $\left(2,5\right.$ y $\left.10^{\circ} \mathrm{C}\right)$, se analizaron tres réplicas. Se colocó una cabeza de lechuga Iceberg $(515 \pm 60 \mathrm{~g}$ y $470 \pm 53 \mathrm{~g}$, respectivamente) en cubos herméticos de plástico de 3,9 y $10,8 \mathrm{~L}$, respectivamente. Los resultados se expresaron en $\mathrm{mL}$ de $\mathrm{CO}_{2} \mathrm{~kg}^{-1} \mathrm{~h}^{-1}$.

\subsubsection{Análisis fisicoquímico}

\section{Pérdida de peso}

Es la relación entre el peso inicial del individuo y el final medido en el último día de ensayo. Para este análisis durante todas las salidas se pesaron los mismos individuos, llamados de referencia, y se aplicó la fórmula siguiente (5):

\section{Color}

$$
\text { \%Pérdida de peso }=\frac{\left(\mathrm{Peso}_{\text {inicial }}-\mathrm{PesO}_{\text {final }}\right) \cdot 100}{\mathrm{PesO}_{\text {inicial }}}
$$

Se determinó utilizando un colorímetro marca Minolta, modelo Chroma Meter CR - 400, fabricado en Tokio (Japón), cuyas especificaciones son:

- Área de medición/iluminación: $\Phi 8 \mathrm{~mm} / \Phi 11 \mathrm{~mm}$.

- Rango de valores de visualización Y: 0,01\% a 160,00\% (reflectancia).

- Detector: Fotoceldas de silicio (6). 
- Fuente de iluminación: Lámpara de xenón pulsada.

- Sistema de iluminación difusa y ángulo de visión de $0^{\circ}$ conforme a la norma JIS Z 8722.

Se calibró utilizando una placa de referencia blanca (fuente de luz C). Para las mediciones se tomaron lecturas en 2 áreas diferentes de la hoja, en el extremo (zona verde de la hoja) y en el área de corte (zona blanca del tallo) y se promediaron todas las mediciones (Figura 56).

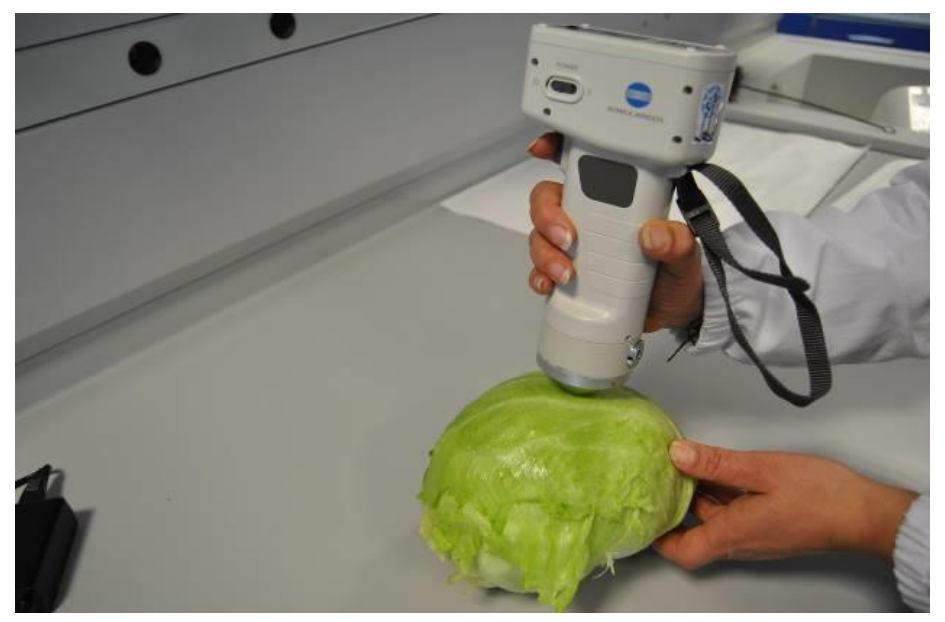

Figura 56. Detalle de la posición de medición de color en la lechuga Iceberg.

El registro de dichas mediciones se realizó utilizando los parámetros triestímulos estándar CIE 1976 L*a*b*, donde:

- $\mathrm{L}^{*}=$ luminosidad ( $\mathrm{L}^{*}=0$ indica negro, $\mathrm{L}=100$ indica blanco)

- $a^{*}=$ coordenadas rojo/verde (+a indica rojo, - a indica verde)

- $b^{*}=$ coordenadas amarillo/azul (+b indica amarillo, $-b$ indica azul)

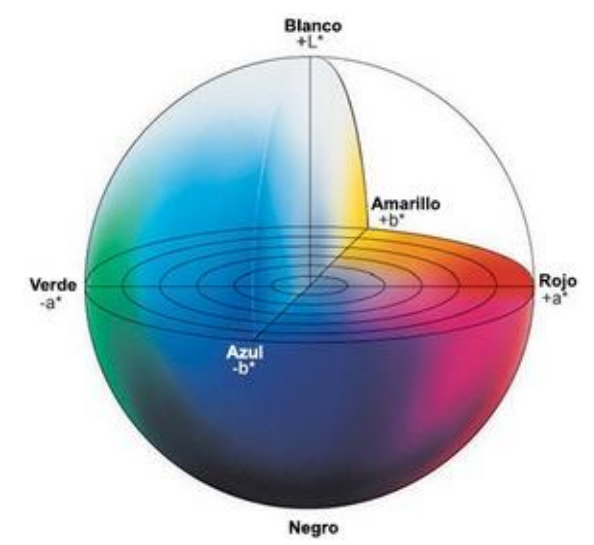

Figura 57. Espacio de color CIE L*a*b* (KONICA MINOLTA, 2000).

Las diferencias de color totales $(\Delta \mathrm{E})$ a lo largo del almacenamiento, en comparación con sus respectivos valores iniciales, se calcularon de acuerdo con la ecuación siguiente (6):

$$
\Delta E^{*}=\left[\left(L_{1}^{*}-L_{2}^{*}\right)^{2}+\left(a_{1}^{*}-a_{2}^{*}\right)^{2}+\left(b_{1}^{*}-b_{2}^{*}\right)^{2}\right]^{\frac{1}{2}}
$$




\section{Firmeza}

La firmeza se registró utilizando un analizador de textura marca Ibertest, modelo eLib5-W, fabricado en Madrid (España) mediante la fuerza de compresión (N) requerida para lograr una deformación del $5 \%$ del diámetro de la lechuga a una velocidad de $100 \mathrm{~mm}$ $\mathrm{min}^{-1}$ según Martínez-Romero et al. (2008). Los resultados se expresaron en $\mathrm{Nmm}^{-1}$.

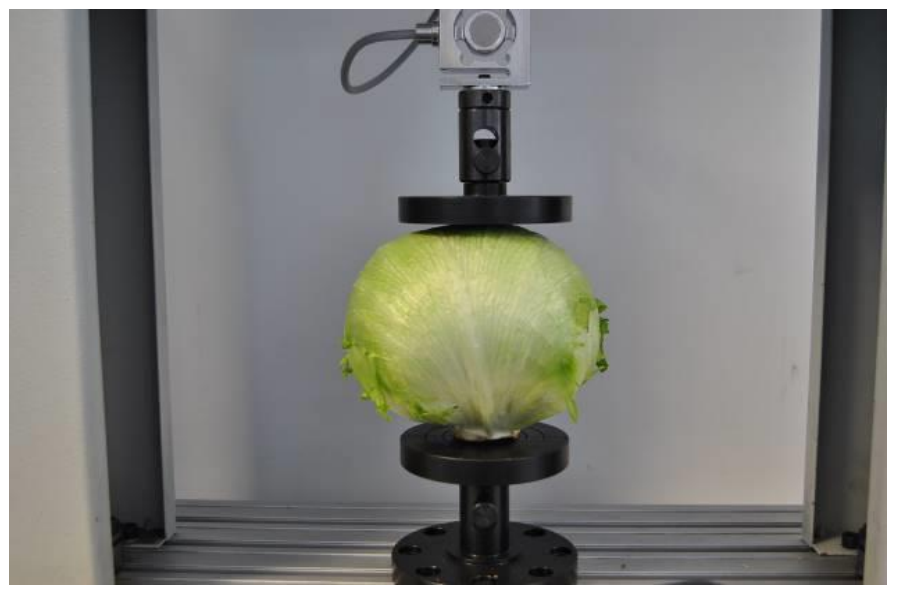

Figura 58. Pruebas de firmeza sobre la lechuga Iceberg.

\section{Contenido total de sólidos solubles (SSC)}

Se determinó mediante un refractómetro de mano digital (Atago N1; Tokio, Kanto, Japón) a $20^{\circ} \mathrm{C}$ y expresado como Brix (g equivalentes de azúcar $100 \mathrm{~g}^{-1}$ ).

\section{pH}

Para determinar el nivel de $\mathrm{pH}$ se usó un medidor de $\mathrm{pH}$, de la marca Crison, modelo Basic20, fabricado en Cataluña (España).

Cuyas especificaciones en las variables medidas son las siguientes:

- Escalas: $-2 \ldots 16 \mathrm{pH}, \pm 2000 \mathrm{mV}$ y $-20 \ldots 150^{\circ} \mathrm{C}$.

- Resolución: $0,01 \mathrm{pH}, 1 \mathrm{mV}, 0,1^{\circ} \mathrm{C}$.

- Error de medida ( \pm 1 dígito): $\leq 0,01 \mathrm{pH}, \leq 1 \mathrm{mV}, \leq 0,2^{\circ} \mathrm{C}$.

\section{Acidez titulable (AT):}

La AT se determinó mediante la titulación de $2 \mathrm{~mL}$ de jugo de lechuga más $48 \mathrm{~mL}$ de agua destilada con $\mathrm{NaOH}$ 0,1 M a pH 8,1 (T50, Metter Toledo; Milán, Italia) y se expresó como g de ácido cítrico $\mathrm{L}^{-1}$. 


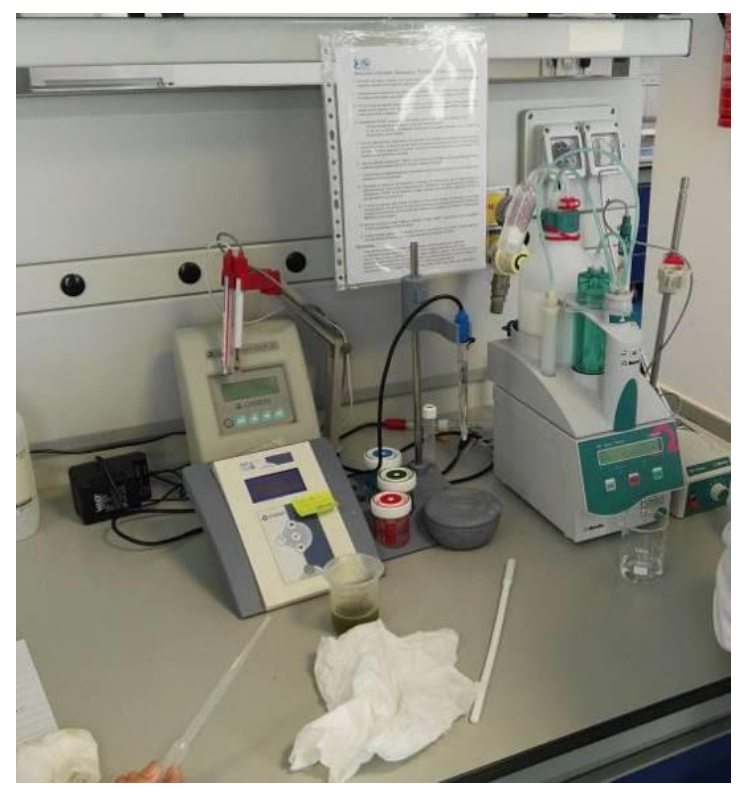

Figura 59. Aparatos de medida para las pruebas químicas.

\subsubsection{Análisis sensorial}

Los análisis sensoriales se realizaron de acuerdo con los estándares internacionales (ASTM, 1986) en los laboratorios del IBV pertenecientes a la UPCT, bajo iluminación artificial tipo luz diurna, temperatura constante a $20^{\circ} \mathrm{C}$ y circulación de aire. El panel consistió en diez evaluadores experimentados de entre 22 y 55 años, evaluados para determinar su capacidad sensorial, frente a aspectos tales como la apariencia visual, color, compacidad, sabor, frescura y calidad general.

En cada uno de los días de pruebas (salidas) se presentaron cinco lechugas, que se encontraban almacenadas en cada una de las cámaras frigoríficas a distintas temperaturas, para estudiar en función de los parámetros preestablecidos, si se encontraban por encima o por debajo del límite de comercialización o venta al por menor (LR - "limit of retail").

Las calificaciones se realizaron bajo una escala o score. La apariencia visual, el color, la compacidad, el sabor y la calidad general se evaluaron utilizando una escala hedónica de aceptabilidad de 5 puntos: 5: excelente; 4: bueno; 3: normal (LR); 2: malo; 1: extremadamente malo. Las alteraciones para mal olor, daños por congelamiento, daños mecánicos y varios trastornos como pardeamiento, punteado pardo (russet spotting) y costilla rosada (pink ribs) se evaluaron utilizando otra escala hedónica de aceptabilidad de 5 puntos: 5: ausencia; 4: leve presencia; 3: aceptable (LR) -; 2: importante presencia; 1: extremada presencia. 
ENSAYOS Y METODOLOGÍA PARA LA DETERMINACIÓN DE LA VIDA ÚTIL

ESTADILLO DE ANÁLISIS SENSORIAL PARA LECHUGA

\begin{tabular}{|c|c|c|c|c|c|}
\hline \multicolumn{2}{|l|}{$\begin{array}{l}\text { Evaluador. Equipo IBV } \\
\text { Fecha 25/02/19 }\end{array}$} & \multicolumn{4}{|c|}{ Producto LECHUGA ICEBERG a $10^{\circ}$} \\
\hline MUESTRA & 6 & 7 & 8 & 9 & 10 \\
\hline ACEPTABILIDAD & & & & & \\
\hline Apariencia visual & 3,5 & 3 & 3 & 3 & 3,5 \\
\hline Color & 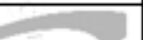 & & & 4 & \\
\hline Compacidad al tacto & 4 & 4 & 4 & 5 & 3 \\
\hline Sabor (frescuralcrujente) & 4,5 & 5 & 4 & 2 & 3 \\
\hline Aceptabilidad Global & 4 & 4 & 4 & 3 & 4 \\
\hline \begin{tabular}{|l|} 
ALTERACIONES \\
\end{tabular} & & & & & \\
\hline Olones extraños & 5 & 58 & 5 & $x=5$ & 5 \\
\hline Daños por congelación & 50 & 50 & 5 & 5 & 5 \\
\hline Pardeamiento & de $30 \mathrm{~s}$ & $\operatorname{TCC} 3,5 \mathrm{TCC}$ & काणा3 14 & CTा/3लन & 7013,5 \\
\hline Bussed spotting & 5 & 5 & 5 & 5 & 5 \\
\hline Pink vil & 5 & 5 & 5 & 5 & 5 \\
\hline \begin{tabular}{|l|} 
Dan̂os mecánicos \\
\end{tabular} & 4 & 4 & 3,5 & 4 & 3,5 \\
\hline
\end{tabular}

\begin{tabular}{|c|c|}
\hline Aceptabilidad & Alteraciones \\
\hline 5: excelerte & 5: ausencia \\
\hline 4: bueno & 4: leve presencia \\
\hline 3: nomal, limite de comercialización & 3: aceptable, limite de comercialización \\
\hline 2: malo & 2: importante presencia \\
\hline 1: extremadamente malo & 1: extremada presencia \\
\hline
\end{tabular}

Observaciones del catador:

Las hojas exteriores han disminuido considerablemente la firmeza inicial.

Figura 60. Estadillo utilizado para el análisis sensorial.

Para ello en un primer paso, las lechugas se evaluaron con las cabezas enteras y posteriormente se procedió a cortarlas mediante un corte longitudinal (Figuras 61 y 62), de modo que también se estudió su aspecto interior. 

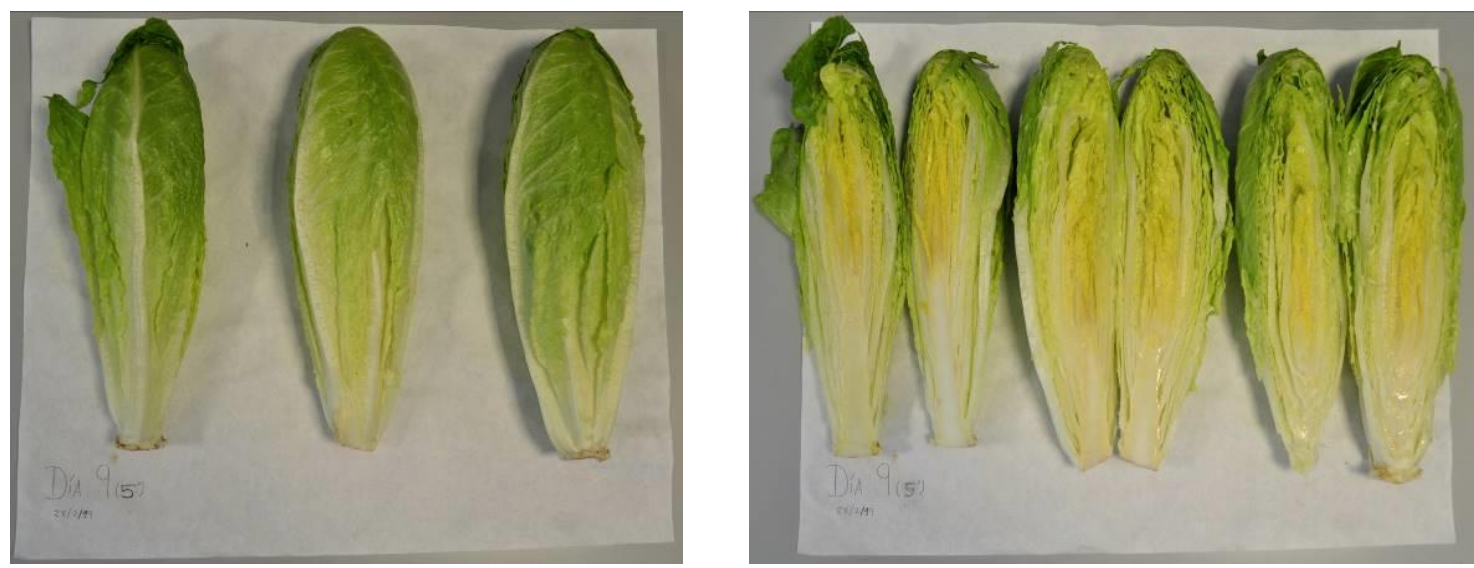

Figura 61. Detalle de las lechugas Romanas enteras y cortadas longitudinalmente.
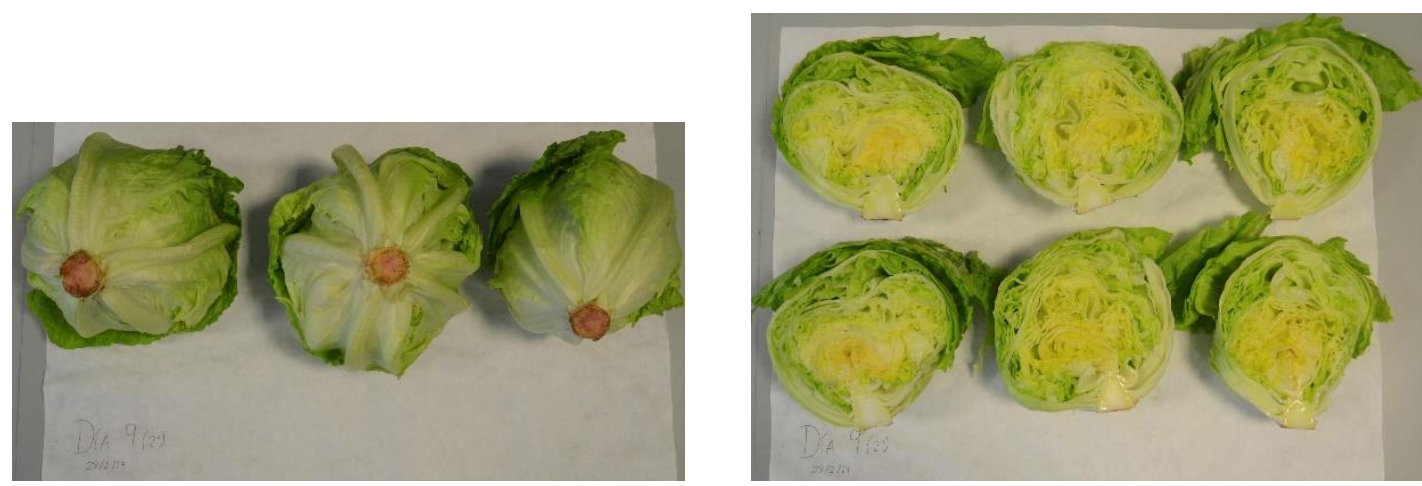

Figura 62. Detalle de las lechugas Iceberg enteras y cortadas longitudinalmente.

Todo ello se realizó de acuerdo con la bibliografía (Cantwell y Suslow, 2002), en la cual se cita las condiciones de maduración, el color, la definición de daños mecánicos, daños por congelación, pardeamiento, punteado pardo ("russet spotting"), costilla rosada ("pink ribs") y manchas pardas ("brown stain").

En el caso de la madurez de una lechuga acogollada tipo Iceberg la característica principal es la compacidad de la cabeza. De esta forma, se dice que la es madurez ideal, cuando la cabeza se puede comprimir con una presión manual normal. En el caso de que la cabeza esté muy suelta (la presión sea mínima), implica inmadurez, mientras que, si hay que ejercer una presión mayor, la cabeza está muy dura y por lo tanto demasiado madura (Figura 63). 

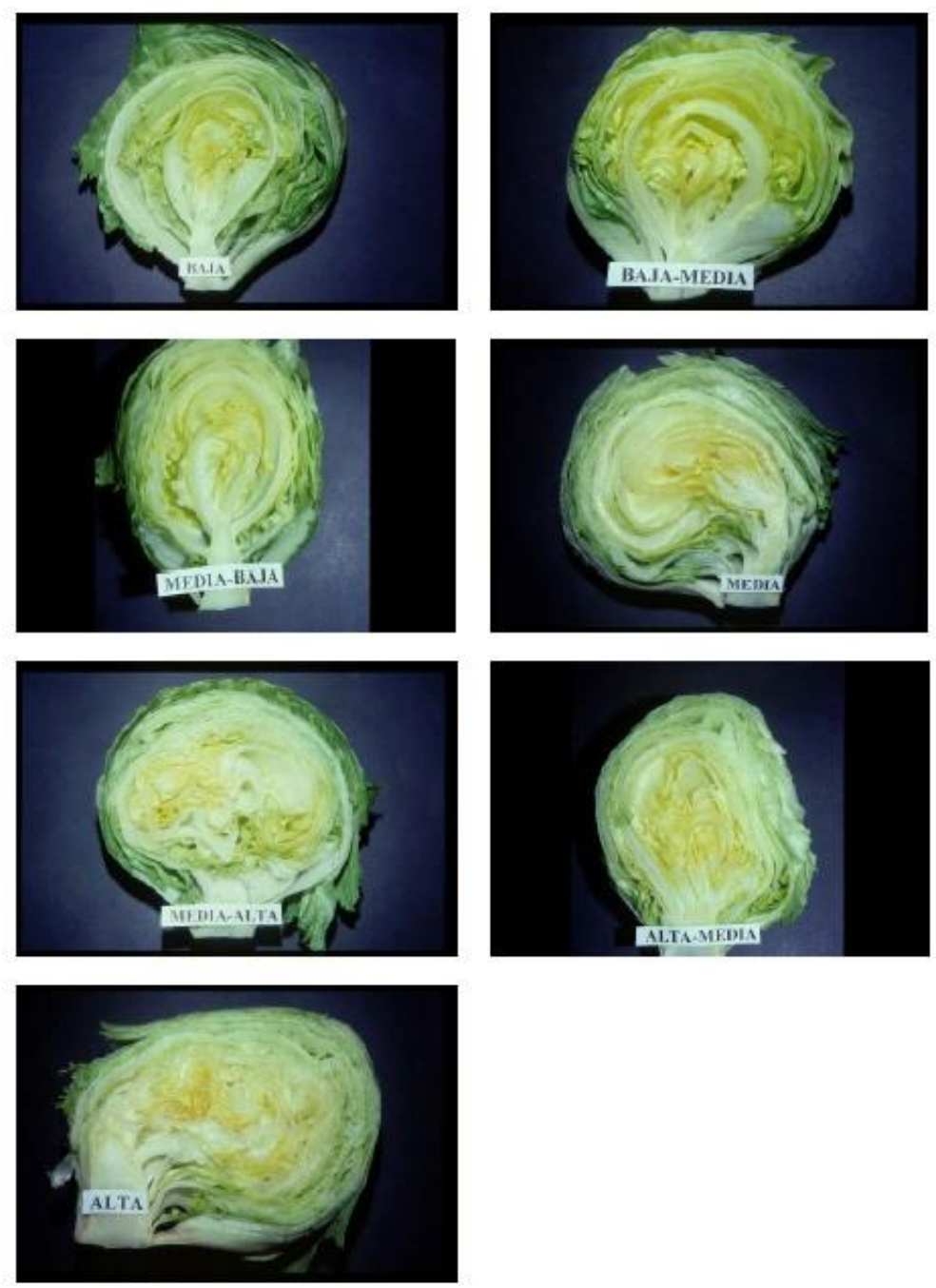

Figura 63. Estados de madurez de la lechuga tipo Iceberg (Martínez-López, 2011).

Las cabezas inmaduras y en su estado de madurez ideal tienen mucho mejor sabor que cabezas sobremaduras y también tienen menos problemas postcosecha. Tras el corte de las hojas externas, las hojas que queden deben ser de un color verde claro brillante.

La lechuga Romana, por ser alargada, basa su madurez en el número de hojas y el desarrollo de la cabeza. Del mismo modo, una cabeza muy suelta o fácilmente compresible es inmadura y una cabeza muy firme o dura es sobremadura. En este caso, el color tras el corte debe ser de un color verde brillante y oscuro en las hojas externas y amarillo o verde claro en las hojas internas de la cabeza.

Por otro lado, la manipulación, así como las condiciones ambientales, producen una serie de desórdenes o alteraciones fisiológicas y físicas, como son daños por congelación, pardeamiento, punteado pardo, manchas pardas, costilla rosada y daños mecánicos.

- Daño por congelación puede ocurrir en el campo y causar la separación de la epidermis de la hoja. Esto debilita la hoja y conduce a podredumbres bacterianas más rápidamente. Durante la conservación frigorífica, pueden producirse daños 
por congelación si la lechuga se almacena a por debajo de los $0^{\circ} \mathrm{C}$. Dicha alteración se manifiesta con manchas oscuras translúcidas o empapadas en agua que se vuelven acuosas y se deterioran rápidamente tras descongelarse (Figura 64) (Artés-Hernández, 2019a).

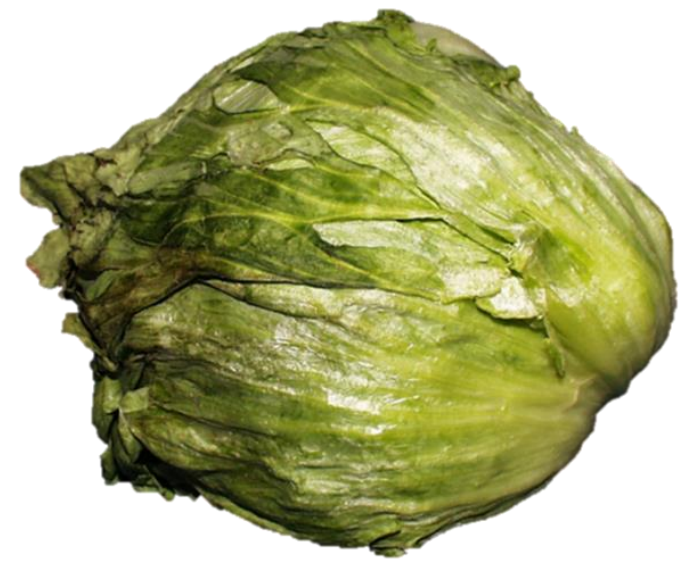

Figura 64. Aspecto de los daños por congelación en lechuga Iceberg.

- Russet spotting. Dicha alteración es debida a la exposición a bajas concentraciones de etileno durante su conservación o transporte que estimula la producción de compuestos fenólicos que conducen a pigmentos marrones (Figura 65). El punteado aparece como manchas marrones oscuras especialmente en las costillas de las lechugas. En condiciones severas, se encuentran en el tejido de la hoja verde y en toda la cabeza. El desorden es estrictamente estético, pero hace que la lechuga no sea comercializable (Cantwell y Suslow, 2002). El daño por etileno puede producirse durante el transporte en cargas mixtas, o almacenamiento con productos hortofrutícolas altamente emisores de etileno, lo cual tiene un especial interés en este producto y es una de las principales razones por las que se ha elegido la lechuga como modelo, dada su susceptibilidad
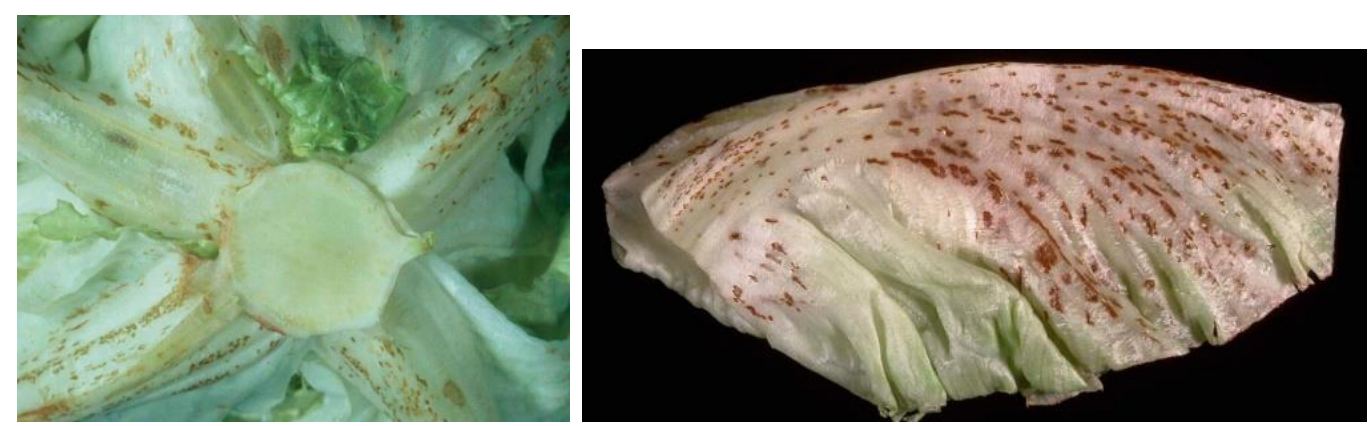

Figura 65. Aspecto del russet spotting en las lechugas Iceberg.

- Brown stain. Los síntomas de este desorden son manchas grandes, con un tono amarillento-rojizo-marrón principalmente en las nervaduras centrales. Pueden oscurecerse o agrandarse con el tiempo. También aparece como rayas de color marrón rojizo en algunos casos. Es causada por la exposición a atmósferas con más del $3 \%$ de $\mathrm{CO}_{2}$, especialmente a bajas temperaturas. 


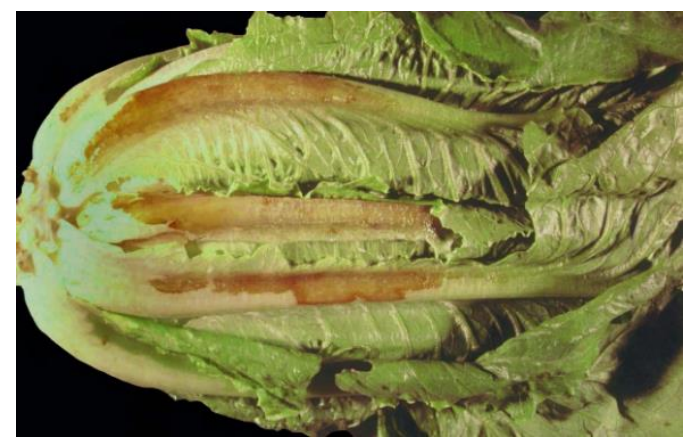

Figura 66. Aspecto del brown stain en lechuga Romana (Cantwell y Suslow, 2002).

- Pink rib. Es una alteración donde las costillas toman una coloración rosada. Las cabezas sobremaduras y las altas temperaturas de almacenamiento aumentan el desorden (Figura 67). La exposición al etileno no aumenta el desorden y las atmósferas bajas de $\mathrm{O}_{2}$ no la controlan (Cantwell y Suslow, 2002).

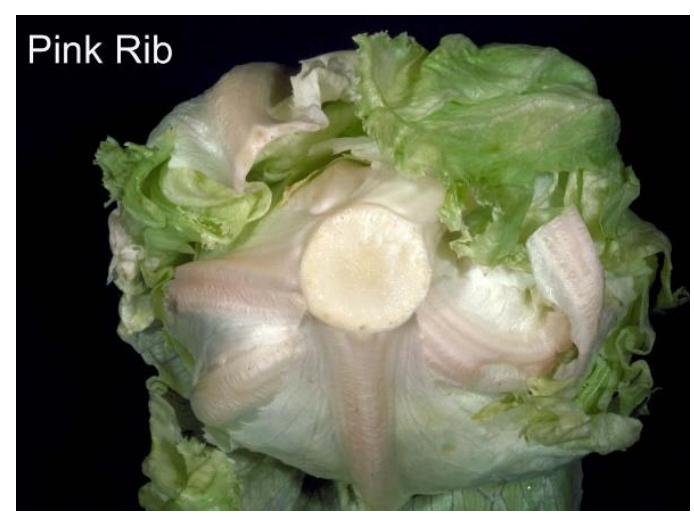

Figura 67. Aspecto del pink rib en las nervaduras centrales.

- Daño mecánico. Se produce en la rotura de las costillas durante el envasado en campo y provoca un aumento de pardeamiento y una mayor susceptibilidad al deterioro y podredumbre (Cantwell y Suslow, 2002).
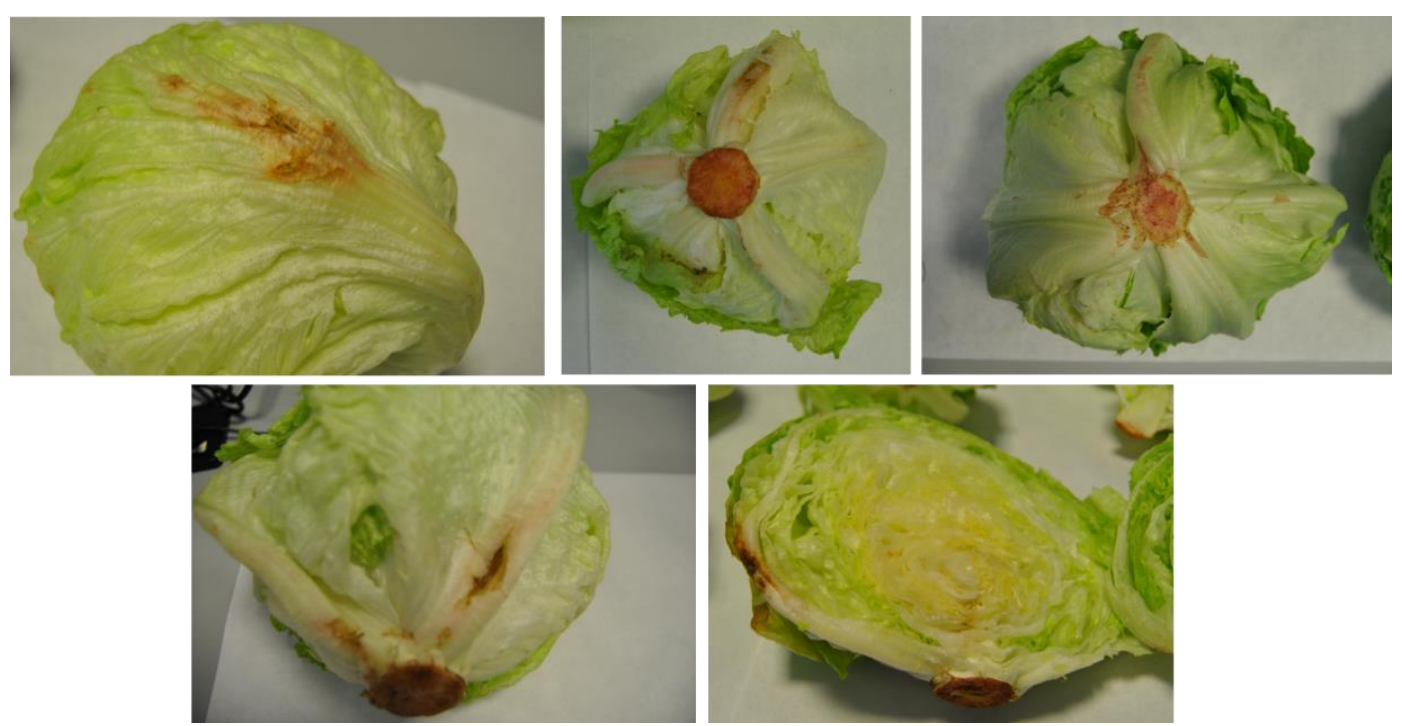

Figura 68. Aspecto de daño mecánico en las nervaduras centrales. 


\subsection{ENSAYOS EN TRANSPORTE TERRESTRE Y ENSAYOS EN CÁMARAS FRIGORÍFICAS EN CONDICIONES DE TRANSPORTE}

De acuerdo con la Figura 52, la metodología de ensayos se dividió, por un lado, en ensayos del dispositivo en transportes terrestres, donde se evaluó el funcionamiento correcto del sistema y se obtuvieron las condiciones reales de transporte de la mercancía y, por otro lado, se realizaron ensayos supervisados en cámaras frigoríficas emulando las condiciones climáticas del transporte registradas en los transportes terrestres.

Respecto a los ensayos en transporte terrestre, se realizaron quince instalaciones del sistema en transportes frigoríficos terrestres de lechugas por distintos países de la UE durante tres años. La escasez de pruebas durante este tiempo se debió a tres motivos fundamentales, por un lado, debido a la estacionalidad de la lechuga que en el caso de la Región de Murcia parte de finales de octubre hasta finales de abril. Por otro lado, los transportistas que colaboraron en los ensayos de esta Tesis permitiendo la instalación del sistema en su carga (Transportes Directos del Segura SL y Transportes Mesa SL) no siempre transportaban ese producto o era complicada la sincronización con ellos. Por último, aunque los viajes duraban una media de 4-5 días, era necesario prever dos o tres días antes para realizar la instalación del Gateway y la recuperación de los equipos después del viaje demoraba como media quince días más debido a que los camiones no volvían inmediatamente después de descargar o transportaban otras cargas de vuelta.

Los primeros ensayos de transportes sirvieron, además de medir las variaciones de temperatura durante esta etapa de la cadena alimentaria, para depurar y probar el correcto funcionamiento del sistema desarrollado. Los cuatro primeros ensayos se realizaron con sistema V1 durante 2017, el cual no disponía de medición multipunto. El sistema de monitorización compuesto por el Gateway y los nodos Slaves se instaló a partir del año 2018 en los camiones refrigerados de transporte comercial que partieron de Murcia (España) a diferentes países europeos, como Inglaterra, Alemania, Bélgica y Holanda.

La carga de dichos camiones se distribuyó en 33 euro-pallets con 52 cajas de tamaño $60 \times 40 \times 15 \mathrm{~cm}$ por pallet, cada una con diez lechugas por caja. Los nodos se colocaron a lo largo del camión, en la puerta, el techo y debajo del sistema de refrigeración para observar la diferencia de temperaturas del aire dentro del camión. De esta forma se invadió el mínimo espacio posible en el interior del remolque frigorífico de modo que no se interfiriera con el proceso de carga y descarga del mismo. 

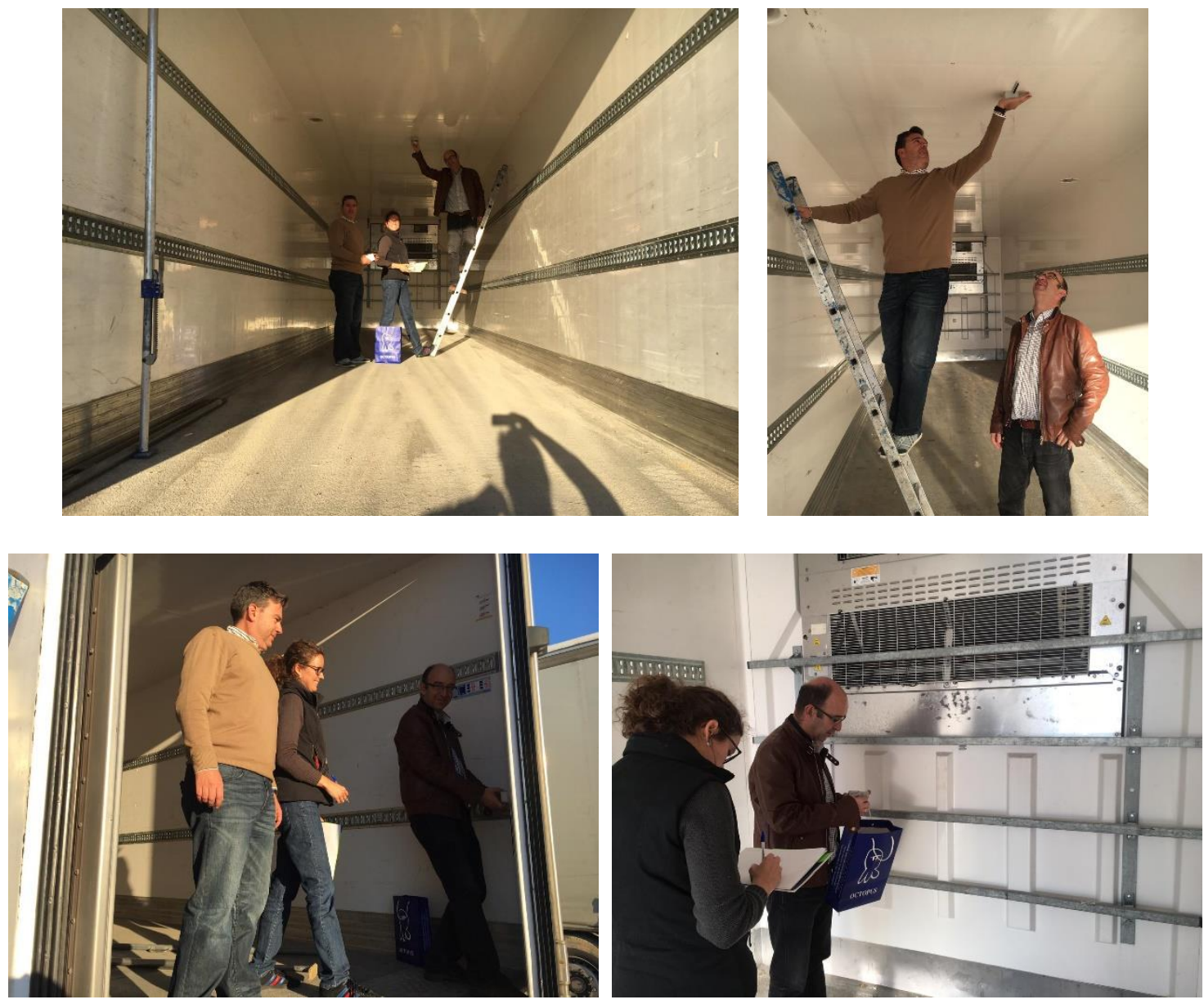

Figura 69. Imágenes de Equipo de Investigación colocando los nodos en un camión.

Esta distribución y elección de la posición de los nodos, se justifica por ser los puntos más críticos del interior del contenedor (Jedermann et al., 2008). Para probar la capacidad del sistema, en alguno de los viajes realizados se han llegado a instalar hasta cuatro nodos Slave haciendo un total de cinco puntos de medida, aunque la mayor parte de los ensayos se han realizado siguiendo la distribución esquematizada en la Figura 70.

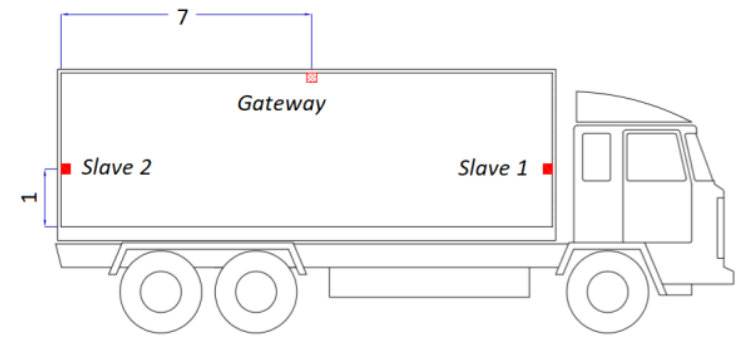

(a)

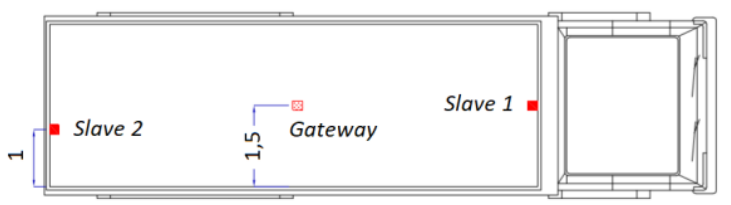

(b)

Figura 70. Distribución de los nodos y distancia en metros en la instalación en el remolque refrigerado del transporte (a) vista longitudinal y (b) vista planta.

Respecto a los ensayos en las cámaras frigoríficas, el objetivo pretendido es obtener datos que permitan correlacionar las variaciones de temperatura que sufre el producto, con la variación de la duración de la vida comercial del producto o "shelf-life" para un determinado umbral de calidad. Los ensayos en las cámaras responden a la necesidad de supervisar los ensayos (comprobar la calidad del producto) después de haber sufrido 
variaciones térmicas en el periodo inicial de su etapa postcosecha (durante el transporte). Se realizaron ensayos en las cámaras climáticas simulando las condiciones de transporte terrestre medidas por los sensores durante los viajes realizados Figura 71. Como se ha comentado, en estos ensayos, la temperatura varió alrededor del punto de consigna de transporte definido, en los primeros 4-5 días, de acuerdo con las observaciones de temperatura del aire observadas en los viajes. Después de estos días, las lechugas se conservaron a la temperatura establecida sin variaciones hasta su extracción para análisis de laboratorio. Tanto en las cámaras climáticas como en el transporte terrestre real, la temperatura fue medida por los nodos Gateway y Slave.
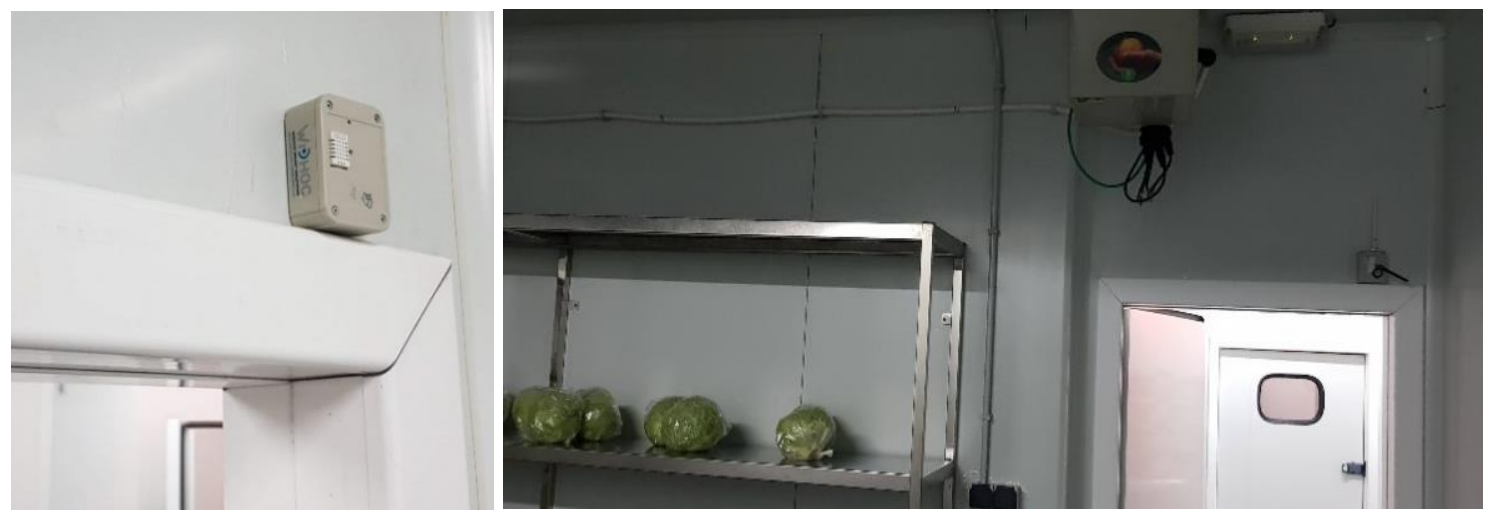

Figura 71. Nodos Gateway y Slave registrando datos en el interior de las cámaras.

\subsection{MODELO DE REGRESIÓN PARA LA ESTIMACION DE LA VIDA COMERCIAL BASADO EN APRENDIZAJE}

Plantear bien un problema de aprendizaje se basa en que un programa de ordenador aprende de la experiencia $E$, con respecto a alguna tarea $T$, y alguna medida de rendimiento $\mathrm{P}$, si su rendimiento en $\mathrm{T}$, medido por $\mathrm{P}$, mejora con la experiencia $\mathrm{E}$ (Mitchell, 1997).

Existen dos modos de entrenamiento para modelos de aprendizaje:

- Aprendizaje supervisado: al ejecutar el algoritmo, utilizando los datos de entrenamiento, la salida ya es conocida (supervisada o validada), por lo que el desarrollador actúa como guía en el proceso de aprendizaje.

- Aprendizaje no supervisado: es el propio algoritmo el que ofrece la salida identificando los procesos y patrones complejos sin necesidad de un guía o salida conocida.

Para el desarrollo del modelo propuesto en este trabajo se han utilizado metodologías regresivas supervisadas. Entre los algoritmos que utilizan estas metodologías se encuentran (Amat, 2017): 
- Regresión Lineal Múltiple (MLR - “Multiple Linear Regression”): predicción de la variable de respuesta cuantitativa a partir de dos variables predictoras cuantitativas.

- Regresión No Lineal Múltiple (MNLR - "Multiple Nonlinear Regression"): predicción de la variable de respuesta cuantitativa a partir de una variable predictora cuantitativa, donde la relación se modela como una función polinomial de orden $n$.

- Polinomial con interacción: se relacionan las variables predictoras.

- Polinomial sin interacción: no se relacionan las variables predictoras.

Las regresiones lineales pueden depender de más de una variable denominándose regresiones lineales múltiples, de tal forma que el grado del polinomio que forma la hipótesis sigue siendo uno, pero depende de más de una variable.

En el caso de las regresiones polinomiales, la técnica permite establecer una ecuación en forma de una polinomial, cuyo grado es igual o mayor que dos, de tal forma que se pueden realizar estimaciones acerca del valor que asumirá las variables dependientes según el valor que tome el valor independiente. Del mismo modo, se pueden establecer regresiones polinomiales múltiples.

La no linealidad de la regresión múltiple viene dada por la interacción entre las variables o por la presencia de operaciones no lineales dentro del polinomio.

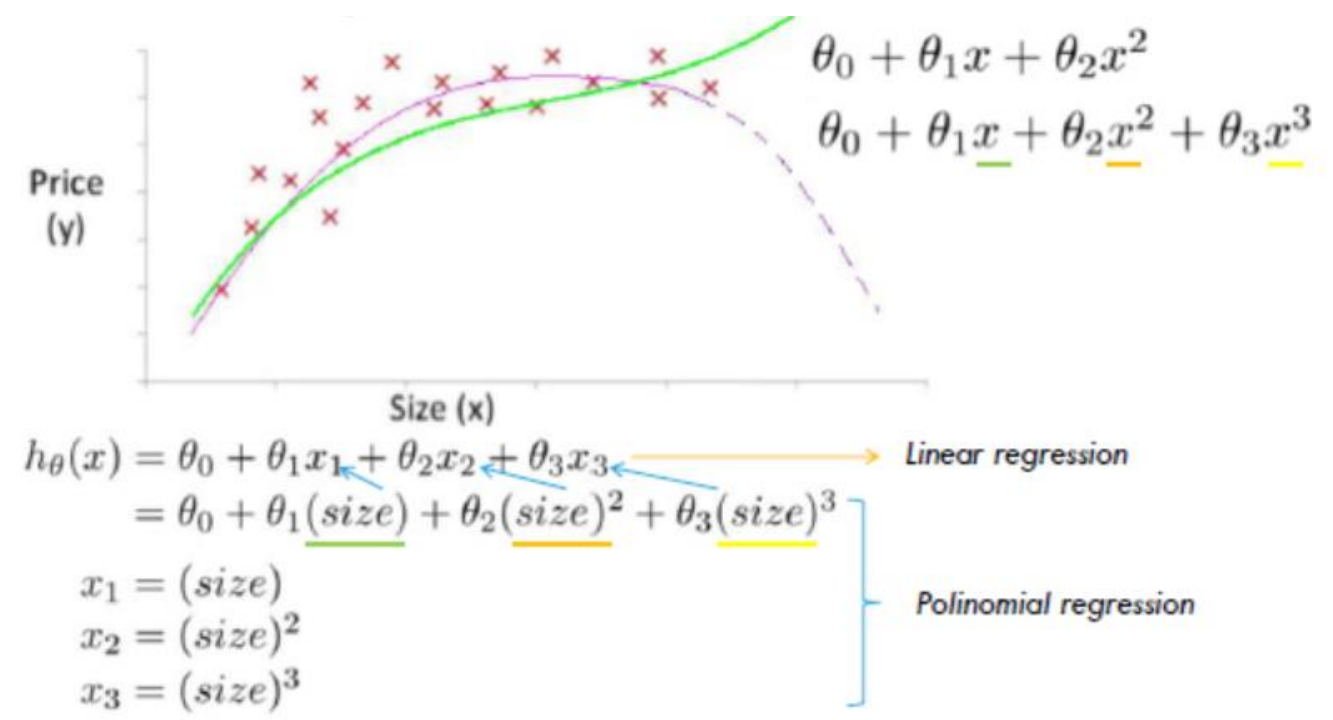

Figura 72. Diferenciación entre regresión lineal múltiple y regresión polinomial ( $\mathrm{Ng}, 2016)$.

Las mediciones realizadas tanto de las características observadas y medidas por los sensores (variables predictoras $\mathrm{X}$ ), como la duración de la vida útil (variable respuesta $\mathrm{Y}$ ) del producto, se utilizan para desarrollar los modelos de predicción basados en regresiones con ajustes por mínimos cuadrados.

La extracción de las variables predictoras se ha realizado atendiendo a las características dinámicas de las variaciones de temperatura entre el aire y el producto transportado. 
Se realizó un ensayo inicial comprobando la dinámica de la temperatura dentro del producto utilizando sensores de temperatura y humedad muy pequeños para poder ser introducidos en el interior de la lechuga (Figura 73). A partir de la diferencia de evolución entre las temperaturas del aire y del producto, se extrajo el indicador "área" como característica integradora de la temperatura. Esto es, alteraciones bruscas y no sostenidas en el tiempo de la temperatura del aire (como los desescarches) no tienen una alteración importante del área, ya que el indicador "área" actúa como filtro paso bajo eliminando esas alteraciones que, realmente, no tienen influencia en el producto.
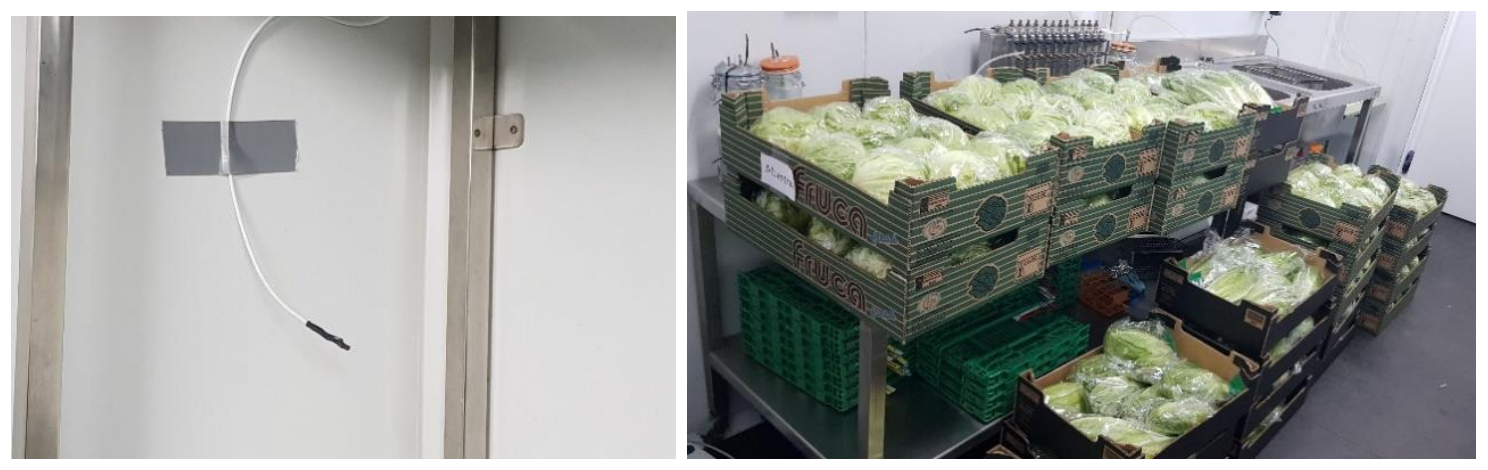

Figura 73. Detalle de los sensores utilizados para la medición de la diferencia dinámica entre la temperatura del aire en la cámara y en el interior de la lechuga.

Las características que se han probado para definir el mejor modelo de predicción que determine la duración a partir de la evolución de la temperatura de los productos en tiempo real durante el transporte son:

- SP (“Set-point"): temperatura de consigna (temperatura fijada en el registro de la mercancía para su transporte).

- A: área medida por los sensores de la temperatura que ha superado el set-point

- $\Delta T$ : variación máxima de la temperatura.

- AT: temperatura media.

Las lechugas almacenadas en las cámaras climáticas se analizaron los días anteriores y posteriores a la fecha de duración teórica para la temperatura fijada en el Set-point, y de las recomendaciones de vida útil de acuerdo con temperaturas similares (Cantwell y Suslow, 2002) (Tabla 4) obteniendo la variable de respuesta Y como el último día en el cual la calidad de la lechuga fue puntuada con score 3.

El modelo se desarrolla a partir de un conjunto de entrenamiento $D=\{\mathrm{X}, \mathrm{Y}\}$ de muestras $\mathrm{S}$, que se compone de

- Matriz predictora (o matriz de diseño): $X=\left[\mathrm{x}_{1}, \ldots, \mathrm{x}_{\mathrm{i}}, \ldots, \mathrm{x}_{\mathrm{S}}\right]^{\top}$, donde $\mathrm{x}_{\mathrm{i}}$ es un vector de columna de elementos $K$, que puede contener todas las características en una prueba dada i.

- Matriz de respuesta: $\mathrm{Y}=\left[\mathrm{y}_{1}, \ldots, \mathrm{y}_{\mathrm{i}}, \ldots, \mathrm{y}_{\mathrm{s}}\right]^{\top}$.

Para el modelo MLR, la matriz $\mathrm{X}$ se define por: 


$$
x_{i}=[S P ; A ; \Delta T ; A T]^{\top}
$$

E $y_{i}$ es un vector de columna de $M$ elementos, que contiene los días correspondientes que se evaluarán en ese ensayo i. Puesto que, en la valoración de la calidad realizada en el laboratorio, estos son solo los días en que el producto mantiene la puntuación por encima de $3, M=1$ e $y_{i}$ se reduce a un escalar definido como el número de días que la puntuación se mantiene por encima de 3 .

Se define el MLR como:

$$
y_{i}=\beta_{0}+\beta_{1} x_{1 i}+\beta_{2} x_{2 i}+\beta_{3} x_{3 i}+\beta_{4} x_{4 i}+\epsilon_{i} \quad i=1, \ldots, n
$$

Para el modelo MNLR, se estudia la influencia de los términos cuadráticos, así como la posible interacción las diferentes características de una observación, de tal forma que la matriz $X$ se define por:

$$
x_{i}=\left[S P ; A ; \Delta T ; A T ; S P^{2} ; A^{2} ; S P \cdot A\right]^{\top}
$$

En este caso el MNLR se define como:

$$
y_{i}=\beta_{0}+\beta_{1} x_{1 i}+\beta_{2} x_{2 i}+\beta_{11} x_{1 i}^{2}+\beta_{22} x_{2 i}^{2}+\beta_{12} x_{1 i} x_{2 i}+\ldots+\epsilon_{i} \quad i=1, \ldots, n
$$

Ambos modelos se pueden expresar en forma de matriz como: $y=X \beta+\epsilon$

aplicando el criterio de mínimos cuadrados, debemos estimar aquellos valores que minimizan el error cuadrático medio, es decir:

$$
\sum_{i=1}^{n} \epsilon_{i}^{2}=\epsilon^{\prime} \epsilon=(y-X \beta)^{\prime}(y-X \beta)
$$

Este criterio determina aquellos modelos que mantienen un alto nivel explicativo y contienen regresores con influencia estadísticamente significativa en la variable de respuesta sin problemas de colinealidad.

Tras la representación topográfica de las características extraídas se obtienen mejores resultados utilizando la temperatura del Set-point (SP) que utilizando la temperatura media (AT) y en ningún caso, aparece significativo el efecto de la variación de temperatura $(\Delta T)$.

Se proponen, por tanto, tres modelos de regresión, un modelo MLR (modelo 2 ) y dos modelos MLNR ( 1 y 3 ) utilizando combinaciones de las variables descritas para determinar cuál es la mejor regresión para la estimación de la vida útil de las lechugas con un score por encima de tres en días (DD):

$$
D D=29,005-2,1871 S P+0,1654 A+0,04994 S P^{2}-0,03721 S P \cdot A
$$


Modelo 2

$$
D D=25,795-1,1785 S P-0,02492 A
$$

Modelo 3

$$
D D=29,604-2,313 S P+0,02063 A+0,05492 S P^{2}
$$

Los parámetros de los modelos han sido obtenidos utilizando el criterio de los mínimos cuadrados, que minimiza la suma de los errores entre las respuestas validadas (reales) y las respuestas estimadas por el modelo. Hay varias variantes del criterio de ajuste por mínimos cuadrados:

- $\quad \mathrm{R}^{2}$ es el porcentaje de variación en la respuesta que es explicada por el modelo.

$$
R^{2}=1-\frac{\sum_{i=1}^{n}\left(\widehat{y_{i}}-\bar{y}\right)^{2}}{\sum_{i=1}^{n}\left(y_{i}-\bar{y}\right)^{2}}
$$

Cuanto mayor sea el valor de $\mathrm{R}^{2}$, mejor se ajustará el modelo a los datos (Kelmansky, 2015).

- $\mathrm{R}^{2}$ ajustado es el porcentaje de la variación en la respuesta que es explicada por el modelo, ajustado para el número de predictores en el modelo relativo al número de observaciones.

$$
R_{a}^{2}=1-\frac{\text { Error cuadrático medio (ECM) }}{\text { Cuadrado medio del total (CM Total) }}=1-\frac{\frac{1}{n} \cdot \sum_{i=1}^{n}\left(\widehat{y_{i}}-\bar{y}\right)^{2}}{\frac{1}{n} \cdot \sum_{i=1}^{n}\left(y_{i}-\bar{y}\right)^{2}}
$$

Este coeficiente se utiliza cuando se desea comparar modelos que tengan diferentes números de predictores (regresores). El $\mathrm{R}^{2}$ siempre aumenta cuando se agrega un predictor al modelo, incluso cuando no haya una mejora real en el modelo. El valor de $R_{a}^{2}$ tiene en cuenta el número de predictores del modelo para ayudar a elegir el modelo correcto (Kelmansky, 2015).

- $\mathrm{R}^{2}$ pronosticado se calcula con una expresión que equivale a eliminar sistemáticamente cada una de las observaciones del conjunto de datos, estimando la ecuación de regresión y determinando hasta qué punto el modelo predice la observación eliminada: es similar al Leave-one-out cross validation (LOOCV) utilizado en validaciones de algoritmos de machine learning.

Este coeficiente se utiliza para determinar cómo de bien predice el modelo la respuesta para nuevas observaciones: cuanto mayor sea su valor el modelo tendrá mejor capacidad de predicción. Un $\mathrm{R}^{2}$ pronosticado que sea sustancialmente menor que el $R^{2}$ puede indicar que el modelo está sobreajustado debido a que se agregan términos para efectos que no son importantes en la población. El modelo se adapta a los datos de la muestra y, por lo tanto, es posible que no sea útil para hacer predicciones acerca de la población. 
- Error estándar (ES - "Standard Error"): mide la variabilidad de las medias muestrales utilizando su desviación estándar, es decir, muestra cómo varían las estimaciones del coeficiente si las muestras de la misma población se tomaran una y otra vez.

$$
\mathrm{SE}=\frac{\sigma}{\sqrt{\mathrm{N}}}=\frac{\mathrm{s}}{\sqrt{\mathrm{N}}}
$$

Siendo $\sigma$ la desviación estándar de la población; s la desviación estándar de la muestra y $\mathrm{N}$ el número de observaciones de la muestra. Cuanto menor sea el error estándar, más precisa será la estimación (Dietrichson, 2019).

- Factor de inflación de la varianza (FIV - "Variance Inflation Factor"): indica cuánto aumenta la varianza de un coeficiente a causa de las correlaciones entre los predictores en el modelo.

$$
\mathrm{FIV}=\frac{\operatorname{Var}\left(\widehat{\left.\beta_{i}\right)}\right.}{\operatorname{Var}\left(\widehat{\beta_{i}^{0}}\right)}=\frac{1}{1-R_{i}^{2}} \quad i=2, \ldots, n
$$

Se asume que valores del FIV $>5$ indican que existe colinealidad (correlación entre predictores) y si existe colinealidad, el modelo desde el punto de vista teórico no sería válido (Rodríguez et al., 2017).

- p-valor: es una medida directa de lo verosímil que resulta obtener una muestra como la actual bajo una hipótesis nula (o hipótesis de partida) que es cierta. El p-valor se emplea para indicar cuánto (o cuán poco) contradice la muestra actual la hipótesis alternativa. Si el p-valor cumple con la condición de ser menor que un nivel de significancia impuesto arbitrariamente, este se considera como un resultado estadísticamente significativo y, por lo tanto, permite rechazar la hipótesis nula (Schervish, 1996).

- T-valor: mide las diferencias entre dos muestras independientes y pequeñas que tengan distribución normal y homogeneidad en sus varianzas.

Para determinar si puede rechazar la hipótesis nula usando el T-valor se compara con el valor crítico, que depende del nivel de significancia, el número de observaciones en la muestra y el número de predictores. Si el valor absoluto del T-valor es mayor que el valor crítico, se rechaza la hipótesis nula. Si el valor absoluto del T-valor es menor que el valor crítico, no se puede rechazar la hipótesis nula (Sánchez-Turcios, 2015).

Los tres modelos de predicción propuestos estiman la duración de la vida útil de los productos perecederos (variable de respuesta $Y$ medida en días) teniendo en cuenta la evolución de las temperaturas durante el transporte (variable predictora) con relación al Set-point. 
Al ser los datos recibidos durante el transporte series de tiempo y temperatura en tiempo real, la estimación de las pérdidas de calidad del producto estarían relacionadas con el tiempo estimado para que el producto mantenga una calidad mínima (score 3) que permita su comercialización. De este modo, es posible determinar en tiempo real cuánto tiempo se reducirá la vida comercial de las lechugas en tales condiciones atmosféricas (variable predictora).

Sin embargo, estos modelos no son lo suficientemente eficientes debido a la escasa información registrada e involucrada. Los datos necesarios para construir el modelo de estimación eficaces han de ser validados por el experto, lo que significa realizar múltiples pruebas de verificación de calidad del producto en destino, esto es, cuando el producto transportado alcanza el límite de su vida comercial para entrenar el modelo en las mismas condiciones en las que se quiere predecir. 
RESULTADOS

6. RESULTADOS 


\subsection{RESULTADOS DE LA VIDA COMERCIAL DE LAS LECHUGAS}

\subsubsection{Análisis fisicoquímico}

Se encontraron diferencias significativas en las tasas de respiración a diferentes temperaturas y variedades. El aumento de la temperatura resultó en un aumento en la tasa de respiración de lechuga Iceberg y Romana (Tabla 5).

Tabla 5. Rangos de respiración ( $\mathrm{mL} \mathrm{CO} / \mathrm{kg} \mathrm{h}$ ) de las lechugas Iceberg y Romana.

\begin{tabular}{cccc}
\hline \hline Temperatura & $\mathbf{2}^{\circ} \mathbf{C}$ & $\mathbf{5}^{\circ} \mathrm{C}$ & $10^{\circ} \mathrm{C}$ \\
\hline \hline Iceberg & $5,2 \pm 1,1$ & $8,0 \pm 1,7$ & $17,5 \pm 3,3$ \\
\hline Romana & $8,9 \pm 1,7$ & $10,3 \pm 2,0$ & $18,6 \pm 3,8$ \\
\hline \hline
\end{tabular}

A continuación, se muestran los parámetros fisicoquímicos de lechuga Iceberg y Romana almacenados a las 5 temperaturas diferentes $\left(2,5,10,15\right.$ y $\left.20^{\circ} \mathrm{C}\right)$ hasta $29,21,15,9$ y 6 días, respectivamente. (Tabla 6 y 7). 
RESULTADOS

Tabla 6. Resultados de los parámetros fisicoquímicos de la lechuga Iceberg.

\begin{tabular}{|c|c|c|c|c|c|c|}
\hline $\mathbf{T} \underline{\mathbf{a}}$ & Día & SSC ( ${ }^{\circ} B$ rix) & pH & $\begin{array}{l}\text { AT (g ácido } \\
\text { cítrico } \mathrm{L}^{-1} \text { ) }\end{array}$ & $\begin{array}{l}\text { Firmeza } \\
\left(\mathrm{N} \mathrm{mm}^{-1}\right)\end{array}$ & $\Delta \mathrm{E}$ \\
\hline \multirow[t]{5}{*}{$20^{\circ} \mathrm{C}$} & 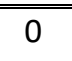 & $4,16 \pm 0,17_{\mathrm{ab}}^{\mathrm{A}}$ & $6,0,04 \pm 0,06_{a}^{A}$ & $0,68 \pm 0,09_{\mathrm{ab}}^{\mathrm{A}}$ & $4,84 \pm 3,29_{a}^{A}$ & - \\
\hline & 1 & $3,58 \pm 0,06_{c}$ & $6,02 \pm 0,06_{a}$ & $0,61 \pm 0,06_{b}$ & $4,36 \pm 1,19 a$ & $2,69 \pm 2,56_{a}$ \\
\hline & 2 & $4,60 \pm 0,61_{a}^{A}$ & $6,02 \pm 0,00_{\mathrm{a}}^{\mathrm{B}}$ & $0,78 \pm 0,06_{a}^{A}$ & $3,78 \pm 0,69_{a}^{A}$ & $4,55 \pm 2,30_{a}^{A}$ \\
\hline & 3 & $3,96 \pm 0,17_{b c}^{A}$ & $5,98 \pm 0,06_{a}^{C}$ & $0,68 \pm 0,12_{\mathrm{ab}}^{\mathrm{AB}}$ & $3,74 \pm 0,73_{a}^{B}$ & $2,28 \pm 0,70_{a}^{A}$ \\
\hline & 6 & $4,16 \pm 0,06_{\mathrm{ab}}^{\mathrm{A}}$ & $6,04 \pm 0,06_{a}^{A}$ & $0,73 \pm 0,09_{\mathrm{ab}}^{\mathrm{A}}$ & $4,79 \pm 1,98_{a}^{A}$ & $2,83 \pm 1,81_{a}^{A}$ \\
\hline \multirow[t]{5}{*}{$15^{\circ} \mathrm{C}$} & 0 & $4,16 \pm 0,17_{\mathrm{ab}}^{\mathrm{A}}$ & $6,04 \pm 0,06_{a}^{A}$ & $0,68 \pm 0,09_{a}^{A}$ & $4,84 \pm 3,29_{a}^{A}$ & - \\
\hline & 2 & $3,80 \pm 0,25_{\mathrm{ab}}^{\mathrm{B}}$ & $6,10 \pm 0,00_{a}^{A}$ & $0,64 \pm 0,04_{a}^{A}$ & $3,97 \pm 1,31_{a}^{A}$ & $2,22 \pm 1,08_{\mathrm{ab}}^{\mathrm{A}}$ \\
\hline & 3 & $4,34 \pm 0,47_{a}^{A}$ & $6,04 \pm 0,06_{a}^{B C}$ & $0,71 \pm 0,04_{a}^{A}$ & $5,35 \pm 2,01_{a}^{A B}$ & $3,17 \pm 1,98_{a b}^{A}$ \\
\hline & 6 & $4,22 \pm 0,42_{a b}^{A}$ & $6,08 \pm 0,06_{a}^{A}$ & $0,63 \pm 0,03_{a}^{A}$ & $4,88 \pm 1,36_{a}^{A}$ & $4,43 \pm 1,78_{a}^{A}$ \\
\hline & 9 & $3,54 \pm 0,35_{b}^{A}$ & $6,10 \pm 0,00_{\mathrm{a}}^{\mathrm{B}}$ & $0,66 \pm 0,04_{a}^{A}$ & $4,26 \pm 0,65_{a}^{A}$ & $1,57 \pm 1,20_{b}^{A}$ \\
\hline \multirow[t]{5}{*}{$10^{\circ} \mathrm{C}$} & 0 & $4,16 \pm 0,17_{a}^{A}$ & $6,04 \pm 0,06^{A}{ }_{a}$ & $0,68 \pm 0,09_{a}^{A}$ & $4,84 \pm 3,29_{a}^{A}$ & - \\
\hline & 3 & $3,76 \pm 0,47_{a}^{A}$ & $6,04 \pm 0,06_{a}^{A B}$ & $0,58 \pm 0,02_{a}^{B C}$ & $5,86 \pm 2,33_{a}^{A B}$ & $2,16 \pm 1,31_{a}^{A}$ \\
\hline & 6 & $3,52 \pm 0,26_{a}^{\mathrm{B}}$ & $6,10 \pm 0,00_{a}^{A}$ & $0,64 \pm 0,03_{a}^{A}$ & $4,07 \pm 0,70_{\mathrm{a}}^{\mathrm{A}}$ & $4,09 \pm 2,80_{a}^{A}$ \\
\hline & 9 & $3,58 \pm 0,40_{a}^{A}$ & $6,10 \pm 0,00_{a}^{B}$ & $0,63 \pm 0,07_{a}^{A}$ & $4,73 \pm 1,26_{a}^{A}$ & $3,34 \pm 1,27_{a}^{A}$ \\
\hline & 15 & $3,62 \pm 0,10_{a}^{A}$ & $6,12 \pm 0,06_{a}^{A}$ & $0,62 \pm 0,11_{a}^{B}$ & $4,32 \pm 0,76_{a}^{A}$ & $5,37 \pm 1,38_{a}^{A}$ \\
\hline \multirow[t]{5}{*}{$5^{\circ} \mathrm{C}$} & 0 & $4,16 \pm 0,17_{a}^{A}$ & $6,04 \pm 0,06_{c}^{A}$ & $0,68 \pm 0,09_{a}^{A}$ & $4,84 \pm 3,29_{a}^{A}$ & - \\
\hline & 3 & $4,18 \pm 0,00_{a}^{A}$ & $6,20 \pm 0,00_{\mathrm{ab}}^{\mathrm{A}}$ & $0,58 \pm 0,03_{a}^{B C}$ & $3,94 \pm 2,26_{a}^{B}$ & $3,33 \pm 2,08_{a}^{A}$ \\
\hline & 9 & $3,88 \pm 0,15_{a}^{A}$ & $6,16 \pm 0,00_{b}^{B}$ & $0,61 \pm 0,03_{\mathrm{a}}^{\mathrm{A}}$ & $4,13 \pm 1,78_{a}^{A}$ & $2,97 \pm 1,56_{a}^{A}$ \\
\hline & 15 & $3,88 \pm 0,26_{a}^{A}$ & $6,20 \pm 0,00_{\mathrm{ab}}^{\mathrm{A}}$ & $0,46 \pm 0,07_{b}^{\mathrm{A}}$ & $3,87 \pm 0,67_{a}^{A B}$ & $3,09 \pm 2,199_{a}^{A B}$ \\
\hline & 21 & $3,16 \pm 0,31_{b}^{A}$ & $6,28 \pm 0,00_{a}^{A}$ & $0,61 \pm 0,03_{a}^{A}$ & $6,16 \pm 3,41_{a}^{A}$ & $2,75 \pm 1,48_{a}^{A}$ \\
\hline \multirow[t]{6}{*}{$2^{\circ} \mathrm{C}$} & 0 & $4,16 \pm 0,17_{a}^{A}$ & $6,04 \pm 0,06_{c}^{A}$ & $0,68 \pm 0,09_{a}^{A}$ & $4,84 \pm 3,29_{\mathrm{ab}}^{\mathrm{A}}$ & - \\
\hline & 3 & $3,80 \pm 0,20_{\mathrm{ab}}^{\mathrm{A}}$ & $6,26 \pm 0,00_{a}^{A}$ & $0,55 \pm 0,02_{b c}^{C}$ & $7,59 \pm 0,00_{a}^{A}$ & $3,80 \pm 2,47_{a}^{A}$ \\
\hline & 9 & $3,66 \pm 0,00_{b c d}^{A}$ & $6,24 \pm 0,00_{\mathrm{ab}}^{\mathrm{A}}$ & $0,53 \pm 0,03_{c}^{B}$ & $2,83 \pm 0,80_{b}^{A}$ & $2,20 \pm 0,70_{a}^{A}$ \\
\hline & 15 & $3,70 \pm 0,35_{\mathrm{abc}}^{\mathrm{A}}$ & $6,12 \pm 0,06_{b c}^{A}$ & $0,64 \pm 0,04_{a}^{A}$ & $2,84 \pm 0,72_{b}^{B}$ & $1,80 \pm 0,68_{a}^{B}$ \\
\hline & 21 & $3,32 \pm 0,06_{c d}^{A}$ & $6,28 \pm 0,06_{a}^{A}$ & $0,63 \pm 0,02_{\mathrm{ab}}^{\mathrm{A}}$ & $4,21 \pm 1,06_{b}^{A}$ & $2,55 \pm 1,70_{a}^{A}$ \\
\hline & 29 & $3,20 \pm 0,40_{d}$ & $6,16 \pm 0,06_{a b c}$ & $0,66 \pm 0,04_{a}$ & $3,68 \pm 1,58_{b}$ & $4,04 \pm 2,39_{a}$ \\
\hline
\end{tabular}

Las diferentes letras mayúsculas denotan diferencias significativas $(p \leq 0,05)$ entre temperaturas para el mismo día de muestreo. Mientras que las distintas letras minúsculas denotan diferencias significativas $(p \leq 0,05)$ entre los días de muestreo para la misma temperatura. 
Tabla 7. Resultados de los parámetros fisicoquímicos de la lechuga Romana.

\begin{tabular}{|c|c|c|c|c|c|c|}
\hline Tá & Día & $\operatorname{SSC}\left({ }^{\circ}\right.$ Brix $)$ & $\mathrm{pH}$ & $\begin{array}{l}\text { AT (g ácido } \\
\text { cítrico } \mathrm{L}^{-1} \text { ) }\end{array}$ & $\begin{array}{l}\text { Firmeza } \\
\left(\mathrm{N} \mathrm{mm}^{-1}\right)\end{array}$ & $\Delta \mathrm{E}$ \\
\hline \multirow[t]{5}{*}{$20^{\circ} \mathrm{C}$} & 0 & $4,74 \pm 0,12_{a}^{A}$ & $6,0,06 \pm 0,06_{a}^{A}$ & $0,0,83 \pm 0,09_{a}^{A}$ & $2,64 \pm 0,36_{a}^{A}$ & - \\
\hline & 1 & $4,84 \pm 0,23 a$ & $6,02 \pm 0,00_{a}$ & $0,77 \pm 0,03_{\mathrm{ab}}$ & $3,38 \pm 1,39 a$ & $2,20 \pm 1,07 \mathrm{a}$ \\
\hline & 2 & $3,60 \pm 0,15_{c}^{B}$ & $6,00 \pm 0,06_{\mathrm{ab}}^{\mathrm{A}}$ & $0,67 \pm 0,07_{\mathrm{b}}^{\mathrm{A}}$ & $2,65 \pm 0,77_{a}^{A}$ & $2,68 \pm 0,52_{a}^{A}$ \\
\hline & 3 & $4,62 \pm 0,15_{a b}^{A}$ & $5,86 \pm 0,06_{b}^{C}$ & $0,89 \pm 0,06_{a}^{A}$ & $2,79 \pm 0,24_{a}^{A}$ & $2,51 \pm 0,55_{a}^{B}$ \\
\hline & 6 & $4,32 \pm 0,10_{b}^{A}$ & $6,06 \pm 0,17_{a}^{A}$ & $0,84 \pm 0,11_{a}^{A}$ & $2,90 \pm 0,89_{\mathrm{a}}^{\mathrm{A}}$ & $3,97 \pm 1,87_{a}^{A}$ \\
\hline \multirow[t]{5}{*}{$15^{\circ} \mathrm{C}$} & 0 & $4,74 \pm 0,12_{a}^{A}$ & $6,06 \pm 0,06_{a}^{A}$ & $0,83 \pm 0,09_{a}^{A}$ & $2,64 \pm 0,36_{a}^{A}$ & - \\
\hline & 2 & $4,36 \pm 0,23_{a}^{A}$ & $6,02 \pm 0,12_{a}^{A}$ & $0,68 \pm 0,05_{b}^{A}$ & $2,74 \pm 0,48_{a}^{A}$ & $3,83 \pm 1,98_{a}^{A}$ \\
\hline & 3 & $4,42 \pm 0,10_{a}^{A B}$ & $6,02 \pm 0,00_{\mathrm{a}}^{\mathrm{B}}$ & $0,80 \pm 0,04_{a b}^{A B}$ & $3,57 \pm 1,02_{a}^{A}$ & $2,79 \pm 1,40_{a}^{B}$ \\
\hline & 6 & $3,88 \pm 0,25_{a}^{A}$ & $6,04 \pm 0,12_{a}^{A}$ & $0,78 \pm 0,07_{\mathrm{ab}}^{\mathrm{AB}}$ & $3,71 \pm 2,19_{a}^{A}$ & $2,68 \pm 0,31_{a}^{A}$ \\
\hline & 9 & $4,64 \pm 0,26_{a}^{A}$ & $6,12 \pm 0,10_{a}^{A}$ & $0,78 \pm 0,10_{\mathrm{ab}}^{\mathrm{A}}$ & $2,88 \pm 0,70_{a}^{A}$ & $3,50 \pm 1,33_{a}^{B}$ \\
\hline \multirow[t]{5}{*}{$10^{\circ} \mathrm{C}$} & 0 & $4,74 \pm 0,12_{a}^{A}$ & $6,06 \pm 0,06_{b}^{A}$ & $0,83 \pm 0,09_{a}^{A}$ & $2,64 \pm 0,36_{a}^{A}$ & - \\
\hline & 3 & $4,36 \pm 0,21_{a}^{A B}$ & $6,06 \pm 0,00_{b}^{A B}$ & $0,64 \pm 0,05_{a}^{c}$ & $2,65 \pm 0,62_{a}^{A}$ & $1,68 \pm 0,57_{b}^{B}$ \\
\hline & 6 & $4,30 \pm 0,26_{a}^{A}$ & $6,06 \pm 0,06_{b}^{A}$ & $0,63 \pm 0,09_{a}^{B}$ & $3,72 \pm 1,29_{a}^{A}$ & $3,34 \pm 1,51_{b}^{A}$ \\
\hline & 9 & $4,28 \pm 0,12_{a}^{A}$ & $6,16 \pm 0,06_{a}^{A}$ & $0,69 \pm 0,03_{a}^{A B}$ & $4,14 \pm 1,20_{a}^{A}$ & $6,95 \pm 1,80_{a}^{A}$ \\
\hline & 15 & $4,40 \pm 0,06_{a}^{A}$ & $6,10 \pm 0,00_{\mathrm{ab}}^{\mathrm{B}}$ & $0,63 \pm 0,19_{a}^{A}$ & $3,50 \pm 1,00_{a}^{A}$ & $2,74 \pm 1,52_{b}^{A}$ \\
\hline \multirow[t]{5}{*}{$5^{\circ} \mathrm{C}$} & 0 & $4,74 \pm 0,12_{a}^{A}$ & $6,06 \pm 0,06_{b}^{A}$ & $0,83 \pm 0,09_{a}^{A}$ & $2,64 \pm 0,36_{a}^{A}$ & - \\
\hline & 3 & $4,24 \pm 0,10_{a}^{B}$ & $6,12 \pm 0,00_{b}^{A B}$ & $0,71 \pm 0,10_{\mathrm{ab}}^{\mathrm{BC}}$ & $3,33 \pm 0,42_{a}^{A}$ & $2,92 \pm 1,79_{a}^{B}$ \\
\hline & 9 & $4,42 \pm 0,06_{a}^{A}$ & $6,14 \pm 0,00_{b}^{A}$ & $0,82 \pm 0,07_{a}^{A}$ & $3,91 \pm 1,37_{a}^{A}$ & $2,28 \pm 1,67_{a}^{B}$ \\
\hline & 15 & $4,46 \pm 0,61_{a}^{A}$ & $6,16 \pm 0,10_{b}^{A B}$ & $0,69 \pm 0,01_{\mathrm{ab}}^{\mathrm{A}}$ & $3,41 \pm 1,11_{a}^{A}$ & $3,96 \pm 1,43_{a}^{A}$ \\
\hline & 21 & $4,34 \pm 0,40_{a}^{A}$ & $6,36 \pm 0,06_{a}^{A}$ & $0,62 \pm 0,06_{b}^{A}$ & $2,91 \pm 0,98_{a}^{A}$ & $3,15 \pm 1,61_{a}^{A}$ \\
\hline \multirow[t]{6}{*}{$2^{\circ} \mathrm{C}$} & 0 & $4,74 \pm 0,12_{a}^{A}$ & $6,06 \pm 0,06_{c}^{A}$ & $0,83 \pm 0,09_{a}^{A}$ & $2,64 \pm 0,36_{a}^{A}$ & - \\
\hline & 3 & $4,42 \pm 0,10_{a}^{A B}$ & $6,20 \pm 0,12_{b}^{A}$ & $0,61 \pm 0,04_{b c}^{c}$ & $3,11 \pm 0,79_{a}^{A}$ & $5,42 \pm 1,59_{a}^{A}$ \\
\hline & 9 & $4,52 \pm 0,36_{a}^{A}$ & $6,16 \pm 0,06_{\mathrm{bc}}^{\mathrm{A}}$ & $0,57 \pm 0,06_{c}^{B}$ & $3,36 \pm 1,65_{a}^{A}$ & $5,25 \pm 1,92_{a}^{A B}$ \\
\hline & 15 & $4,46 \pm 0,17_{a}^{A}$ & $6,26 \pm 0,06_{\mathrm{ab}}^{\mathrm{A}}$ & $0,78 \pm 0,11_{\mathrm{ab}}^{\mathrm{A}}$ & $3,02 \pm 0,23_{a}^{A}$ & $3,43 \pm 1,42_{a}^{A}$ \\
\hline & 21 & $4,38 \pm 0,47_{a}^{A}$ & $6,38 \pm 0,06_{a}^{A}$ & $0,72 \pm 0,11_{\mathrm{abc}}^{\mathrm{A}}$ & $2,68 \pm 0,63_{a}^{A}$ & $3,72 \pm 0,81_{a}^{A}$ \\
\hline & 29 & $3,60 \pm 0,57_{b}$ & $6,24 \pm 0,06_{b}$ & $0,76 \pm 0,08_{a b}$ & $4,01 \pm 2,13 a$ & $5,15 \pm 1,27 \mathrm{a}$ \\
\hline
\end{tabular}

Las diferentes letras mayúsculas denotan diferencias significativas $(p \leq 0.05)$ entre temperaturas para el mismo día de muestreo. Mientras que las distintas letras minúsculas denotan diferencias significativas $(p \leq 0.05)$ entre los días de muestreo para la misma temperatura. 
No se encontraron diferencias significativas en AT a diferentes temperaturas entre el día inicial y el último día de almacenamiento en cada temperatura. Sin embargo, la AT de la lechuga Romana almacenada durante 21 días a $5^{\circ} \mathrm{C}$ disminuyó significativamente, un $24,1 \%$ en comparación con el día inicial.

Los SSC y el pH no se vieron significativamente afectados por las altas temperaturas de conservación $\left(20,15\right.$ y $\left.10^{\circ} \mathrm{C}\right)$ durante períodos cortos de almacenamiento. Sin embargo, los SSC de la lechuga Romana almacenada a $20^{\circ} \mathrm{C}$ disminuyeron significativamente, un $8,9 \%$ en comparación con el día inicial. Además, el efecto combinado entre tiempo y temperatura se apreció a la temperatura más baja de conservación. Se observó una disminución de 24,0 y $23,1 \%$ en los SSC a 5 y $2^{\circ} \mathrm{C}$ respectivamente en lechuga Iceberg y una disminución de $24,1 \%$ en los SSC a $2^{\circ} \mathrm{C}$ en lechuga Romana durante largos períodos de almacenamiento ( 21 y 29 días respectivamente).

Aunque la AT permaneció constante, el pH aumentó $4,0 \%$ a $5^{\circ} \mathrm{C}$ en lechuga Iceberg y 5,0 y $5,3 \%$ a 5 y $2^{\circ} \mathrm{C}$ respectivamente, en lechuga Romana durante largos períodos de almacenamiento ( 21 y 29 días respectivamente).

Debido a su estructura, la firmeza de las cabezas de lechuga Iceberg y Romana fue de 4,84 y $2,64 \mathrm{~N} \mathrm{~mm}^{-1}$. Los valores de firmeza de la lechuga Iceberg son similares a los reportados por (Martínez-Romero et al., 2008). La firmeza no se vio afectada por las condiciones de temperatura o tiempo de almacenamiento. Sin embargo, se observaron mayores desviaciones estándar en la lechuga Iceberg debido a que el estado de compactación era diferente en cada lechuga. De hecho, el tercer día de prueba, con la clase Iceberg a $5^{\circ} \mathrm{C}$ se observó, al seccionar las lechugas los 5 estados de compacidad que se describen en la bibliografía (Figura 74).

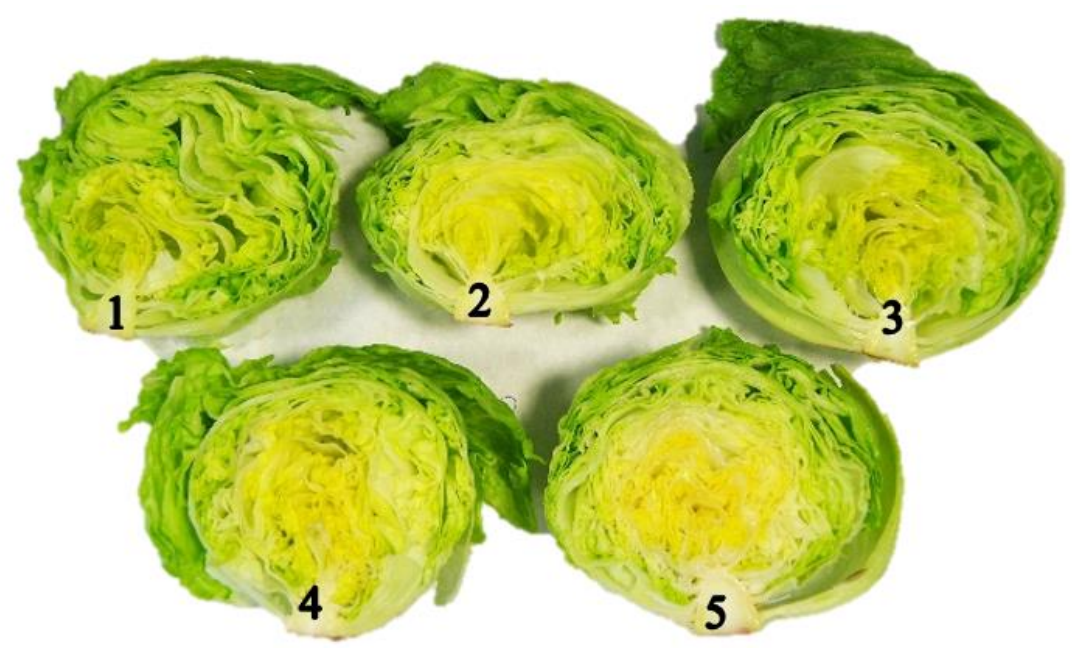

Figura 74. Los 5 estados de compacidad.

La pérdida de peso fue mayor en el último día de salida para cada una de las temperaturas (Tabla 8). Visualmente se observa que la pérdida de peso en las lechugas Iceberg es más acusada a temperaturas más altas $\left(20\right.$ y $\left.15^{\circ} \mathrm{C}\right)$, mientras que, en el caso de las lechugas Romana, su mayor pérdida de peso es para la temperatura de $2^{\circ} \mathrm{C}$, hecho 
que se pudiera justificar por su estructura, ya que al poseer la lechuga Romana una cabeza más alargada, sus hojas ofrecen una mayor superficie frente a la deshidratación (Figura 75).

Tabla 8. Porcentajes de pérdida de peso por temperaturas y tipo de lechuga.

\begin{tabular}{cccccc}
\hline Temperatura & $\mathbf{2}^{\circ} \mathbf{C}$ & $\mathbf{5}^{\circ} \mathbf{C}$ & $10^{\circ} \mathbf{C}$ & $15^{\circ} \mathbf{C}$ & $\mathbf{2 0}^{\circ} \mathbf{C}$ \\
\hline \hline Iceberg & $2,2 \%$ & $2,1 \%$ & $2,4 \%$ & 3,4 & $4,0 \%$ \\
\hline Romana & $2,9 \%$ & $0,65 \%$ & $1,26 \%$ & $1,4 \%$ & $1,64 \%$ \\
\hline \hline
\end{tabular}

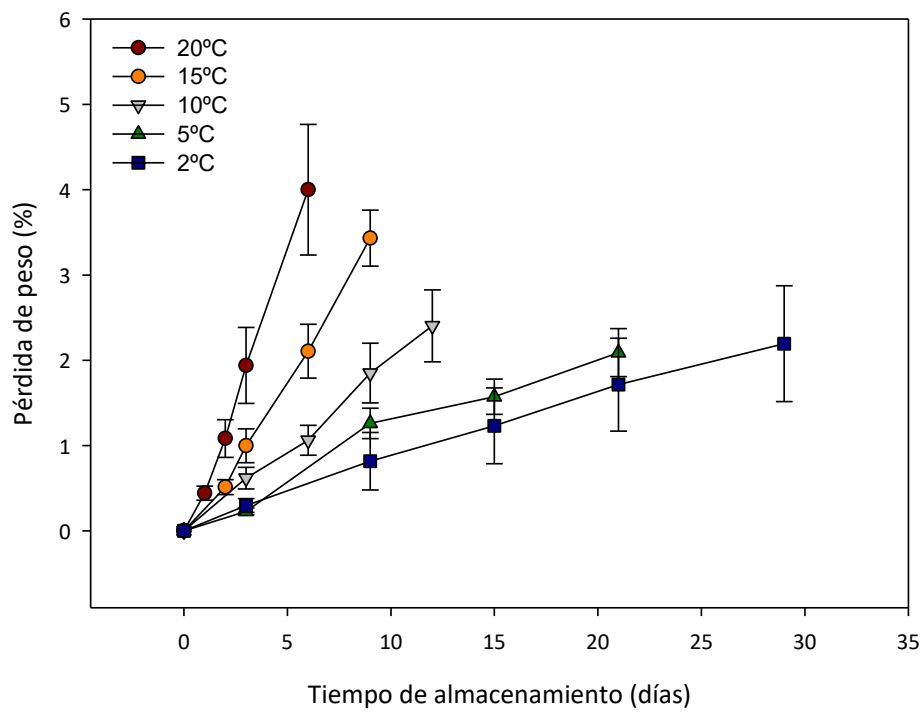

(a)

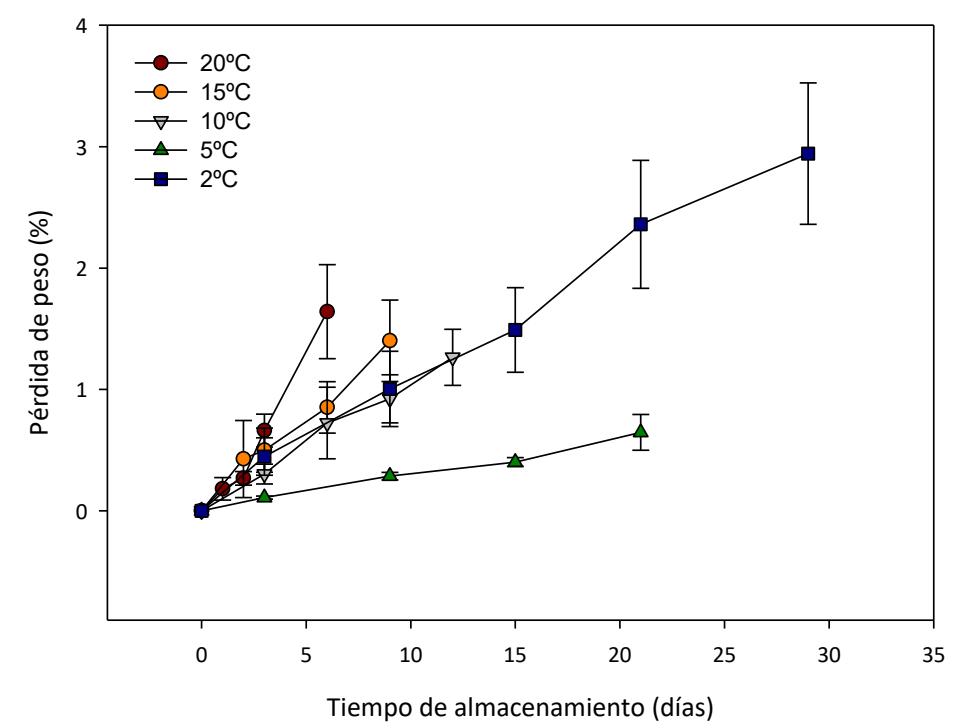

(b)

Figura 75. Evolución de las pérdidas de peso para (a) Iceberg y (b) Romana.

La pérdida de peso de las lechugas Iceberg fue aumentando en cada uno de los días de almacenamiento, siendo la lechuga almacenada a temperaturas más altas la que perdió 
más peso. Sin embargo, se observó una pérdida de peso moderada para todas las temperaturas de almacenamiento en comparación con Managa et al. (2018), cuyas investigaciones aportaron una pérdida de peso del $45,31 \%$ en lechuga Iceberg almacenada durante 3 días a temperatura ambiente. De acuerdo con Manolopoulou et al. (2010), esto puede deberse a la alta humedad relativa generada alrededor de la cabeza de la lechuga cuando están embolsadas.

\subsubsection{Análisis sensorial}

La pérdida de peso está asociada con la pérdida de calidad en la lechuga. Por esta razón, la Tabla 9 presenta los coeficientes de correlación de la pérdida de peso con algunos parámetros de calidad subjetivos que pueden evaluarse cuando se recibe lechuga en una planta de frutas y verduras. Ambos parámetros, apariencia visual y aceptabilidad global, obtuvieron coeficientes de correlación altos significativos $(p \leq 0,001)$. Las correlaciones fueron negativas, lo que indica que una mayor pérdida de peso es perjudicial para los parámetros de calidad.

Tabla 9. Coeficientes de correlación lineal para la pérdida de peso con parámetros de calidad subjetivos bajo 5 temperaturas de almacenamiento diferentes, en lechuga Iceberg y lechuga Romana.

\begin{tabular}{ccccc}
\hline \hline & \multicolumn{3}{c}{ Parámetros subjetivos de calidad } \\
\cline { 2 - 5 } & $\begin{array}{c}\text { Apariencia } \\
\text { visual }\end{array}$ & Olor & Color & $\begin{array}{c}\text { Aceptabilidad } \\
\text { global }\end{array}$ \\
\hline Iceberg & & & & \\
$20^{\circ} \mathrm{C}$ & $-0,733^{* * *}$ & $-0,812^{* * *}$ & $-0,859^{* * *}$ & $-0,851^{* * *}$ \\
$15^{\circ} \mathrm{C}$ & $-0,953^{* * *}$ & $-0,564^{* *}$ & $-0,788^{* * *}$ & $-0,910^{* * *}$ \\
$10^{\circ} \mathrm{C}$ & $-0,795^{* * *}$ & $-0,740^{* * *}$ & $-0,765^{* * *}$ & $-0,786 * *$ \\
$5^{\circ} \mathrm{C}$ & $-0,819^{* * *}$ & $-0,811^{* * *}$ & $-0,804^{* * *}$ & $-0,924 * * *$ \\
$2^{\circ} \mathrm{C}$ & $-0,756^{* * *}$ & $-0,756^{* * *}$ & $-0,794^{* * *}$ & $-0,7119^{* * *}$ \\
\hline Romana & & & & \\
$20^{\circ} \mathrm{C}$ & $-0,808^{* * *}$ & $-0,893^{* * *}$ & - & $-0,639 * * *$ \\
$15^{\circ} \mathrm{C}$ & $-0,863^{* * *}$ & $-0,210 \mathrm{~ns}$ & $-0,741^{* * *}$ & $-0,806 * * *$ \\
$10^{\circ} \mathrm{C}$ & $-0,708^{* * *}$ & $-0,746^{* * *}$ & $-0,422^{*}$ & $-0,621 * * *$ \\
$5^{\circ} \mathrm{C}$ & $-0,827^{* * *}$ & $-0,888^{* * *}$ & $-0,900^{* * *}$ & $-0,853^{* * *}$ \\
$2^{\circ} \mathrm{C}$ & $-0,883^{* * *}$ & $-0,792^{* * *}$ & $-0,750^{* * *}$ & $-0,847^{* * *}$ \\
\hline \hline
\end{tabular}

Si bien es cierto, para el aspecto físico del color, se realizaron dos tasaciones. La realizada con el colorímetro (Tabla 10 ) para determinar el $\Delta E$ según las directrices citadas en el apartado 3.2.1 y la realizada por el panel de expertos (Tabla 11) descrito en el apartado 3.2.2. El $\Delta \mathrm{E}$ de las cabezas de lechuga Iceberg y Romana no se vio significativamente afectado en ninguna de las 5 temperaturas analizadas. 
Tabla 10. Resultados de la medición de $\Delta \mathrm{E}$ obtenidos con el colorímetro por temperatura, día de ensayo y tipo de lechuga.

\begin{tabular}{|c|c|c|c|c|c|c|}
\hline \multicolumn{7}{|c|}{$\Delta$ E ICEBERG (a) } \\
\hline \multirow{2}{*}{$20^{\circ} \mathrm{C}$} & 0 & 1 & 2 & 3 & 6 & \\
\hline & $0,00 \pm 0,00$ & $2,69 \pm 2,56$ & $4,55 \pm 2,30$ & $2,28 \pm 0,70$ & $2,83 \pm 1,81$ & \\
\hline \multirow{2}{*}{$15^{\circ} \mathrm{C}$} & 0 & 2 & 3 & 6 & 9 & \\
\hline & $0,00 \pm 0,00$ & $2,22 \pm 1,08$ & $3,17 \pm 1,98$ & $4,43 \pm 1,78$ & $1,57 \pm 1,20$ & \\
\hline \multirow{2}{*}{$10^{\circ} \mathrm{C}$} & 0 & 3 & 6 & 9 & 15 & \\
\hline & $0,00 \pm 0,00$ & $2,16 \pm 1,31$ & $4,09 \pm 2,80$ & $3,34 \pm 1,27$ & $5,37 \pm 1,38$ & \\
\hline \multirow{2}{*}{$5^{\circ} \mathrm{C}$} & 0 & 3 & 9 & 15 & 21 & \\
\hline & $0,00 \pm 0,00$ & $3,33 \pm 2,08$ & $2,97 \pm 1,56$ & $3,09 \pm 2,19$ & $2,75 \pm 1,48$ & \\
\hline \multirow{2}{*}{$2^{\circ} \mathrm{C}$} & 0 & 3 & 9 & 15 & 21 & 29 \\
\hline & $0,00 \pm 0,00$ & $3,80 \pm 2,47$ & $2,20 \pm 0,70$ & $1,80 \pm 0,68$ & $2,55 \pm 1,70$ & $4,04 \pm 2,40$ \\
\hline \multicolumn{7}{|c|}{$\triangle E$ ROMANA (b) } \\
\hline \multirow{2}{*}{$20^{\circ} \mathrm{C}$} & 0 & 1 & 2 & 3 & 6 & \\
\hline & $0,00 \pm 0,00$ & $2,20 \pm 1,07$ & $2,68 \pm 0,52$ & $5,00 \pm 0,55$ & $3,97 \pm 1,87$ & \\
\hline \multirow{2}{*}{$15^{\circ} \mathrm{C}$} & 0 & 2 & 3 & 6 & 9 & \\
\hline & $0,00 \pm 0,00$ & $3,83 \pm 1,98$ & $2,79 \pm 1,40$ & $5,00 \pm 0,31$ & $3,50 \pm 1,33$ & \\
\hline \multirow{2}{*}{$10^{\circ} \mathrm{C}$} & 0 & 3 & 6 & 9 & 15 & \\
\hline & $0,00 \pm 0,00$ & $1,68 \pm 0,57$ & $3,34 \pm 1,51$ & $5,00 \pm 1,80$ & $2,74 \pm 1,52$ & \\
\hline \multirow{2}{*}{$5^{\circ} \mathrm{C}$} & 0 & 3 & 9 & 15 & 21 & \\
\hline & $0,00 \pm 0,00$ & $2,92 \pm 1,79$ & $2,28 \pm 1,67$ & $4,10 \pm 1,43$ & $3,15 \pm 1,61$ & \\
\hline \multirow{2}{*}{$2^{\circ} \mathrm{C}$} & 0 & 3 & 9 & 15 & 21 & 29 \\
\hline & $0,00 \pm 0,00$ & $5,42 \pm 1,59$ & $5,25 \pm 1,92$ & $5,00 \pm 1,42$ & $3,72 \pm 0,81$ & $5,15 \pm 1,30$ \\
\hline
\end{tabular}

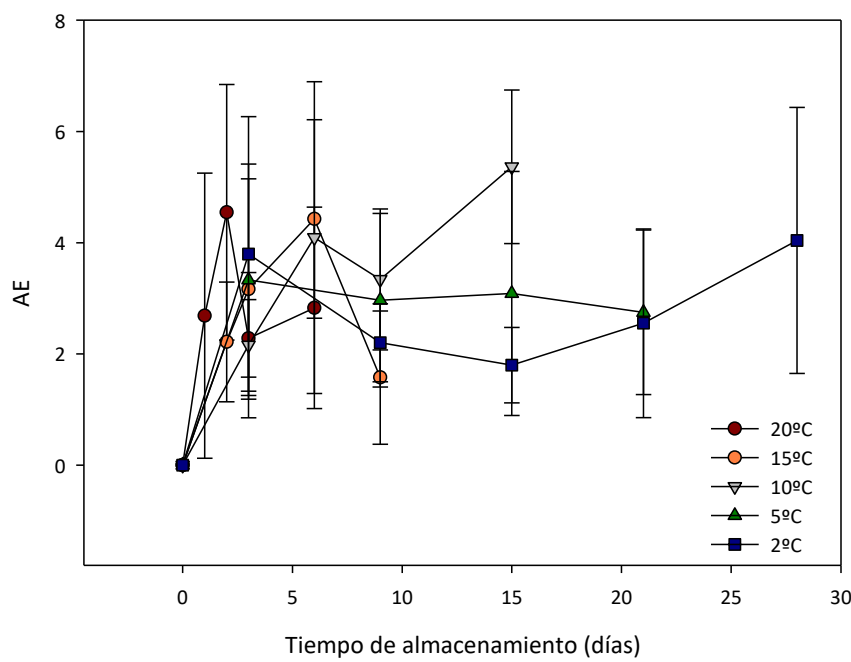

(a)

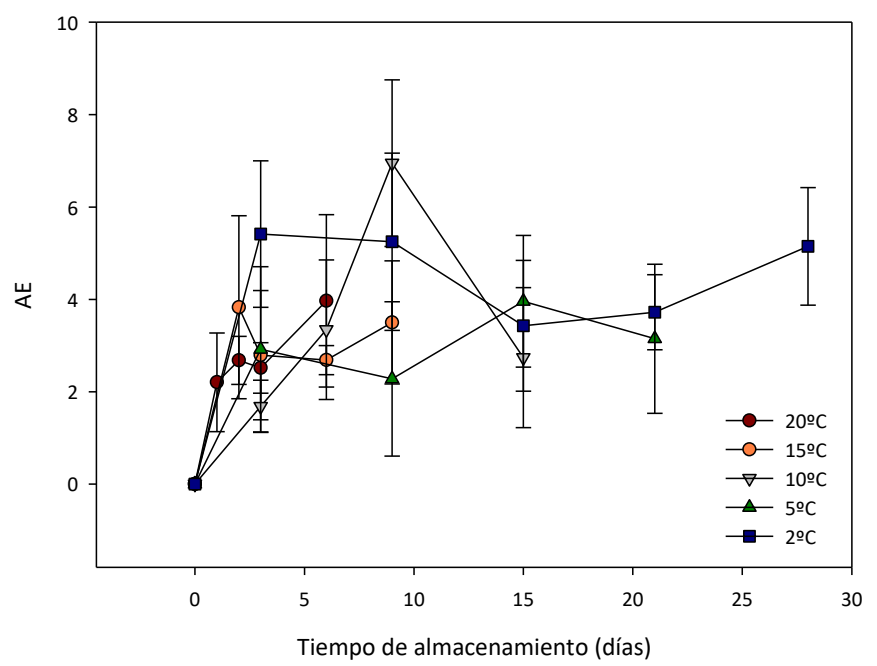

(b)

Al analizar el color mediante el análisis sensorial, se tuvo en cuenta el brillo de las hojas, su aspecto deshidratado y su amarilleamiento. Se observa que las puntuaciones decaen 
conforme pasa el tiempo, pese a que los colores pudieran estar dentro del rango admisible. Los observadores indican para las lechugas Iceberg del día 9 a $15^{\circ} \mathrm{C}$ : "Las hojas de todos los individuos presentan un estado de deshidratación considerable y las puntas en los individuos número 16 y 18 han empezado a amarillear, mientras que en los individuos 19 y 20 ya están amarillas y marrones". Es para esa salida para cuando las lechugas Iceberg sobrepasan su LR.

Tabla 11. Puntuaciones para el color obtenidas mediante el análisis sensorial por temperatura, día de ensayo y tipo de lechuga.

\begin{tabular}{|c|c|c|c|c|c|c|}
\hline \multicolumn{7}{|c|}{ Color ICEBERG (a) } \\
\hline \multirow{2}{*}{$20^{\circ} \mathrm{C}$} & 0 & 1 & 2 & 3 & 6 & \\
\hline & $5,00 \pm 0,00$ & $5,00 \pm 0,00$ & $5,00 \pm 0,00$ & $5,00 \pm 0,00$ & $3,00 \pm 0,00$ & \\
\hline \multirow{2}{*}{$15^{\circ} \mathrm{C}$} & 0 & 2 & 3 & 6 & 9 & \\
\hline & $5,00 \pm 0,00$ & $5,00 \pm 0,00$ & $4,00 \pm 0,00$ & $4,70 \pm 0,45$ & $2,60 \pm 0,55$ & \\
\hline \multirow{2}{*}{$10^{\circ} \mathrm{C}$} & 0 & 3 & 6 & 9 & 15 & \\
\hline & $5,00 \pm 0,00$ & $5,00 \pm 0,00$ & $4,00 \pm 0,00$ & $3,80 \pm 0,84$ & $2,10 \pm 0,74$ & \\
\hline \multirow{2}{*}{$5^{\circ} \mathrm{C}$} & 0 & 3 & 9 & 15 & 21 & \\
\hline & $5,00 \pm 0,00$ & $5,00 \pm 0,00$ & $5,00 \pm 0,00$ & $3,50 \pm 0,00$ & $1,50 \pm 0,35$ & \\
\hline \multirow{2}{*}{$2^{\circ} \mathrm{C}$} & 0 & 3 & 9 & 15 & 21 & 29 \\
\hline & $5,00 \pm 0,00$ & $5,00 \pm 0,00$ & $5,00 \pm 0,00$ & $4,00 \pm 0,00$ & $3,70 \pm 0,45$ & $2,00 \pm 0,70$ \\
\hline \multicolumn{7}{|c|}{ Color ROMANA (b) } \\
\hline \multirow{2}{*}{$20^{\circ} \mathrm{C}$} & 0 & 1 & 2 & 3 & 6 & \\
\hline & $5,00 \pm 0,00$ & $5,00 \pm 0,00$ & $5,00 \pm 0,00$ & $5,00 \pm 0,00$ & $5,00 \pm 0,00$ & \\
\hline \multirow{2}{*}{$15^{\circ} \mathrm{C}$} & 0 & 2 & 3 & 6 & 9 & \\
\hline & $5,00 \pm 0,00$ & $5,00 \pm 0,00$ & $5,00 \pm 0,00$ & $5,00 \pm 0,00$ & $4,50 \pm 0,00$ & \\
\hline \multirow{2}{*}{$10^{\circ} \mathrm{C}$} & 0 & 3 & 6 & 9 & 15 & \\
\hline & $5,00 \pm 0,00$ & $5,00 \pm 0,00$ & $5,00 \pm 0,00$ & $5,00 \pm 0,00$ & $4,40 \pm 0,82$ & \\
\hline \multirow{2}{*}{$5^{\circ} \mathrm{C}$} & 0 & 3 & 9 & 15 & 21 & \\
\hline & $5,00 \pm 0,00$ & $5,00 \pm 0,00$ & $4,00 \pm 0,00$ & $4,10 \pm 0,22$ & $3,50 \pm 0,00$ & \\
\hline \multirow{2}{*}{$2^{\circ} \mathrm{C}$} & 0 & 3 & 9 & 15 & 21 & 29 \\
\hline & $5,00 \pm 0,00$ & $5,00 \pm 0,00$ & $5,00 \pm 0,00$ & $5,00 \pm 0,00$ & $4,00 \pm 0,00$ & $1,80 \pm 0,00$ \\
\hline
\end{tabular}




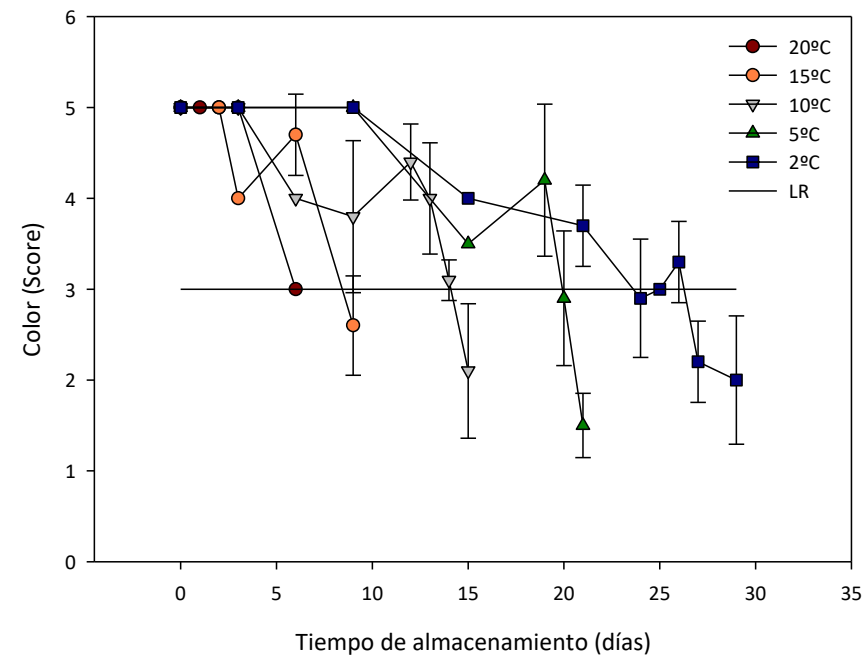

(a)

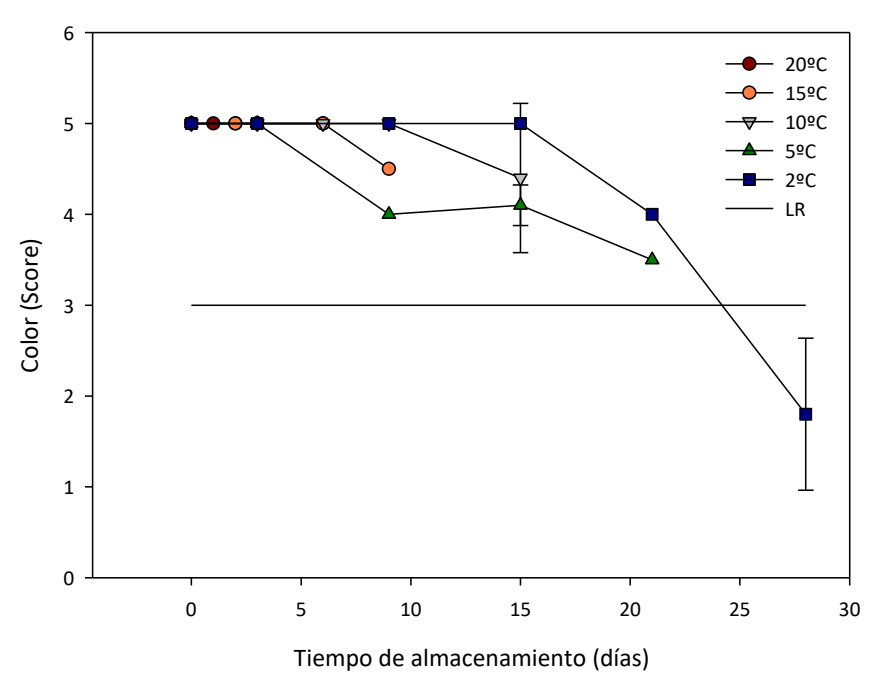

(b)

Del mismo modo, la firmeza de las lechugas fue analizada mediante el analizador de textura (Tabla 12) para obtener valores objetivos y mediante el panel sensorial (Tabla 13) para obtener valores subjetivos.

Tabla 12. Mediciones de firmeza realizadas mediante el analizador de textura por temperatura, día de ensayo y tipo de lechuga.

\begin{tabular}{|c|c|c|c|c|c|c|}
\hline & & & Firmeza I & EBERG (a) & & \\
\hline \multirow{2}{*}{$20^{\circ} \mathrm{C}$} & 0 & 1 & 2 & 3 & 6 & \\
\hline & $4,84 \pm 3,29$ & $4,36 \pm 1,19$ & $3,78 \pm 0,69$ & $3,74 \pm 0,73$ & $4,79 \pm 1,98$ & \\
\hline \multirow{2}{*}{$15^{\circ} \mathrm{C}$} & 0 & 2 & 3 & 6 & 9 & \\
\hline & $4,84 \pm 3,29$ & $4,80 \pm 1,31$ & $5,35 \pm 2,01$ & $4,88 \pm 1,36$ & $4,26 \pm 0,65$ & \\
\hline \multirow{2}{*}{$10^{\circ} \mathrm{C}$} & 0 & 3 & 6 & 9 & 15 & \\
\hline & $4,84 \pm 3,29$ & $5,86 \pm 2,33$ & $4,07 \pm 0,70$ & $4,73 \pm 1,26$ & $4,32 \pm 0,76$ & \\
\hline \multirow{2}{*}{$5^{\circ} \mathrm{C}$} & 0 & 3 & 9 & 15 & 21 & \\
\hline & $4,84 \pm 3,29$ & $3,94 \pm 2,26$ & $4,13 \pm 1,78$ & $3,87 \pm 0,67$ & $6,16 \pm 3,41$ & \\
\hline \multirow{3}{*}{$2^{\circ} \mathrm{C}$} & 0 & 3 & 9 & 15 & 21 & 29 \\
\hline & $4,84 \pm 3,29$ & $7,59 \pm 0,00$ & $2,83 \pm 0,80$ & $2,84 \pm 0,72$ & $4,21 \pm 1,06$ & $3,68 \pm 1,58$ \\
\hline & \multicolumn{6}{|c|}{ Firmeza ROMANA (b) } \\
\hline \multirow{2}{*}{$20^{\circ} \mathrm{C}$} & 0 & 1 & 2 & 3 & 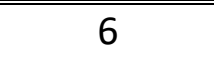 & \\
\hline & $2,64 \pm 0,36$ & $3,38 \pm 1,39$ & $2,65 \pm 0,77$ & $2,79 \pm 0,24$ & $2,90 \pm 0,89$ & \\
\hline \multirow{2}{*}{$15^{\circ} \mathrm{C}$} & 0 & 2 & 3 & 6 & 9 & \\
\hline & $2,64 \pm 0,36$ & $2,74 \pm 0,48$ & $3,57 \pm 1,02$ & $3,71 \pm 2,19$ & $2,88 \pm 0,70$ & \\
\hline \multirow{2}{*}{$10^{\circ} \mathrm{C}$} & 0 & 3 & 6 & 9 & 15 & \\
\hline & $2,64 \pm 0,36$ & $2,65 \pm 0,62$ & $3,72 \pm 1,29$ & $4,14 \pm 1,20$ & $3,50 \pm 1,00$ & \\
\hline \multirow{2}{*}{$5^{\circ} \mathrm{C}$} & 0 & 3 & 9 & 15 & 21 & \\
\hline & $2,64 \pm 0,36$ & $3,33 \pm 0,42$ & $3,91 \pm 1,37$ & $3,41 \pm 1,11$ & $2,91 \pm 0,98$ & \\
\hline \multirow{2}{*}{$2^{\circ} \mathrm{C}$} & 0 & 3 & 9 & 15 & 21 & 29 \\
\hline & $2,64 \pm 0,36$ & $3,11 \pm 0,79$ & $3,36 \pm 1,65$ & $3,02 \pm 0,23$ & $2,68 \pm 0,63$ & $4,01 \pm 2,13$ \\
\hline
\end{tabular}




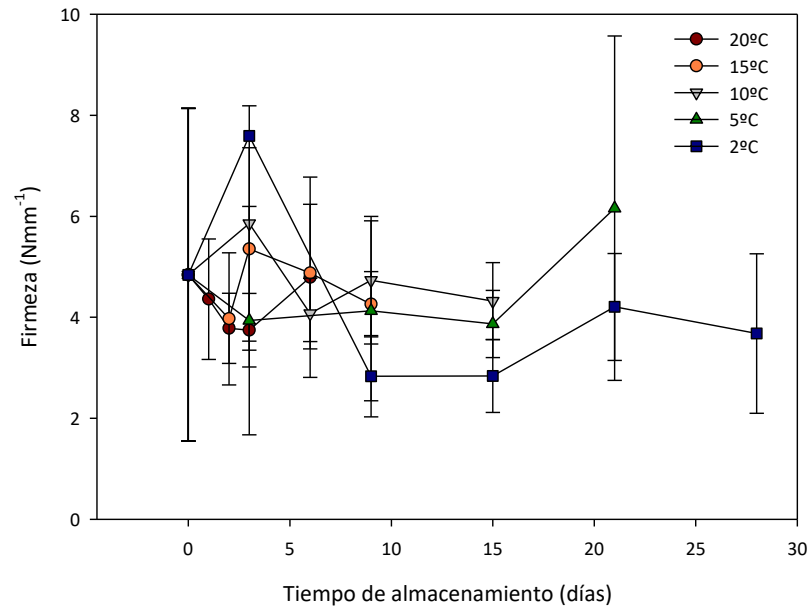

(a)

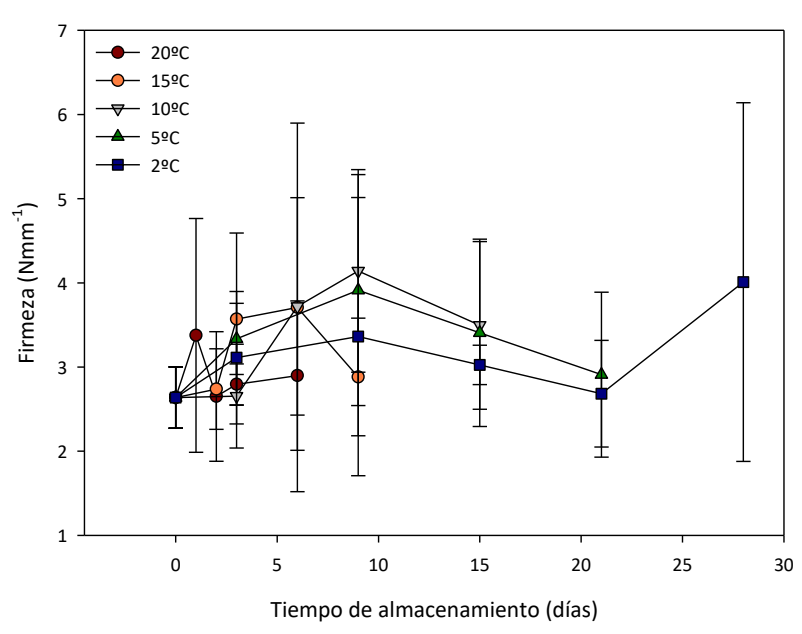

(b)

Se muestran a continuación las puntuaciones obtenidas en el análisis sensorial indicando el día en el que se realizó el test y la temperatura correspondientes a cada uno de los tipos de lechugas.

Tabla 13. Mediciones de compacidad al tacto mediante sensorial por temperatura, día de ensayo y tipo de lechuga.

\begin{tabular}{|c|c|c|c|c|c|c|}
\hline \multirow{3}{*}{$20^{\circ} \mathrm{C}$} & \multicolumn{6}{|c|}{ Compacidad al tacto ICEBERG (a) } \\
\hline & 0 & 1 & 2 & 3 & 6 & \\
\hline & $5,00 \pm 0,00$ & $4,20 \pm 0,84$ & $4,00 \pm 1,00$ & $4,90 \pm 0,22$ & $1,40 \pm 0,55$ & \\
\hline \multirow{2}{*}{$15^{\circ} \mathrm{C}$} & 0 & 2 & 3 & 6 & 9 & \\
\hline & $4,84 \pm 3,29$ & $4,80 \pm 1,31$ & $5,35 \pm 2,01$ & $4,88 \pm 1,36$ & $4,26 \pm 0,65$ & \\
\hline \multirow{2}{*}{$10^{\circ} \mathrm{C}$} & 0 & 3 & 6 & 9 & 15 & \\
\hline & $4,84 \pm 3,29$ & $5,86 \pm 2,33$ & $4,07 \pm 0,70$ & $4,73 \pm 1,26$ & $4,32 \pm 0,76$ & \\
\hline \multirow{2}{*}{$5^{\circ} \mathrm{C}$} & 0 & 3 & 9 & 15 & 21 & \\
\hline & $4,84 \pm 3,29$ & $3,94 \pm 2,26$ & $4,13 \pm 1,78$ & $3,87 \pm 0,67$ & $6,16 \pm 3,41$ & \\
\hline \multirow{3}{*}{$2^{\circ} \mathrm{C}$} & 0 & 3 & 9 & 15 & 21 & 29 \\
\hline & $4,84 \pm 3,29$ & $7,59 \pm 0,00$ & $2,83 \pm 0,80$ & $2,84 \pm 0,72$ & $4,21 \pm 1,06$ & $3,68 \pm 1,58$ \\
\hline & \multicolumn{6}{|c|}{ Compacidad al tacto ROMANA (b) } \\
\hline \multirow{2}{*}{$20^{\circ} \mathrm{C}$} & 0 & 1 & 2 & 3 & 6 & \\
\hline & $2,64 \pm 0,36$ & $3,38 \pm 1,39$ & $2,65 \pm 0,77$ & $2,79 \pm 0,24$ & $2,90 \pm 0,89$ & \\
\hline \multirow{2}{*}{$15^{\circ} \mathrm{C}$} & 0 & 2 & 3 & 6 & 9 & \\
\hline & $2,64 \pm 0,36$ & $2,74 \pm 0,48$ & $3,57 \pm 1,02$ & $3,71 \pm 2,19$ & $2,88 \pm 0,70$ & \\
\hline \multirow{2}{*}{$10^{\circ} \mathrm{C}$} & 0 & 3 & 6 & 9 & 15 & \\
\hline & $2,64 \pm 0,36$ & $2,65 \pm 0,62$ & $3,72 \pm 1,29$ & $4,14 \pm 1,20$ & $3,50 \pm 1,00$ & \\
\hline \multirow{2}{*}{$5^{\circ} \mathrm{C}$} & 0 & 3 & 9 & 15 & 21 & \\
\hline & $2,64 \pm 0,36$ & $3,33 \pm 0,42$ & $3,91 \pm 1,37$ & $3,41 \pm 1,11$ & $2,91 \pm 0,98$ & \\
\hline \multirow{2}{*}{$2^{\circ} \mathrm{C}$} & 0 & 3 & 9 & 15 & 21 & 29 \\
\hline & $2,64 \pm 0,36$ & $3,11 \pm 0,79$ & $3,36 \pm 1,65$ & $3,02 \pm 0,23$ & $2,68 \pm 0,63$ & $4,01 \pm 2,13$ \\
\hline
\end{tabular}




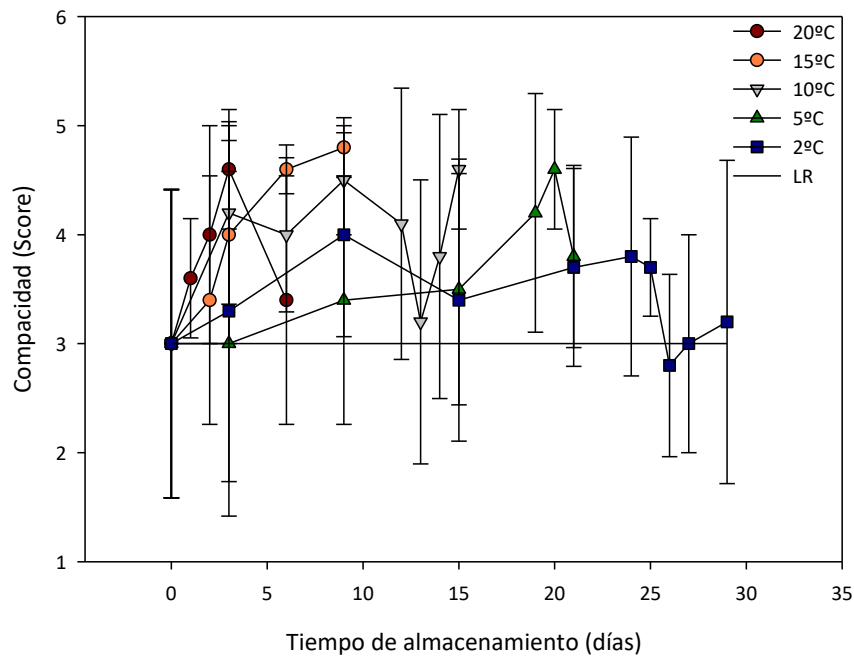

(a)

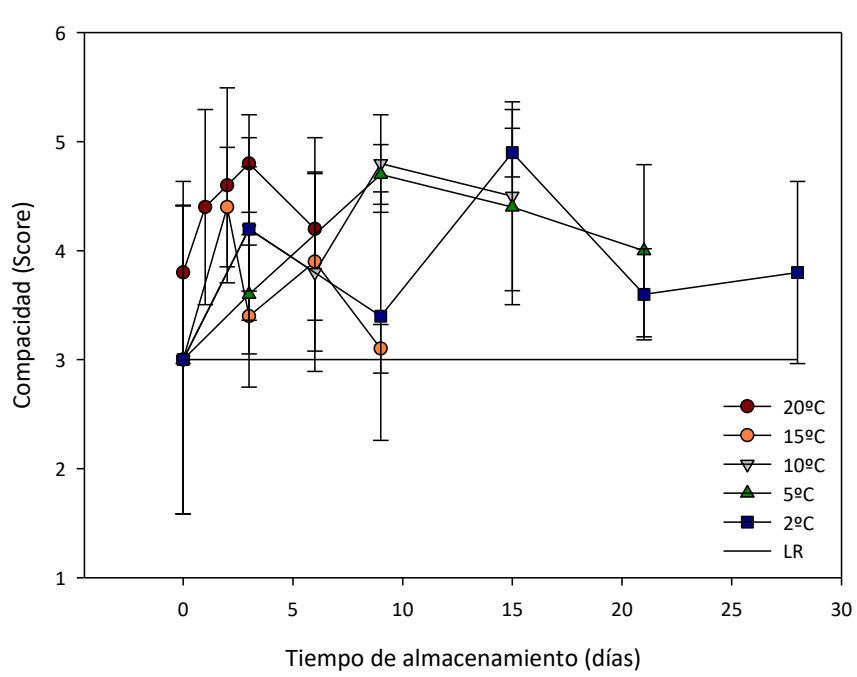

(b)

Tabla 14. Mediciones de apariencia visual por temperatura, día de ensayo y tipo de lechuga.

\begin{tabular}{|c|c|c|c|c|c|c|}
\hline \multirow{3}{*}{$20^{\circ} \mathrm{C}$} & \multicolumn{6}{|c|}{ Apariencia visual ICEBERG (a) } \\
\hline & 0 & 1 & 2 & 3 & 6 & \\
\hline & $5,00 \pm 0,00$ & $4,20 \pm 0,84$ & $4,00 \pm 1,00$ & $4,90 \pm 0,22$ & $1,40 \pm 0,55$ & \\
\hline \multirow{2}{*}{$15^{\circ} \mathrm{C}$} & 0 & 2 & 3 & 6 & 9 & \\
\hline & $5,00 \pm 0,00$ & $4,80 \pm 0,45$ & $4,00 \pm 0,00$ & $3,50 \pm 0,35$ & $2,20 \pm 0,27$ & \\
\hline \multirow{2}{*}{$10^{\circ} \mathrm{C}$} & 0 & 3 & 6 & 9 & 15 & \\
\hline & $5,00 \pm 0,00$ & $4,50 \pm 0,00$ & $3,20 \pm 0,27$ & $3,60 \pm 0,55$ & $1,80 \pm 0,76$ & \\
\hline \multirow{2}{*}{$5^{\circ} \mathrm{C}$} & 0 & 3 & 9 & 15 & 21 & \\
\hline & $5,00 \pm 0,00$ & $5,00 \pm 0,00$ & $4,80 \pm 0,45$ & $3,40 \pm 0,22$ & $1,50 \pm 0,50$ & \\
\hline \multirow{3}{*}{$2^{\circ} \mathrm{C}$} & 0 & 3 & 9 & 15 & 21 & 29 \\
\hline & $5,00 \pm 0,00$ & $5,00 \pm 0,00$ & $5,00 \pm 0,00$ & $3,20 \pm 0,45$ & $3,90 \pm 0,22$ & $1,60 \pm 0,40$ \\
\hline & \multicolumn{6}{|c|}{ Apariencia visual ROMANA (b) } \\
\hline \multirow{2}{*}{$20^{\circ} \mathrm{C}$} & 0 & 1 & 2 & 3 & 6 & \\
\hline & $4,80 \pm 0,27$ & $4,60 \pm 0,55$ & $4,60 \pm 0,55$ & $4,20 \pm 0,45$ & $3,00 \pm 0,00$ & \\
\hline \multirow{2}{*}{$15^{\circ} \mathrm{C}$} & 00 & 2 & 3 & 6 & 9 & \\
\hline & $5,00 \pm 0,00$ & $5,00 \pm 0,00$ & $4,70 \pm 0,27$ & $4,40 \pm 0,22$ & $3,50 \pm 0,50$ & \\
\hline \multirow{2}{*}{$10^{\circ} \mathrm{C}$} & 0 & 3 & 6 & 9 & 15 & \\
\hline & $5,00 \pm 0,00$ & $4,90 \pm 0,22$ & $4,70 \pm 0,45$ & $4,40 \pm 0,22$ & $3,50 \pm 0,89$ & \\
\hline \multirow{2}{*}{$5^{\circ} \mathrm{C}$} & 0 & 3 & 9 & 15 & 21 & \\
\hline & $5,00 \pm 0,00$ & $5,00 \pm 0,00$ & $4,80 \pm 0,45$ & $4,50 \pm 0,00$ & $2,90 \pm 0,22$ & \\
\hline \multirow{2}{*}{$2^{\circ} \mathrm{C}$} & 0 & 3 & 9 & 15 & 21 & 29 \\
\hline & $5,00 \pm 0,00$ & $4,80 \pm 0,27$ & $4,40 \pm 0,22$ & $3,80 \pm 0,45$ & $3,40 \pm 0,22$ & $1,70 \pm 0,80$ \\
\hline
\end{tabular}

Para la temperatura de $20^{\circ} \mathrm{C}$ del sexto día de ensayo en las lechugas Romanas, se observa que hojas están blandas y más maduras que en las pruebas anteriores. Para la temperatura de $15^{\circ} \mathrm{C}$ del noveno día de ensayo en las lechugas Iceberg, las hojas se están deshidratando por las puntas y perdiendo el color, presentando un aspecto amarillento. 


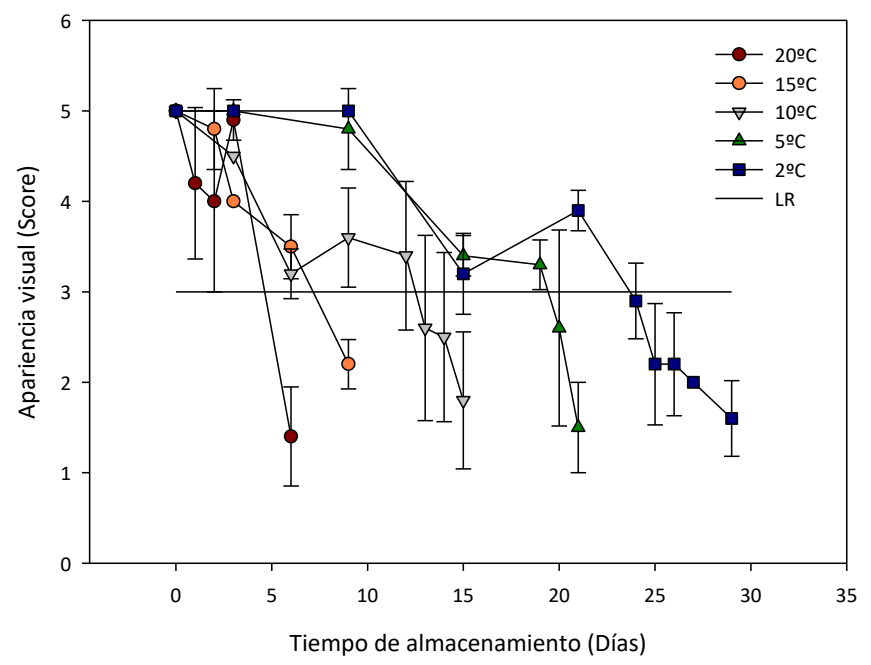

(a)

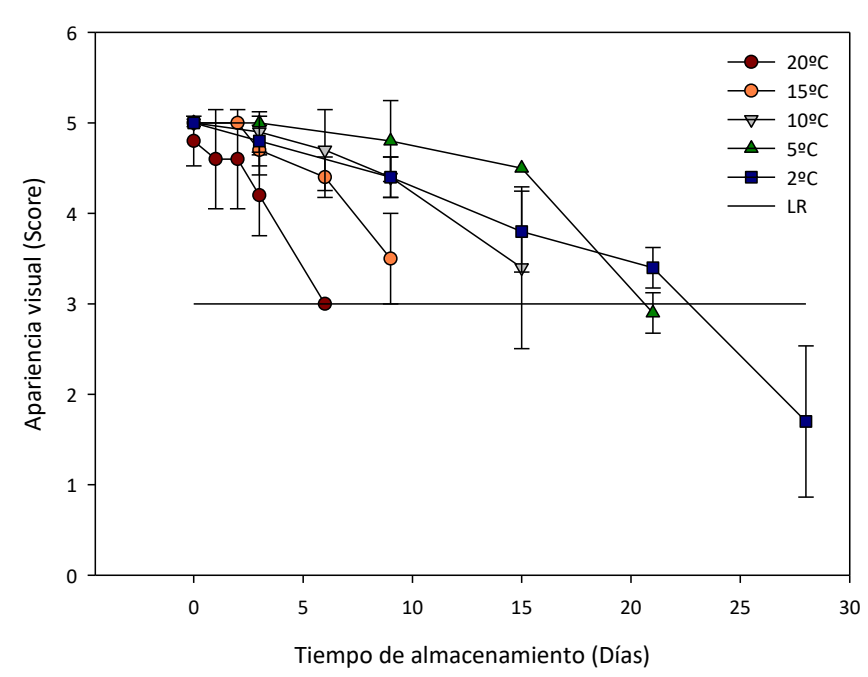

(b)

Tabla 15. Mediciones de sabor por temperatura, día de ensayo y tipo de lechuga.

\begin{tabular}{|c|c|c|c|c|c|c|}
\hline \multicolumn{7}{|c|}{ Sabor ICEBERG (a) } \\
\hline \multirow{2}{*}{$20^{\circ} \mathrm{C}$} & 0 & 1 & 2 & 3 & 6 & \\
\hline & $5,00 \pm 0,00$ & $4,80 \pm 0,45$ & $4,10 \pm 0,89$ & $4,30 \pm 0,84$ & $2,60 \pm 0,55$ & \\
\hline \multirow{2}{*}{$15^{\circ} \mathrm{C}$} & 0 & 2 & 3 & 6 & 9 & \\
\hline & $5,00 \pm 0,00$ & $4,70 \pm 0,75$ & $4,10 \pm 0,89$ & $4,60 \pm 0,42$ & $4,20 \pm 0,84$ & \\
\hline \multirow{2}{*}{$10^{\circ} \mathrm{C}$} & 0 & 3 & 6 & 9 & 15 & \\
\hline & $5,00 \pm 0,00$ & $4,40 \pm 0,42$ & $3,70 \pm 1,20$ & $3,60 \pm 0,42$ & $2,50 \pm 0,61$ & \\
\hline \multirow{2}{*}{$5^{\circ} \mathrm{C}$} & 0 & 3 & 9 & 15 & 21 & \\
\hline & $5,00 \pm 0,00$ & $5,00 \pm 0,00$ & $4,00 \pm 0,50$ & $1,90 \pm 0,89$ & $2,50 \pm 0,50$ & \\
\hline \multirow{2}{*}{$2^{\circ} \mathrm{C}$} & 0 & 3 & 9 & 15 & 21 & 29 \\
\hline & $5,00 \pm 0,00$ & $4,70 \pm 0,45$ & $3,30 \pm 0,67$ & $2,50 \pm 0,79$ & $3,40 \pm 0,65$ & $1,30 \pm 0,30$ \\
\hline \multicolumn{7}{|c|}{ Sabor ROMANA (b) } \\
\hline \multirow{2}{*}{$20^{\circ} \mathrm{C}$} & 0 & 1 & 2 & 3 & 6 & \\
\hline & $5,00 \pm 0,00$ & $4,00 \pm 1,00$ & $3,90 \pm 1,14$ & $3,20 \pm 1,04$ & $3,20 \pm 0,27$ & \\
\hline \multirow{2}{*}{$15^{\circ} \mathrm{C}$} & 0 & 2 & 3 & 6 & 9 & \\
\hline & $5,00 \pm 0,00$ & $4,20 \pm 0,76$ & $3,90 \pm 0,42$ & $2,90 \pm 0,55$ & $2,70 \pm 0,67$ & \\
\hline \multirow{2}{*}{$10^{\circ} \mathrm{C}$} & 0 & 3 & 6 & 9 & 15 & \\
\hline & $5,00 \pm 0,00$ & $4,40 \pm 0,42$ & $3,20 \pm 0,84$ & $3,50 \pm 1,22$ & $3,00 \pm 0,50$ & \\
\hline \multirow{2}{*}{$5^{\circ} \mathrm{C}$} & 0 & 3 & 9 & 15 & 21 & \\
\hline & $5,00 \pm 0,00$ & $4,70 \pm 0,45$ & $4,20 \pm 0,76$ & $3,10 \pm 0,74$ & $2,80 \pm 0,76$ & \\
\hline \multirow{2}{*}{$2^{\circ} \mathrm{C}$} & 0 & 3 & 9 & 15 & 21 & 29 \\
\hline & $5,00 \pm 0,00$ & $4,50 \pm 0,50$ & $4,00 \pm 0,50$ & $2,40 \pm 0,96$ & $3,20 \pm 0,57$ & $1,10 \pm 0,20$ \\
\hline
\end{tabular}

Para la temperatura de $20^{\circ} \mathrm{C}$ del sexto día, las hojas de las Romanas no presentan la frescura en cuanto a crujiente del primer día y empiezan a estar amargas. Las Iceberg amargan dejando el sabor en la boca. $\mathrm{A} 15^{\circ} \mathrm{C}$ el noveno día las Iceberg que no presentan un ligero sabor amargo han perdido el sabor. A partir del decimoquinto día para las 
temperaturas de 10 y $5^{\circ} \mathrm{C}$ ambos tipos ha aumentado considerablemente el sabor amargo y agrio de las hojas, el cual empieza a notarse en las lechugas de $2^{\circ} \mathrm{C}$.

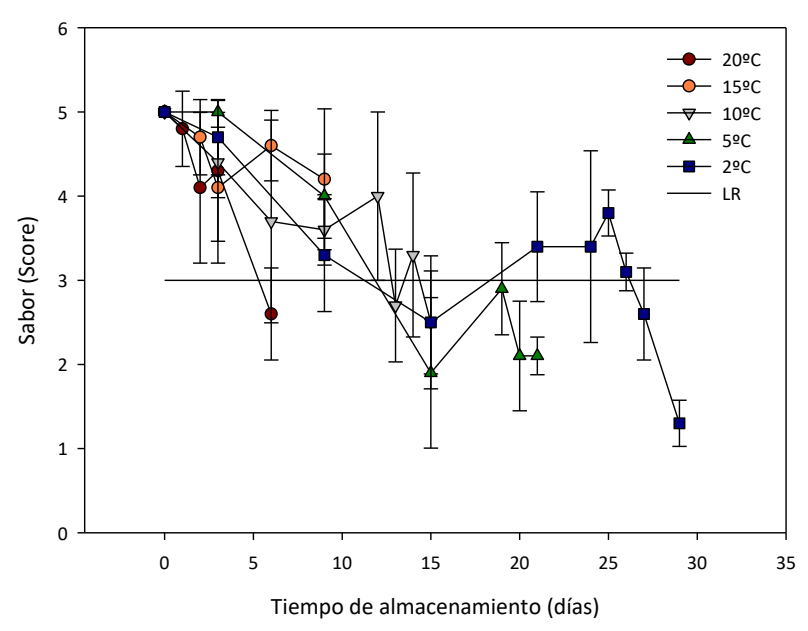

(a)

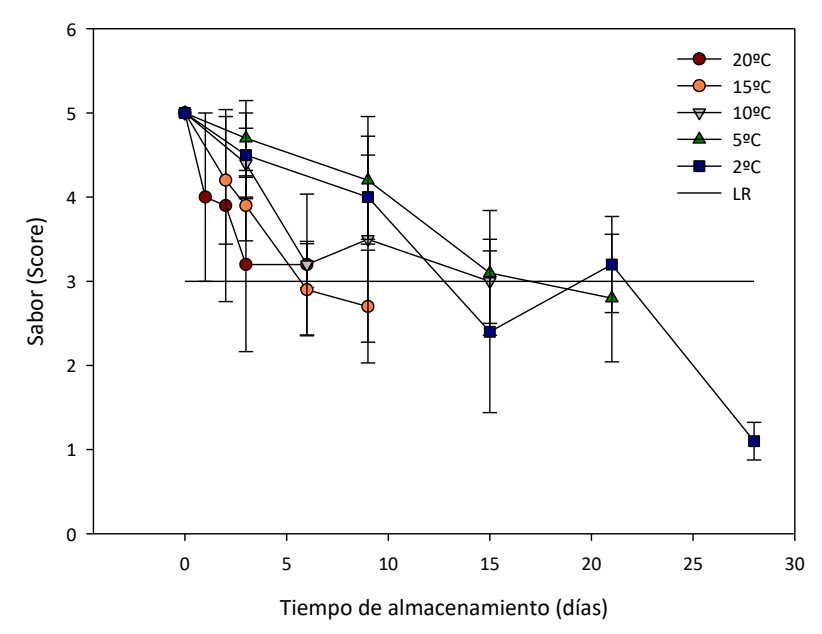

(b)

Tabla 16. Mediciones de aceptabilidad global por temperatura, día de ensayo y tipo de lechuga.

\begin{tabular}{|c|c|c|c|c|c|c|}
\hline \multicolumn{7}{|c|}{ Aceptabilidad global ICEBERG (a) } \\
\hline \multirow{2}{*}{$20^{\circ} \mathrm{C}$} & 0 & 1 & 2 & 3 & 6 & \\
\hline & $5,00 \pm 0,00$ & $5,00 \pm 0,00$ & $5,00 \pm 0,00$ & $4,80 \pm 0,27$ & $1,90 \pm 0,65$ & \\
\hline \multirow{2}{*}{$15^{\circ} \mathrm{C}$} & 0 & 2 & 3 & 6 & 9 & \\
\hline & $5,00 \pm 0,00$ & $4,80 \pm 0,45$ & $4,30 \pm 0,27$ & $3,80 \pm 0,45$ & $2,60 \pm 0,55$ & \\
\hline \multirow{2}{*}{$10^{\circ} \mathrm{C}$} & 0 & 3 & 6 & 9 & 15 & \\
\hline & $5,00 \pm 0,00$ & $4,20 \pm 0,45$ & $3,80 \pm 0,45$ & $3,40 \pm 0,42$ & $2,40 \pm 0,82$ & \\
\hline \multirow{2}{*}{$5^{\circ} \mathrm{C}$} & 0 & 3 & 9 & 15 & 21 & \\
\hline & $5,00 \pm 0,00$ & $5,00 \pm 0,00$ & $3,90 \pm 0,22$ & $3,40 \pm 0,22$ & $2,10 \pm 0,42$ & \\
\hline \multirow{2}{*}{$2^{\circ} \mathrm{C}$} & 0 & 3 & 9 & 15 & 21 & 29 \\
\hline & $5,00 \pm 0,00$ & $4,70 \pm 0,67$ & $4,20 \pm 0,57$ & $3,70 \pm 0,67$ & $3,50 \pm 0,50$ & $1,80 \pm 0,60$ \\
\hline \multicolumn{7}{|c|}{ Aceptabilidad global ROMANA (b) } \\
\hline \multirow{2}{*}{$20^{\circ} \mathrm{C}$} & 0 & 1 & 2 & 3 & 6 & \\
\hline & $5,00 \pm 0,00$ & $4,20 \pm 0,84$ & $4,20 \pm 0,84$ & $4,20 \pm 0,45$ & $3,20 \pm 0,27$ & \\
\hline \multirow{2}{*}{$15^{\circ} \mathrm{C}$} & 0 & 2 & 3 & 6 & 9 & \\
\hline & $5,00 \pm 0,00$ & $5,00 \pm 0,00$ & $4,40 \pm 0,55$ & $3,30 \pm 0,27$ & $3,20 \pm 0,27$ & \\
\hline \multirow{2}{*}{$10^{\circ} \mathrm{C}$} & 0 & 3 & 6 & 9 & 15 & \\
\hline & $5,00 \pm 0,00$ & $4,20 \pm 0,45$ & $4,30 \pm 0,67$ & $4,60 \pm 0,89$ & $2,00 \pm 0,61$ & \\
\hline \multirow{2}{*}{$5^{\circ} \mathrm{C}$} & 0 & 3 & 9 & 15 & 21 & \\
\hline & $5,00 \pm 0,00$ & $5,00 \pm 0,00$ & $4,60 \pm 0,42$ & $3,60 \pm 0,42$ & $2,60 \pm 0,42$ & \\
\hline \multirow{2}{*}{$2^{\circ} \mathrm{C}$} & 0 & 3 & 9 & 15 & 21 & 29 \\
\hline & $5,00 \pm 0,00$ & $4,80 \pm 0,27$ & $4,00 \pm 0,35$ & $3,40 \pm 0,65$ & $3,40 \pm 0,22$ & $1,30 \pm 0,40$ \\
\hline
\end{tabular}




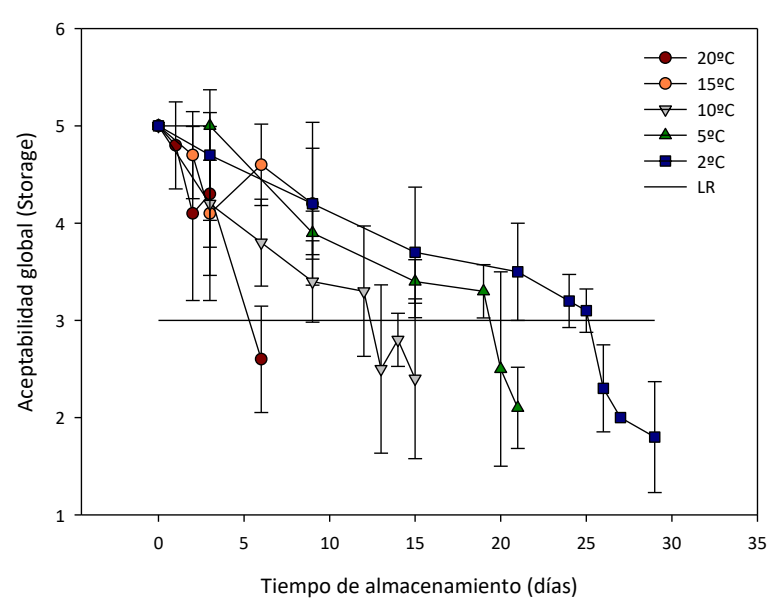

(a)

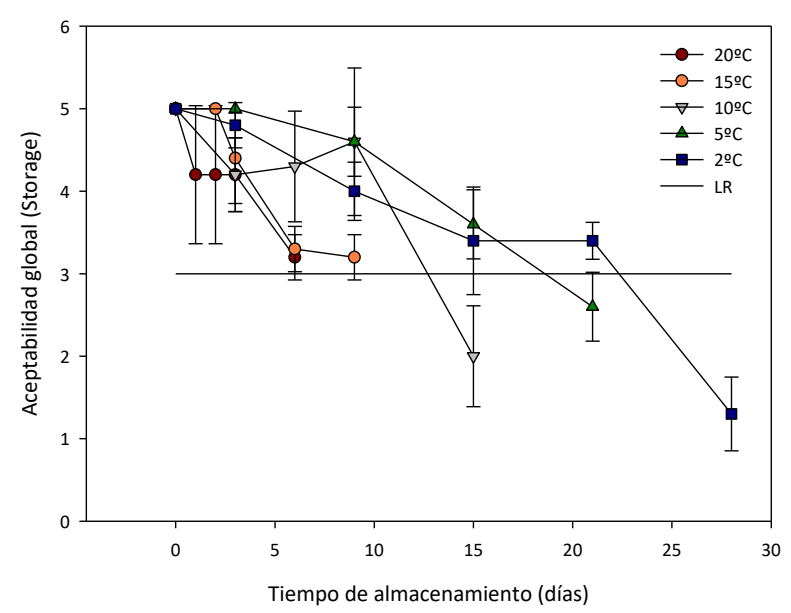

(b)

Se observa que para la temperatura de $2^{\circ} \mathrm{C}$ la lechuga Iceberg aguanta más días y existe una mayor linealidad y similitud en la evolución entre sus temperaturas. Si bien es cierto, en el caso de las Iceberg a $20^{\circ} \mathrm{C}$, su aceptación disminuye drásticamente a partir del tercer ensayo, mientras las Romanas descienden más paulatinamente sin patrón.

Tabla 17. Mediciones de olor por temperatura, día de ensayo y tipo de lechuga.

\begin{tabular}{|c|c|c|c|c|c|c|}
\hline \multicolumn{7}{|c|}{ "Olor ICEBERG (a) } \\
\hline \multirow{2}{*}{$20^{\circ} \mathrm{C}$} & 0 & 1 & 2 & 3 & 6 & \\
\hline & $5,00 \pm 0,00$ & $5,00 \pm 0,00$ & $5,00 \pm 0,00$ & $5,00 \pm 0,00$ & $3,20 \pm 0,45$ & \\
\hline \multirow{2}{*}{$15^{\circ} \mathrm{C}$} & 0 & 2 & 3 & 6 & 9 & \\
\hline & $5,00 \pm 0,00$ & $5,00 \pm 0,00$ & $5,00 \pm 0,00$ & $5,00 \pm 0,00$ & $4,20 \pm 0,84$ & \\
\hline \multirow{2}{*}{$10^{\circ} \mathrm{C}$} & 0 & 3 & 6 & 9 & 15 & \\
\hline & $5,00 \pm 0,00$ & $4,80 \pm 0,45$ & $5,00 \pm 0,00$ & $4,00 \pm 0,00$ & $2,00 \pm 1,00$ & \\
\hline \multirow{2}{*}{$5^{\circ} \mathrm{C}$} & 0 & 3 & 9 & 15 & 21 & \\
\hline & $5,00 \pm 0,00$ & $5,00 \pm 0,00$ & $4,80 \pm 0,45$ & $3,40 \pm 0,22$ & $1,00 \pm 0,00$ & \\
\hline \multirow{2}{*}{$2^{\circ} \mathrm{C}$} & 0 & 3 & 9 & 15 & 21 & 29 \\
\hline & $5,00 \pm 0,00$ & $5,00 \pm 0,00$ & $4,80 \pm 0,27$ & $3,70 \pm 0,27$ & $4,00 \pm 0,00$ & $1,80 \pm 0,76$ \\
\hline \multicolumn{7}{|c|}{ Olor ROMANA (b) } \\
\hline \multirow{2}{*}{$20^{\circ} \mathrm{C}$} & 0 & 1 & 2 & 3 & 6 & \\
\hline & $5,00 \pm 0,00$ & $5,00 \pm 0,00$ & $5,00 \pm 0,00$ & $5,00 \pm 0,00$ & $4,00 \pm 0,00$ & \\
\hline \multirow{2}{*}{$15^{\circ} \mathrm{C}$} & 0 & 2 & 3 & 6 & 9 & \\
\hline & $5,00 \pm 0,00$ & $5,00 \pm 0,00$ & $5,00 \pm 0,00$ & $4,50 \pm 0,00$ & $4,00 \pm 0,00$ & \\
\hline \multirow{2}{*}{$10^{\circ} \mathrm{C}$} & 0 & 3 & 6 & 9 & 15 & \\
\hline & $5,00 \pm 0,00$ & $5,00 \pm 0,00$ & $5,00 \pm 0,00$ & $4,40 \pm 0,55$ & $3,20 \pm 0,45$ & \\
\hline \multirow{2}{*}{$5^{\circ} \mathrm{C}$} & 0 & 3 & 9 & 15 & 21 & \\
\hline & $5,00 \pm 0,00$ & $5,00 \pm 0,00$ & $5,00 \pm 0,00$ & $4,00 \pm 0,00$ & $7,20 \pm 0,27$ & \\
\hline \multirow{2}{*}{$2^{\circ} \mathrm{C}$} & 0 & 3 & 9 & 15 & 21 & 29 \\
\hline & $5,00 \pm 0,00$ & $4,80 \pm 0,27$ & $5,00 \pm 0,00$ & $3,80 \pm 0,45$ & $4,00 \pm 0,00$ & $1,30 \pm 0,27$ \\
\hline
\end{tabular}




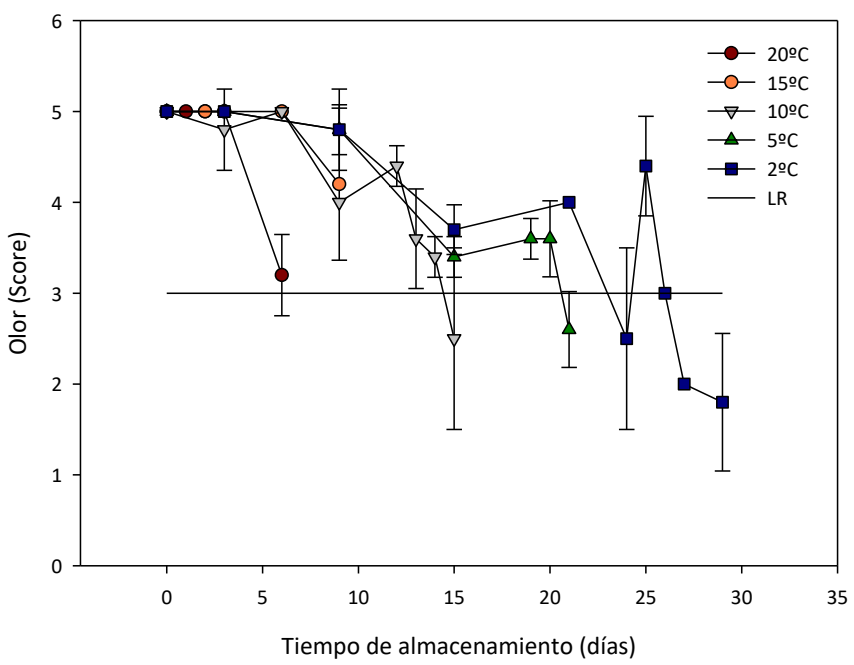

(a)

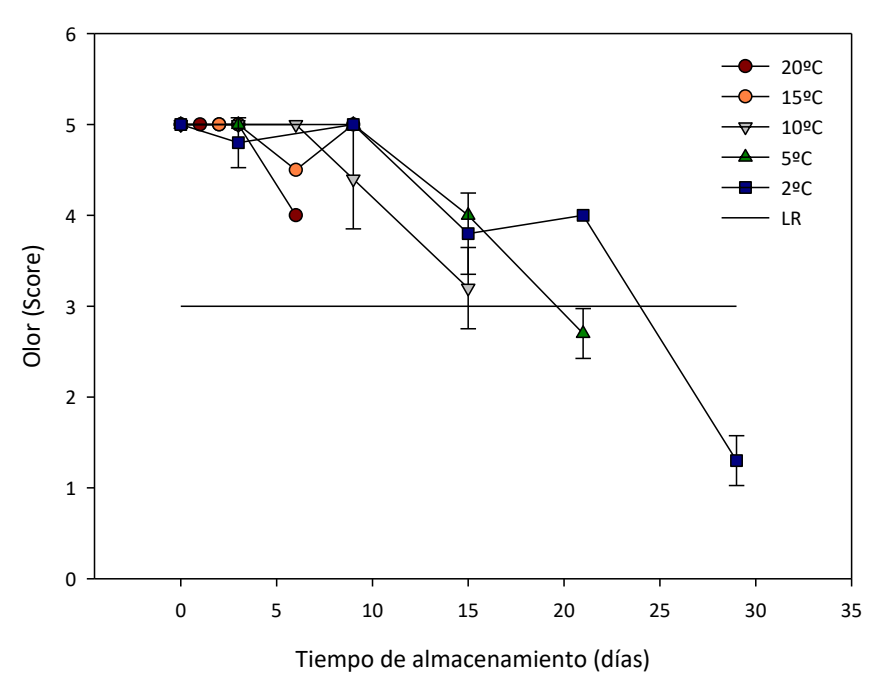

(b)

Tabla 18. Mediciones de daños mecánicos por temperatura, día de ensayo y tipo de lechuga.

\begin{tabular}{|c|c|c|c|c|c|c|}
\hline \multicolumn{7}{|c|}{ Daños por congelación ICEBERG (a) } \\
\hline \multirow{2}{*}{$20^{\circ} \mathrm{C}$} & 0 & 1 & 2 & 3 & 6 & \\
\hline & $5,00 \pm 0,00$ & $4,60 \pm 0,55$ & $5,00 \pm 0,00$ & $5,00 \pm 0,00$ & $5,00 \pm 0,00$ & \\
\hline \multirow{2}{*}{$15^{\circ} \mathrm{C}$} & 0 & 2 & 3 & 6 & 9 & \\
\hline & $5,00 \pm 0,00$ & $5,00 \pm 0,00$ & $5,00 \pm 0,00$ & $5,00 \pm 0,00$ & $5,00 \pm 0,00$ & \\
\hline \multirow{2}{*}{$10^{\circ} \mathrm{C}$} & 0 & 3 & 6 & 9 & 15 & \\
\hline & $5,00 \pm 0,00$ & $5,00 \pm 0,00$ & $5,00 \pm 0,00$ & $5,00 \pm 0,00$ & $5,00 \pm 0,00$ & \\
\hline \multirow{2}{*}{$5^{\circ} \mathrm{C}$} & 0 & 3 & 9 & 15 & 21 & \\
\hline & $5,00 \pm 0,00$ & $5,00 \pm 0,00$ & $5,00 \pm 0,00$ & $5,00 \pm 0,00$ & $5,00 \pm 0,00$ & \\
\hline \multirow{2}{*}{$2^{\circ} \mathrm{C}$} & 0 & 3 & 9 & 15 & 21 & 29 \\
\hline & $5,00 \pm 0,00$ & $5,00 \pm 0,00$ & $5,00 \pm 0,00$ & $5,00 \pm 0,00$ & $5,00 \pm 0,00$ & $5,00 \pm 0,00$ \\
\hline \multicolumn{7}{|c|}{ Daños por congelación ROMANA (b) } \\
\hline \multirow{2}{*}{$20^{\circ} \mathrm{C}$} & 0 & 1 & 2 & 3 & 6 & \\
\hline & $5,00 \pm 0,00$ & $5,00 \pm 0,00$ & $5,00 \pm 0,00$ & $5,00 \pm 0,00$ & $5,00 \pm 0,00$ & \\
\hline \multirow{2}{*}{$15^{\circ} \mathrm{C}$} & 0 & 2 & 3 & 6 & 9 & \\
\hline & $5,00 \pm 0,00$ & $5,00 \pm 0,00$ & $5,00 \pm 0,00$ & $5,00 \pm 0,00$ & $5,00 \pm 0,00$ & \\
\hline \multirow{2}{*}{$10^{\circ} \mathrm{C}$} & 0 & 3 & 6 & 9 & 15 & \\
\hline & $5,00 \pm 0,00$ & $5,00 \pm 0,00$ & $5,00 \pm 0,00$ & $5,00 \pm 0,00$ & $5,00 \pm 0,00$ & \\
\hline \multirow{2}{*}{$5^{\circ} \mathrm{C}$} & 0 & 3 & 9 & 15 & 21 & \\
\hline & $5,00 \pm 0,00$ & $5,00 \pm 0,00$ & $5,00 \pm 0,00$ & $5,00 \pm 0,00$ & $5,00 \pm 0,00$ & \\
\hline \multirow{2}{*}{$2^{\circ} \mathrm{C}$} & 0 & 3 & 9 & 15 & 21 & 29 \\
\hline & $5,00 \pm 0,00$ & $5,00 \pm 0,00$ & $5,00 \pm 0,00$ & $5,00 \pm 0,00$ & $5,00 \pm 0,00$ & $5,00 \pm 0,00$ \\
\hline
\end{tabular}




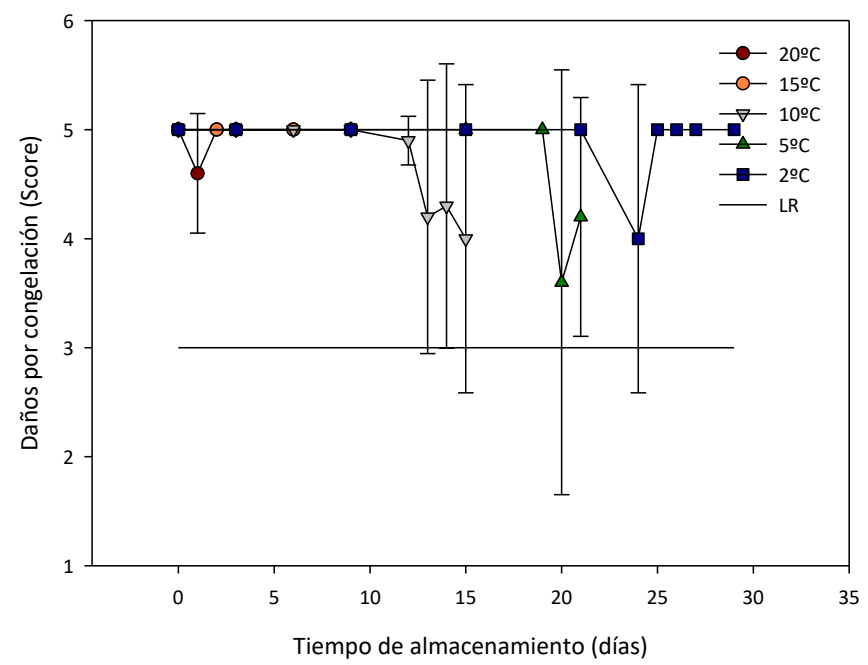

(a)

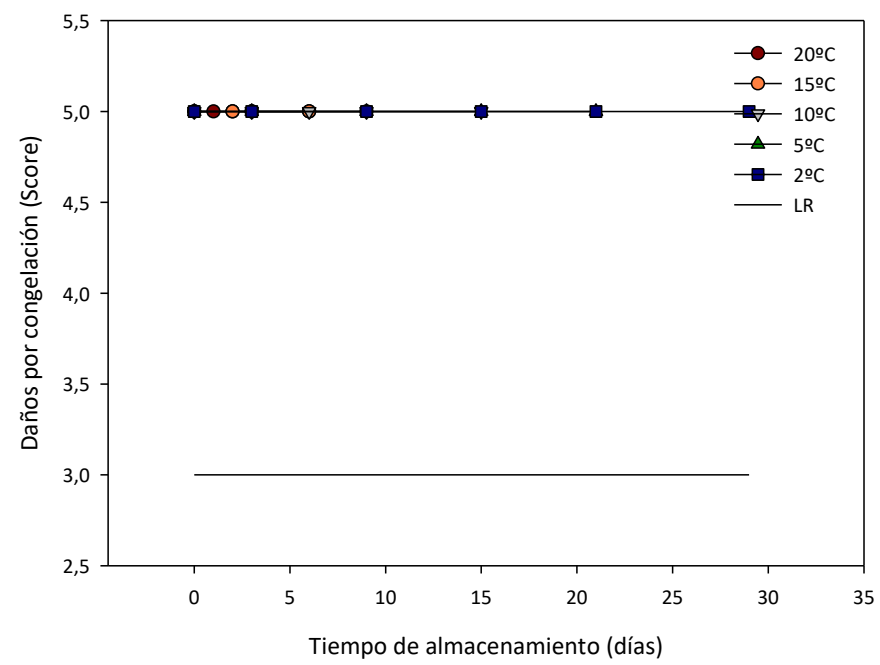

(b)

Los daños por congelación que se observaron fueron puntuales, indicando un buen proceso de preenfriamiento, así como de almacenamiento. En aquellos individuos que sí presentaban estos daños (en las lechugas Iceberg) esto aumentaba el proceso de podredumbre en las zonas afectadas.

Tabla 19. Mediciones de pardeamiento por temperatura, día de ensayo y tipo de lechuga.

\begin{tabular}{|c|c|c|c|c|c|c|}
\hline \multicolumn{7}{|c|}{ Pardeamiento ICEBERG (a) } \\
\hline \multirow{2}{*}{$20^{\circ} \mathrm{C}$} & 0 & 1 & 2 & 3 & 6 & \\
\hline & $5,00 \pm 0,00$ & $4,80 \pm 0,45$ & $5,00 \pm 0,00$ & $3,70 \pm 0,67$ & $3,00 \pm 0,00$ & \\
\hline \multirow{2}{*}{$15^{\circ} \mathrm{C}$} & 0 & 2 & 3 & 6 & 9 & \\
\hline & $5,00 \pm 0,00$ & $4,00 \pm 0,00$ & $4,00 \pm 0,00$ & $3,40 \pm 0,42$ & $2,20 \pm 0,45$ & \\
\hline \multirow{2}{*}{$10^{\circ} \mathrm{C}$} & 0 & 3 & 6 & 9 & 15 & \\
\hline & $5,00 \pm 0,00$ & $4,70 \pm 0,67$ & $3,20 \pm 0,27$ & $3,00 \pm 0,00$ & $2,80 \pm 0,45$ & \\
\hline \multirow{2}{*}{$5^{\circ} \mathrm{C}$} & 0 & 3 & 9 & 15 & 21 & \\
\hline & $5,00 \pm 0,00$ & $4,30 \pm 0,27$ & $3,90 \pm 0,22$ & $3,50 \pm 0,00$ & $3,50 \pm 0,00$ & \\
\hline \multirow{2}{*}{$2^{\circ} \mathrm{C}$} & 0 & 3 & 9 & 15 & 21 & 29 \\
\hline & $5,00 \pm 0,00$ & $3,30 \pm 1,57$ & $3,00 \pm 0,00$ & $3,40 \pm 0,22$ & $3,60 \pm 0,22$ & $1,20 \pm 0,27$ \\
\hline \multicolumn{7}{|c|}{ Pardeamiento ROMANA (b) } \\
\hline \multirow{2}{*}{$20^{\circ} \mathrm{C}$} & 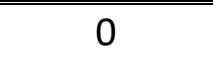 & 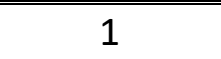 & 2 & 3 & 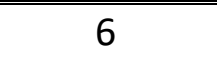 & \\
\hline & $5,00 \pm 0,00$ & $4,90 \pm 0,22$ & $4,40 \pm 0,42$ & $4,50 \pm 0,50$ & $2,60 \pm 0,55$ & \\
\hline \multirow{2}{*}{$15^{\circ} \mathrm{C}$} & 0 & 2 & 3 & 6 & 9 & \\
\hline & $5,00 \pm 0,00$ & $4,40 \pm 0,42$ & $4,40 \pm 0,22$ & $4,20 \pm 0,27$ & $4,00 \pm 0,35$ & \\
\hline \multirow{2}{*}{$10^{\circ} \mathrm{C}$} & 0 & 3 & 6 & 9 & 15 & \\
\hline & $5,00 \pm 0,00$ & $4,40 \pm 0,22$ & $4,20 \pm 0,57$ & $4,40 \pm 0,22$ & $4,40 \pm 0,22$ & \\
\hline \multirow{2}{*}{$5^{\circ} \mathrm{C}$} & 0 & 3 & 9 & 15 & 21 & \\
\hline & $5,00 \pm 0,00$ & $4,40 \pm 0,22$ & $4,30 \pm 0,27$ & $4,40 \pm 0,22$ & $2,80 \pm 0,57$ & \\
\hline \multirow{2}{*}{$2^{\circ} \mathrm{C}$} & 0 & 3 & 9 & 15 & 21 & 29 \\
\hline & $5,00 \pm 0,00$ & $4,20 \pm 0,57$ & $4,00 \pm 0,35$ & $3,00 \pm 0,00$ & $3,80 \pm 0,27$ & $1,70 \pm 0,57$ \\
\hline
\end{tabular}




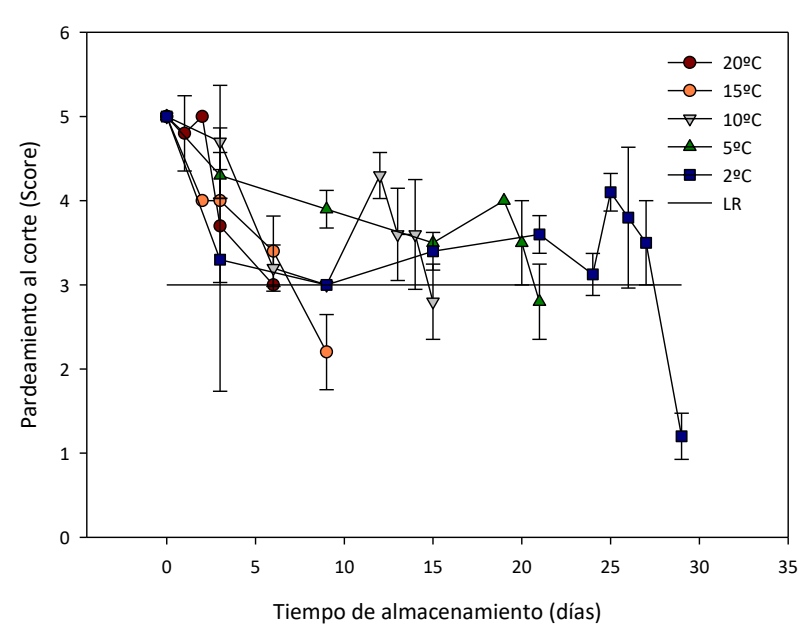

(a)

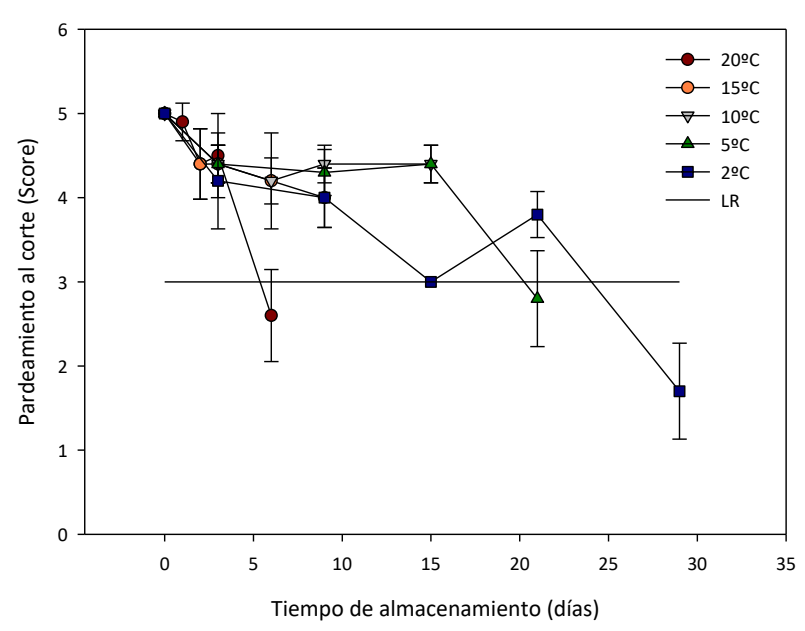

(b)

Para la temperatura de $20^{\circ} \mathrm{C}$ del sexto día de ensayo en las lechugas Romanas, se observó que los tallos se habían puesto oscuros y algunas zonas del interior estaban muy maduras y pardeadas. En el caso de las lechugas Iceberg, se hizo más notable el pardeamiento del tallo extendiéndose hacia el corazón de estas y produciendo así un mayor olor.

Tabla 20. Mediciones de Russet spotting por temperatura, día de ensayo y tipo de lechuga.

\begin{tabular}{|c|c|c|c|c|c|c|}
\hline \multicolumn{7}{|c|}{ Russet spotting ICEBERG (a) } \\
\hline \multirow{2}{*}{$20^{\circ} \mathrm{C}$} & 0 & 1 & 2 & 3 & 6 & \\
\hline & $5,00 \pm 0,00$ & $5,00 \pm 0,00$ & $4,80 \pm 0,45$ & $5,00 \pm 0,00$ & $5,00 \pm 0,00$ & \\
\hline \multirow{2}{*}{$15^{\circ} \mathrm{C}$} & 0 & 2 & 3 & 6 & 9 & \\
\hline & $5,00 \pm 0,00$ & $5,00 \pm 0,00$ & $5,00 \pm 0,00$ & $5,00 \pm 0,00$ & $5,00 \pm 0,00$ & \\
\hline \multirow{2}{*}{$10^{\circ} \mathrm{C}$} & 0 & 3 & 6 & 9 & 15 & \\
\hline & $5,00 \pm 0,00$ & $5,00 \pm 0,00$ & $5,00 \pm 0,00$ & $5,00 \pm 0,00$ & $5,00 \pm 0,00$ & \\
\hline \multirow{2}{*}{$5^{\circ} \mathrm{C}$} & 0 & 3 & 9 & 15 & 21 & \\
\hline & $5,00 \pm 0,00$ & $4,80 \pm 0,45$ & $5,00 \pm 0,00$ & $5,00 \pm 0,00$ & $5,00 \pm 0,00$ & \\
\hline \multirow{2}{*}{$2^{\circ} \mathrm{C}$} & 0 & 3 & 9 & 15 & 21 & 29 \\
\hline & $5,00 \pm 0,00$ & $4,70 \pm 0,45$ & $5,00 \pm 0,00$ & $5,00 \pm 0,00$ & $5,00 \pm 0,00$ & $5,00 \pm 0,00$ \\
\hline \multicolumn{7}{|c|}{ Russet spotting ROMANA (b) } \\
\hline \multirow{2}{*}{$20^{\circ} \mathrm{C}$} & 0 & 1 & 2 & 3 & 6 & \\
\hline & $5,00 \pm 0,00$ & $4,60 \pm 0,55$ & $4,60 \pm 0,55$ & $5,00 \pm 0,00$ & $5,00 \pm 0,00$ & \\
\hline \multirow{2}{*}{$15^{\circ} \mathrm{C}$} & 0 & 2 & 3 & 6 & 9 & \\
\hline & $5,00 \pm 0,00$ & $4,80 \pm 0,45$ & $5,00 \pm 0,00$ & $5,00 \pm 0,00$ & $4,90 \pm 0,22$ & \\
\hline \multirow{2}{*}{$10^{\circ} \mathrm{C}$} & 0 & 3 & 6 & 9 & 15 & \\
\hline & $5,00 \pm 0,00$ & $5,00 \pm 0,00$ & $5,00 \pm 0,00$ & $5,00 \pm 0,00$ & $5,00 \pm 0,00$ & \\
\hline \multirow{2}{*}{$5^{\circ} \mathrm{C}$} & 0 & 3 & 9 & 15 & 21 & \\
\hline & $5,00 \pm 0,00$ & $5,00 \pm 0,00$ & $5,00 \pm 0,00$ & $5,00 \pm 0,00$ & $4,90 \pm 0,20$ & \\
\hline \multirow{2}{*}{$2^{\circ} \mathrm{C}$} & 0 & 3 & 9 & 15 & 21 & 29 \\
\hline & $5,00 \pm 0,00$ & $4,50 \pm 0,50$ & $5,00 \pm 0,00$ & $5,00 \pm 0,00$ & $5,00 \pm 0,00$ & $2,80 \pm 1,10$ \\
\hline
\end{tabular}




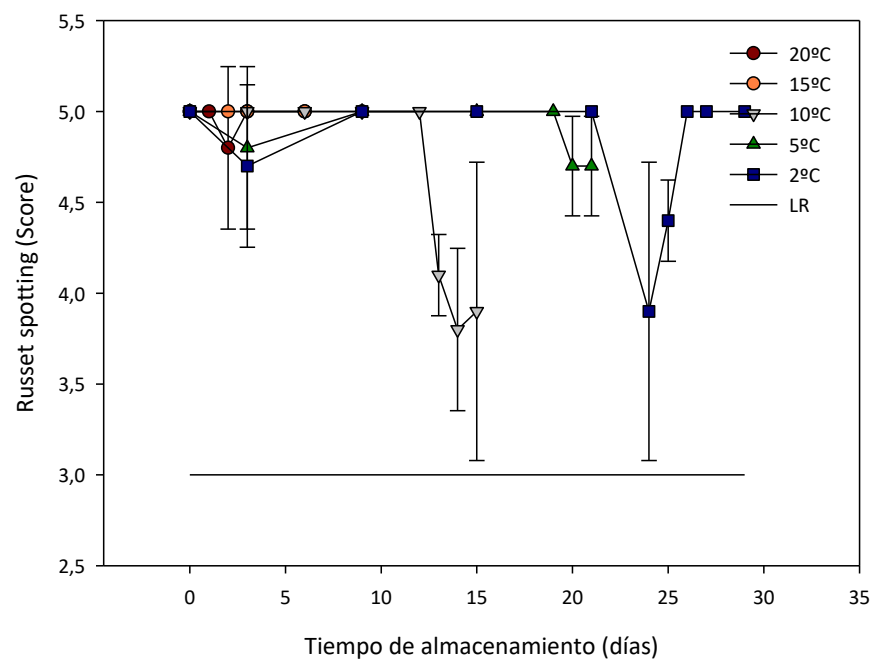

(a)

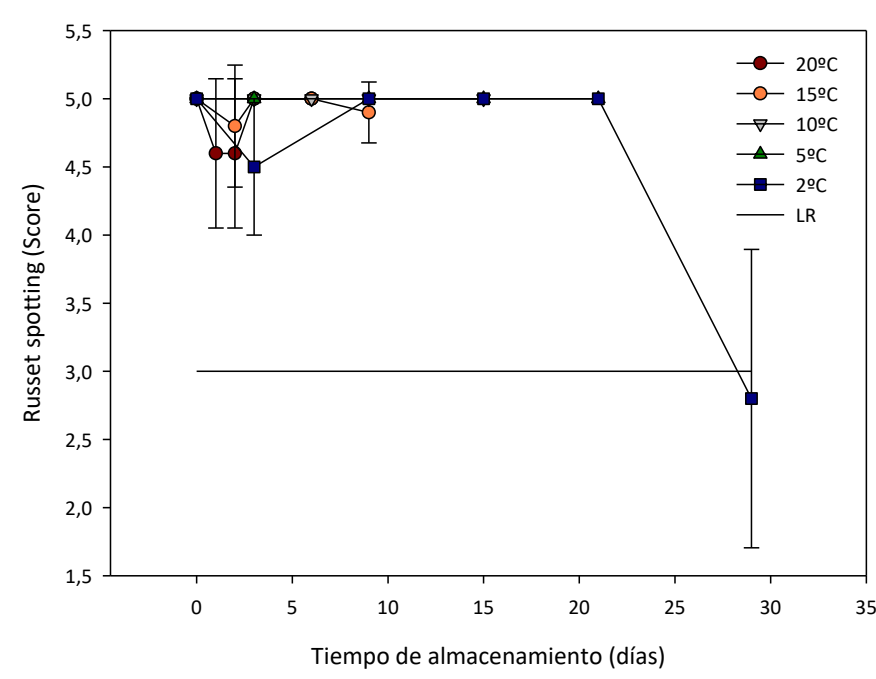

(b)

Este tipo de alteración también se mostró de forma puntual independientemente del tipo de lechuga y de su temperatura de almacenamiento.

Tabla 21. Mediciones de Pink ribs por temperatura, día de ensayo y tipo de lechuga.

\begin{tabular}{|c|c|c|c|c|c|c|}
\hline \multicolumn{7}{|c|}{ Pink ribs ICEBERG (a) } \\
\hline \multirow{2}{*}{$20^{\circ} \mathrm{C}$} & 0 & 1 & 2 & 3 & 6 & \\
\hline & $5,00 \pm 0,00$ & $5,00 \pm 0,00$ & $5,00 \pm 0,00$ & $5,00 \pm 0,00$ & $5,00 \pm 0,00$ & \\
\hline \multirow{2}{*}{$15^{\circ} \mathrm{C}$} & 0 & 2 & 3 & 6 & 9 & \\
\hline & $5,00 \pm 0,00$ & $5,00 \pm 0,00$ & $5,00 \pm 0,00$ & $5,00 \pm 0,00$ & $5,00 \pm 0,00$ & \\
\hline \multirow{2}{*}{$10^{\circ} \mathrm{C}$} & 0 & 3 & 6 & 9 & 15 & \\
\hline & $5,00 \pm 0,00$ & $5,00 \pm 0,00$ & $5,00 \pm 0,00$ & $5,00 \pm 0,00$ & $5,00 \pm 0,00$ & \\
\hline \multirow{2}{*}{$5^{\circ} \mathrm{C}$} & 0 & 3 & 9 & 15 & 21 & \\
\hline & $5,00 \pm 0,00$ & $5,00 \pm 0,00$ & $5,00 \pm 0,00$ & $5,00 \pm 0,00$ & $5,00 \pm 0,00$ & \\
\hline \multirow{2}{*}{$2^{\circ} \mathrm{C}$} & 0 & 3 & 9 & 15 & 21 & 29 \\
\hline & $5,00 \pm 0,00$ & $5,00 \pm 0,00$ & $5,00 \pm 0,00$ & $5,00 \pm 0,00$ & $5,00 \pm 0,00$ & $2,30 \pm 0,76$ \\
\hline \multicolumn{7}{|c|}{ Pink ribs ROMANA (b) } \\
\hline \multirow{2}{*}{$20^{\circ} \mathrm{C}$} & 0 & 1 & 2 & 3 & 6 & \\
\hline & $5,00 \pm 0,00$ & $5,00 \pm 0,00$ & $5,00 \pm 0,00$ & $5,00 \pm 0,00$ & $5,00 \pm 0,00$ & \\
\hline \multirow{2}{*}{$15^{\circ} \mathrm{C}$} & 0 & 2 & 3 & 6 & 9 & \\
\hline & $5,00 \pm 0,00$ & $5,00 \pm 0,00$ & $5,00 \pm 0,00$ & $5,00 \pm 0,00$ & $4,90 \pm 0,22$ & \\
\hline \multirow{2}{*}{$10^{\circ} \mathrm{C}$} & 0 & 3 & 6 & 9 & 15 & \\
\hline & $5,00 \pm 0,00$ & $5,00 \pm 0,00$ & $5,00 \pm 0,00$ & $5,00 \pm 0,00$ & $5,00 \pm 0,00$ & \\
\hline \multirow{2}{*}{$5^{\circ} \mathrm{C}$} & 0 & 3 & 9 & 15 & 21 & \\
\hline & $5,00 \pm 0,00$ & $5,00 \pm 0,00$ & $5,00 \pm 0,00$ & $5,00 \pm 0,00$ & $4,90 \pm 0,22$ & \\
\hline \multirow{2}{*}{$2^{\circ} \mathrm{C}$} & 0 & 3 & 9 & 15 & 21 & 29 \\
\hline & $5,00 \pm 0,00$ & $4,50 \pm 0,50$ & $5,00 \pm 0,00$ & $5,00 \pm 0,00$ & $5,00 \pm 0,00$ & $2,40 \pm 1,52$ \\
\hline
\end{tabular}




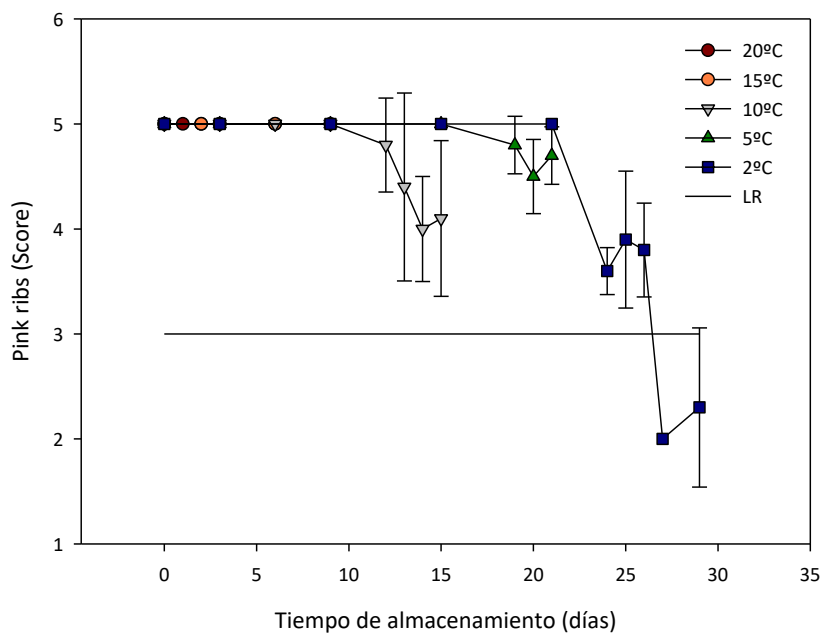

(a)

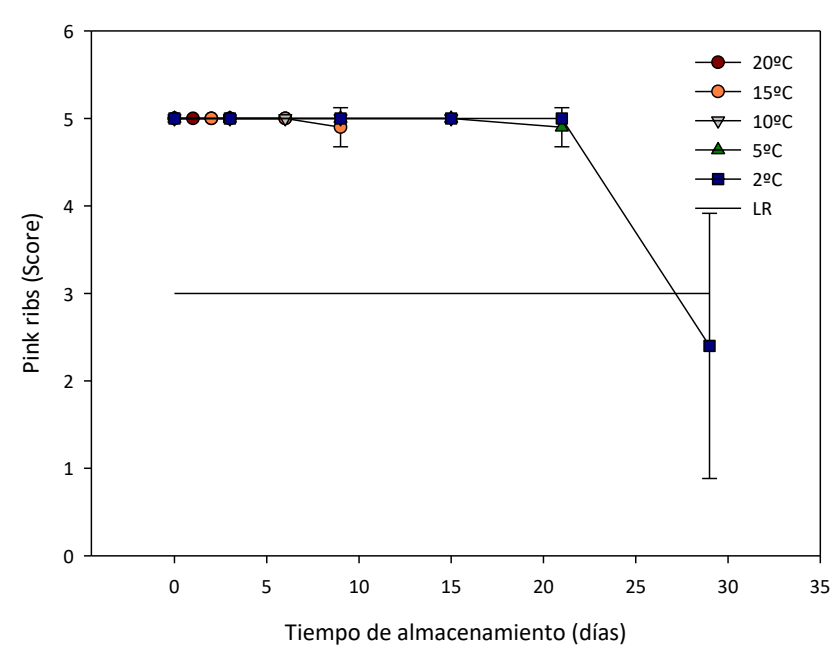

(b)

En este tipo de alteración en el caso de las lechugas Iceberg se observa una evolución aumentando su presencia para las temperaturas de 105 y $2^{\circ} \mathrm{C}$ en los últimos días de los ensayos, lo que se interpreta como pérdida de calidad por su influencia en la maduración de los individuos. En el caso de la lechuga Romana, dichas alteraciones solo son representativas en el último día de conservación de la lechuga a $2^{\circ} \mathrm{C}$.

Tabla 22. Mediciones de daños mecánicos por temperatura, día de ensayo y tipo de lechuga.

\begin{tabular}{|c|c|c|c|c|c|c|}
\hline \multicolumn{7}{|c|}{ Daño mecánico ICEBERG (a) } \\
\hline \multirow{2}{*}{$20^{\circ} \mathrm{C}$} & 0 & 1 & 2 & 3 & 6 & \\
\hline & $5,00 \pm 0,00$ & $5,00 \pm 0,00$ & $4,80 \pm 0,45$ & $4,80 \pm 0,45$ & $3,60 \pm 0,00$ & \\
\hline \multirow{2}{*}{$15^{\circ} \mathrm{C}$} & 0 & 2 & 3 & 6 & 9 & \\
\hline & $5,00 \pm 0,00$ & $4,40 \pm 0,55$ & $4,50 \pm 0,71$ & $3,60 \pm 0,55$ & $2,80 \pm 0,84$ & \\
\hline \multirow{2}{*}{$10^{\circ} \mathrm{C}$} & 0 & 3 & 6 & 9 & 15 & \\
\hline & $5,00 \pm 0,00$ & $5,00 \pm 0,00$ & $3,80 \pm 0,27$ & $4,51 \pm 0,35$ & $4,10 \pm 0,82$ & \\
\hline \multirow{2}{*}{$5^{\circ} \mathrm{C}$} & 0 & 3 & 9 & 15 & 21 & \\
\hline & $5,00 \pm 0,00$ & $4,80 \pm 0,45$ & $4,80 \pm 0,45$ & $4,40 \pm 0,55$ & $4,50 \pm 0,50$ & \\
\hline \multirow{2}{*}{$2^{\circ} \mathrm{C}$} & 0 & 3 & 9 & 15 & 21 & 29 \\
\hline & $5,00 \pm 0,00$ & $4,60 \pm 0,55$ & $4,90 \pm 0,22$ & $4,00 \pm 0,00$ & $4,30 \pm 0,27$ & $2,00 \pm 0,61$ \\
\hline \multicolumn{7}{|c|}{ Daño mecánico ROMANA (b) } \\
\hline \multirow{2}{*}{$20^{\circ} \mathrm{C}$} & 0 & 1 & 2 & 3 & 6 & \\
\hline & $5,00 \pm 0,00$ & $5,00 \pm 0,00$ & $5,00 \pm 0,00$ & $4,90 \pm 0,22$ & $4,50 \pm 0,50$ & \\
\hline \multirow{2}{*}{$15^{\circ} \mathrm{C}$} & 0 & 2 & 3 & 6 & 9 & \\
\hline & $5,00 \pm 0,00$ & $5,00 \pm 0,00$ & $5,00 \pm 0,00$ & $5,00 \pm 0,00$ & $5,00 \pm 0,00$ & \\
\hline \multirow{2}{*}{$10^{\circ} \mathrm{C}$} & 0 & 3 & 6 & 9 & 15 & \\
\hline & $5,00 \pm 0,00$ & $4,90 \pm 0,22$ & $4,80 \pm 0,45$ & $4,90 \pm 0,22$ & $5,00 \pm 0,00$ & \\
\hline \multirow{2}{*}{$5^{\circ} \mathrm{C}$} & 0 & 3 & 9 & 15 & 21 & \\
\hline & $5,00 \pm 0,00$ & $5,00 \pm 0,00$ & $5,00 \pm 0,00$ & $5,00 \pm 0,00$ & $4,20 \pm 0,84$ & \\
\hline \multirow{2}{*}{$2^{\circ} \mathrm{C}$} & 0 & 3 & 9 & 15 & 21 & 29 \\
\hline & $5,00 \pm 0,00$ & $4,50 \pm 0,50$ & $5,00 \pm 0,00$ & $4,80 \pm 0,45$ & $4,70 \pm 0,27$ & $1,80 \pm 1,10$ \\
\hline
\end{tabular}




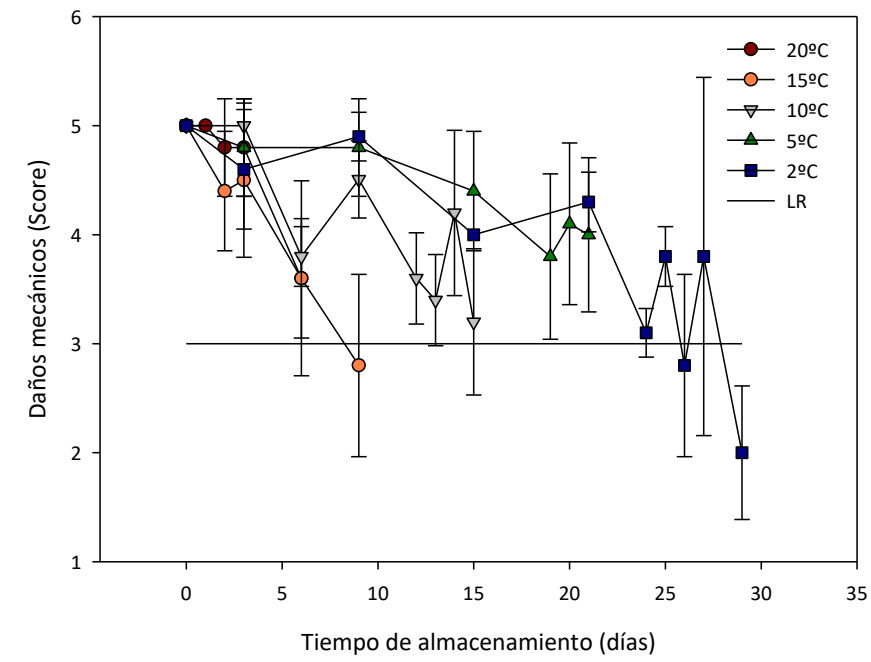

(a)

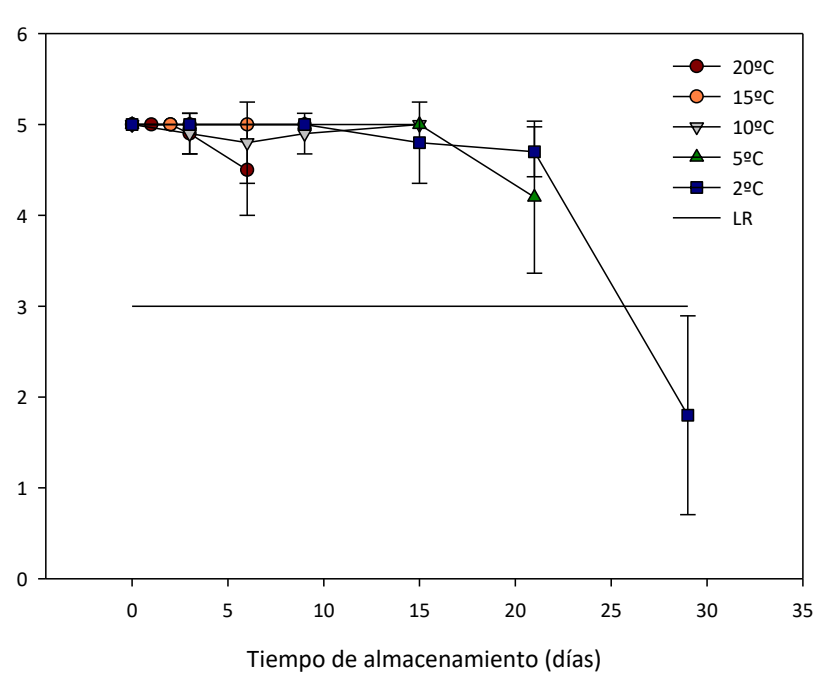

(b)

El daño mecánico se produce durante los procesos de recogida, limpieza de las hojas exteriores, embalaje y transporte, por lo que tiene una mayor presencia en ambos tipos de lechuga, aunque mayor en el caso de la Iceberg. Este tipo de lesiones sobre las hojas, nervios y tallos hacen que la lechuga madure más rápidamente en las zonas en las que posee dicho daño. Un ejemplo de ello es un individuo que estando a $20^{\circ} \mathrm{C}$ en el sexto día de ensayo presentó en la zona de daño mecánico una maduración de la pieza más rápida que se vio reflejada en un reblandecimiento de dicha zona llegando a mostrar podredumbre. Lo mismo ocurrió en otros individuos en las correspondientes temperaturas.

Los parámetros de calidad se vieron influenciados negativamente por los aumentos de temperatura. La calidad general de las cabezas de las lechugas estaba por encima del límite de vida útil, excepto el último día de almacenamiento para cada temperatura. Sin embargo, en dicho día las cabezas de las lechugas parecían estar en buenas condiciones para ser consumidas, pero no para ser comercializadas y vendidas a un consumidor que todavía necesitaría entre 4 y 5 días para comerlas.

La evolución del aspecto global de las lechugas se muestra a continuación (Figura 75 y 76) en función de sus temperaturas de almacenamiento y el último día de ensayo realizado. Se puede observar en el caso de las lechugas Iceberg como las hojas comienzan a amarillear e incluso se muestran marrones en las puntas. Este ligero marchitamiento de las hojas externas, debido a una mayor exposición a factores ambientales que facilitan su deterioro, no se observa en la zona interna y su apariencia visual se conserva mejor (Agüero et al., 2008). Más difícil de ver es el nivel de deshidratación de ambos tipos de lechugas, pero que se hizo latente conforme pasaban los días durante el ensayo. 


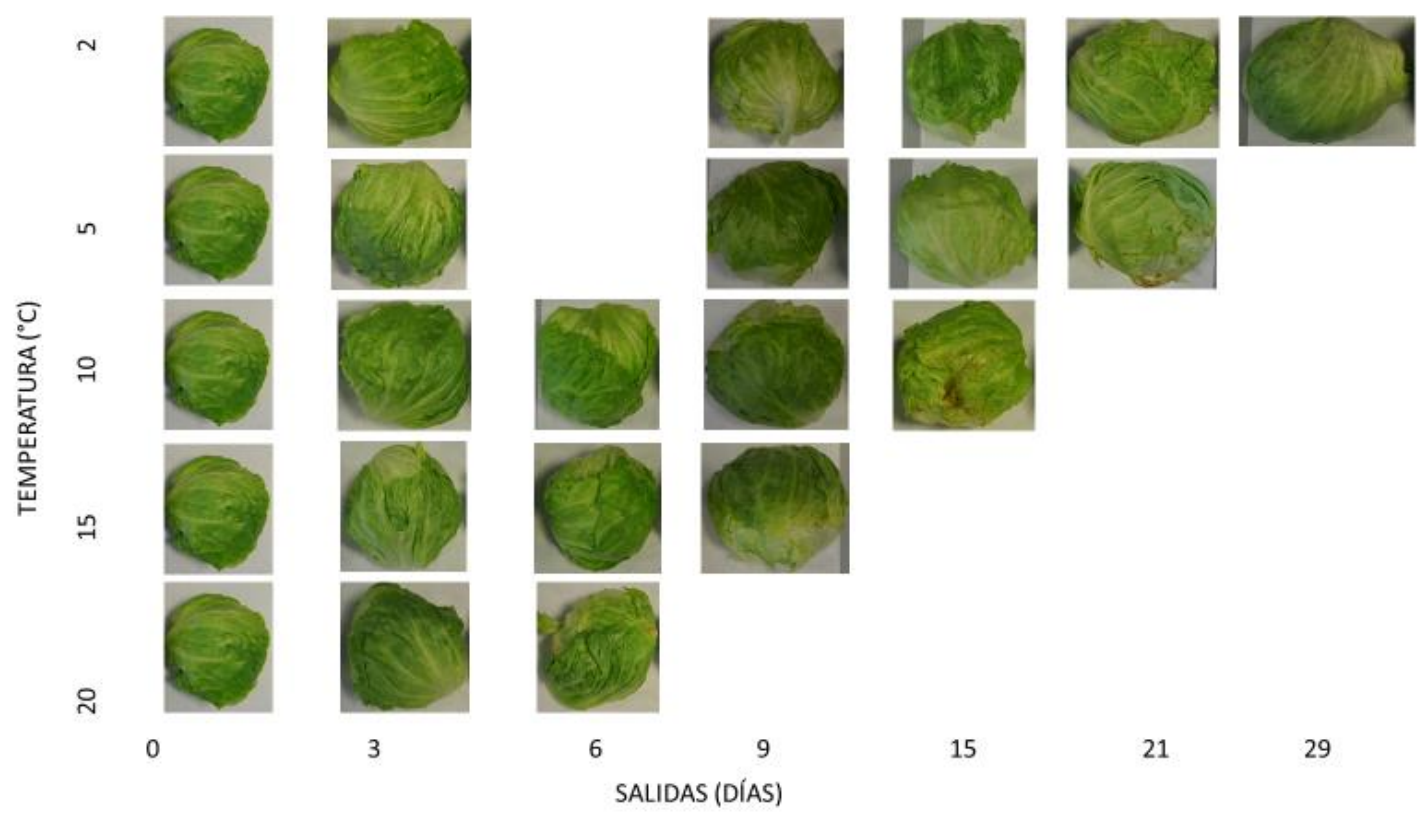

Figura 76. Evolución de las lechugas tipo Iceberg en cada salida (día de ensayo) y temperatura.

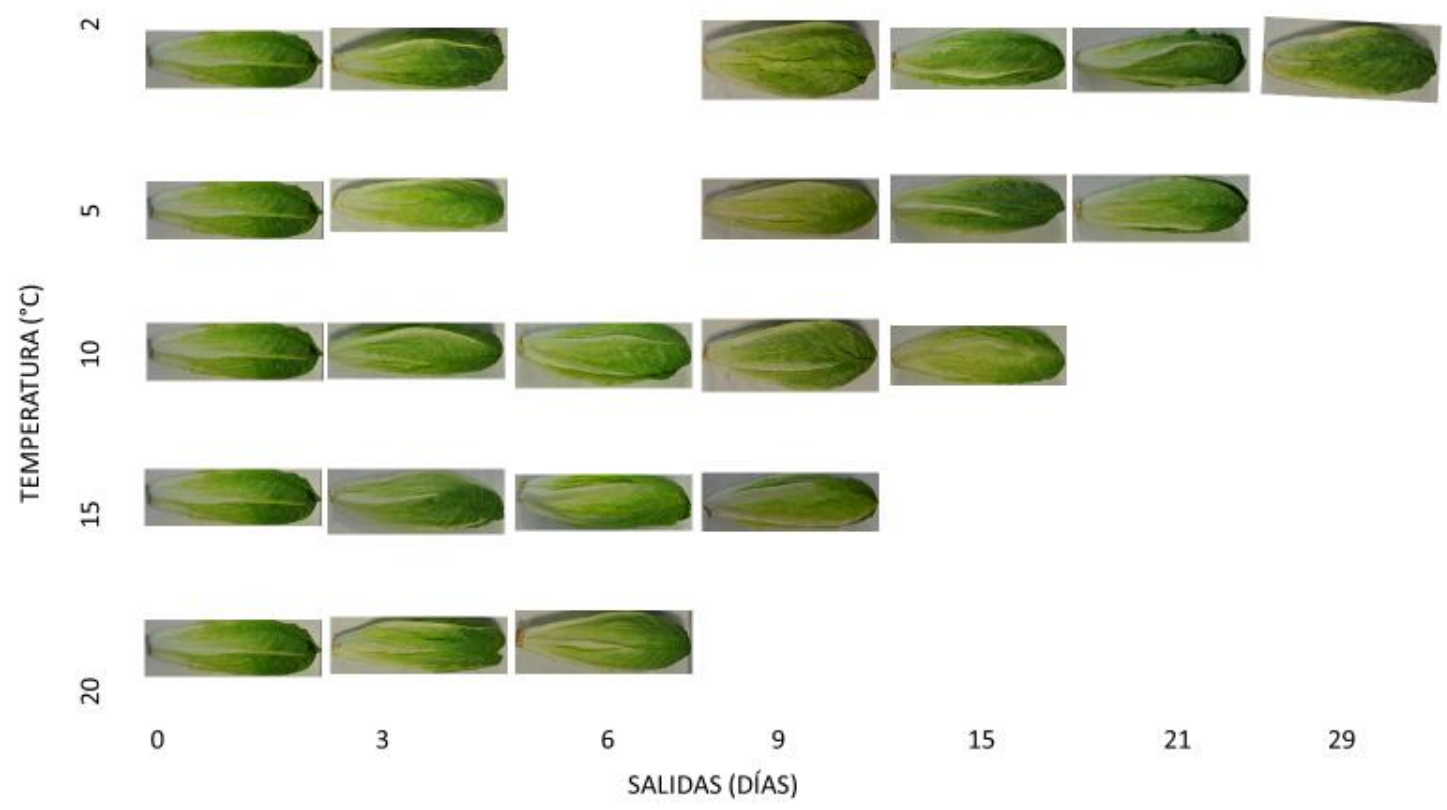

Figura 77. Evolución de las lechugas tipo Romana en cada salida (día de ensayo) y temperatura.

La aceptabilidad global se muestra como el parámetro que relaciona el resto de las características estudiadas y que ofrece gracias a las pruebas realizadas una estimación del último día en el cual la calidad de las lechugas para su comercialización es como mínimo de 3, en la escala de puntuación establecida (score) (Tabla 23). 
Tabla 23. Vida comercial en función de las temperaturas de almacenamiento de ambos tipos de lechugas (Score 3).

\begin{tabular}{ccc}
\hline \hline Ta $\left({ }^{\circ} \mathrm{C}\right)$ & Vida comercial Iceberg (días) & $\begin{array}{c}\text { Vida comercial } \\
\text { Romana (días) }\end{array}$ \\
\hline \hline $20^{\circ} \mathrm{C}$ & 5 & 6 \\
\hline $15^{\circ} \mathrm{C}$ & 8 & 9 \\
\hline $10^{\circ} \mathrm{C}$ & 12 & 9 \\
\hline $5^{\circ} \mathrm{C}$ & 19 & 15 \\
\hline $2{ }^{\circ} \mathrm{C}$ & 25 & 21 \\
\hline \hline
\end{tabular}

Durante la realización de los ensayos, se registraron las temperaturas de las cámaras frigoríficas para estudiar su evolución y estabilidad en el tiempo (Tabla 24). Para ello se introdujo un sensor por cámara e individuo. Dicho individuo se escogió para realizarle las pruebas fisicoquímicas su último día de ensayo.

Tabla 24. Temperaturas y desviaciones promedio

\begin{tabular}{ccc}
\hline \hline $\begin{array}{c}\text { Ta teórica } \\
\left({ }^{\circ} \mathrm{C}\right)\end{array}$ & $\begin{array}{c}\text { Ta promedio } \\
\left({ }^{\circ} \mathrm{C}\right)\end{array}$ & $\begin{array}{c}\text { SD promedio } \\
\left({ }^{\circ} \mathrm{C}\right)\end{array}$ \\
\hline \hline $10^{\circ} \mathrm{C}$ & 10,464 & 0,257 \\
\hline $5^{\circ} \mathrm{C}$ & 4,971 & 0,350 \\
\hline $2^{\circ} \mathrm{C}$ & 2,484 & 0,278 \\
\hline \hline
\end{tabular}

La Figura 78 a-c muestran un período de medición de cuatro días en el interior de las cámaras de 2,5 y $10^{\circ} \mathrm{C}$, respectivamente. Dichas tendencias se repiten durante los posteriores días de medición y excepto para la temperatura de $2^{\circ} \mathrm{C}$ que muestra un pico de temperatura cada 8 horas que no representa una gran desviación, y que se mantiene estable a aproximadamente $2,5^{\circ} \mathrm{C}$. Ocurre lo mismo para la cámara a $10^{\circ} \mathrm{C}$ la cual se encuentra medio grado por encima de la temperatura teórica. En cuanto a la cámara de $5^{\circ} \mathrm{C}$ presenta una mayor desviación aun sin ser significativa, siendo la cámara que más se ajusta a la temperatura teórica. Las diferencias entre las mediciones realizadas en las temperaturas de 15 y $20^{\circ} \mathrm{C}$ en cuanto a la frecuencia de medición y al tiempo, hacen que no se puedan comparar con estas tres además de ser temperaturas que no se alcanzan durante el transporte de las lechugas. 


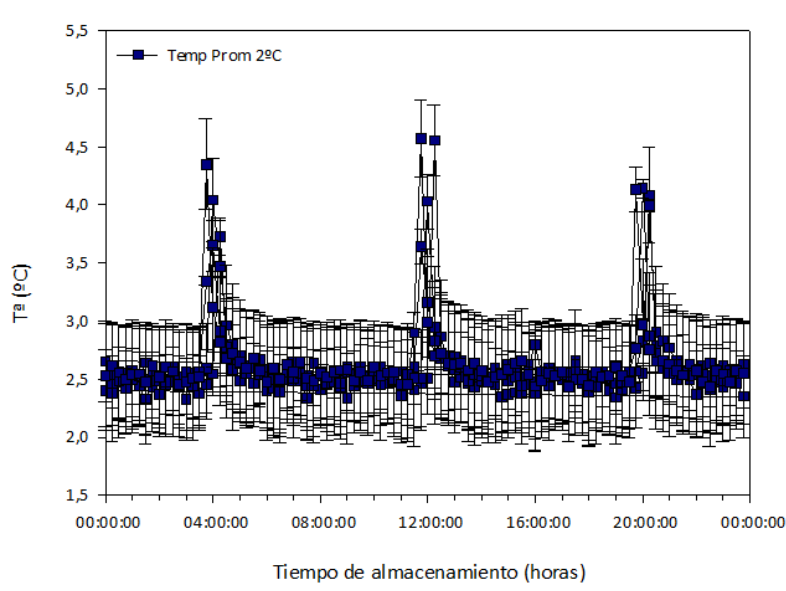

(a)

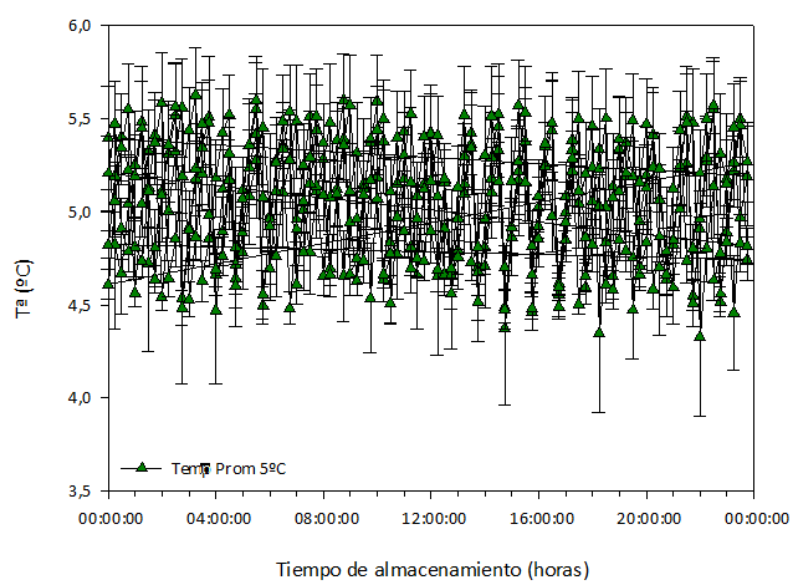

(b)

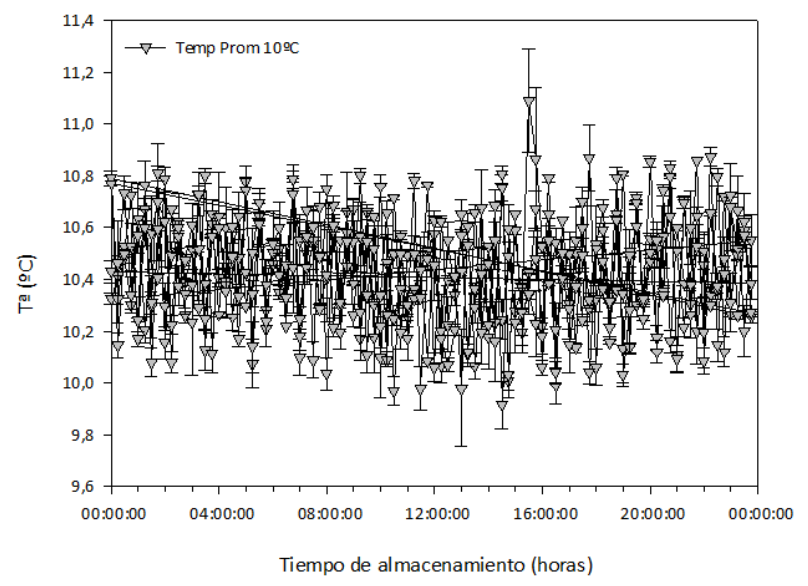

(c)

Figura 78. Historial tiempo temperatura en las tres cámaras.

\subsection{RESULTADOS DE LAS MEDIDAS CON EL SISTEMA DE MONITORIZACION}

Durante los días de viaje, los nodos estuvieron registrando y enviando datos en intervalos de quince minutos, mediante los cuales se pudo estudiar tanto la variación de temperatura registrada de modo individual como entre ellos a lo largo del contenedor del camión. También se determinaron las variaciones con respecto al set-point causadas o bien por la refrigeración y el sistema anti-escarcha o sistema libre de heladas del contenedor, o incluso debido a la distribución de los productos dentro del contenedor (Deza-Durand y Petersen, 2011) (Tabla 25). 
RESULTADOS

Tabla 25. Estudio de las temperaturas en los viajes más representativos.

\begin{tabular}{|c|c|c|c|c|c|}
\hline Destino & $\begin{array}{c}\text { Duración } \\
\text { (días) }\end{array}$ & $\begin{array}{c}\text { Set-point } \\
\left({ }^{\circ} \mathrm{C}\right)\end{array}$ & $\begin{array}{c}\Delta \mathrm{T}^{\mathrm{a}}{ }^{\circ} \mathrm{C} \\
(\max -\min )\end{array}$ & $\begin{array}{c}\text { Tá Media } \\
\left({ }^{\circ} \mathrm{C}\right)\end{array}$ & $\begin{array}{c}\text { Área sobre } \\
\text { set-point }\end{array}$ \\
\hline Alemania & 3 & 4 & 8,2 & 4,4 & 22,7 \\
\hline Países Bajos & 3 & 4 & 6,4 & 4,5 & 28,7 \\
\hline Reino Unido & 4 & 5 & 9,7 & 5,5 & 11,3 \\
\hline Bélgica & 3 & 7 & 7 & 7,1 & 14,9 \\
\hline Alemania & 3 & 4 & 5 & 4,1 & 18,6 \\
\hline Dummy 1 & 4 & 5 & 7,6 & 7,2 & 171,3 \\
\hline Dummy 2 & 4 & 5 & 12,5 & 5,1 & 36,8 \\
\hline Dummy 3 & 5 & 5 & 10,6 & 5,1 & 55,7 \\
\hline Dummy 4 & 5 & 10 & 1,7 & 10,5 & 9,5 \\
\hline Dummy 5 & 5 & 5 & 1,8 & 5 & 3,6 \\
\hline Dummy 6 & 5 & 2,5 & 2,4 & 2,5 & 4,2 \\
\hline
\end{tabular}

La Figura 79 ilustra los datos ambientales registrados para los cuatro primeros viajes terrestres, indicando el set-point mediante la línea roja horizontal. Se observa la variación de temperatura causada por el sistema No Frost del contenedor. En estos casos, las diferencias de temperaturas alcanzadas, así como su evolución y homogeneidad no depende de la distribución de los nodos, puesto que todos se encontraban en la misma posición. Aun así, se observan diferencias entre los viajes.

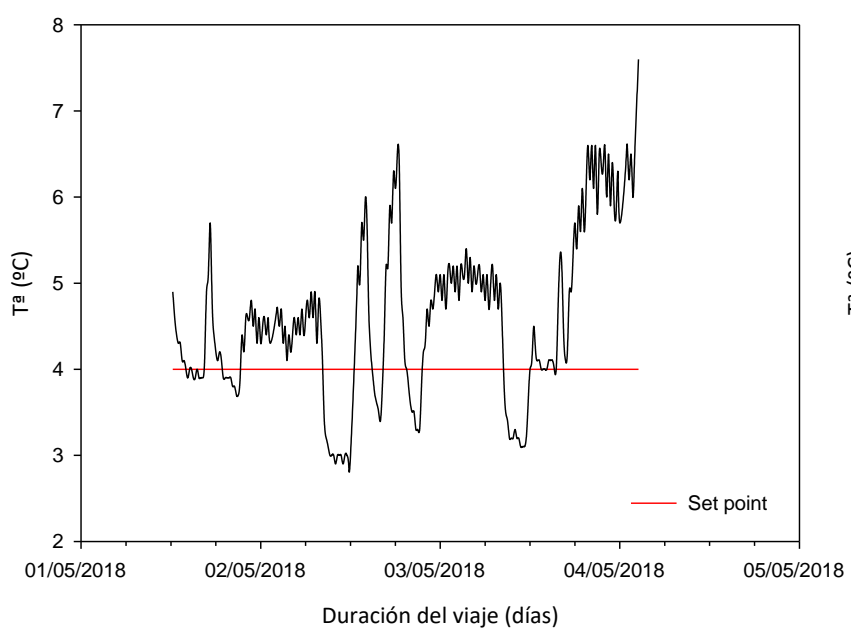

(a)

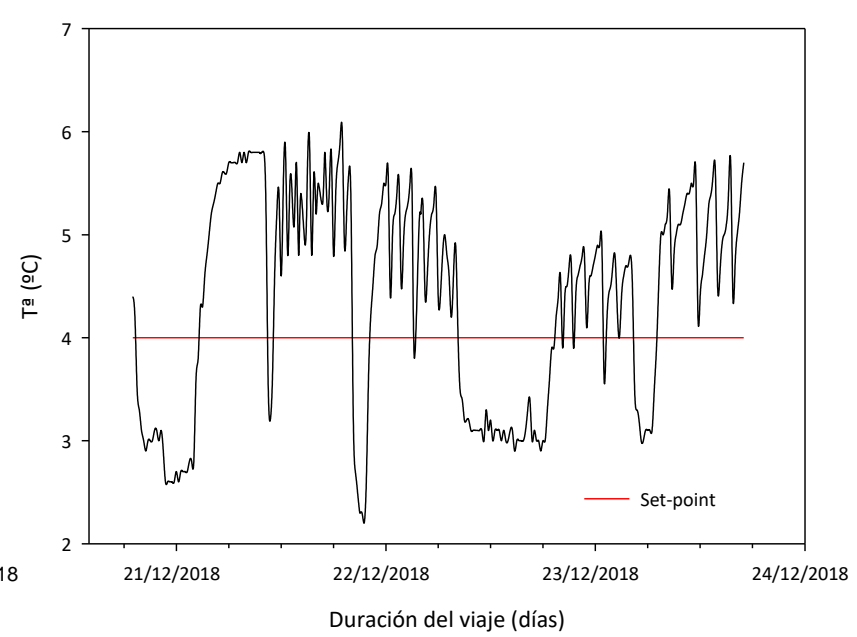

(b) 


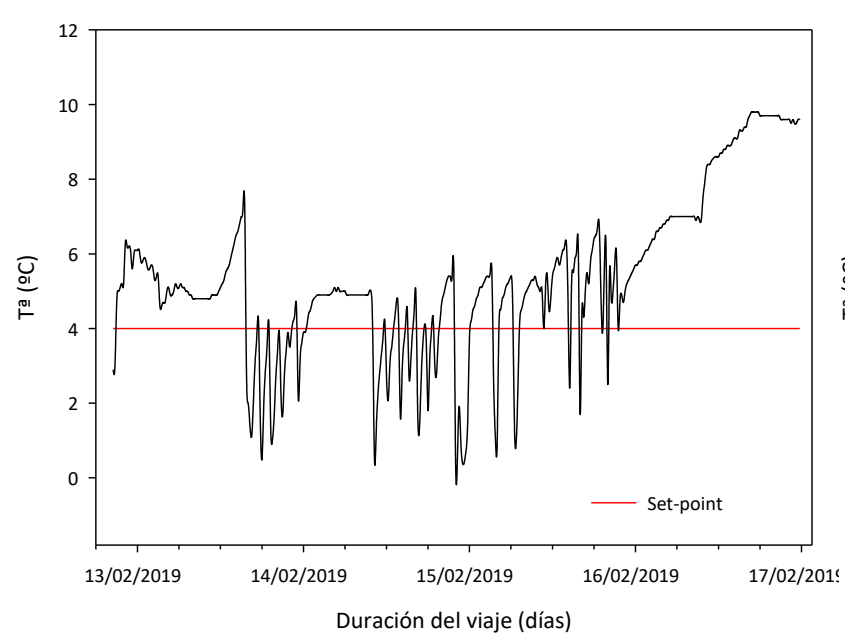

(c)

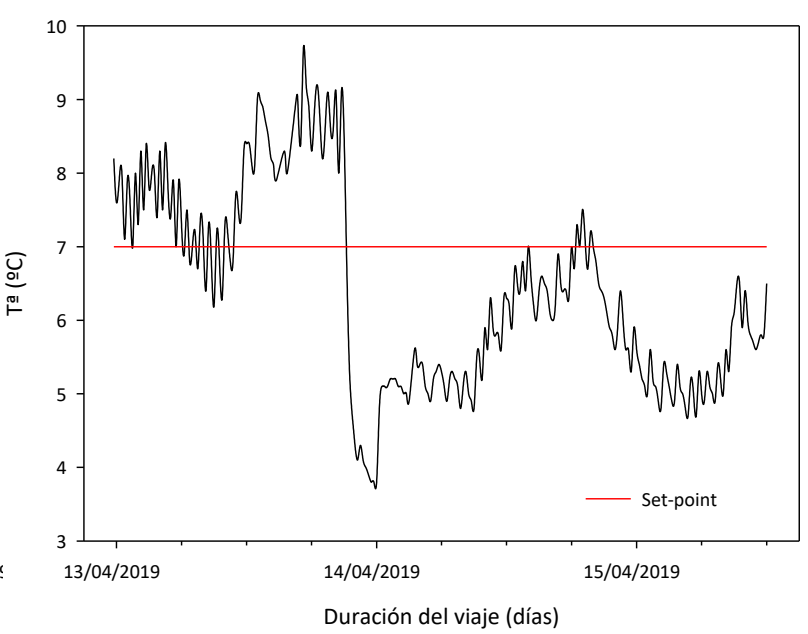

(d)

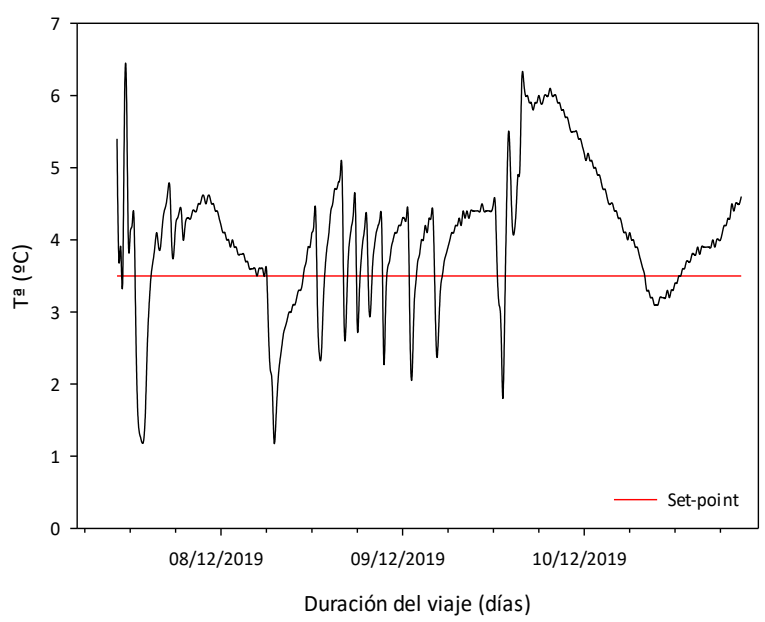

(e)

Figura 79. Temperaturas registradas en tiempo real para (a) Alemania, (b) Países Bajos, (c) Reino Unido, (d) Bélgica y (e) Alemania. La línea horizontal es la temperatura de consigna o set-point.

La Figura 79 (a) muestra un viaje de tres días con una temperatura de punto de consigna de $4^{\circ} \mathrm{C}$, como la Figura 79 (b), pero con una fluctuación de temperatura mayor para un mayor rango de temperaturas entre $2,9^{\circ} \mathrm{C}$ y $7,6^{\circ} \mathrm{C}$, mientras que en la Figura 8 (b) incluso con el sistema libre de heladas hay diferencias de temperatura de hasta $3,8^{\circ} \mathrm{C}$.

La Figura 79 (c) muestra menos diferencia de temperatura hasta que el contenedor comienza a calentarse, pero está por debajo de la temperatura de punto de ajuste durante un período de tiempo mayor que para los otros viajes. La variación que se muestra en la Figura 79 (d) es la más significativa en comparación con las otras, donde el pico en el gráfico puede corresponder a una temperatura de almacenamiento ajustada, o simplemente al sistema libre de heladas que causa una caída de temperatura de $3,2^{\circ} \mathrm{C}$ desde la temperatura de consigna de $7^{\circ} \mathrm{C}$. La Figura 79 (e) muestra mayor homogeneidad pese a tener dos picos inferiores de aproximadamente $1,5^{\circ} \mathrm{C}$ y otros dos que superan $\operatorname{los} 6^{\circ} \mathrm{C}$. 
De la comparación de las gráficas, se observa que mientras el sistema libre de heladas no funciona, muestran pequeñas fluctuaciones que no son relevantes para la calidad de los productos ya que la inercia térmica de los mismos "absorbe" dichas variaciones.

Por otro lado, se pueden relacionar para cada uno de los viajes, las mediciones multipunto realizadas por el Gateway y los nodos Slave ubicados en los diferentes puntos del remolque del camión. Aunque se han realizado quince monitorizaciones de transporte (cuatro de la versión 1 y once de la versión 2), se analizan los cinco más representativos con monitorización multipunto (en varias ubicaciones del mismo transporte) sino por el resto de los nodos colocados en el sistema antirretorno y en la puerta de acceso al contenedor.

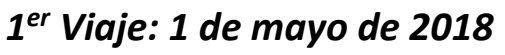

En este primer viaje, se colocaron los nodos a lo largo del contenedor, situando el Gateway en el techo a la mitad de la longitud del contenedor y los otros nodos en el retorno y la parte posterior de la carga (puerta) (Figura 80).
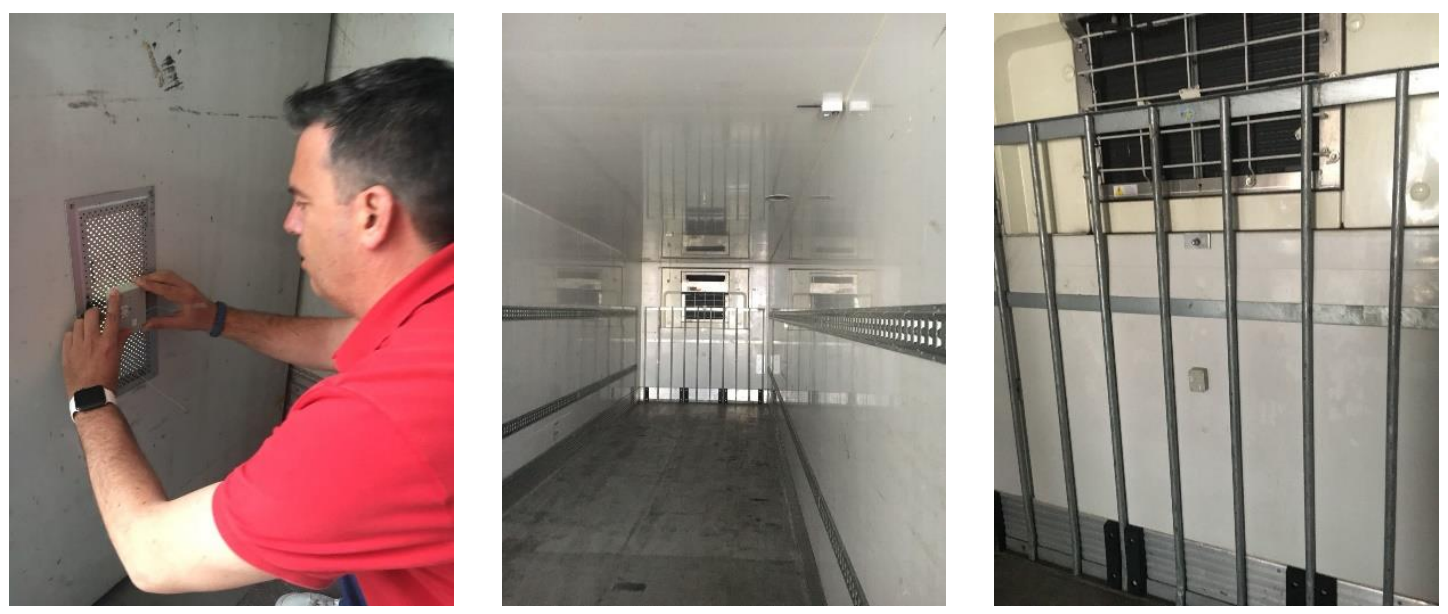

Figura 80. Nodos instalados en el contenedor.

Tabla 26. Información del viaje.

\begin{tabular}{|c|c|c|c|c|c|c|}
\hline Destino & Mercancía & Pallets & $\begin{array}{c}\text { Set } \\
\text { point }\end{array}$ & Gateway & Slave 1 & Slave 2 \\
\hline \multirow{8}{*}{ Alemania } & \multirow{8}{*}{ Lechugas } & \multirow{8}{*}{33} & \multirow{8}{*}{$4^{\circ} \mathrm{C}$} & T⿱一土丷 $\left({ }^{\circ} \mathrm{C}\right)$ & $\mathrm{T} \underline{\mathrm{a}}\left({ }^{\circ} \mathrm{C}\right)$ & Ta $\left({ }^{\circ} \mathrm{C}\right)$ \\
\hline & & & & $4,60 \pm 0,95$ & $2,95 \pm 0,68$ & $5,66 \pm 1,15$ \\
\hline & & & & HR (\%) & HR (\%) & HR (\%) \\
\hline & & & & $83,44 \pm 5,11$ & $89,13 \pm 4,11$ & $66,55 \pm 4,60$ \\
\hline & & & & $\mathrm{CO}_{2}(\%)$ & $\mathrm{CO}_{2}(\%)$ & $\mathrm{CO}_{2}(\%)$ \\
\hline & & & & $0,13 \pm 0,03$ & - & - \\
\hline & & & & V(volts) & V(volts) & V(volts) \\
\hline & & & & $3,95 \pm 0,06$ & $4,04 \pm 0,00$ & $4,11 \pm 0,01$ \\
\hline
\end{tabular}

En la Figura 81 se observa el histórico de los datos para cada uno de los nodos. El nodo Gateway se mantiene durante más tiempo cerca de la temperatura de consiga, mientras 
que en el caso del Slave 2 siempre se encuentra a una temperatura inferior, todo lo contrario que el Slave 1. Pese a todo, los históricos muestran paralelismos en cuanto a temperatura y HR (Figura 82)

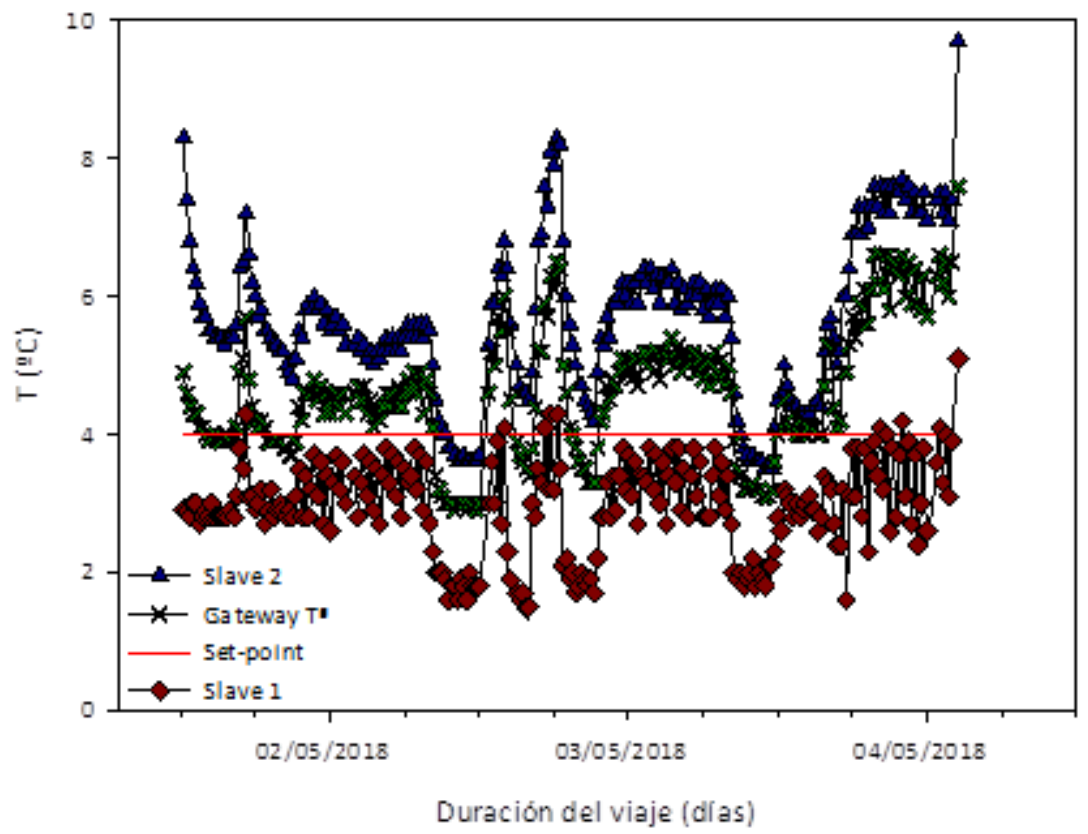

Figura 81. Históricos de las temperaturas registradas en tiempo real para cada nodo.

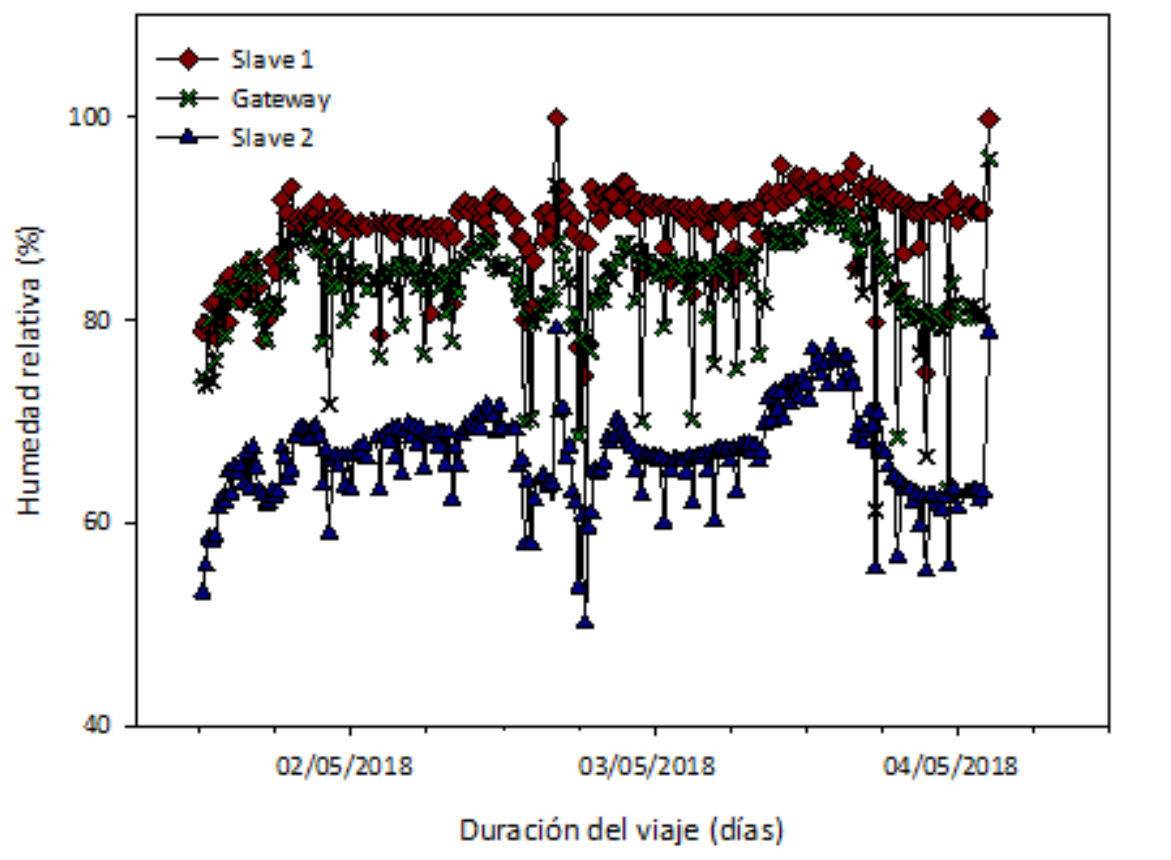

Figura 82. Históricos de las HR registradas en tiempo real para cada nodo. 


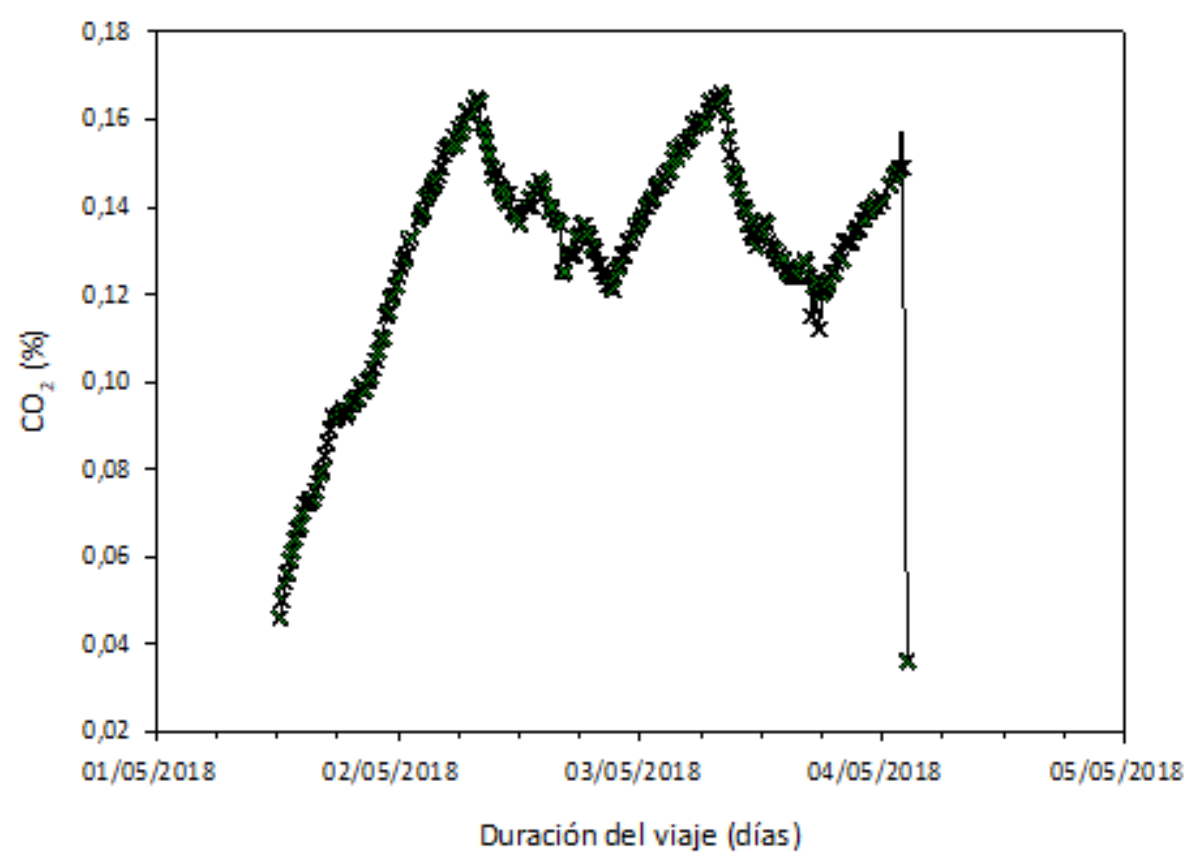

Figura 83. Históricos del $\mathrm{CO}_{2}$ registrado en tiempo real por el Gateway.

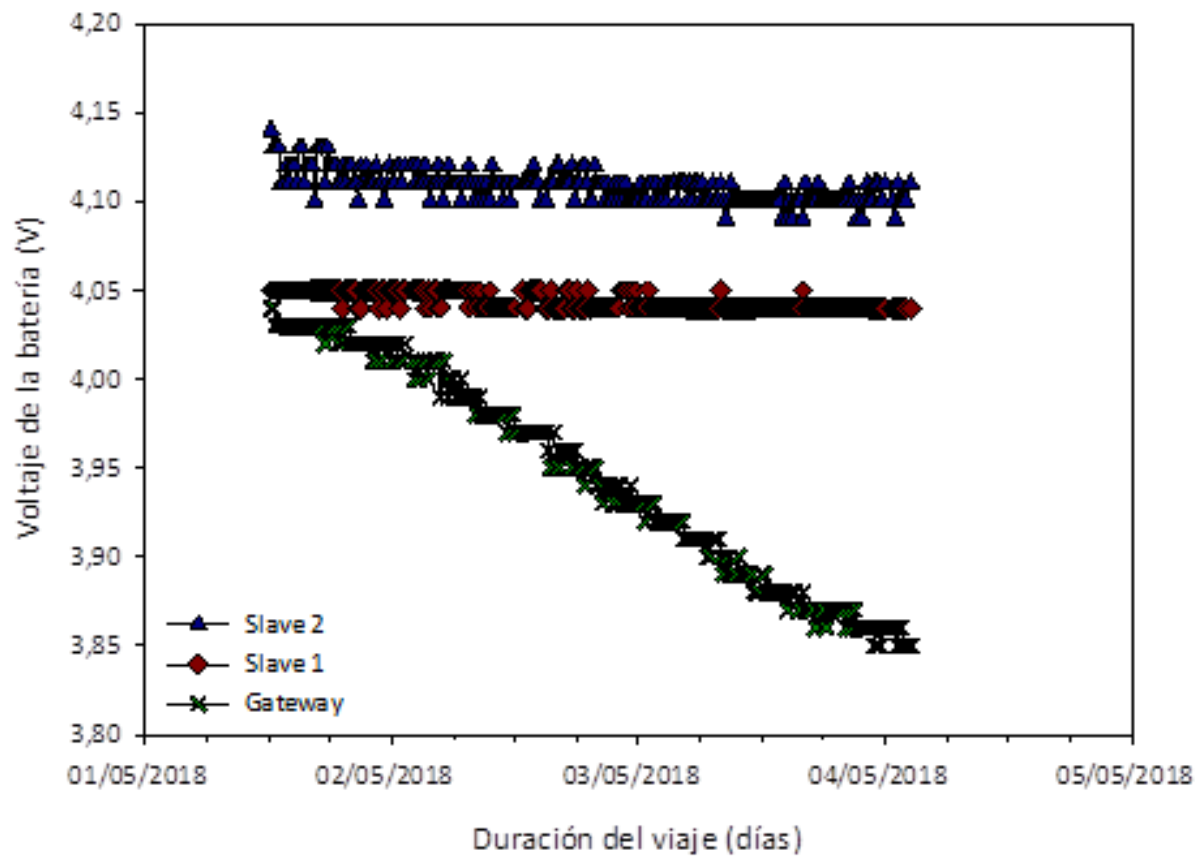

Figura 84. Históricos de las tensiones de las baterías registradas en tiempo real en cada nodo.

En el histórico del voltaje de las baterías se observa un mayor consumo por parte del Gateway que en el caso de los Slave, debido al envío en tiempo real de los datos. Aun así, el consumo energético garantiza el uso del sistema durante varios días. 


\section{Viaje: 20 de diciembre de 2018}

En este viaje se colocaron 3 nodos a lo largo del contenedor, situando el Gateway, como siempre en el techo a la mitad de la longitud del contenedor, el Slave 1 en el retorno y el Slave 2 en la puerta (Figura 85). De esta forma como además se había montado otro Gateway se podía instalar en cada visita al transportista dos equipos en contenedores distintos con la finalidad de recoger un mayor número de viajes y analizar sus datos.
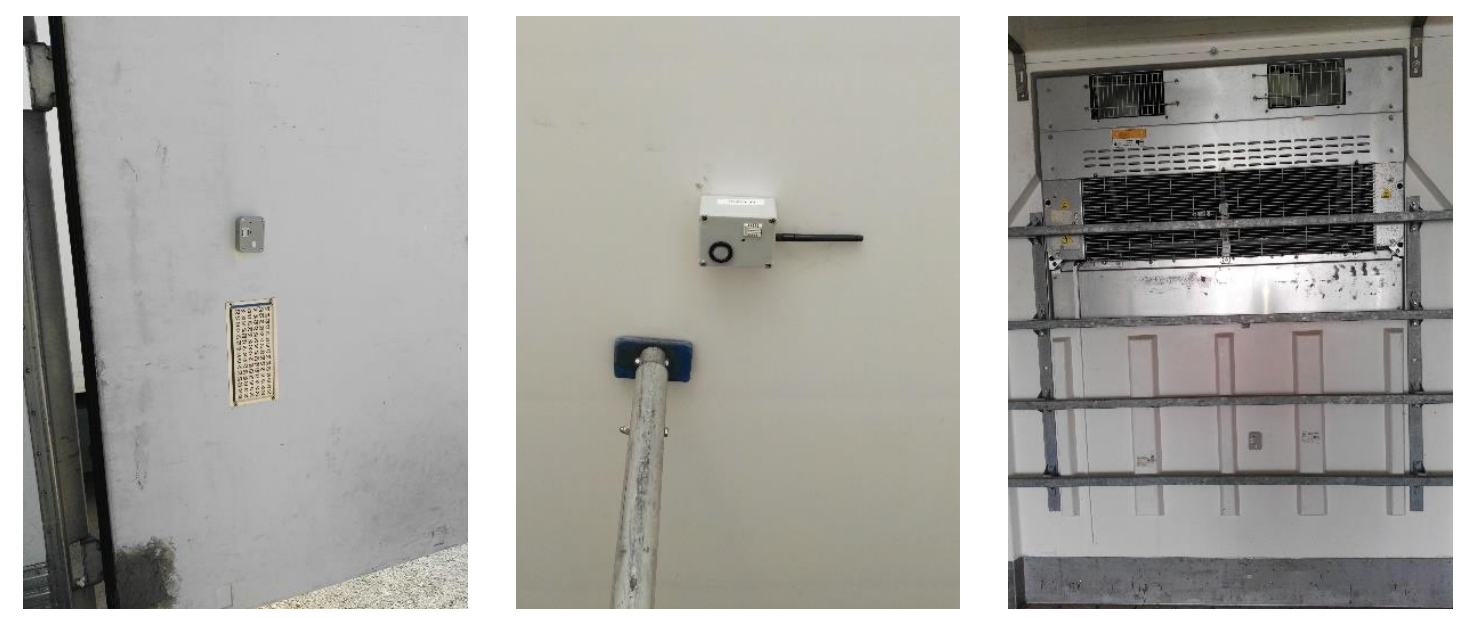

Figura 85. Nodos instalados en el contenedor.

Tabla 27. Información del viaje.

\begin{tabular}{|c|c|c|c|c|c|c|}
\hline Destino & Mercancía & Pallets & $\begin{array}{c}\text { Set } \\
\text { point }\end{array}$ & Gateway & Slave 1 & Slave 2 \\
\hline \multirow{8}{*}{$\begin{array}{l}\text { Países } \\
\text { Bajos }\end{array}$} & \multirow{8}{*}{$\begin{array}{l}\text { Lechuga } \\
\text { Romana }\end{array}$} & \multirow{8}{*}{34} & \multirow{8}{*}{$4^{\circ} \mathrm{C}$} & Tа $\left({ }^{\circ} \mathrm{C}\right)$ & $\mathrm{T}^{\mathrm{a}}\left({ }^{\circ} \mathrm{C}\right)$ & Tа $\left({ }^{\circ} \mathrm{C}\right)$ \\
\hline & & & & $4,36 \pm 1,05$ & - & $4,56 \pm 0,99$ \\
\hline & & & & HR (\%) & HR (\%) & HR (\%) \\
\hline & & & & $92,82 \pm 2,92$ & - & $86,18 \pm 9,64$ \\
\hline & & & & $\mathrm{CO}_{2}(\%)$ & $\mathrm{CO}_{2}(\%)$ & $\mathrm{CO}_{2}(\%)$ \\
\hline & & & & $0,21 \pm 0,08$ & - & - \\
\hline & & & & V(volts) & V(volts) & V(volts) \\
\hline & & & & $3,90 \pm 0,07$ & - & $4,16 \pm 0,01$ \\
\hline
\end{tabular}

En la Figura 86 se observa el histórico de las temperaturas para cada uno de los nodos. Durante este viaje y debido a la cobertura, el nodo Slave 1 tuvo problemas de funcionamiento con lo que los datos no son útiles. Sin embargo, sí se observa una mayor homogeneidad en el registro de temperaturas pese a los picos del Slave 2 con un máximo aislado de $8,6{ }^{\circ} \mathrm{C}$. En cuanto a la HR (Figura 87) se observa una mayor homogeneidad en el Gateway diferenciándose del Slave. Los dos picos del $\mathrm{CO}_{2}$ se deben, como se ha observado en otros casos, a aperturas de puertas (Figura 88). 


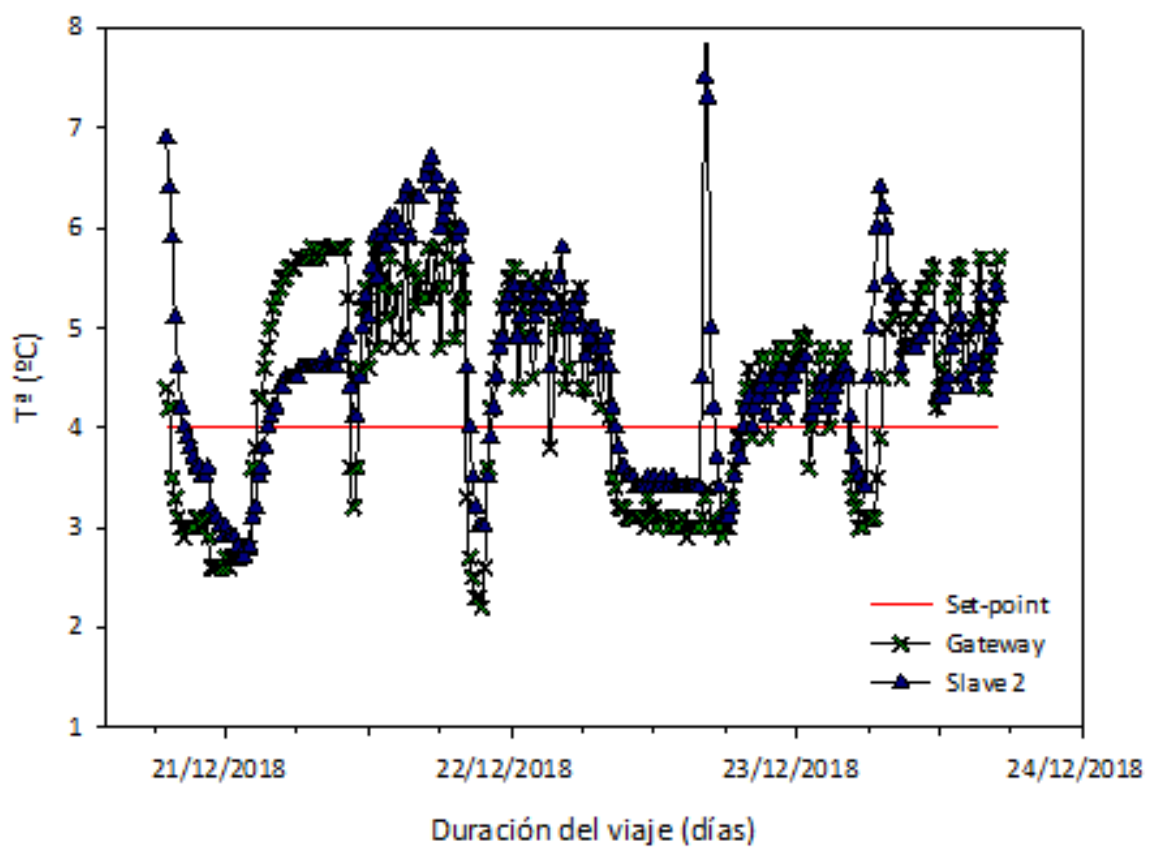

Figura 86. Históricos de las temperaturas registradas en tiempo real para cada nodo.

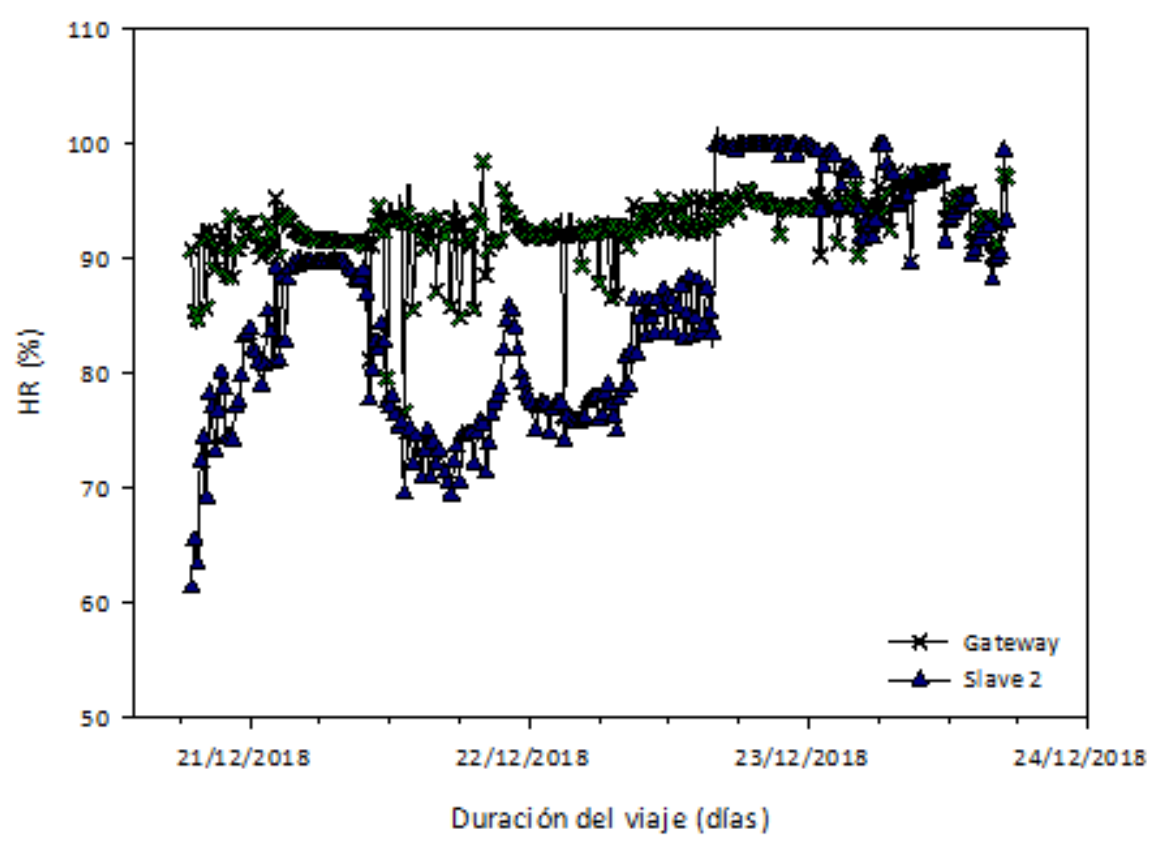

Figura 87. Históricos de las HR registradas en tiempo real para cada nodo. 


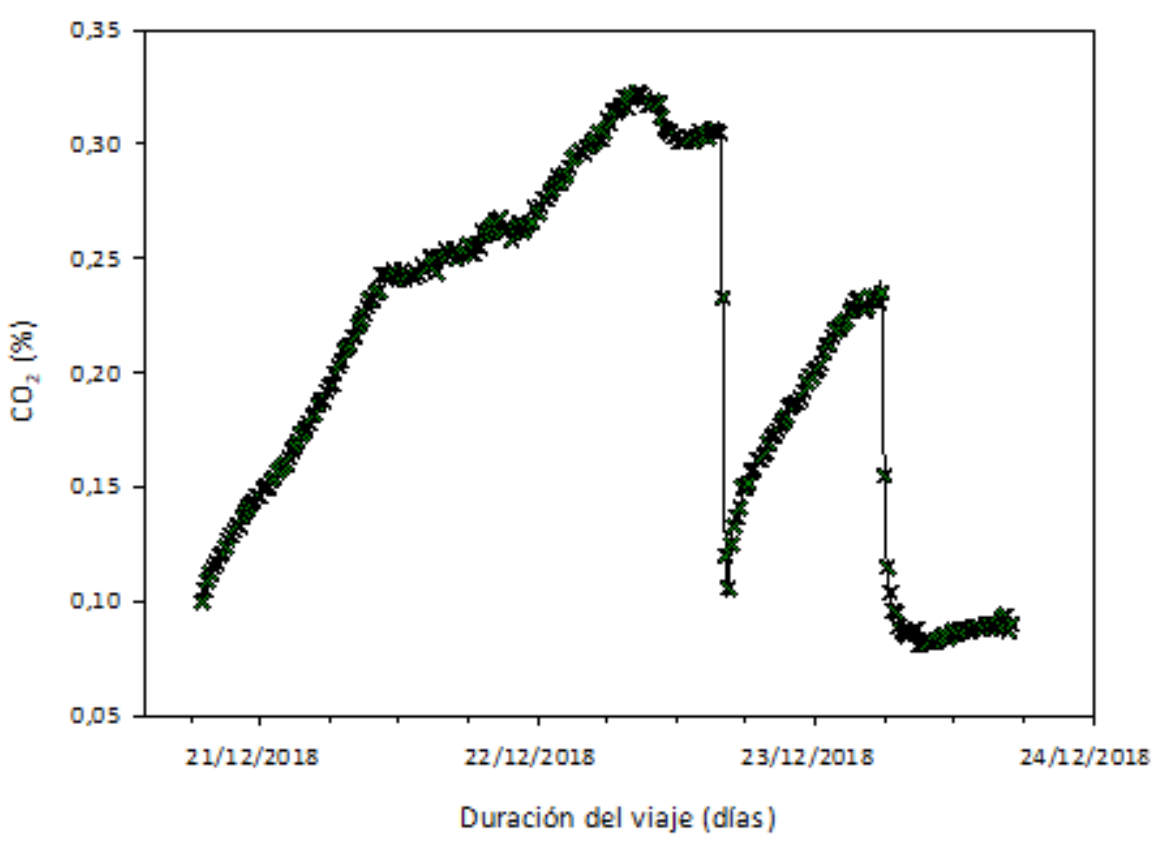

Figura 88. Históricos del $\mathrm{CO}_{2}$ registrado en tiempo real por el Gateway.

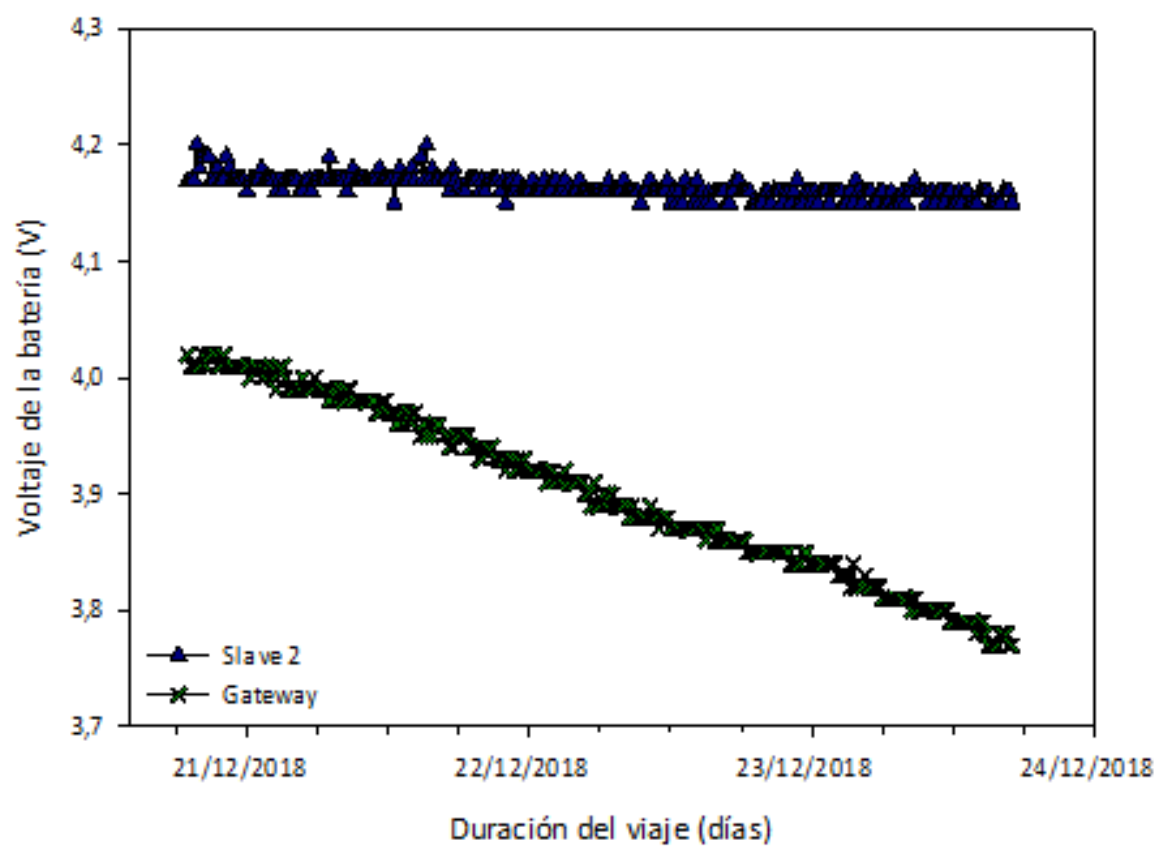

Figura 89. Históricos de las tensiones de las baterías registradas en tiempo real en cada nodo. 


\section{3ㅇ Viaje: 12 de febrero de 2019}

En este tercer viaje los 3 nodos se colocaron igual que en el anterior: el Gateway en el techo a la mitad de la longitud del contenedor, el Slave 1 en el retorno y el Slave 2 en la puerta. En este viaje, el problema del Slave 1 volvió a repetirse, con lo que los datos recogidos por el Slave 1 fueron insuficientes. Además, el sensor de $\mathrm{CO}_{2}$ del Gateway sufrió un desajuste en la calibración y los datos no fueron relevantes ni significativos (se incluyen para que se observe dicho desajuste).

Tabla 28. Información del viaje.

\begin{tabular}{|c|c|c|c|c|c|c|}
\hline Destino & Mercancía & Pallets & $\begin{array}{c}\text { Set } \\
\text { point }\end{array}$ & Gateway & Slave 1 & Slave 2 \\
\hline \multirow{8}{*}{$\begin{array}{l}\text { Reino } \\
\text { Unido }\end{array}$} & \multirow{8}{*}{$\begin{array}{l}\text { Lechuga } \\
\text { Iceberg }\end{array}$} & \multirow{8}{*}{33} & \multirow{8}{*}{$4^{\circ} \mathrm{C}$} & $\mathrm{T}^{\mathrm{a}}\left({ }^{\circ} \mathrm{C}\right)$ & Ta $\left({ }^{\circ} \mathrm{C}\right)$ & $\mathrm{T} \underline{\mathrm{a}}\left({ }^{\circ} \mathrm{C}\right)$ \\
\hline & & & & $5,35 \pm 2,14$ & - & $5,74 \pm 1,71$ \\
\hline & & & & HR (\%) & HR (\%) & HR (\%) \\
\hline & & & & $99,68 \pm 2,14$ & - & $95,87 \pm 5,42$ \\
\hline & & & & $\mathrm{CO}_{2}(\%)$ & $\mathrm{CO}_{2}(\%)$ & $\mathrm{CO}_{2}(\%)$ \\
\hline & & & & $4,41 \pm 6,22$ & - & - \\
\hline & & & & V(volts) & V(volts) & V(volts) \\
\hline & & & & $3,96 \pm 0,09$ & - & $3,91 \pm 0,04$ \\
\hline
\end{tabular}

En la Figura 90 se observa una evolución del (pese a tener desviaciones más altas) registro de temperaturas sin datos atípicos y con similitudes entre Gateway y Slave. La subida de temperaturas a partir del sábado se justifica con la posterior descarga de la mercancía.

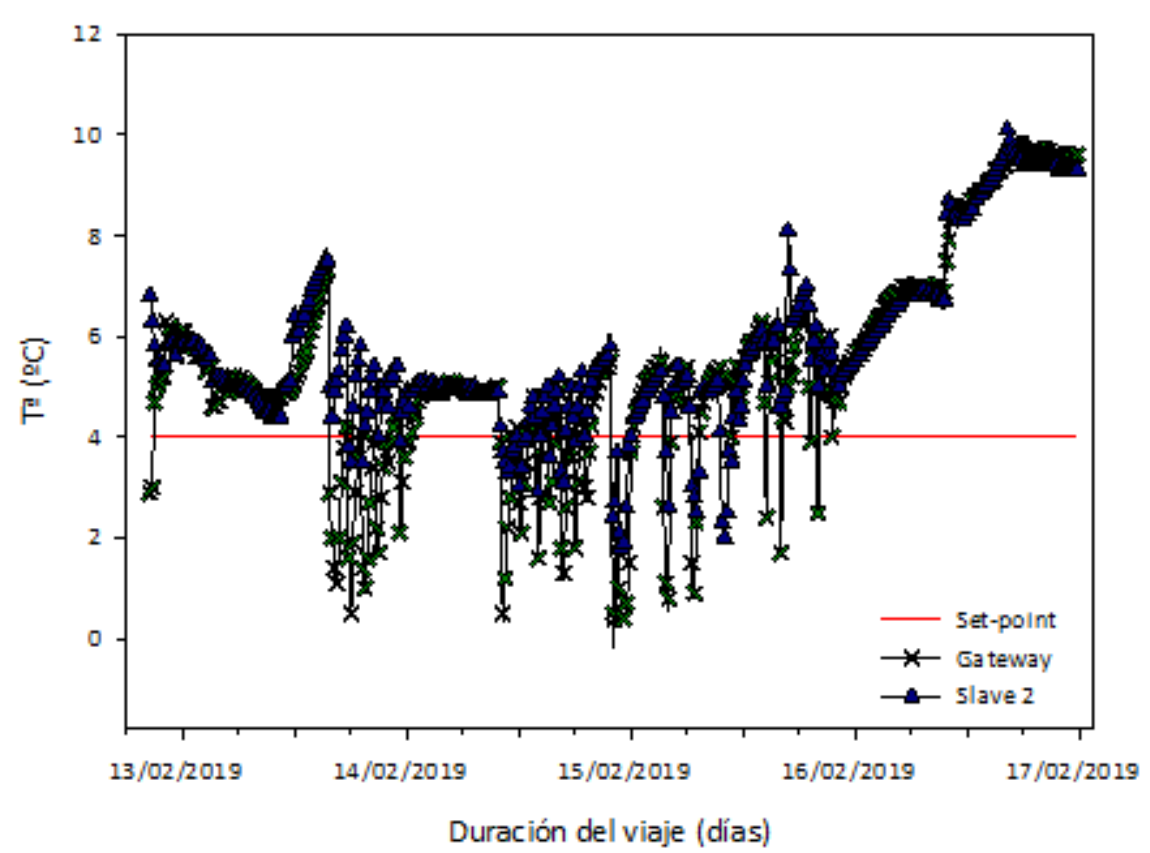

Figura 90. Históricos de las temperaturas registradas en tiempo real para cada nodo. 


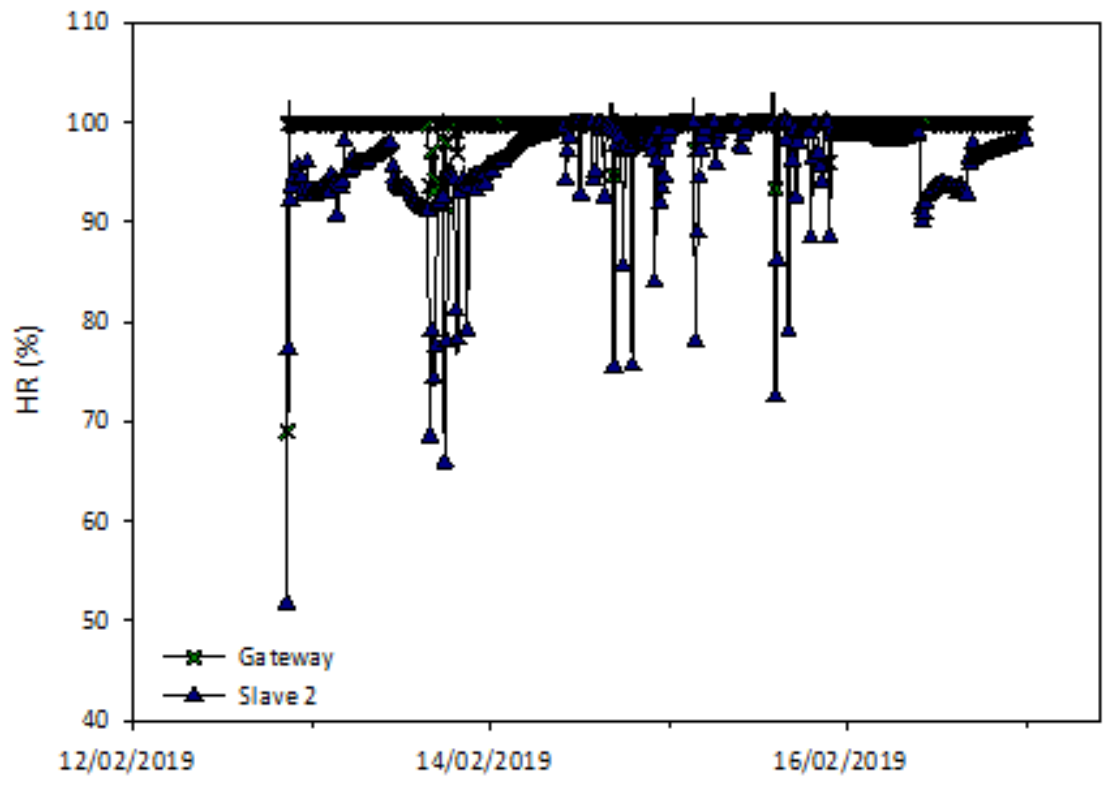

Figura 91. Históricos de las HR registradas en tiempo real para cada nodo.

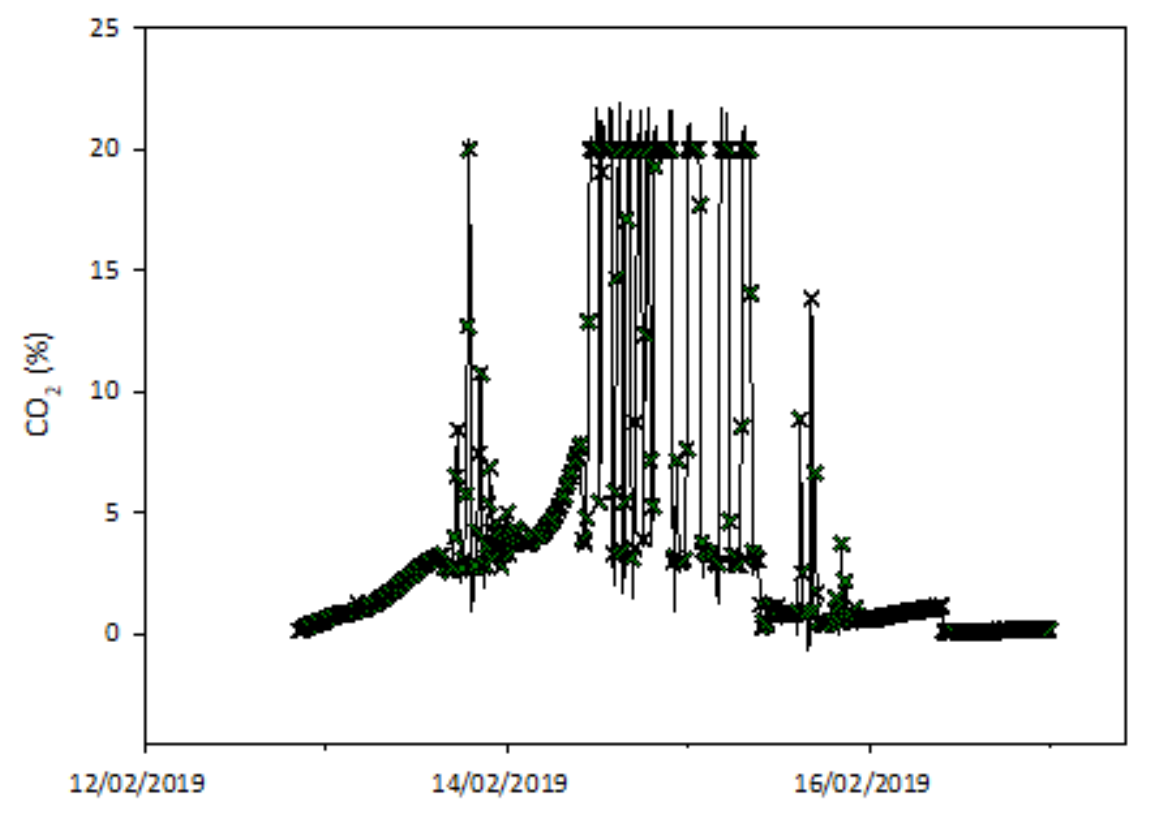

Figura 92. Históricos del $\mathrm{CO}_{2}$ registrado en tiempo real por el Gateway. 


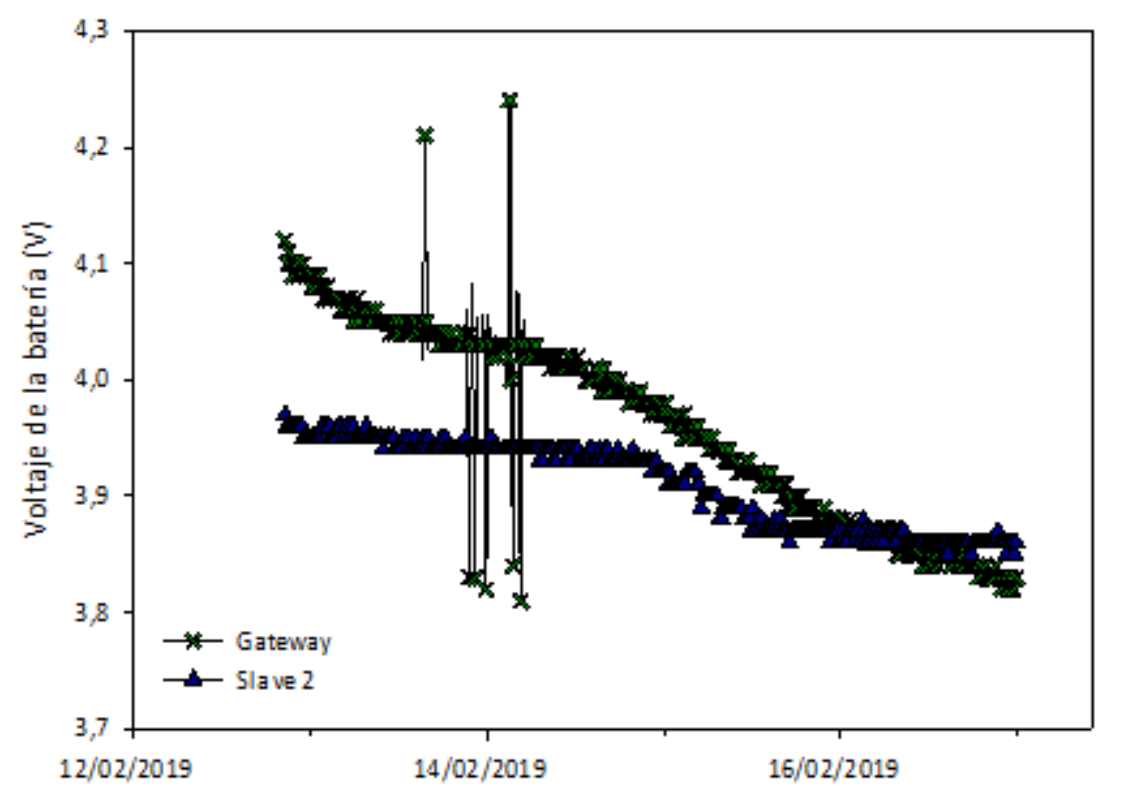

Figura 93. Históricos de las tensiones de las baterías registradas en tiempo real en cada nodo.

En el histórico del voltaje de las baterías se observa un mayor consumo por parte del Gateway con una disminución de la tensión mucho más pronunciada que en el caso se los Slaves, pese a que a mitad del viaje el Slave sufriera una degradación rápida debido a una batería defectuosa

\section{4ㅇ Viaje: 12 de marzo de 2019}

En este cuarto viaje se realizó una actualización operativa de los nodos, modificando su firmware. Los 3 nodos se colocaron igual: el Gateway en el techo a la mitad de la longitud del contenedor, el Slave 1 en el retorno y el Slave 2 en la puerta. El Gateway no llevaba el sensor de $\mathrm{CO}_{2}$ operativo.

Tabla 29. Información del viaje.

\begin{tabular}{|c|c|c|c|c|c|c|}
\hline Destino & Mercancía & Pallets & $\begin{array}{c}\text { Set } \\
\text { point }\end{array}$ & Gateway & Slave 1 & Slave 2 \\
\hline \multirow{8}{*}{ Bélgica } & \multirow{8}{*}{ Lechuga } & \multirow{8}{*}{35} & \multirow{8}{*}{$7^{\circ} \mathrm{C}$} & $\mathrm{T} \underline{\mathrm{a}}\left({ }^{\circ} \mathrm{C}\right)$ & $\mathrm{T} \underline{\mathrm{a}}\left({ }^{\circ} \mathrm{C}\right)$ & $\mathrm{T}$ a $\left({ }^{\circ} \mathrm{C}\right)$ \\
\hline & & & & $6,39 \pm 1,35$ & $7,89 \pm 0,49$ & $7,11 \pm 1,42$ \\
\hline & & & & HR (\%) & HR (\%) & HR (\%) \\
\hline & & & & $96,98 \pm 7,50$ & $99,90 \pm 0,00$ & $99,90 \pm 0,00$ \\
\hline & & & & $\mathrm{CO}_{2}(\%)$ & $\mathrm{CO}_{2}(\%)$ & $\mathrm{CO}_{2}(\%)$ \\
\hline & & & & - & - & - \\
\hline & & & & V(volts) & V(volts) & V(volts) \\
\hline & & & & $4,06 \pm 0,01$ & $4,15 \pm 0,01$ & $4,02 \pm 0,01$ \\
\hline
\end{tabular}

En la Figura 94 se observa como el Slave 1 registra temperaturas más altas y sin similitudes con los otros dos que sí son más homogéneos. Además, la HR (Figura 95) de ambos Slave permanece constante, pese a que el Gateway sí registra variaciones. 


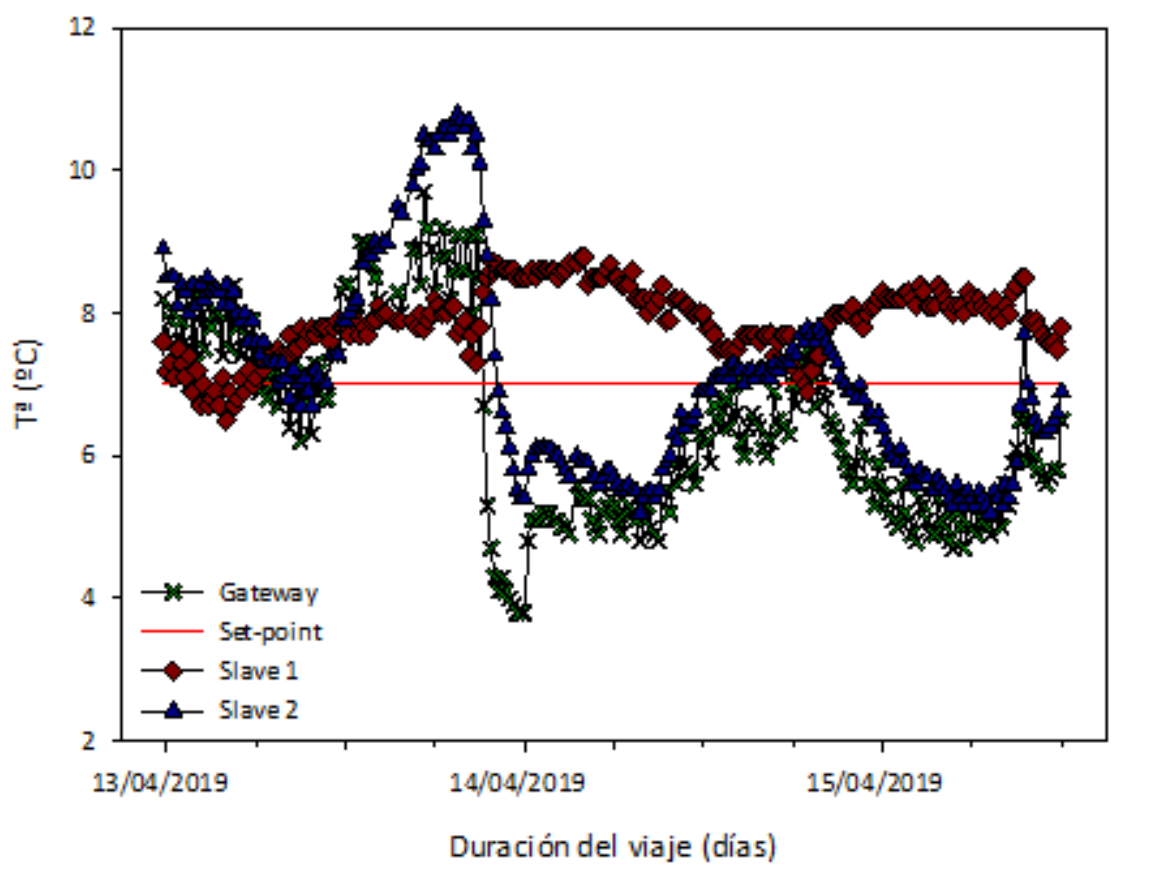

Figura 94. Históricos de las temperaturas registradas en tiempo real para cada nodo.

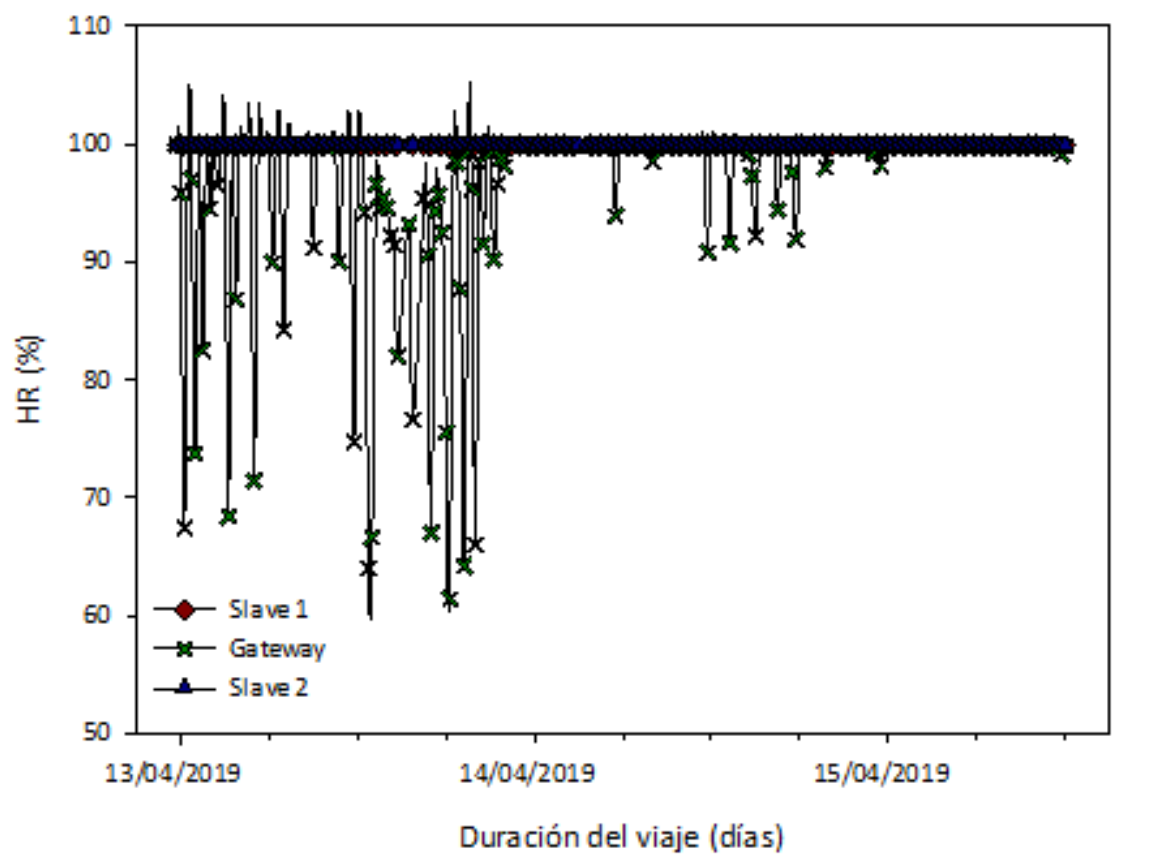

Figura 95. Históricos de las HR registradas en tiempo real para cada nodo. 


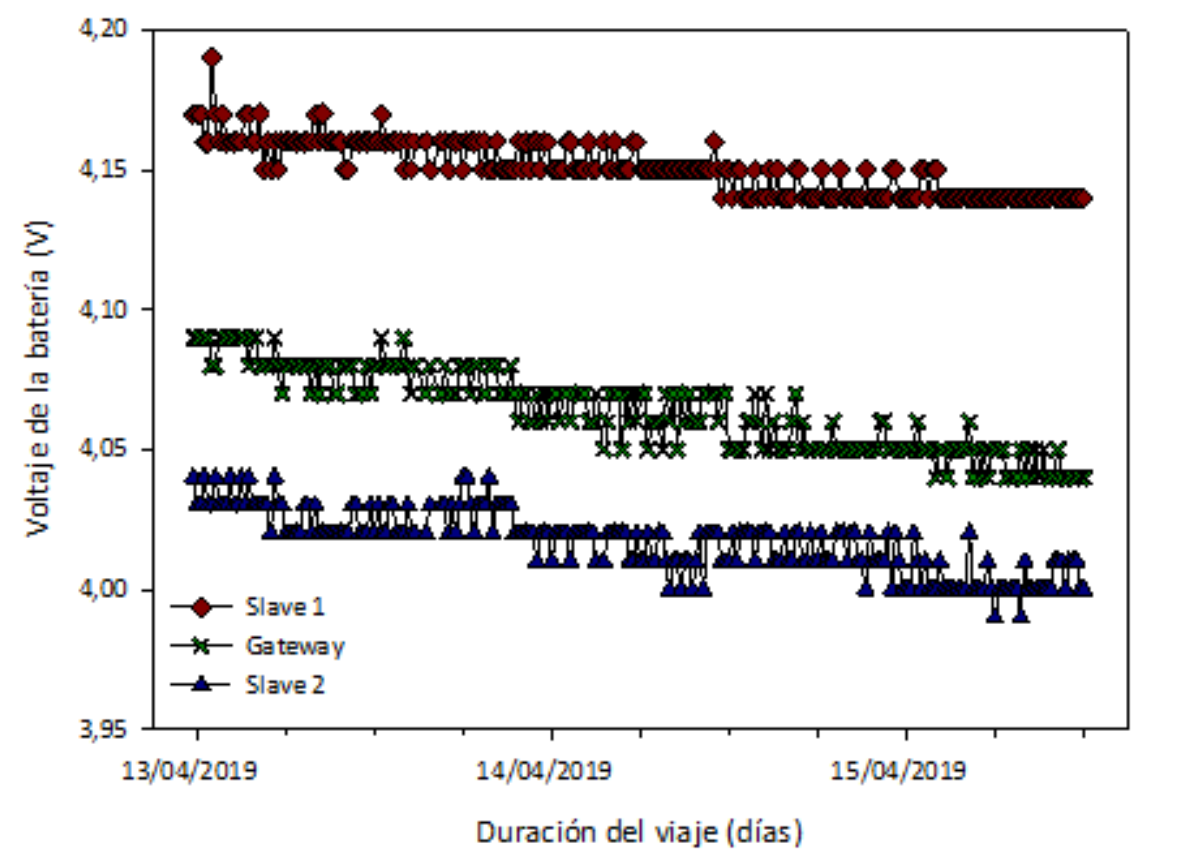

Figura 96. Históricos de las tensiones de las baterías registradas en tiempo real en cada nodo.

En el histórico del voltaje de las baterías se observa tendencias de disminución de las barías mucho más similares entre Gateway y Slaves.

\section{5o Viaje: 7 de diciembre de 2019}

En este quinto viaje sólo se utilizó el nodo Gateway por motivos operativos.

Tabla 30. Información del viaje.

\begin{tabular}{|c|c|c|c|c|c|c|}
\hline Destino & Mercancía & Pallets & $\begin{array}{c}\text { Set } \\
\text { point }\end{array}$ & Gateway & Slave 1 & Slave 2 \\
\hline \multirow{8}{*}{ Alemania } & \multirow{8}{*}{ Lechuga } & \multirow{8}{*}{32} & \multirow{8}{*}{$4^{\circ} \mathrm{C}$} & T⿳亠丷厂 $\left({ }^{\circ} \mathrm{C}\right)$ & $\mathrm{T} \underline{\mathrm{a}}\left({ }^{\circ} \mathrm{C}\right)$ & $\mathrm{T}^{\mathrm{a}}\left({ }^{\circ} \mathrm{C}\right)$ \\
\hline & & & & $4,06 \pm 0,94$ & - & - \\
\hline & & & & HR (\%) & HR (\%) & HR (\%) \\
\hline & & & & $99,62 \pm 1,57$ & - & - \\
\hline & & & & $\mathrm{CO}_{2}(\%)$ & $\mathrm{CO}_{2}(\%)$ & $\mathrm{CO}_{2}(\%)$ \\
\hline & & & & $0,47 \pm 0,60$ & - & - \\
\hline & & & & V (volts) & V (volts) & V (volts) \\
\hline & & & & $3,66 \pm 0,06$ & - & - \\
\hline
\end{tabular}

En la Figura 97 se observa una mayor homogeneidad en el registro de temperaturas sin datos atípicos, pese al pico que coincide con la subida brusca del $\mathrm{CO}_{2}$ (Figura 99). 


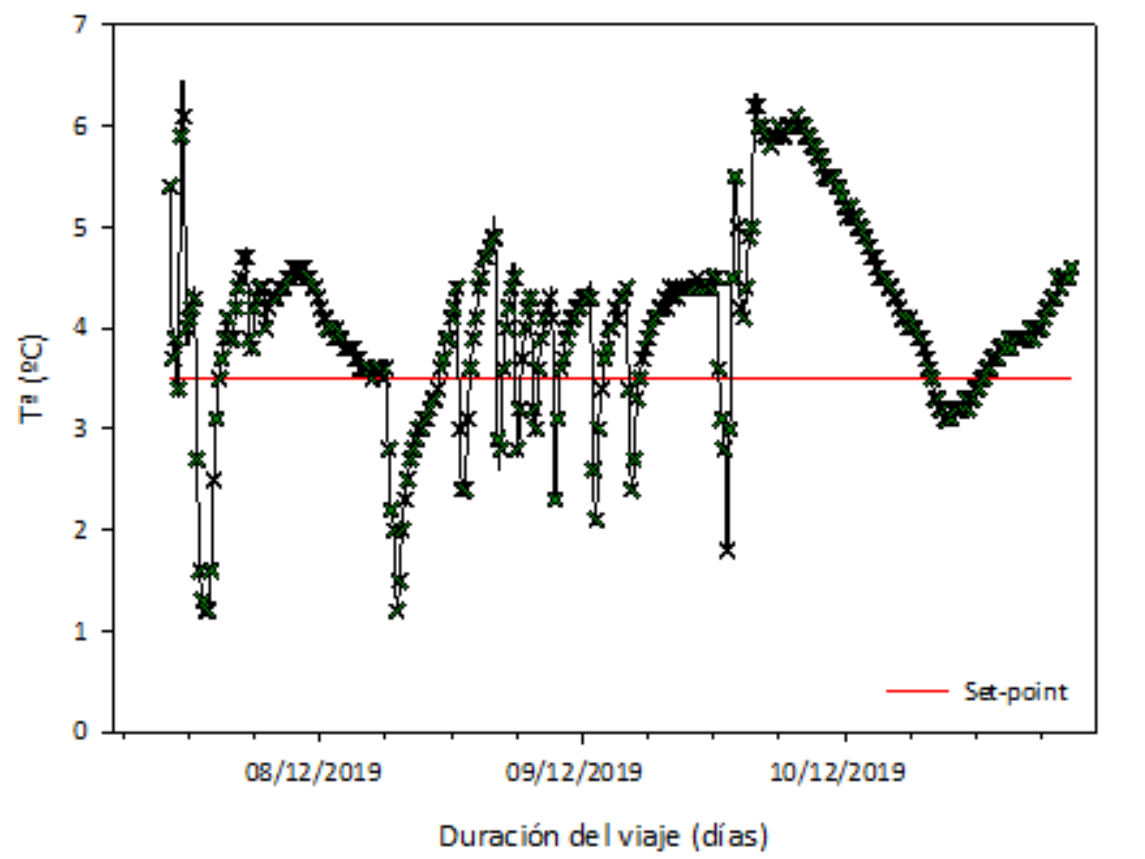

Figura 97. Históricos de las temperaturas registradas en tiempo real para cada nodo.

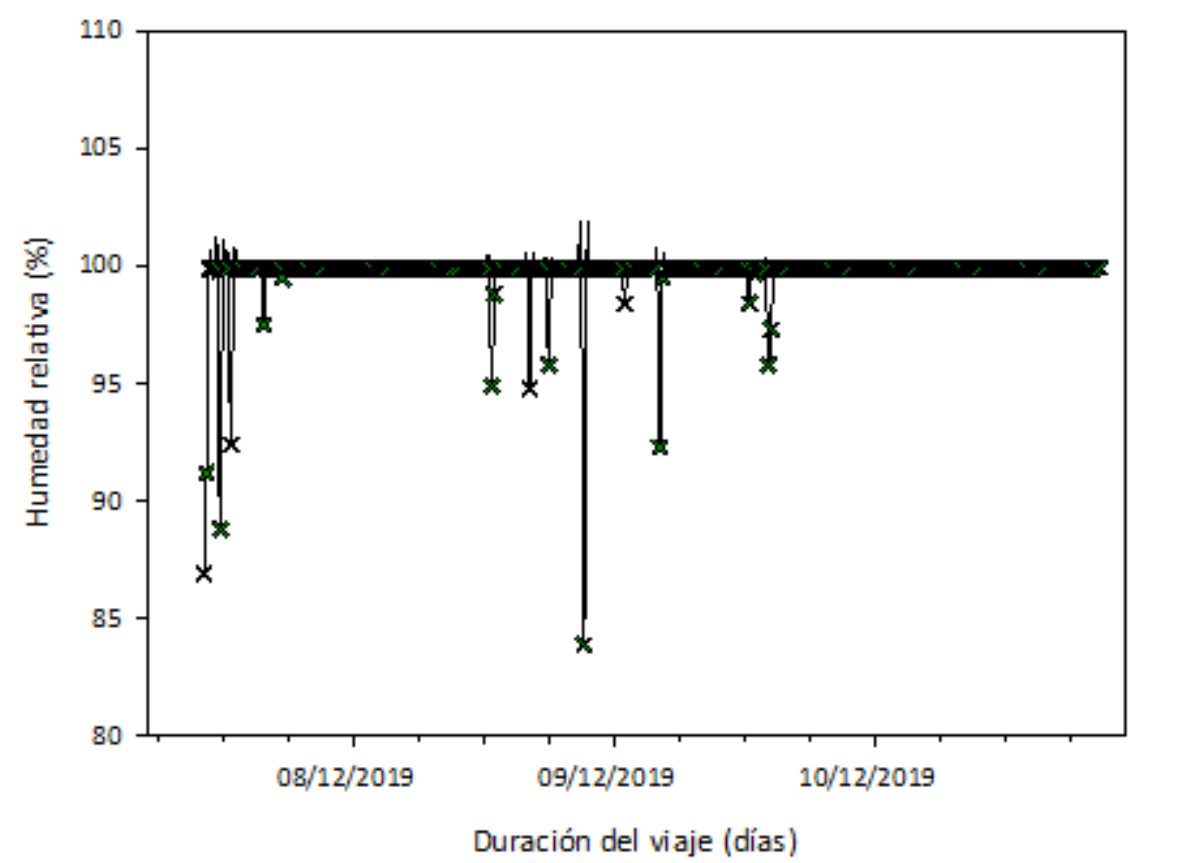

Figura 98. Históricos de las HR registradas en tiempo real para cada nodo. 


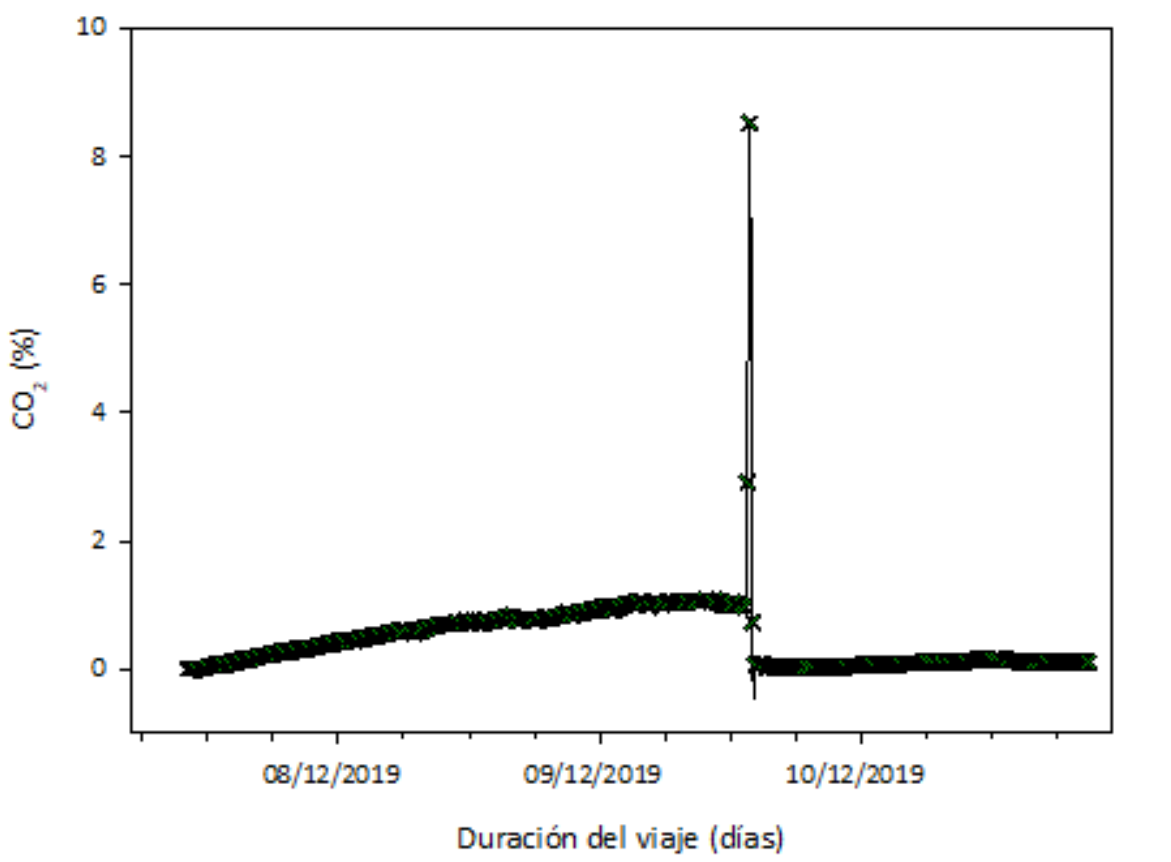

Figura 99. Históricos del $\mathrm{CO}_{2}$ registrado en tiempo real por el Gateway.

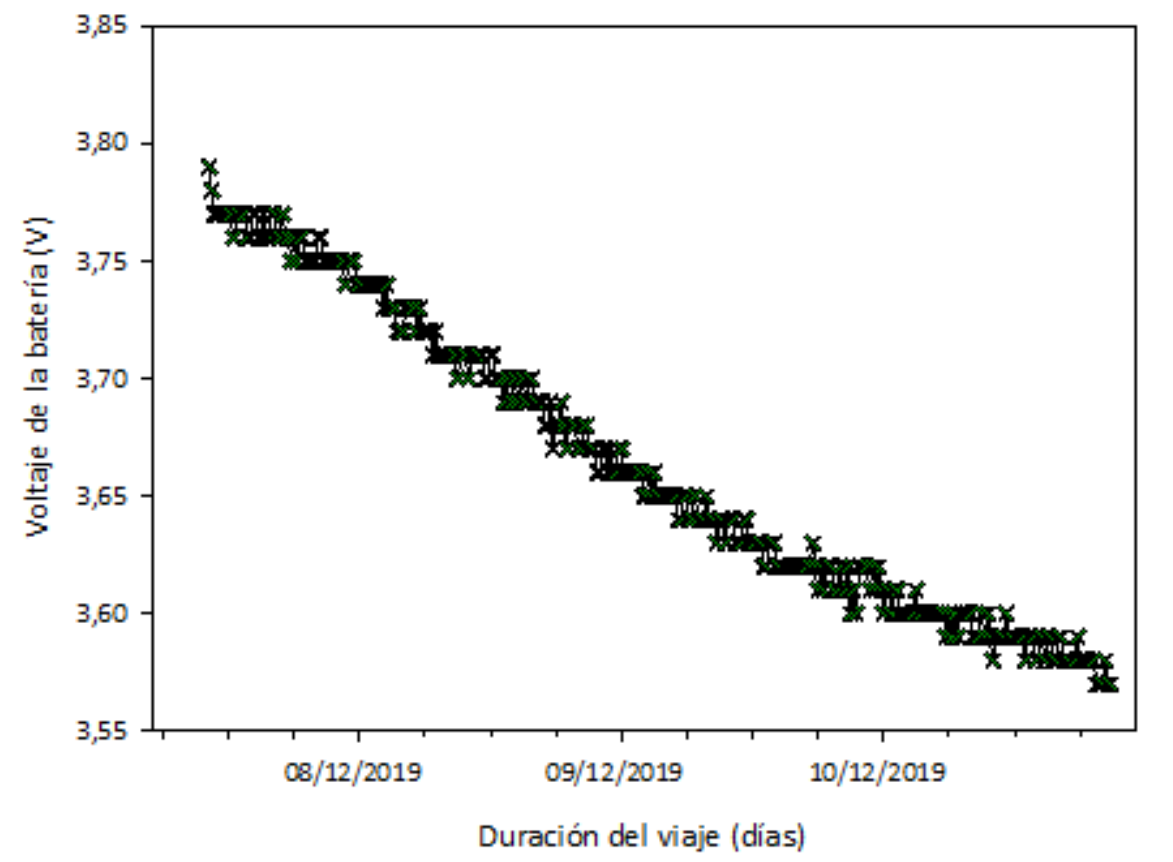

Figura 100. Históricos de las tensiones de las baterías registradas en tiempo real en cada nodo.

En el histórico del voltaje de las baterías se observa la mejora en el consumo de energía al reducir sólo $0,2 \mathrm{~V}$ durante todo el trayecto de medida. 


\subsection{MODELO DE PREDICCIÓN DE PÉRDIDAS DE CALIDAD}

Los resultados de las evaluaciones de los tres modelos de regresión se muestran a continuación.

$$
\text { Modelo } 1 \quad \mathrm{DD}=29,005-2,1871 S P+0,1654 \mathrm{~A}+0,04994 \mathrm{SP}^{2}-0,03721 \mathrm{SP} \cdot \mathrm{A}
$$

Tabla 31. Análisis coeficientes de validación del modelo 1 MNLR con interacciones.

\begin{tabular}{cccccc}
\hline \hline Término & Coef $\boldsymbol{\beta}$ & EE & T Valor & p Valor & FIV \\
\hline \hline Constante & 29,005 & 0,389 & 74,56 & 0,000 & \\
SP & $-2,1871$ & 0,0981 & $-22,30$ & 0,000 & 19,00 \\
A & 0,1654 & 0,0461 & 3,59 & 0,003 & 353,58 \\
SP $^{2}$ & 0,04994 & 0,00453 & 11,01 & 0,000 & 18,65 \\
SP*A & $-0,03721$ & 0,00920 & $-4,04$ & 0,001 & 353,34 \\
\hline \hline
\end{tabular}

Tabla 32. Resumen análisis mínimos cuadrados del modelo 1.

\begin{tabular}{cccc}
\hline \hline ES & $\mathbf{R}^{\mathbf{2}}$ & $\mathbf{R}^{\mathbf{2}}$ ajustado & $\mathbf{R}^{\mathbf{2}}$ pronosticado \\
\hline 0,434060 & $99,51 \%$ & $99,36 \%$ & $98,37 \%$ \\
\hline \hline
\end{tabular}

Este modelo 1 es el modelo que mejor se correlaciona con los resultados. Predice muy bien la duración en días y los errores son siempre conservadores (propone una duración inferior a la observada) con un error máximo de 1 día. Sin embargo, tiene una interpretación complicada.

Modelo 2

$$
\mathrm{DD}=25,795-1,1785 \mathrm{SP}-0,02492 \mathrm{~A}
$$

Tabla 33. Análisis coeficientes de validación del modelo 2 MLR con interacciones.

\begin{tabular}{cccccc}
\hline \hline Término & Coef $\boldsymbol{\beta}$ & EE & T Valor & p Valor & FIV \\
\hline \hline Constante & 25,795 & 0,667 & 38,70 & 0,000 & \\
\hline SP & $-1,1785$ & 0,0787 & $-14,97$ & 0,000 & 1,04 \\
\hline $\mathrm{A}$ & $-0,02492$ & 0,00857 & $-2,91$ & 0,010 & 1,04 \\
\hline \hline
\end{tabular}

Tabla 34. Resumen análisis mínimos cuadrados del modelo 2.

\begin{tabular}{cccc}
\hline \hline$E S$ & $R^{2}$ & $R^{2}$ ajustado & $R^{2}$ pronosticado \\
\hline 1,49051 & $93,34 \%$ & $92,51 \%$ & $85,98 \%$ \\
\hline \hline
\end{tabular}

Este modelo 2 se interpreta fácilmente. Cada mayor grado causa una pérdida de 1,17 días de duración y un aumento unitario del área también produce una disminución de 0,025 días. Comete errores en ambas direcciones, en un rango de 3 a 2 días. El modelo puede tener algún problema ya que hay una disminución en el predictor $R^{2}$ en relación con los demás. 
Tabla 35. Análisis coeficientes de validación del modelo 3 MNLR sin interacciones.

\begin{tabular}{cccccc}
\hline \hline Término & Coef $\boldsymbol{\beta}$ & EE & T Valor & $\boldsymbol{p}$ Valor & FIV \\
\hline \hline Constante & 29,604 & 0,512 & 57,85 & 0,000 & \\
SP & $-2,313$ & 0,132 & $-17,48$ & 0,000 & 17,09 \\
A & $-0,02063$ & 0,00358 & $-5,76$ & 0,000 & 1,06 \\
$S P^{2}$ & 0,05492 & 0,00621 & 8,84 & 0,000 & 17,28 \\
\hline \hline
\end{tabular}

Tabla 36. Resumen análisis mínimos cuadrados del modelo 3.

\begin{tabular}{cccc}
\hline \hline ES & $\mathbf{R}^{\mathbf{2}}$ & $\mathbf{R}^{\mathbf{2}}$ ajustado & $\mathbf{R}^{\mathbf{2}}$ pronosticado \\
\hline 0,617536 & $98,93 \%$ & $98,71 \%$ & $97,45 \%$ \\
\hline
\end{tabular}

En este modelo 3, el término cuadrático del área no es significativo, mostrándose muy conservador a la hora de estimar los errores en un rango de 0 a 2 días.

Aunque los modelos 1 y 3 tienen un comportamiento similar, el modelo 3 es mucho más fácil de interpretar que el modelo 1, ya que un aumento en el valor del predictor A (Área) conduce a una reducción en la vida útil. Así, en el modelo 3 , el coeficiente correspondiente al predictor $A$ es negativo $(-0,02063)$, mientras que en el modelo 1 es positivo $(0,1654)$, en este último caso compensa la duración con el coeficiente negativo de la interacción $(-0,03721)$.

La relación descrita anteriormente permite estimar en cuánto tiempo (días) se ve reducida la calidad de las lechugas, considerando el set-point en tiempo real y los datos registrados por los sensores. De esta forma se compara el área teórica con el área situada por encima del Set-point y su desviación de las gráficas reales de los viajes. Por lo tanto, al igual que los sensores se colocaron en diferentes ubicaciones (mostradas en la Figura 70) dentro del contenedor, las pérdidas no pueden ser las mismas debido a las diferentes temperaturas registradas en cada una, ya que se sabe que la temperatura no siempre se distribuye regularmente dentro del pallet, y un solo sensor para todo el palé no proporciona una distribución realista (Lang y Jedermann, 2014). Jedermann et al. (2008) observaron que la inercia térmica de los productos influye en las diferencias entre la temperatura ambiente y la temperatura del núcleo del pallet. Además, las diferencias entre los nodos durante el mismo viaje están influenciadas por su posición en el contenedor (Agüero et al., 2008; Lang et al., 2011) tal y como muestra la Tabla 37. 
Tabla 37. Días perdidos en los destinos más significativos, calculados para la temperatura promedio y para cada uno de los nodos.

\begin{tabular}{ccccc}
\hline \hline Destino & $\begin{array}{c}\text { Set-point } \\
\left({ }^{\circ} \mathrm{C}\right)\end{array}$ & $\begin{array}{c}\text { Días } \\
\text { perdidos } \\
\text { Gateway }\end{array}$ & $\begin{array}{c}\text { Días } \\
\text { perdidos } \\
\text { Slave 1 }\end{array}$ & $\begin{array}{c}\text { Días } \\
\text { perdidos } \\
\text { Slave 2 }\end{array}$ \\
\hline \hline Alemania & 4 & 0 & 0 & 1 \\
\hline Países Bajos & 4 & 0 & - & 0 \\
\hline Reino Unido & 5 & 1 & - & 1 \\
\hline Bélgica & 7 & 0 & 0 & 0 \\
\hline \hline
\end{tabular}

Las Figuras 101 a-c muestran como el modelo propuesto analiza el histórico de las temperaturas en los distintos nodos (a: Gateway; b: Slave 1; c: Slave 2) del viaje a Alemania. Se observan las áreas encerradas entre la curva de las temperaturas y el Setpoint marcadas por tres colores: el color verde indica que la variación registrada de temperatura no es suficiente para reducir la vida comercial de la carga; el color naranja significa que la vida comercial probablemente se está reduciendo y el color rojo significa que las condiciones registradas han reducido la vida comercial teórica. De esta forma y coincidiendo con los resultados de la Tabla 37, según las condiciones ambientales registradas por el Gateway, la vida comercial de la carga no se ve reducida en ningún día, al igual que ocurre con el Slave 1 que registra la mayor parte del tiempo temperaturas por debajo del Set-point. En cambio, para el Slave 2 sí se observa un rango de temperaturas más elevadas lo que se traduce en una reducción del tiempo de vida comercial en un día.

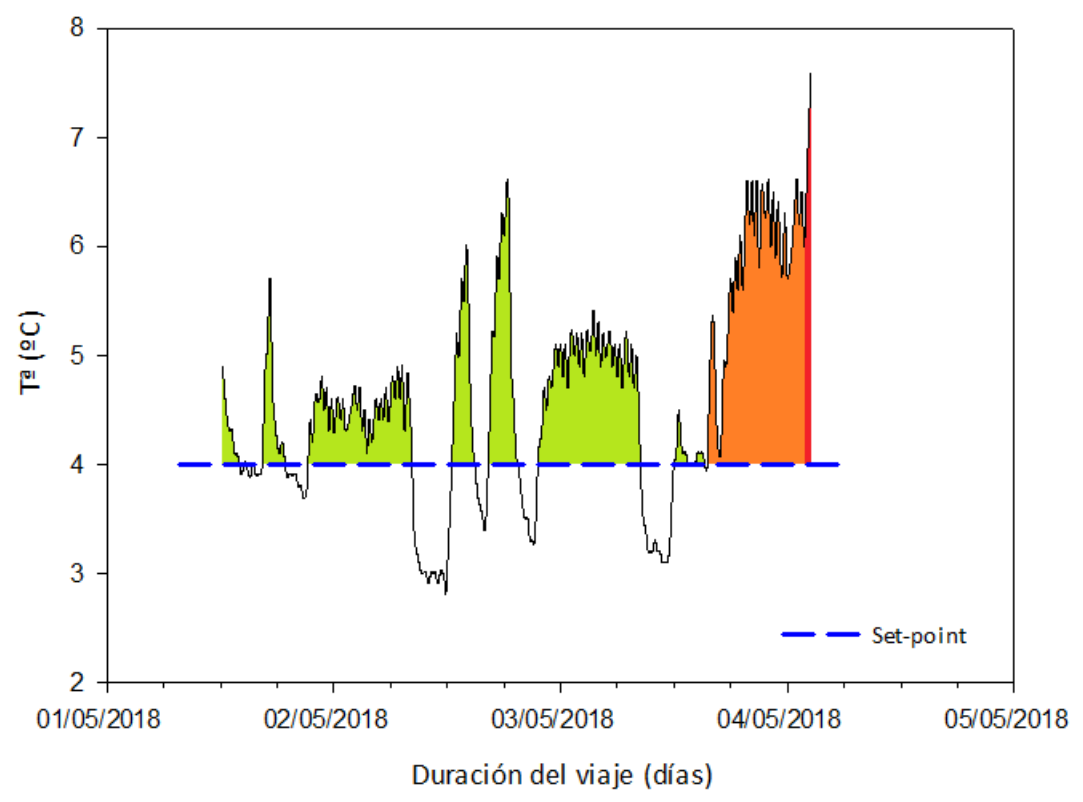

(a) 


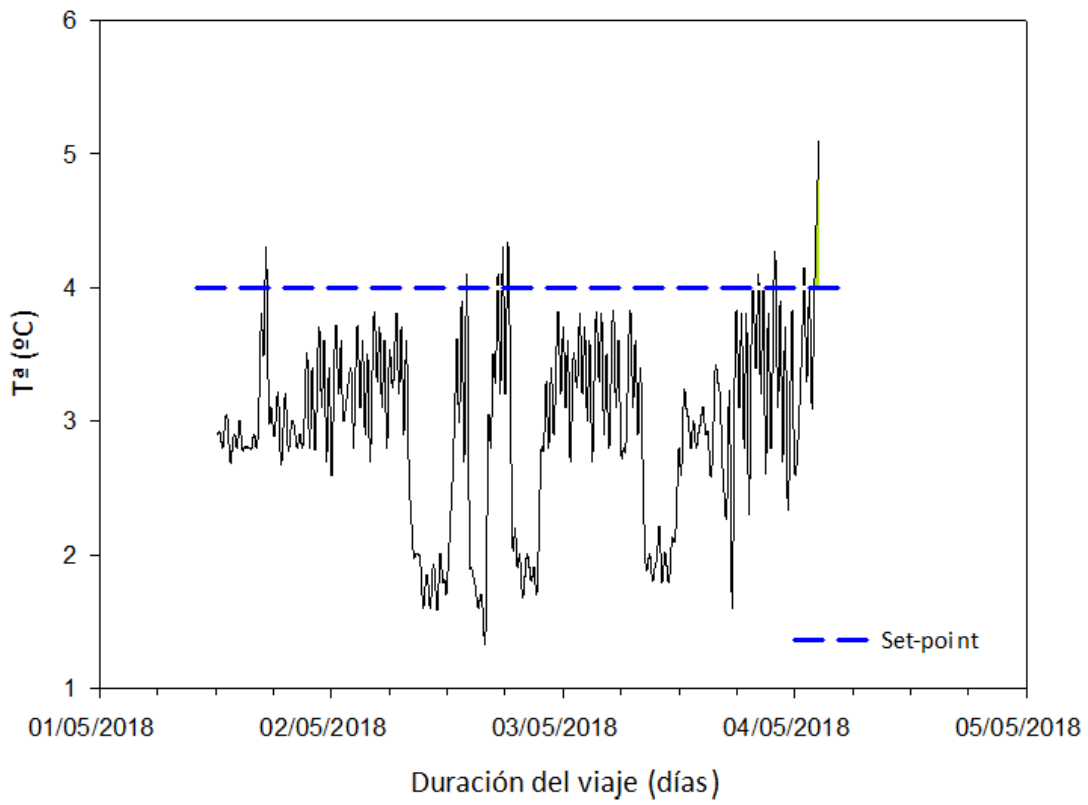

(b)

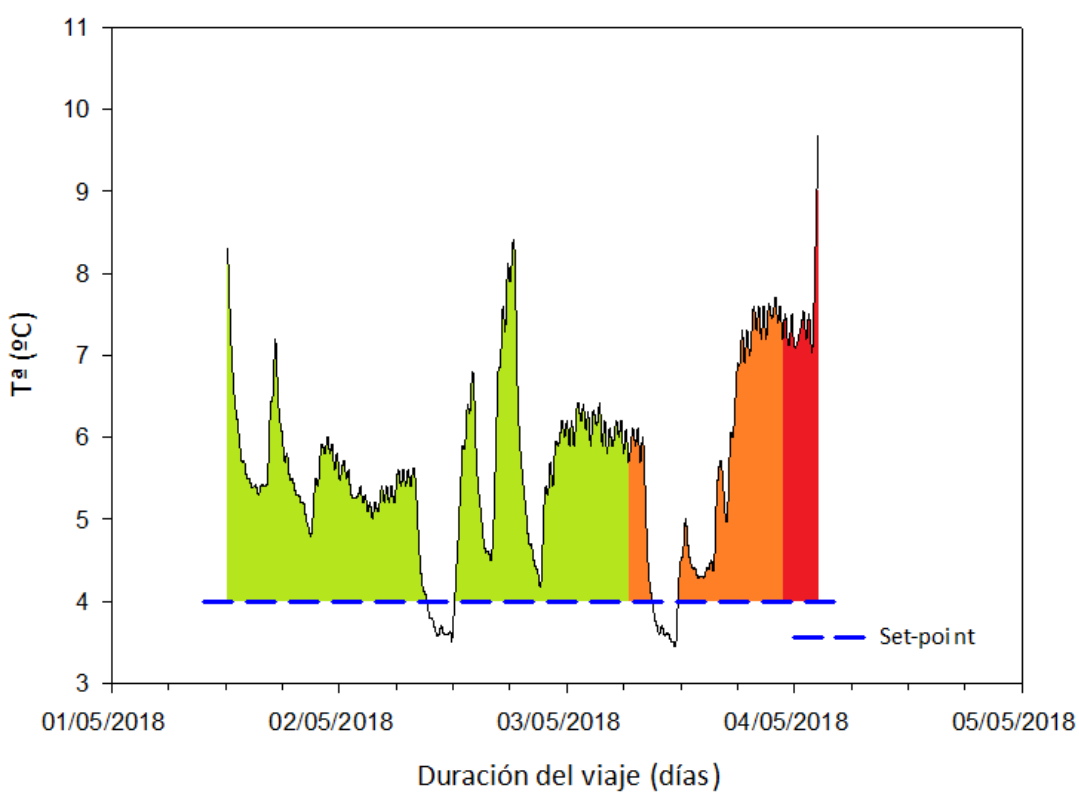

(c)

Figura 101. Históricos de las temperaturas registradas en tiempo real analizando la calidad con el índice de área para (a) Gateway, (b) Slave 1 y (c) Slave 2. El destino de este transporte fue Alemania, y los nodos se colocaron como se muestra en la Figura 70. 
CONCLUSIONES

7. CONCLUSIONES 
A continuación, se enumeran algunas de las conclusiones más relevante a las que se han llegado durante el desarrollo de esta Tesis Doctoral:

- El propósito de esta Tesis no es hacer un estudio exhaustivo de la vida útil del producto, que conllevaría medir las condiciones "dentro" del propio producto, sino proporcionar un modelo de estimación utilizando los medios técnicos usados actualmente en el transporte terrestre de lechuga (condiciones térmicas del aire) y su determinación del tiempo de vida comercial teórico bajo condiciones ambientales estables (situación ideal) y variables (situación real).

- El dispositivo presentado permite, gracias a su principio de funcionamiento y a la facilidad de instalación de los sensores, su evolución prueba tras prueba analizando los puntos débiles, cubriendo brechas del resto de dispositivos existentes y mejorando a criterio de los potenciales usuarios del sistema para la instalación de una amplia gama de tipos de sensores y la optimización de uso.

- La hipótesis de uso del protocolo Wi-Fi para realizar redes de nodos colaborativos en mediciones multipunto, ha sido probada con este sistema y se ha demostrado que, aunque el protocolo Wi-Fi no está diseñado para un uso energeticamente eficiente, el diseño de algoritmos y herramientas software, permite utilizar este protocolo reduciendo el tiempo de uso y, por tanto, maximizando el tiempo de autonomía en los sipositivos a baterias.

- La validación de esta hipótesis de uso del protocolo Wi-Fi ha permitido, por un lado, que el sistema desarrollado sea una herramienta muy versátil capaz de adaptarse a las diferentes infraestructuras de comunicación que tengan las etapas o estancias donde los productos pasan en su postcosecha. Por otro lado, es barato y sencillo que los diferentes actores de la fase postcosecha, puedan utilizar estos equipos ya que, o bien la mayoría de los agentes (almacenes, supermercados, mayoristas, etc.) disponen de infraestructura Wi-Fi en sus estancias, o es una instalación barata y sencilla dada la amplia gama de routers o puntos de acceso Wi-Fi comerciales existentes en el mercado.

- La adopción del protocolo Wi-Fi ha permitido también diseñar equipos más pequeños y baratos, dado que los módulos basados en el microcontrolador ESP32 integran Wi-Fi y, por lo tanto, se dispone de una herramienta flexible para desarrollar sistemas de medida, que incorpora esta capacidad de comunicación desde precios muy económicos $(<10 €)$.

- Las condiciones en las cuales las lechugas son recolectadas afectan directamente a su posterior maduración, puesto que de presentar problemas de preenfriamiento y/o daños mecánicos, estos acelerarían el proceso de maduración y podredumbre del producto. Este hecho condiciona, por tanto, el 
uso de estos sistemas para determinar con exactitud la vida comercial del producto.

- Existe una relación entre el número de días de almacenamiento y la pérdida de peso de las lechugas, que en el caso de las lechugas Iceberg es más notable que en el de las Romanas. Esta pérdida de peso está asociada, a su vez, con la pérdida de calidad en la lechuga, de tal forma que, cuanto menor sea la temperatura, más tiempo podrá ser almacenada la lechuga sin ver disminuida su calidad.

- La comunicación entre transportistas y técnicos debe ser fluida y veraz para conocer las condiciones en que se ha almacenado y/o transportado la carga y así contribuir a reducir el desperdicio de alimentos debido a malas condiciones de conservación o transporte. No cabe duda de que el uso de los sistemas de monitorización se considera imprescindible para esta labor.

- Para realizar la experimentacion en este tipo de proyectos, es necesaria una planificación conjunta entre la universidad y las empresas colaboradoras. En el desarrollo de la experimentacion durante esta Tesis, ha habido episodios de mala coordinación en cuanto a fechas de instalación de los equipos en camiones, lo que ha conllevado a instalaciones en remolques que no han sido cargados hasta días más tarde, con el consiguiente registro de datos sin relevancia y consumo de batería, o incluso cargados con mercanciás diferentes de las previstas. Esto puede ocasionar que en el momento que se cargue la mercancía ya no se puedan registrar los datos durante todo el transporte o en transportes consecutivos. Del mismo modo, una falta de información sobre la carga y las condiciones ambientales conlleva un análisis erróneo, ya que el comportamiento de los productos perecederos y sus temperaturas de consigna deben tenerse en cuenta para la determinación de su vida comercial.

- Para diseñar un modelo de predicción de pérdida de calidad más preciso, es necesario extender constantemente el trabajo de capacitación y validación a lo largo del tiempo, no solo después del transporte sino también en las diferentes fases de la cadena de frío. De esta forma se obtendrían más observaciones en campo, permitiendo utilizar el sistema presentado como un "sensor estimador de vida comercial". Cuantos más datos se registren, mejor podrá predecir el modelo la calidad y la vida útil restante.

- En los modelos de regresión, el área por encima de la temperatura de consigna se considera una observación relevante que permite predecir la pérdida de calidad durante el almacenamiento o el tránsito de alimentos refrigerados, debido a que su cálculo puede realizarse en tiempo real analizando las serie tiempo-temperatura medias y recogidas en los servidores. Sin embargo, otros parámetros estadísticos como la temperatura media o las variaciones de temperaturas extremas no son decisivas en la estimación del modelo. 
Tras el análisis de todas estas conclusiones, este dispositivo basado en sensores se muestra como un instrumento muy útil para ayudar a reducir las pérdidas de alimentos. Por ejemplo, puede ayudar a precisar las variaciones de temperatura entre las distintas etapas de la cadena de frío; puede analizar si las modificaciones de temperatura en uno u otro punto mejorarían la duración de la vida comercial; puede detectar fallos en la cadena de frío e informar a los actores involucrados; puede evitar el rechazo del producto después de una mala conservación de la temperatura durante el transporte, puede darnos información sobre la vida útil restante estimada. Esta herramienta puede ayudar a decidir enviar dichos productos a los usuarios finales con una vida útil más corta o a supermercados con una alta rotación de productos.

Dichas decisiones se pueden optimizar en futuras investigaciones implantando el dispositivo a lo largo de la cadena de frío, en una mayor variedad de productos y no únicamente en transporte terrestre, sino también en aéreo y marítimo. Además, debe incluir atributos de calidad no sensoriales como, por ejemplo, compuestos nutricionales, como la pérdida de contenido de vitamina $\mathrm{C}$, o la concentración de otros gases como el etileno, que los consumidores demandan cada vez más para obtener alimentos frescos.

La integración óptima de estos dispositivos en la cadena comercial postcosecha implicaría la colaboración de todos los actores. Por ejemplo, es factible tecnológicamente realizar una trazabilidad entre el código de barras (o código BIDI) asociado al envoltorio, paquete o caja donde el producto se conserva, con las distintas etapas postcosecha y las diferentes condiciones de temperatura, lo que daría a los usuarios finales una estimación mucho más cercana de la duración real del producto. Dicho código de barras (o código BIDI), podría estar también asociado a las diferentes SSIDs para la programación inicial del sistema y así poder utilizar toda la infraestructura de comunicación disponible.

La visualización final de estos sistemas es que nosotros, como consumidores, podamos escanear con nuestro Smartphone el código del producto y se pueda obtener, no sólo la trazabilidad de este, sino la estimación de su duración según unos parámetros de calidad definidos por los modelos como los desarrollados en esta Tesis.

De esta forma, la idea que siempre ha sido reducir al máximo las pérdidas en la cadena de frío de los alimentos, se convierte en una realidad gracias a la cooperación entre conocimiento, tecnología y conciencia social. 
REFERENCIAS BIBLIOGRÁFICAS

8. REFERENCIAS BIBLIOGRÁFICAS 
Abad, E., Palacio, F., Nuin, M., Zárate, A. G. de, Juarros, A., Gómez, J. M., \& Marco, S. (2009). RFID smart tag for traceability and cold chain monitoring of foods: Demonstration in an intercontinental fresh fish logistic chain. Journal of Food Engineering, 93(4), 394-399. https://doi.org/10.1016/j.jfoodeng.2009.02.004

Accent Systems. (2018). Diferencias entre NB-IOT y LTE-M. Recuperado 19 de julio de 2019, de https://accent-systems.com/es/blog/diferencias-nb-iot-Ite-m/

Acuña Reyes, D., Domper Rodríguez, A., Eguillor Recabarren, P., Gloria González, C., \& Zacarías Hasbín, I. (2018). Manual de pérdidas y despercidios de alimentos. Santiago de Chile.

AENOR. (2016). AENOR Certificación Tesco Nurture - Producción hortofrutícola. Recuperado 9 de febrero de 2020, de https://www.aenor.com/certificacion/alimentacion/proveedores-frutashortalizas-tesco

Agüero, M. V., Barg, M. V., Yommi, A., Camelo, A., \& Roura, S. I. (2008). Postharvest changes in water status and chlorophyll content of lettuce (Lactuca Sativa L.) and their relationship with overall visual quality. Journal of Food Science, 73(1). https://doi.org/10.1111/j.1750-3841.2007.00604.x

Al-Kashoash, H. A. A., \& Kemp, A. H. (2016). Comparison of 6LoWPAN and LPWAN for the Internet of Things. Australian Journal of Electrical and Electronics Engineering, 13(4), 268-274. https://doi.org/10.1080/1448837X.2017.1409920

Álvarez-Hernández, M. H., Artés-Hernández, F., Ávalos-Belmontes, F., CastilloCampohermoso, M. A., Contreras-Esquivel, J. C., Ventura-Sobrevilla, J. M., \& Martínez-Hernández, G. B. (2018, marzo 1). Current Scenario of Adsorbent Materials Used in Ethylene Scavenging Systems to Extend Fruit and Vegetable Postharvest Life. Food and Bioprocess Technology. Springer New York LLC. https://doi.org/10.1007/s11947-018-2076-7

Amat, J. (2017). Regresión no lineal: Regresión Polinómica, Regression Splines, Smooth Splines y GAMs. Recuperado 18 de noviembre de 2019, de https://rpubs.com/Joaquin_AR/250069

Amodio, M. L., Derossi, A., Mastrandrea, L., \& Colelli, G. (2015). A study of the estimated shelf life of fresh rocket using a non-linear model. Journal of Food Engineering, 150, 19-28. https://doi.org/10.1016/j.jfoodeng.2014.10.030

Aosong Electronics Co. (2003). DHT22 Temperature and Humidity Sensor Datasheet. https://doi.org/10.1093/acprof:oso/9780195179477.003.0005

Arias-Méndez, A., Vilas, C., Alonso, A. A., \& Balsa-Canto, E. (2014). Time-temperature integrators as predictive temperature sensors. Food Control, 44, 258-266. https://doi.org/10.1016/j.foodcont.2014.04.001 
Artés-Hernández, F. (2016a). Conservación en atmósfera modificada. Diseño de envases y nuevas tendencias de envasado. $10^{\circ}$ Curso Internacional Tecnologia Postcosecha y Procesado Mínimo., 16, 40.

Artés-Hernández, F. (2016b). Factores de riesgo en el transporte del banano. Revista Agroentorno. Publicación del sector agroexportador de Costa Rica., 1, 12-15.

Artés-Hernández, F. (2019a). Apuntes de la asignatura "Tecnología de la Postrecolección". Universidad Politécnica de Cartagena.

Artés-Hernández, F. (2019b). Estrategias para prevenir las pérdidas postcosecha de frutas y hortalizas. Jornada AgroBank Retos tecnológicos en el cultivo y la postcosecha hortofrutícola. Recuperado de http://www.catedragrobank.udl.cat/sites/default/files/documentacion/14_ficha_ tecnica_artes_hernandez_jornada_agrobank.pdf

Artés-Hernández, F. (2019c). Factors affecting postharvest quality. En Apuntes del $4^{\circ}$ International on-line Course on Postharvest and Fresh-cut Technologies. (p. 13).

Artés-Hernández, F. (2020). Pérdida y desperdicio alimentario. En Apuntes de la asignatura Tecnología Postrecolección. (p. 15). Universidad Politécnica de Cartagena.

Artés-Hernández, F., Martínez-Zafra, M. T., \& Torres-Sánchez, R. (2017). ES 2640027 B1. BOLETÍN OFICIAL DE LA PROPIEDAD INDUSTRIAL TOMO II: INVENCIONES. Spain. Recuperado de http://consultas2.oepm.es/bopiwebStatic/35823384.pdf

Artés, F. (2006). El envasado en atmósfera modificada mejora la calidad de consumo de los productos hortofrutícolas intactos y mínimamente procesados en fresco. Revista Iberoamericana de Tecnología Postcosecha, 7(2), 61-85.

Artés, F., Gomez, P. A., \& Artés-Hernández, F. (2006). Modified atmosphere packaging for fruits and vegetables. Stewart Postharvest Review, (5:2), 1-13. https://doi.org/10.1201/EBK1420068627

Artés, F., Gómez, P., Aguayo, E., \& Artés-Hernández, F. (2012). Modified atmosphere packaging. En Da-Wen Sun (Ed.), Handbook of Food Safety Engineering (First, pp. 513-533). Oxford, UK: Blackwell Publishing Ltd.

Artés, F., Gómez, P., Aguayo, E., Escalona, V., \& Artés-Hernández, F. (2009). Sustainable sanitation techniques for keeping quality and safety of fresh-cut plant commodities. Postharvest Biology and Technology, 51(3), 287-296. https://doi.org/10.1016/j.postharvbio.2008.10.003

Asociación de Industrias de Alimentación de Aragón, A. (2017). ¿Qué factores influyen en la compra de alimentos? - elEconomista.es. Recuperado 2 de julio de 2019, de https://www.eleconomista.es/aragon/noticias/8673071/10/17/Que-factoresinfluyen-en-la-compra-de-alimentos.html 
ASTM. (1986). Physical requirements guidelines for sensory evaluation laboratories. American Society for Testing Materials, Philadelphia, PA.

Aung, M. M., \& Chang, Y. S. (2014). Traceability in a food supply chain: Safety and quality $\begin{array}{llll}\text { perspectives. } \quad \text { Food } & \text { Control, 172-184. }\end{array}$ https://doi.org/10.1016/j.foodcont.2013.11.007

Ávalos-García, A., \& Pérez-Urria, E. (2009). Metabolismo secundario de plantas. Reduca, 2(3), 119-145.

Awuah, G. B., Ramaswamy, H. S., \& Economides, A. (2007). Thermal processing and quality: Principles and overview. Chemical Engineering and Processing: Process Intensification, 46(6), 584-602. https://doi.org/10.1016/j.cep.2006.08.004

Badia-Melis, R., \& Ruiz-García, L. (2016). Real-Time Tracking and Remote Monitoring in Food Traceability. En Advances in Food Traceability Techniques and Technologies (pp. 209-224). https://doi.org/10.1016/B978-0-08-100310-7.00011-9

Becker, M., Beylot, A., \& Dhaou, R. (2009). Experimental Study: Link Quality and Deployment Issues in Wireless Sensor Networks, 5550(May 2016). https://doi.org/10.1007/978-3-642-01399-7

Bonnin-Torres, M. Á., \& Alorda, B. (2012). Diseño y definición de un sistema de comunicaciones inalámbrico entre equipos domésticos mediante ZigBee. Recuperado de https://drive.google.com/drive/folders/OBzIS2oS_19RiMm9SYVhxbk5Oc0E

BRC. (2019). Recuperado 3 de octubre de 2019, de https://brc.org.uk/

CAAE. (2015). ALBERT HEIJN. Recuperado 9 de febrero de 2020, de https://www.caae.es/index.php/component/k2/agricultura/albert-heijn-2

Cantwell, M., \& Suslow, T. (2002). Lettuce, Crisphead: Recommendations for Maintaining Postharvest Quality. Recuperado 6 de noviembre de 2019, de http://ucanr.edu/sites/Postharvest_Technology_Center_/Commodity_Resources/ Fact_Sheets/Datastores/Vegetables_English/?uid=19\&ds=799

Carignano, M. F., \& Ferreyra, P. (2011). Tecnología inalámbrica Near Field Communication y sus aplicaciones en sistemas embebidos (pp. 97-102). Recuperado de http://www.sase.com.ar/2011/files/2011/02/case2011_submission_15.pdf

Carrera, M. B. (2014). Metabolitos Vegetales. Tema 1. En Apuntes de Biotecnología (p. 3). Sevilla: Universidad Pablo de Olavide. Recuperado de https://www.docsity.com/es/metabolitos-vegetales-tema-1/3531116/

Chill-On. (2010). Ideas and solutions to improve food quality, safety and traceability. Supply Chain Management, 34. 
Derens-Bertheau, E., Osswald, V., Laguerre, O., \& Alvarez, G. (2014). Cold chain of chilled food in France. International Journal of Refrigeration, 52, 161-167. https://doi.org/10.1016/j.ijrefrig.2014.06.012

Deza-Durand, K. M., \& Petersen, M. A. (2011). The effect of cutting direction on aroma compounds and respiration rate of fresh-cut iceberg lettuce (Lactuca sativa L.). Postharvest Biology and Technology, 61(1), 83-90. https://doi.org/10.1016/j.postharvbio.2011.02.011

Díaz-Ruiz, R., Costa-Font, M., López-i-Gelats, F., \& Gil, J. M. (2019). Food waste prevention along the food supply chain: A multi-actor approach to identify effective solutions. Resources, Conservation and Recycling. https://doi.org/10.1016/j.resconrec.2019.05.031

Dietrichson, A. (2019). Métodos Cuantitativos. Recuperado 22 de marzo de 2020, de https://bookdown.org/dietrichson/metodos-cuantitativos/

Do Nascimento Nunes, M. C., Nicometo, M., Emond, J. P., Melis, R. B., \& Uysal, I. (2014). Improvement in fresh fruit and vegetable logistics quality: Berry logistics field studies. Philosophical Transactions of the Royal Society A: Mathematical, Physical and Engineering Sciences, 372(2017). https://doi.org/10.1098/rsta.2013.0307

Doganis, P., Alexandridis, A., Patrinos, P., \& Sarimveis, H. (2006). Time series sales forecasting for short shelf-life food products based on artificial neural networks and evolutionary computing. Journal of Food Engineering, 75(2), 196-204. https://doi.org/10.1016/J.JFOODENG.2005.03.056

Efor. (2016). Tecnologias de comunicación para loT. Recuperado de https://www.efor.es/sites/default/files/tecnologias-de-comunicacioon-paraiot.pdf

ESP32 Overview | Espressif Systems. (2017). Recuperado 1 de febrero de 2020, de https://www.espressif.com/en/products/hardware/esp32/overview

European Proyect. (2010). Frisbee european project - Home. Recuperado 13 de julio de 2019, de https://www.frisbee-project.eu/

FAO. (1989). Manual para el mejoramiento del manejo poscosecha de frutas y hortalizas. Recuperado 15 de febrero de 2020, de http://www.fao.org/3/x5056s/x5056S00.htm

FAO. (2012). Pérdidas y desperdicio de alimentos en el mundo - Alcance, causas y prevención. Roma. https://doi.org/10.3738/1982.2278.562

FAO. (2013). Hallazgos clave I SAVE FOOD: Iniciativa mundial sobre la reducción de la pérdida y el desperdicio de alimentos | Organización de las Naciones Unidas para la Alimentación y la Agricultura. Recuperado 10 de febrero de 2020, de http://www.fao.org/save-food/recursos/keyfindings/es/ 
FAO. (2014). Food wastage footprint. Impacts on natural resources. Food and Agriculture Organization of the United Nations (FAO). Recuperado de www.fao.org/publications

FAO. (2017). El futuro de la alimentación y la agricultura. Tendencias y desafíos. Recuperado 9 de marzo de 2020, de moz-extension://5b782a14-a663-4a43-9cb9534b0943a870/enhancedreader.html?openApp\&pdf=http\%3A\%2F\%2Fwww.fao.org\%2F3\%2Fa-i6881s.pdf

FAO. (2019a). The Future of Food Safety. There is no food security without food safety, 28. Recuperado de http://www.fao.org/3/ca4289en/CA4289EN.pdf

FAO. (2019b). The State of Food and Agriculture 2019. Moving forward on food loss and waste reduction. Rome. https://doi.org/10.4324/9781315764788

FAO. (2020). FAOSTAT. Recuperado 14 de abril de 2020, de http://www.fao.org/faostat/en/\#data/QC/visualize

FSSC 22000. (2019). Recuperado 3 de octubre de 2019, de https://www.fssc22000.com/

Giannakourou, M. C., Koutsoumanis, K., Nychas, G. J. E., \& Taoukis, P. S. (2001). Development and Assessment of an Intelligent Shelf Life Decision System for Quality Optimization of the Food Chill Chain. Journal of Food Protection, 64(7), 1051-1057. https://doi.org/10.4315/0362-028X-64.7.1051

GLOBALG.A.P. (2019). Recuperado 3 de octubre de 2019, de https://www.globalgap.org/es/

Golan, E., Krissoff, B., Kuchler, F., Calvin, L., Nelson, K., \& Price, G. (2007). Traceability in the U.S. Food Supply: Economic Theory and Industry Studies, . Washington DC, USA: United States Department of Agriculture (USDA) . Recuperado de mozextension://5b782a14-a663-4a43-9cb9-534b0943a870/enhancedreader.html?openApp\&pdf=https\%3A\%2F\%2Fwww.ers.usda.gov\%2Fwebdocs\%2F publications\%2F41623\%2F28673_aer830_1_.pdf\%3Fv\%3D41073

Gómez, P., Artés-Hernández, F., Aguayo, E., \& Artés, F. (2013). Condiciones óptimas para el transporte marítimo hortofrutícola entre Latinoamérica y Europa. Desafíos y Oportunidades Tecnológicas en el Intercambio Comercial Hortofrutícola América Latina-Europa. Monitorización del Transporte Frigorífico., 4(1), 2-15.

Guillory, M., \& Strandhardt, G. (2012). NVC World Review on Supply Chain Applications of RFID and Sensors in Packaging Michael Guillory-Strategic Action Consulting Services Ger Standhardt-NVC Netherlands Packaging Centre. www.nvc.nl

Gwanpua, S. G., Verboven, P., Leducq, D., Brown, T., Verlinden, B. E., Bekele, E., ... Geeraerd, A. H. (2015). The FRISBEE tool, a software for optimising the trade-off between food quality, energy use, and global warming impact of cold chains. Journal

$$
\text { of Food }
$$

Engineering,

148 ,

2-12. 
https://doi.org/10.1016/j.jfoodeng.2014.06.021

Hsiao, H. I., \& Huang, K. L. (2016). Time-temperature transparency in the cold chain. Food Control, 64, 181-188. https://doi.org/10.1016/j.foodcont.2015.12.020

IFS Database - Home. (2019). Recuperado 3 de octubre de 2019, de https://www.ifscertification.com/index.php/es/

Institut Cerdà. (2018). Observatorio de Innovación en Gran Consumo en España 2018. Recuperado de www.icerda.org

Introduction. (2018). Recuperado 1 de febrero de 2020, de https://docs.pycom.io/

ISO 22000 Sistema de gestión de la Seguridad Alimentaria. (2019). Recuperado 3 de octubre de 2019, de https://www.normas-iso.com/iso-22000/

Jareño, N. (2017). Tendencias en alimentación de productos frescos - Industria alimentaria. Recuperado 2 de julio de 2019, de http://www.interempresas.net/Alimentaria/Articulos/197752-Tendencias-enalimentacion-de-productos-frescos.html

Jedermann, R., Becker, M., Gorg, C., \& Lang, W. (2011). Testing network protocols and signal attenuation in packed food transports. International Journal of Sensor Networks, 9(3/4), 170. https://doi.org/10.1504/ijsnet.2011.040238

Jedermann, R., Nicometo, M., Uysal, I., \& Lang, W. (2014). Reducing food losses by intelligent food logistics. Philosophical Transactions of the Royal Society A: Mathematical, Physical and Engineering Sciences, 372(2017), 20130302-20130302. https://doi.org/10.1098/rsta.2013.0302

Jedermann, R., Potsch, T., \& Lloyd, C. (2014). Communication techniques and challenges for wireless food quality monitoring. Philosophical Transactions of the Royal Society A: Mathematical, Physical and Engineering Sciences, 372(2017), 2013030420130304. https://doi.org/10.1098/rsta.2013.0304

Jedermann, R., Praeger, U., \& Lang, W. (2017). Challenges and opportunities in remote monitoring of perishable products. Food Packaging and Shelf Life, 14, 18-25. https://doi.org/10.1016/j.fpsl.2017.08.006

Jedermann, R., Ruiz-García, L., \& Lang, W. (2008). Spatial temperature profiling by semipassive RFID loggers for perishable food transportation. Computers and Electronics in Agriculture, 5, 145-154. https://doi.org/10.1016/j.compag.2008.08.006

Kader, A. (1990). Modified atmospheres during transport and storage of fresh fruits and vegetables. En I International Congress on Food Technology and Development (pp. 1: 149-163). Murcia, Spain.

Kelmansky, D. (2015). Regresión Lineal Simple. Recuperado 22 de febrero de 2020, de 
moz-extension://5b782a14-a663-4a43-9cb9-534b0943a870/enhancedreader.html?openApp\&pdf=https\%3A\%2F\%2Fwww.dm.uba.ar\%2Fmaterias\%2Fes tadistica_Q\%2F2010\%2F2\%2FC014\%2520Regresion\%2520Lineal\%2520Simple\%25 20.pdf

KONICA MINOLTA. (2000). Entendiendo El Espacio de Color CIE L*A*B*. Recuperado 14 de abril de 2020, de http://sensing.konicaminolta.com.mx/2014/09/entendiendoel-espacio-de-color-cie-lab/

Koutsoumanis, K. P., \& Gougouli, M. (2015). Use of Time Temperature Integrators in food safety management. Trends in Food Science and Technology, 43(2), 236-244. https://doi.org/10.1016/j.tifs.2015.02.008

Labuza, T. P. (1982). Shelf-life dating of foods. Shelf-life dating of foods. Recuperado de https://www.cabdirect.org/cabdirect/abstract/19820482746

Lang, W., \& Jedermann, R. (2014). The Intelligent Container A Cognitive Sensor Net for Fruit Logistics. En International Conference on Sensor Networks (pp. 351-359).

Lang, W., Jedermann, R., Mrugala, D., Jabbari, A., Krieg-Brückner, B., \& Schill, K. (2011). The "Intelligent Container"-A Cognitive Sensor Network for Transport Management. IEEE Sensors Journal, 11(3), 688-698. https://doi.org/10.1109/JSEN.2010.2060480

Le, G. T., Tran, T. V., Lee, H. S., \& Chung, W. Y. (2016). Long-range batteryless RF sensor for monitoring the freshness of packaged vegetables. Sensors and Actuators, A: Physical, 237, 20-28. https://doi.org/10.1016/j.sna.2015.11.013

López-Camelo, A. F. (2003). Capítulo 3. Conservación. En Manual Para la Preparación y Venta de Frutas y Hortalizas Del campo al mercado (pp. 72-75). Balcarce, Argentina. Recuperado de http://www.fao.org/3/Y4893S/y4893s06.htm

Lorite, G. S., Selkälä, T., Sipola, T., Palenzuela, J., Jubete, E., Viñuales, A., ... Toth, G. (2017). Novel, smart and RFID assisted critical temperature indicator for supply chain monitoring. Journal of Food Engineering, 193, 20-28. https://doi.org/10.1016/j.jfoodeng.2016.06.016

Managa, M. G., Tinyani, P. P., Senyolo, G. M., Soundy, P., Sultanbawa, Y., \& Sivakumar, D. (2018). Impact of transportation, storage, and retail shelf conditions on lettuce quality and phytonutrients losses in the supply chain. Food Science and Nutrition, 6(6), 1527-1536. https://doi.org/10.1002/fsn3.685

Manolopoulou, H., Lambrinos, G. R., Chatzis, E., Xanthopoulos, G., \& Aravantinos, E. (2010). Effect of temperature and modified atmosphere packaging on storage quality of fresh-cut romaine lettuce. Journal of Food Quality, 33(SUPPL. 1), 317-336. https://doi.org/10.1111/j.1745-4557.2010.00321.x

Martínez-López, J. A. (2011). Optimización del envasado en atmósfera modificada de la 
lechuga iceberg. Universidad de Murcia.

Martínez-Romero, D., Serrano, M., Bailén, G., Guillén, F., Zapata, P. J., Valverde, J. M., ... Valero, D. (2008). The use of a natural fungicide as an alternative to preharvest synthetic fungicide treatments to control lettuce deterioration during postharvest storage. Postharvest Biology and Technology, 47(1), 54-60. https://doi.org/10.1016/j.postharvbio.2007.05.020

Martínez Hernández, O. (2016). Tecnologías GSM, CDMA, TDMA, GPRS, EDGE, UMTS. Recuperado 8 de agosto de 2019, de https://www.monografias.com/trabajos75/tecnologias-gsm-cdma-tdmagprs/tecnologias-gsm-cdma-tdma-gprs.shtml

Mayne, J. (2005). Estado actual de las comunicaciones inalámbricas. SILICA, 1-53. Recuperado http://clusterfie.epn.edu.ec/ibernal/html/CURSOS/AbrilAgosto06/Inalambricas/C LASES/IntroduccionPUB2.pdf

Mercier, S., Villeneuve, S., Mondor, M., \& Uysal, I. (2017). Time-Temperature Management Along the Food Cold Chain: A Review of Recent Developments. Comprehensive Reviews in Food Science and Food Safety, 16(4), 647-667. https://doi.org/10.1111/1541-4337.12269

Ministerio de Agricultura Pesca y Alimentación, G. de E. (2018a). Informe del Consumo Alimentario en España 2018. Recuperado de https://www.mapa.gob.es/es/alimentacion/temas/consumo-y-comercializaciony-distribucion-alimentaria/panel-de-consumo-alimentario/ultimosdatos/default.aspx

Ministerio de Agricultura Pesca y Alimentación, G. de E. (2018b). Superficies y producciones anuales de cultivos. Recuperado 5 de julio de 2019, de https://www.mapa.gob.es/es/estadistica/temas/estadisticasagrarias/agricultura/superficies-producciones-anuales-cultivos/

Mitchell, T. (1997). Machine Learning. McGraw-Hill Science/Engineering/Math.

Montanari, R. (2008). Cold chain tracking: a managerial perspective. Trends in Food Science and Technology, 19(8), 425-431. https://doi.org/10.1016/j.tifs.2008.03.009

Ndraha, N., Hsiao, H., Vlajic, J., Yang, M., \& Lin, H. V. (2018). Time-temperature abuse in the food cold chain: Review of issues, challenges, and recommendations. Food Control, 89, 12-21. https://doi.org/10.1016/j.foodcont.2018.01.027

$\mathrm{Ng}$, A. (2016). Linear Regression with multiple variables. En Apuntes Curso Machine Learning (p. 31). Stanford University.

Nicola, S., \& Fontana, E. (2010). Global horticulture: Challenges and opportunities. Acta Horticulturae, 856(August), 49-54. 
https://doi.org/10.17660/ActaHortic.2010.856.5

NVC Netherlands Packaging Centre. (2012). PASTEUR Sensor enabled RFID. Recuperado 22 de julio de 2019, de https://www.en.nvc.nl/pasteur-sensor-enabled-rfid/

Opara, L. U. (2002). Engineering and Technological Outlook on Traceability of Agricultural Production and Products. CIGR Journal of Scientific Research and Development, IV, 1-13.

Opara, L. U. (2003). Traceability in agriculture and food supply chain: A review of basic concepts, technological implications, and future prospects. CIGR Journal of Scientific Research and Development, I, 101-106. Recuperado de www.worldfood.net

Pedro, A. M. K., \& Ferreira, M. M. C. (2006). Multivariate accelerated shelf-life testing: a novel approach for determining the shelf-life of foods. Journal of Chemometrics, 20(1-2), 76-83. https://doi.org/10.1002/cem.995

Pedro, A. M. K., \& Ferreira, M. M. C. (2009). The Use of Near-Infrared Spectroscopy and Chemometrics for Determining the Shelf-Life of Products, 63(11), 1308-1314.

Praeger, U., Linke, M., Jedermann, R., Moehrke, A., \& Geyer, M. (2013). Effect of storage climate on green-life duriation of bananas. 5th International Workshop - Cold Chain Management, At Bonn, Germany. Recuperado de http://ccm.ytally.com/fileadmin/user_upload/downloads/publications_5th_work shop/Praeger_paper.pdf

Proexport. (2019). Datos de exportación de lechuga en la Región de Murcia. Recuperado 13 de julio de 2019, de http://www.proexport.es/agrocifras-lechuga/

Qi, L., Xu, M., Fu, Z., Mira, T., \& Zhang, X. (2014). C2SLDS: A WSN-based perishable food shelf-life prediction and LSFO strategy decision support system in cold chain $\begin{array}{llll}\text { logistics. Food } \quad \text { Control, } & \text { 19-29. }\end{array}$ https://doi.org/10.1016/J.FOODCONT.2013.09.023

ReFED. (2015). The multi-billion dollar food waste problem. Recuperado 13 de julio de 2019, de https://www.refed.com/?sort=economic-value-per-ton

Rodríguez, A., García, C., Salmerón, R., \& García, C. B. (2017). El Factor de Inflación de la Varianza en R. Recuperado 23 de marzo de 2020, de moz-extension://5b782a14a663-4a43-9cb9-534b0943a870/enhancedreader.html?openApp\&pdf=http\%3A\%2F\%2Fres.org\%2F9jornadasR\%2Fpdf\%2F9JUR_paper_31.pdf

Ruiz-García, L., \& Lunadei, L. (2011). The role of RFID in agriculture: Applications, limitations and challenges. Computers and Electronics in Agriculture, 79(1), 42-50. https://doi.org/10.1016/j.compag.2011.08.010 
Samuel, A. (1959). Some Studies in Machine Learning Using the Game of Checkers. IBM Journal of Research and Development, 3(3), 210-229. https://doi.org/10.1147/rd. 33.0210

Sánchez-Gamborino, F. (2019). Transporte CMR, ¿exceso de temperatura o mala estiba? Recuperado 11 de abril de 2020, de https://www.transporte3.com/noticia/14096/transporte-cmr-exceso-detemperatura-o-mala-estiba

Sánchez-Turcios, R. A. (2015). t-Student: Usos y abusos. Recuperado 15 de abril de 2020, de http://www.scielo.org.mx/scielo.php?script=sci_arttext\&pid=S018821982015000100009

Schervish, M. J. (1996). P Values: What They Are and What They Are Not. The American Statistician, 50(3), 203. https://doi.org/10.2307/2684655

Sedghy, M., \& Sedghy, B. M. (2018). Evolution of Radio Frequency Identification (RFID) in Agricultural Cold Chain Monitoring: A Literature Review.

Semtech. (2019). Logistics and Supply Chain Management for Internet of Things I Semtech. Recuperado 13 de marzo de 2020, de https://www.semtech.com/applications/internet-of-things/logistics-supply-chainmanagement

Sigfox España. (2015). Recuperado 19 de julio de 2019, de https://www.sigfox.es/

Son, D., Krishnamachari, B., \& Heidemann, J. (2006). Experimental study of concurrent transmission in wireless sensor networks. En Proceedings of the 4th international conference on Embedded networked sensor systems - SenSys '06 (p. 237). New York, New York, USA: ACM Press. https://doi.org/10.1145/1182807.1182831

Stone, H., \& Sidel, J. L. (2004). Sensory evaluation practices. Elsevier Academic Press.

Stuart, T. (2009). Waste: uncovering the global food scandal. London (United Kingdom) Penguin Books.

Taiz, L., \& Zeiger, E. (2006). Fisiología vegetal. Castellón de la Plana: Publicacions de la Universidat Jaume I, Servei de Comunicació i Publicacions.

Taoukis, P., Gogou, E., \& Alvarez, G. (2016). Cold chain management tools for the optimization of redy-to-eat food products cold. 6th International Conference Cold Chain Management Temperature Controlled Logistics.

Taoukis, P. S., \& Labuza, T. P. (2003). Time-temperature indicators (TTIs). Novel Food Packaging Techniques, 103-126. https://doi.org/10.1533/9781855737020.1.103

TelosB. (2015). MTM-CM5000-MSP 802.15.4 TelosB mote Module | IoT Hardware Platforms. Recuperado 10 de abril de 2020, de 
https://www.advanticsys.com/shop/mtmcm5000msp-p-14.html

The WiPy libraries, releases, hardware files and docs. (2015). Recuperado 9 de abril de 2020, de https://github.com/wipy/wipy

Thompson, J. F., Mitchell, F. G., Rumsay, T. R., Kasmire R.F., \& Crisosoto C.H. (2002). Commercial Cooling of Fruits, Vegetables, and Flowers (Vol. 21567). Recuperado de https://books.google.es/books?hl=es\&|r=\&id=jM3eeW5E5u0C\&oi=fnd\&pg=PP4\& $\mathrm{dq}=$ Thompson+J.F.,+Mitchell+F.J,Commercial+cooling+of+fruits,+vegetables+and+ flowers\&ots=sS867JrZVS\&sig=LZ7XuuHKoS6J-

s8ks1fVbInVxmQ\#v=onepage \&q\&f=false

Thomson, J. F., \& Bretch, P. (2002). Refrigerated trailer transport of perishable products. University of California. Pub 21614. Recuperado de https://www.google.com/search?sxsrf=ALeKk01gZuDGE72ctKzokEm4isO5iKUgw\%3A1584119759828\&ei=z79rXsmYMv3TgwfHpZmYAQ $\& q=$ Thompson+JF\%2C+Brecht+P+2002.+Refrigerated+trailer+transport+of+perish able+products.\&oq=Thompson+JF\%2C+Brecht+P+2002.+Refrigerated+trailer $+\mathrm{t}$

Tsang, Y. P., Choy, K. L., Wu, C. H., Ho, G. T. S., Lam, H. Y., \& Tang, V. (2018). An intelligent model for assuring food quality in managing a multi-temperature food distribution centre. Food Control. https://doi.org/10.1016/j.foodcont.2018.02.030

Vázquez Mouzo, J., Parada Medina, R., \& Monzo Sánchez, C. (2017). Control Automatico De Temperatura En Cadena De Frio Mediante Tecnologia Rfid, 94. Recuperado de http://openaccess.uoc.edu/webapps/o2/bitstream/10609/59787/12/jvazquezmo uTFM0117memoria.pdf

Vinuesa, P. (2016). Regresión lineal simple y polinomial: teoría y práctica (Vol. 7). Recuperado http://www.ccg.unam.mx/ vinuesa/R4biosciences/docs/Tema9_regresion.html

WarmMark $^{\circledR}$ Time-Temperature Indicator, Model 51013-51035 - DeltaTrak. (2015). Recuperado 14 de abril de 2020, de https://www.deltatrak.com/warmmarklabels/51013-warmmark-time-temperature-indicator

Wikipedia. (2018). Esquema tecnologías geolocalizables. Recuperado de https://upload.wikimedia.org/wikipedia/commons/b/b4/Comparison_satellite_n avigation_orbits.svg

Wild, F. (2015). What Is Orbit? Recuperado de https://www.nasa.gov/audience/forstudents/5-8/features/nasa-knows/what-isorbit-58.html

WiPy 3.0 - Pycom. (2019). Recuperado 1 de febrero de 2020, de https://pycom.io/product/wipy-3-0/

Zhang, G. P., \& Qi, M. (2005). Neural network forecasting for seasonal and trend time 
series. European Journal of Operational Research, 160(2), 501-514. https://doi.org/10.1016/j.ejor.2003.08.037

Zou, Z., Chen, Q., Uysal, I., \& Zheng, L. (2014). Radio frequency identification enabled wireless sensing for intelligent food logistics. Philosophical Transactions of the Royal Society A: Mathematical, Physical and Engineering Sciences, 372(2021), 17. https://doi.org/10.1098/rsta.2014.0209 
PUBLICACIONES Y PREMIOS

9. PUBLICACIONES Y PREMIOS 
PUBLICACIONES Y PREMIOS

\section{PATENTE}

Inventores: Francisco Artés Hernández, María Teresa Martínez Zafra, Roque Torres Sánchez.

Título: DISPOSITIVO, SISTEMA Y MÉTODO DE MONITORIZACIÓN EN TIEMPO REAL DE LAS VARIABLES FÍSICAS Y AMBIENTALES DURANTE EL TRANSPORTE DE MERCANCIAS PERECEDERAS

N. de publicación: 2640027

(ES2640027) N.o de solicitud: 201730301

Fecha de concesión: 17/04/2018; Fecha de publicación de la concesión: 24/04/2018

Entidad titular: Universidad Politécnica de Cartagena

País de prioridad: España. Fecha de prioridad: 20 años

Empresa/s que la están explotando: Widhoc Smart Solutions S.L.

\section{ARTÍCULOS PUBLICADOS EN REVISTAS LISTADAS EN EL JCR DEL SCI}

Torres-Sánchez R, Martínez-Zafra MT, Castillejo N, Guillamón A., Artés-Hernández F. 2020. Real-time monitoring system for shelf life estimation of fruit and vegetables. Sensors (MDPI) v20(7) pp. 1860-1881. https://doi.org/10.3390/s20071860 . IF: 3.031, Q1-T1, 15/61 (Instruments\&Instrumentation)

\section{CONGRESOS INTERNACIONALES CON REVISIÓN POR PARES}

Torres-Sánchez R., Martínez-Zafra M.T., Artés-Hernández F. 2017. Design of an environmental variables monitoring prototype during transportation of horticultural products. 10th Int. FRUTIC Symposium 'Quality and safety of Fresh Horticultural Commodities'. ISSN: 0947-7314. Berlin, Germany. February 7-9. Oral. S3:38.

Torres-Sánchez R., Martínez-Zafra M.T., Artés-Hernández F. 2019. Environmental variables traceability device to predict postharvest quality and remaining shelf life of fruit and vegetables. 6th International Symposium on Applications of Modelling as an Innovative Technology in the Horticultural Supply Chain (Model-IT). Molfetta, Italy. 9-12 June 2019.

\section{PREMIOS}

Premio al mejor proyecto en categoría doctorando en la convocatoria "CALL TO SOLVE CHALLENGES UPCT", un impulso para ayudar a que salgan a la luz buenas ideas creadas por estudiantes, egresados, PAS/PDI y doctorandos en el año 2018. 